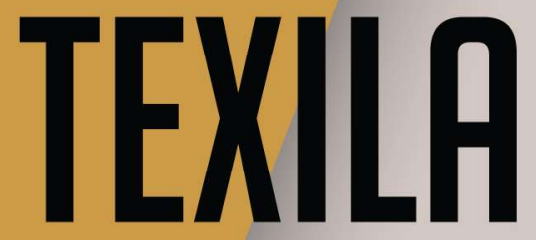

INTERNATIONAL

JOURNAL OF

\title{
PUBLIC HEALITH
}

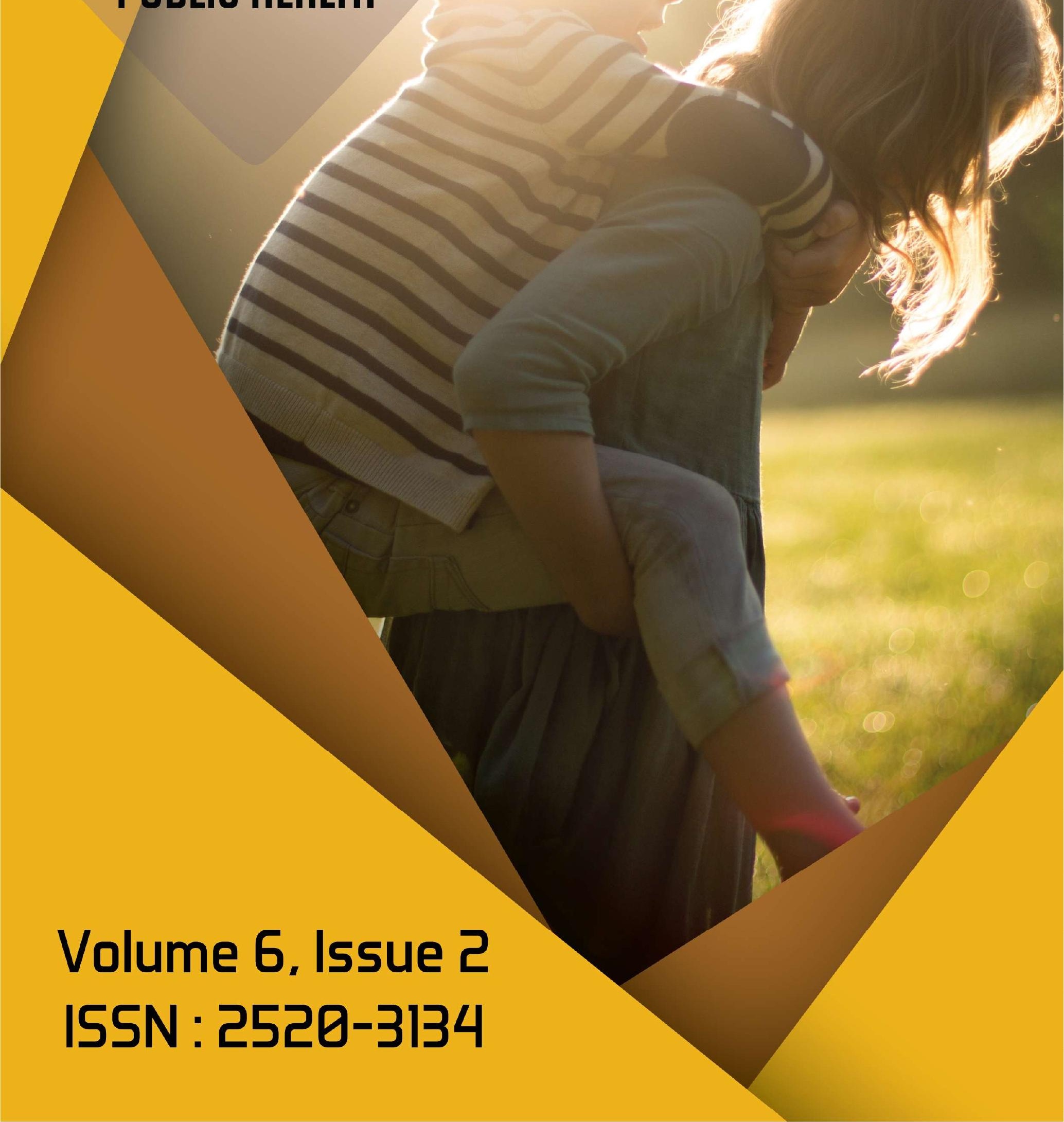




\section{EDITORIAL POLICY}

Papers must be submitted with the understanding that they have not been published elsewhere (except in the form of an abstract or as part of a published lecture, review, or thesis) and are not currently under consideration by another journal published or any other publisher. The submitting (Corresponding) author is responsible for ensuring that the article's publication has been approved by all the other coauthors. It is also the authors' responsibility to ensure that the articles coming from a particular institution are submitted with the approval of the necessary institution. Only an acknowledgment from the editorial office officially establishes the date of receipt. It is a condition for submission of a paper that the authors permit editing of the paper for readability. All enquiries concerning the publication of accepted papers should be addressed to ejournal.assist@tau.edu.gy

\section{PEER REVIEWERS}

Dr. Roy Rillera Marzo, Senior Lecturer/Clinical Coordinator, Asia Metropolitan University.

Dr. Arupkumar Chakrabartty, Assistant Professor, Asian Institute of Public Health, Bhubaneswar, affiliated to Utkal University, Odisha.

Dr. T.Selvankumar, Professor and Head, Mahendra Arts \& Science College.

Dr. Vinoth Raman, Assistant Professor, Imam Abdulrahman Bin Faisal University, Saudi Arabia.

Dr. K. S. Nair, Health Administration, College of Public Health and Health Informatics.

Dr. Jitendra Kumar Chaudhary, Assistant professor, Department of Animal Breeding and Genetics, College of Veterinary Sciences and Animal Husbandry. 


\section{ABOUT PLAGIARISM}

Plagiarism is the use or close imitation of the language and ideas of another author and representation of them as one's own original work. Duplicate publication, sometimes called self-plagiarism, occurs when an author reuses substantial parts of his or her own published work without providing the appropriate references. This can range from getting an identical paper published in multiple journals, where authors add small amounts of new data to a previous paper.

Plagiarism can be said to have clearly occurred when large chunks of text have been cut and pasted. Such manuscripts would not be considered for publication in TIJPH Journal. But minor plagiarism without dishonest intent is relatively frequent, for example when an author reuses parts of an introduction from an earlier paper. The editors will judge any case of which they become aware (either by their own knowledge of and reading about the literature, or when alerted by referees) on its own merits.

The paper containing the plagiarism will be obviously returned back to the author's for review, but we earnestly request the authors to avoid submitting plagiarized. 


\section{DISCLAIMER}

Texila International Journal of Public Health (TIJPH) make every effort to ensure the accuracy of all the information (the "Content") contained in its publications. However, the TIJPH and its agents make no representations or warranties whatsoever as to the accuracy, completeness or suitability for any purpose of the Content and disclaim all such representations and warranties whether express or implied to the maximum extent permitted by law. Any views expressed in this publication are the views of the authors and are not necessarily the views of the Editor's or Texila International Journal of Public Health. 


\section{TABLE OF CONTENT}

1 Seroprevalence of Human Immunodeficiency Virus, Hepatitis B, Hepatitis

C, Syphilis and Co-Infections among Antenatal Women: A Retrospective

Case Study at National Hospital Abuja, Federal Capital Territory (FCT),

Nigeria

Adedamola Amos Ogundeji

2 Malaria Treatment at Community; Can Rapid Diagnostic Test Eliminate

Stock-out of Artemisinin-Based Combination Therapy in South Sudan

Dricile Ratib

3 Family Planning Practices of Female Garment Workers

Irin Hossain

4 Awareness and Knowledge of Diabetic Retinopathy (DR) among Al-

Batinah Population, Oman-A Pilot Study, 2018

Gopi Suresh Vankudre

5 Association between Socio-demographic Characteristics of Community

Health Workers with Compliance to Quality Delivery of Integrated

Community Case Management of Febrile Illness services in Nigeria

Bright Orji

6 A Critical Review of the Articles "Rubella Outbreak Investigation, Gokwe

44

North District, Midlands Province, Zimbabwe 2014

D. Chirundu

7 Knowledge Intervention on Nutrition among the Primary School Students

Irin Hossain

8 Barriers to HIV Testing among Adolescents and Young Adults in Harare

City, Zimbabwe

Notion Gombe

9 Erectile Dysfunction among Diabetic Patients at Parirenyatwa Group of Hospitals in Zimbabwe

Pasipanodya Ian Machingura

10 Strengthening Malaria Service Delivery through Measurement of Quality 
Improvement of Performance Standards in Nigeria: evaluation of

Community Health Workers Performance

$$
\text { Bright Orji }
$$

11 Assessment of Effect of Labour Strikes on Access to Service Delivery in 82 Secondary Health Institutions in Cross River State, Nigeria

Samson Olusegun Aturaka

12 Consistent Condom Use in HIV/AIDS Patients Receiving Antiretroviral Therapy in Northwestern Ethiopia: Implication to Reduce Transmission and Multiple Infections - A Critical Review of Article

D. Chirundu

13 Perception of Refractive Error among Adolescents - A Pilot Study

Janitha Plackal Ayyappan

14 Awareness and Preventions of Malaria in Pregnant Women: A Study of

Mile Four Hospital, Nigeria

Mgbe Chinenye G

15 Menstrual Hygiene Practices of Female Garment Workers

Irin Hossain

16 Pertussis Vaccine; the Past, the Present and the Future (A Mini Review)

Frank Adusei-Mensah

17 Distribution of Socio-Economic Factors with Malaria Occurrence at Federal Capital Territory Abuja, Nigeria: A Retrospective Hospital Based Study

Ibrahim S. A

18 Prevalence of Stress, Psychological Distress and Social Support among

Clinical Medical Rehabilitation Students in a Nigeria University

Arilewola Abosede Omotola

19 Assessment of Antiretroviral Therapy Outcomes among Key Populations after 6 Months of Initiation in Nigeria

Ugbena, Eneojo Richard

20 A Peer Review of the Relationship of Socio-Economic Status on Contraction of Tuberculosis among Tb Patients in Windhoek District, Namibia: A Public Health Practice Perspective

Francis Farai Chikuse

21 Prevalence and Correlates of HIV Testing and Counseling among Sexually Active Adolescents and Young Adults in Harare City, Zimbabwe

Notion Gombe 
22 Family Planning Knowledge, Attitude and Practice among Married Couples in Abakpa Nike, Enugu East Local Government Area, Enugu State, Nigeria

Mgbe Chinenye G

23 Reproductive Health Practices of Female Garment Workers

Irin Hossain 


\title{
Seroprevalence of Human Immunodeficiency Virus, Hepatitis B, Hepatitis C, Syphilis and Co-Infections among Antenatal Women: A Retrospective Case Study at National Hospital Abuja, Federal Capital Territory (FCT), Nigeria
}

\author{
Article by Adedamola Amos Ogundeji \\ PhD (Public Health), Texila American University \\ E-mail: damolaogundeji@gmail.com
}

\begin{abstract}
Objective: The aim of the present study is to determine the seroprevalence of HIV, hepatitis B virus $(H B V)$, hepatitis $C$ virus $(H C V)$, syphilis, and co-infections among antenatal women in National Hospital Abuja, Federal Capital Territory (FCT), Nigeria.

Background: Sexually transmitted infections and human immunodeficiency virus (HIV)/AIDS are a major public health concern owing to both their prevalence and propensity to affect offspring through vertical transmission.

Aim: This study aimed at determining the seroprevalence of HIV, Hepatitis B Virus (HBV), Hepatitis $C$ Virus (HCV), syphilis, and co-infections among antenatal women in National Hospital Abuja, Federal Capital Territory (FCT) Nigeria.

Materials and Methods: A two (2) years retrospective study of antenatal women that attended National Hospital Abuja, Federal Capital Territory (FCT), Nigeria from $1^{\text {st }}$ March, 2013 to $28^{\text {th }}$ February, 2015. A pretested data extraction form was used to obtain data on socio-demographic variables and screening test results from the antenatal records. The analysis was conducted using SPSS version 17 (Chicago, IL, USA).

Results: A total of 3748 antenatal records was used for the study. The seroprevalence of HIV, HCV, HBsAg and syphilis among the pregnant women were $7.9 \%(296 / 3748), 4.7 \%$ (176/3748), $10.6 \%$ ( $397 / 3748)$ and $1.1 \%(41 / 3748)$, respectively. The HIV/HBV, HIV/HCV and HIV/Syphilis co-infection prevalence rates were $0.24 \%(9 / 3748), 0.13 \%(5 / 3748)$ and $0.05 \%(2 / 3748)$ respectively. There was no HBC and HCV co-infection among both HIV positive and negative antenatal women. There was statistically significant difference in $H B V$ and $H C V$ infection between the HIV positive and negative antenatal women.

Conclusion: The prevalence of $H I V, H B V, H C V$, and syphilis is still a challenge in Abuja. Community health education is urgently require to reduce the prevalence of these infections among the most productive and economically viable age bracket. Our study showed that it is very necessary/important for all pregnant women to be requested to test for HBV, HCV alongside the conventional syphilis and HIV infections, in order to prevent vertical transmission to their unborn babies.

Preceptor/location of project: National Hospital Abuja, Federal Capital Territory (FCT), Nigeria.
\end{abstract}

\section{Introduction}

Human immunodeficiency Virus (HIV), Hepatitis B virus (HBV), and Hepatitis C virus (HCV), are the three most common chronic viral infections all over the world ${ }^{1}$. They share similar transmission routes including sexual intercourse, blood-blood contact, mother-to-child transmission and injecting drug usage ${ }^{2}$.

Sub-Saharan Africa, the hardest hit region, is home to more than two-thirds (69\%) of people living with HIV, but only about $12 \%$ of the world's population ${ }^{3}$. Nigeria still has one of the largest HIV prevalence among pregnant women, ranging from as low as $1.6 \%$ in the west, to $8 \%$ in the South-South, $6.5 \%$ in the South-East, and the North-Central region recorded $10 \%{ }^{4}$.Over 2 billion of the world's population have been exposed to HBV and an estimated 387 million of these are now chronically infected with a rate of 10 million new carriers every year ${ }^{5}$. About, $13 \%$ of the carriers will die from the consequences of the HBV infection with an overall annual mortality of about 1 million $^{6}$. The overall prevalence of $\mathrm{HCV}$ in sub-Saharan Africa is $3 \%^{7}$. There are several routes of transmission of HCV but 
direct percutaneous inoculation is the most efficient ${ }^{8}$. In the South-West Nigeria, a higher percentage of those with HCV infection had additional risk factors, especially scarification marks?.

Syphilis is also a systemic disease caused by Treponema pallidium, which can be transmitted by sexual contact, blood transfusion, and vertical transmission ${ }^{10}$.

Mother-to-child transmission of syphilis leads to severe morbidity and mortality including abortion, intrauterine and neonatal death ${ }^{11}$. Congenital syphilis is still a very common occurrence among developing countries, due to non-compliance of women to antenatal care or non-inclusion of syphilis screening as a component in antenatal care ${ }^{12}$.

As a results of the similarity in the routes of transmission, many pregnant women have been exposed to HIV, HBV, HCV, and syphilis infections in different combinations. A study on blood donors showed that prevalence of $\mathrm{HIV}, \mathrm{HBV}, \mathrm{HCV}$, and syphilis were $3.8 \%, 4.7 \%, 0.7 \%$, and $1.3 \%$, respectively ${ }^{13}$. Among the co-infected population, the commonest combinations were HIV/syphilis (38\%) and HIV/HBV $(34 \%)^{13}$. These co-infected population have been categorised with reduced survival, drug associated hepatotoxicity, drug resistance, cross-resistance, and sub-optimal response ${ }^{14}$. Sexually transmitted infections with HIV/AIDS are a major public health concern owing to both their prevalence and propensity to affect offspring through vertical transmission, especially among pregnant women ${ }^{15}$.

Although data on HIV-syphilis co- infection is generally scarce, there is little or no data on the co infections of HIV with HBV, HCV and syphilis especially among pregnant women particularly from Abuja, FCT and its environs where NHA is located. Non-availability of data will cause inability to check and manage the devastating effects of these co infections which will ultimately result in complications of childbirth as well as neonatal infections thus delaying the progression to achieving the MDGs on maternal and child health.

There are worldwide variations in seroprevalence of these infections depending on geographic area, risk groups, and types of exposure involved ${ }^{16}$. Therefore, this study was carried out in order to assess the prevalence of HIV, $\mathrm{HBV}, \mathrm{HCV}$, syphilis, and co-infections among pregnant women receiving care from National Hospital Abuja, Federal Capital Territory (FCT), Nigeria. The rational for choice of this hospital for this study is that it's serve as the final tertiary health care referral centre for the neighbouring states and entire country as a whole due to availability of the state-of-arts and sophisticated modern equipment. The NHA located at the Federal capital city of Nigeria, the seat of power is very unique and best centre for research activities purely because it's attracted patients from the six geo-political zones and will consequently provide a true reflection of Nigeria population research outcome. The outcome will help in formulating intervention plan/policies aimed at reducing the spread of these infections.

\section{Methodology}

\section{Study area and rational for its selection}

The National Hospital Abuja (NHA) is a 350-bed tertiary hospital, located in the Central Business District of the Federal Capital Territory, with state-of-the-art equipment for both clinical and Laboratory settings. This hospital used to serve as the final tertiary health care referral centre for the entire country until recently when some selected teaching hospitals across Nigeria were upgraded to its level in terms of availability of sophisticated modern equipment and adequate manpower with vast experiences in their various disciplines. The hospital currently still serve as epic referral centre for many States around Federal Capital Territory, Abuja. The NHA located at the Federal capital city of Nigeria, the seat of power is very unique and best centre for research activities purely because it's attracted patients from the six geo-political zones and will consequently provide a true reflection of Nigeria expected research outcome. The Medical Microbiology and Parasitology department of the NHA received average of 45 blood samples per week from patients enrolled at the hospital antenatal clinic, which are screened for HIV, HBsAg, HCV and Syphilis (VDRL).

\section{Study design}

This is a retrospective study and so all the data of pregnant women that attended the antenatal clinic of the National Hospital Abuja from $1^{\text {st }}$ March, 2013 to $28^{\text {th }}$ February, 2015 were collated and used for this research. A total of 4986 pregnant women attended the antenatal clinic within that set data collection period. All the antenatal data were completely reviewed and 3748 of them met the inclusion criteria 
while 1238 of them did not. Pretested data extraction form was used to obtain information on the sociodemographic status, parity and screening for HIV, hepatitis B surface antigen (HBsAg), syphilis and $\mathrm{HCV}$ from the antenatal records. The data were extracted by two trained and experience Data Officer who double-checked each other's work to ensure collation of reliable, high quality and accurate data.

\section{Inclusion/exclusion criteria's and ethical review clearance}

All the antenatal data with complete sociodemographic variables, HIV, HBV, HCV, and syphilis screening results were used while incomplete once are excluded from this study. Antenatal women whose mothers were HCV, HBV or HIV carriers were excluded from the study. This study was approved by the Head of Microbiology Department and Ethics Committee of the National Hospital Abuja.

\section{Test kits used for the study}

Antibodies to both HCV and Hepatitis B surface antigen were screened with Clinotech diagnostic enzyme-linked immunosorbent (ELISA) test kits (Clinotech Laboratories, USA with the test specificity of $99.7 \%$ and sensitivity of $100 \%$ for both HbsAg and HCV test kits. Syphilis was screened using Veneral Disease Research Laboratory (Clinotech Biotech Inc., California; with test sensitivity of 100\%, specificity 99.7\%). Antibodies to T. pallidum were confirmed with T. pallidum hemagglutination test. Antibodies to HIV-1 and -2 were screened with Abott Determine and Immunocomb (Alere Medical Company, Limited, Japan; sensitivity 100\%, specificity 99.5\%). All reactive samples were confirmed using ELISA.

\section{Sample collection}

Five millilitres $(5 \mathrm{ml})$ of venous blood was collected from each patient using plain vacutainer tubes (Sterile Separator Tube-SST). Samples were allowed to clot and centrifuged at 1000xg for 10minutes. Serum from the samples tubes were separated into sterile $2 \mathrm{ml}$ cryovial containers and stored at $-20 \mathrm{oC}$ until ready for use.

\section{HIV serology}

HIV screening was carried out using the rapid diagnostics test kits, by adopting serial National Testing algorithm ${ }^{16}$. Samples were first tested using Determine HIV kit (Alere Medical Co., Japan). All positive samples were further tested using Unigold HIV kit (Trinity Biotech Plc, Ireland) and positive results were presumptively considered as positive. Unigold test kit is use as second line (confirmatory) and when it is negative, then Stat-pak HIV kit (a tie breaker) by (CHEMBIO USA) was then used. All test kits procedures were done according to their respective manufacturers' instruction. All reactive samples were confirmed using ELISA.

\section{Syphilis IgM serology}

Screening for syphilis was carried out using Enzyme Immunoassay (ELISA) technique to determine specific IgM antibodies to Treponema palladium in human serum and plasma (DIA.PRO Diagnostic Bio-probes, Milano-Italy). The samples were tested following the manufacturer instructions and was read with a spectrophotometer (name and country of manufacture) at dual wave lengths (450 and $620 \mathrm{~nm})$.

\section{Hepatitis B and C serology}

Hepatitis B virus infection was detected using the commercially available rapid test strip which is a qualitative lateral flow immunoassay kit for testing HBsAg in serum and plasma. Similarly, Hepatitis $\mathrm{C}$ virus infection was tested using the commercially available rapid test strip which is a qualitative, membrane (coated with recombinant $\mathrm{HCV}$ antigen on the test line region of the strip) based immunoassay for the detection of HCV antibodies in serum and plasma. Both HBsAg and HCV test kits were manufacture by Acon Laboratories, Inc., San Diego, USA. All reactive samples were respectively confirmed using ELISA. 
DOI: $10.21522 / \mathrm{TIJPH} .2013 .06 .02$. Art001

ISSN: $2520-3134$

\section{Statistical analysis}

Statistical analysis was achieved using SPSS version 17 (Chicago, IL, USA). Chi-square analysis was used for discrete variables and $P<0.05$ were considered as statistically significant. The results were presented in tables and simple percentages.

\section{Results}

Of 3748 antenatal women, 296 were HIV positive giving a seroprevalence rate of $7.9 \%$ (296/3748), 42 were $\mathrm{HBV}$ positive resulting in an HBV seroprevalence of $10.6 \%$ (397/3748), and 32 of them were positive to HCV antibodies with a seroprevalence rate of $4.7 \%$ (176/3748) [Table 1]. Forty one of the pregnant women was Treponema palladium hemoagglutination assay positive with seroprevalence rate of $1.1 \%(41 / 3748)$.

Table 1. Screening pattern of the antenatal women

\begin{tabular}{|l|l|l|}
\hline $\begin{array}{l}\text { Screening Pattern of } \\
\text { women }\end{array}$ & $\begin{array}{l}\text { Frequency } \\
(\mathbf{n = 3 7 4 8})\end{array}$ & Percentage \\
\hline HIV Screening Pattern & 296 & 7.9 \\
\hline Positive & 3452 & 92.1 \\
\hline Negative & 397 & 10.6 \\
\hline HBsAg Screening Pattern & 89.4 \\
\hline Positive & 3351 \\
\hline Negative & 176 & 4.7 \\
\hline HCV Screening Pattern & 3572 & 95.3 \\
\hline Positive & 1.1 \\
\hline Negative & 41 & 98.9 \\
\hline Syphilis Screening Pattern & 3707 \\
\hline Positive & $\begin{array}{l}\text { Negative } \\
\text { HCV: Hepatitis C Virus, HIV: Human Immunodeficiency Virus, } \\
\text { HBsAg: Hepatitis B Surface Antigen }\end{array}$ \\
\hline
\end{tabular}

Nine (9) out of 3748 women were both HIV and HBV positive with co-prevalent rate of $0.24 \%$ [Table 2]. As was shown by the Chi-square values in [Table 2], there was statistically significant difference in HBV infection between the HIV positive and negative antenatal women. Five (5) women were both HIV and HCV positive with a seroprevalent rate of $0.13 \%$ (5/3748). Similarly in [Table 2], there was no statistically significant difference in HCV infection between the HIV positive and negative women. Again, only two (2) pregnant women that was T. pallidium hemoagglutination test positive was also HIV positive with co-prevalent rate of $0.05 \%$ (2/3748). There was no HBV, HCV, and syphilis co-infection in both HIV positive and negative antenatal women in this study.

Table 2. HIV, HBV, HCV and Syphilis co-infection

\begin{tabular}{|c|c|c|c|}
\hline & \multicolumn{2}{|l|}{ HBV } & \multirow[t]{2}{*}{ TOTAL } \\
\hline & POSITIVE & NEGATIVE & \\
\hline \multicolumn{4}{|l|}{ HIV } \\
\hline Positive & 9 & 287 & 296 \\
\hline Negative & 388 & 3064 & 3452 \\
\hline Total & 397 & 3351 & 3748 \\
\hline \multicolumn{4}{|c|}{$\chi^{2}=19.353, \mathrm{df}=1, P<0.05$ (Significant different) } \\
\hline \multicolumn{4}{|l|}{ HCV } \\
\hline \multicolumn{4}{|l|}{ HIV } \\
\hline Positive & 5 & 291 & 296 \\
\hline Negative & 171 & 3281 & 3452 \\
\hline Total & 176 & 3572 & 3748 \\
\hline
\end{tabular}




\begin{tabular}{|c|c|c|c|}
\hline \multicolumn{4}{|c|}{$\chi^{2}=6.492, \mathrm{df}=1, P<0.05$ (Significant different) } \\
\hline \multicolumn{4}{|l|}{ Syphilis } \\
\hline \multicolumn{4}{|l|}{ HIV } \\
\hline Positive & 2 & 294 & 296 \\
\hline Negative & 39 & 3413 & 3452 \\
\hline Total & 41 & 3707 & 3748 \\
\hline
\end{tabular}

The most predominant age group of the women was 21-30 years 50.4\% (1889/3748). The mean (SD) for age was 30.1 (2.1) years [Table 3]. One thousand five hundred and eighty-six 42.3\%(1586/3748) of the women were public/civil servants followed by the unemployed group 26.1\% (978/3748). [Table 3 ] also shows that most of the antenatal women $41.7 \%$ (1563/3748) were multiparous.

Table 3. Sociodemographic variables among the antenatal women

\begin{tabular}{|l|l|l|}
\begin{tabular}{|l|l|} 
Sociodemographic \\
characteristics
\end{tabular} & $\begin{array}{l}\text { Frequency } \\
(\mathbf{n = 3 7 4 8})\end{array}$ & $\begin{array}{l}\text { Percentage } \\
(\%)\end{array}$ \\
\hline Age (years) & 79 & 2.1 \\
\hline $11-20$ & 1889 & 50.4 \\
\hline $21-30$ & 1638 & 43.7 \\
\hline $31-40$ & 142 & 3.8 \\
\hline $41-50$ & 1586 & 42.3 \\
\hline Occupation & 978 & 26.1 \\
\hline Public/Civil Servants & 506 & 13.5 \\
\hline Unemployed group & 457 & 12.2 \\
\hline Trading & \multicolumn{2}{|l|}{} \\
\hline $\begin{array}{l}\text { Professionals (Engineers, Lawyer, } \\
\text { Doctors, Accountants etc.) }\end{array}$ & 221 & 5.9 \\
\hline Artisans & \multicolumn{2}{|l|}{} \\
\hline Parity Distribution & 1102 & 29.4 \\
\hline 0 & 810 & 21.6 \\
\hline 1 & 1563 & 41.7 \\
\hline $2-4$ & 273 & 7.3 \\
\hline$>5$ & \multicolumn{2}{|l|}{} \\
\hline
\end{tabular}

[Table 4] revealed that the unemployed group, public servants of the antenatal women and the Artisans constitute the bulk of the women that were seropositive to HIV, HBV, and HCV anti-bodies.

Table 4. Occupational distribution of the women HIV, HBsAg and HCV infection

\begin{tabular}{|c|c|c|c|c|c|c|}
\hline \multirow{2}{*}{ Occupation } & \multicolumn{2}{|l|}{ HIV } & \multicolumn{2}{|l|}{ HBsAg } & \multicolumn{2}{|l|}{ HCV } \\
\hline & Positive & Negative & Positive & Negative & Positive & Negative \\
\hline $\begin{array}{l}\text { Public/Civil } \\
\text { Servants }\end{array}$ & $71(4.5 \%)$ & $\begin{array}{l}1515 \\
(95.5 \%)\end{array}$ & $83(5.2 \%)$ & $\begin{array}{l}1503 \\
(94.8 \%)\end{array}$ & $51(3.2 \%)$ & $1535(96.8 \%)$ \\
\hline Unem & $\begin{array}{l}121 \\
(12.4 \%)\end{array}$ & $856(87.6 \%)$ & $\begin{array}{l}123 \\
(12.6 \%)\end{array}$ & $855(87.4 \%)$ & $55(5.6 \%)$ & $923(94.4)$ \\
\hline Trading & $43(8.5 \%)$ & $463(91.5 \%)$ & $68(13.4 \%)$ & $438(86.6 \%)$ & $27(5.3 \%)$ & $479(94.7 \%)$ \\
\hline Professionals & $9(2.0 \%)$ & $448(98.0 \%)$ & $40(8.8 \%)$ & $417(91.2 \%)$ & $5(1.1 \%)$ & $452(98.9 \%)$ \\
\hline Artisan & $52(23.5 \%)$ & $169(76.5 \%)$ & $83(37.6 \%)$ & $138(62.4 \%)$ & $38(17.2 \%)$ & $183(82.8 \%)$ \\
\hline Total & $296(7.9 \%)$ & $\begin{array}{l}3452 \\
(92.1 \%) \\
\end{array}$ & $\begin{array}{l}397 \\
(10.6 \%)\end{array}$ & $\begin{array}{l}3351 \\
(89.4 \%)\end{array}$ & $176(4.7 \%)$ & $3572(95.3 \%)$ \\
\hline
\end{tabular}


DOI: $10.21522 / \mathrm{TIJPH} .2013 .06 .02$. Art001

ISSN: $2520-3134$

\section{Discussion}

The seroprevelance of HIV, HBV, HCV and Syphilis infections is well recognized worldwide but has been reported to be more common in developing countries in Africa and Asia ${ }^{11}$. This study was carried out to assess the seroprevalence of HIV, HBV, HCV and Syphilis co infections among pregnant women attending National Hospital Abuja, Federal Capital Territory, and North central Nigeria. The study demonstrated a high prevalence of HIV (7.9\%) and HBV (10.6\%) and a low prevalence of HCV (4.7\%) and Syphilis (1.1\%).

The findings where the majority of pregnant women tested were between the age bracket of $15-35$ is also in agreement with an earlier report by Ajayi et al 2012 and national survey (FMOH 2002) that the majority of the pregnant women tested (95\%) were between the ages of 15-35 years.

The overall seroprevalence of HIV, 7.9\% among antenatal women in Abuja and its environs recorded in this study is higher than the national HIV prevalence of $4.6 \%$ among pregnant women. It is also in agreement, when compared with the $7.8 \%$ reported in Minna ${ }^{16}$.

In North-West Ethiopia, a seroprevalence of $9.6 \%$ for HIV-1 was observed among pregnant women receiving antenatal services at the University of Gondar Teaching Hospital ${ }^{14}$. The seroprevalence in this study is lower than the $26 \%$ seroprevalence reported in Swaziland ${ }^{17}$. The seroprevalence of HIV, $7.9 \%$ in this study could be due to increased level of awareness among antenatal women in Abuja and environs on the Prevention of Mother to Child Transmission (PMTCT) of HIV/AIDS as well as the functional PMTCT program at National Hospital, Abuja thereby attracting more HIV-positive pregnant women to book at the facility for antenatal care.

The seroprevalence of HBV 10.6\%, among the women is higher than previous reports from Nigeria; $8.2 \%$ in Yola $^{18}$, and 5\% in Niger Delta ${ }^{19}$. It is similar to $3.7 \%$ reported in Jimma, Ethiopia ${ }^{20}$. Higher prevalence was recorded among pregnant Sudanese 5\% $\%^{21}$, and India women $3.07 \%^{22}$.

However, cross-study comparisons may be misleading because of the kits used for different assays. The use of polymerase chain reaction (PCR) and ELISA technique assays in other studies have been shown to be more sensitive than the serological methods used in this study ${ }^{23}$. In addition, the differences in the sociodemographic characteristics of the women should be taken into consideration in such comparisons.

The HCV antibody prevalence among the women in the study was $4.7 \%$. This is in agreement with the overall seroprevalence of HCV in sub-Saharan Africa 3\% $\%^{7}$. It is however, higher than the result from Niger Delta, Nigeria $0.5 \%^{20}$, Iran $0.98 \%^{24}$, and Sudan $<1 \%{ }^{22}$. These variations may be related to the differences in the modes of transmission, which is influenced by socio-cultural practices and environmental factors ${ }^{20}$. In a tertiary Medical Centre in South-West Nigeria where over $90.8 \%$ of the women had scarification marks, a seroprevalence of $9.2 \%$ was reported ${ }^{9}$. The differences have also been attributed to the choice of serological tests to determine HCV prevalence especially in developing countries where intercurrent infections contribute to false-positive enzyme immunoassay results ${ }^{25}$.

From this study, the seroprevalence of syphilis among antenatal attendees in Abuja is $1.1 \%$. The seroprevalence is higher than the national average for syphilis in pregnant Nigeria women, $0.3 \%{ }^{26}$. However, a higher prevalence of $10 \%$ was reported among pregnant women in Oshogbo, south western Nigeria $^{27}$. In agreement with this study, the seroprevalence of syphilis among antenatal women in Gondar, Ethiopia, was $1 \%{ }^{10}$. The variation is seroprevalence could be attributed to the differences in sexual practices and behaviour. Late seeking of effective medical treatment for sexually transmitted infections among the largely literate urban antenatal women may explain the elevation. The high prevalence has also been attributed to over-the-counter abuse of antibiotics for minor complaints leading to drug resistance ${ }^{10}$.

From this study, HIV and HBV co-infection prevalent rate of $0.24 \%$ was recorded. This is lower than $0.7 \%$ reported in Anambra state ${ }^{17}$. Also, in this study, $0.13 \%$ and $0.05 \%$ of the antenatal women were positive for HIV-HCV and HIV-Syphilis respectively. Again, only $0.05 \%$ of the women that was positive for syphilis was also HIV positive and whether syphilis predisposed them to HIV and vice versa could not be ascertained by this study. There was no HBV and HCV co-infection in both HIV positive and negative women and this supported the study in Rwanda and Uganda ${ }^{28}$, but varied with the results from Malekan City, Iran ${ }^{25}$. The difference in HBV and HCV infection in both HIV-positive and negative antenatal women in National Hospital Abuja was statistically significant $(\mathrm{p}<0.05)$. The 
absence of HCV and HBV infections in both HIV negative and positive women may be due to the absence of such risk factors as injection drug use commonly seen in the West and scarification marks that are not common in Abuja and its environs, where the study was conducted.

The age group of 21-40 years had the predominant HIV, HBV, and HCV prevalence and this supported the studies in North-West Ethiopia ${ }^{10}$. This calls for concerted efforts aimed at preventive measures to reduce risky lifestyle practices among the most productive and economically viable age bracket $^{13}$.

The unemployed group and artisans similarly had the highest seroprevalence of HIV, HBV and HCV. This study generally recorded high prevalence of HIV (23.5\%), HBV (37.6\%) and HCV (17.2\%) among artisans population as against very low prevalence of HIV (2.0\%), HBV (8.8\%) and HCV (1.1\%) among professionals population that participated in the study. This study shows a very significant different in the seroprevalence of HIV, HBV and HCV among artisan/unemployed and professionals respectively (i.e. poorer society and upper class). A similar observation in Anambra State, Nigeria ${ }^{29}$ showed that the occupation of the antenatal women influenced the infection of the women. Low socioeconomic factor initiates multiple sexual partnership, unprotected sex, and predisposes to sexually transmitted infections ${ }^{30}$

This study has a number of limitations. This is a retrospective study conducted in an urban area based hospital and consisted of only pregnant women who were able to access hospital; for this reason, the seroprevalence reported here maybe a lower estimate of the true prevalence among pregnant women in Abuja, FCT, Nigeria. The rate might be higher in individuals who had a lower socioeconomic status such that they could not even reach a hospital from the rural area. No data is available for such risk factors as residence and place of birth. The population size is relatively small when compare to about 170million Nigerian population, and it will not be possible to generalize the outcome of the study.

\section{Conclusion}

Human immunodeficiency virus, $\mathrm{HBV}$, and $\mathrm{HCV}$ infection is a major global health problem necessitating a high priority in their prevention and control. There is a need for effective health education on behavioral change as well as the inclusion of HBV immunization for women of reproductive age to reduce the risk of spread to neonates through mother to child transmission. The significantly high seroprevalence of HIV, HBV and HCV recorded in this study especially among artisans/unemployed should the vigorously address by way of education and enlightenment campaign targeted among this population in order to reduce this scourge to barest minimum. The low seroprevalence of syphilis observed in this study should not engender complacency in view of the deleterious effect of untreated maternal infection on pregnancy outcome and spread of HIV.

\section{Acknowledgement}

Special appreciation goes to the management of National Hospital Abuja, Head of Department (HOD), the Chief Medical Laboratory Scientist (CMLS) and the entire staffs of Department of Medical Microbiology and Parasitology for granting me access to the data for this study.

\section{References}

[1].Awole M, Gebre-Selassie S. Sero prevalence of HBsAg and its risk factors among pregnant women in Jimma, South west Ethiopia. Ethiop J Health Dev 2005; 19:45-50.

[2].Awang EW, Cheung R. Global epidemiology of hepatitis B virus (HBV) infection. N Am J Med Sci 2011; $4: 7-13$

[3].Bahaf F, Tanom A, Montazam H, Sany AA. Seroprevalence of hepatitis C, hepatitis B and HIV and coinfections among pregnant women: A retrospective study in 2006 Malekan City, Iran. Res J Med Sci 2007; 1:13841.

[4].Buseri F, Seiyaboh E, Jeremiah Z. Surveying infections among pregnant women in the Niger Delta, Nigeria. J Glob Infect Dis 2010; 2:203-11.

[5].Drosten C, Nippraschk T, Manegold C, Meisel H, Brixner V, Roth WK, et al. Prevalence of hepatitis B virus DNA in anti-HBc-positive/HBsAg-negative sera correlates with HCV but not HIV serostatus. J Clin Virol 2004; 29:59-68. 
DOI: $10.21522 / \mathrm{TIJPH} .2013 .06 .02$. Art001

ISSN: $2520-3134$

[6].Elsheikh RM, Daak AA, Elsheikh MA, Karsany MS, Adam I. Hepatitis B virus and hepatitis C virus in pregnant Sudanese women. Virol J 2007; 4:104.

[7].FMOH, (2010) Department of public health, National AIDS/STI control Programme ANC Sentinel Survey Nigeria, 2010; Pg 9-10.

[8].Federal Ministry of Health, Nigeria (FMOH). Technical Report on 2003 National HIV/Syphilis Sentinel Survey among Women Attending Antenatal Clinics in Nigeria. Abuja: Nigeria Federal Ministry of Health; 2004. [9].Gonçales FL Jr, Pereira JS, Da Silva C, Thomaz GR, Pavan MH, Fais VC, et al. Hepatitis B virus DNA in sera of blood donors and of patients infected with hepatitis $\mathrm{C}$ virus and human immunodeficiency virus. Clin Diagn Lab Immunol 2003; 10:718-20.

[10]. Hou J, Liu Z, Gu F. Epidemiology and prevention of hepatitis B virus infection. Int J Med Sci 2005; 2:50-7. [11]. Kebede E, Chamiso B. Prevalence of syphilis in pregnancy in Addis Ababa. East Afr Med J 2000; 77:2126.

[12]. Koziel M, Peters M: Viral hepatitis in HIV infection. N Engl J Med 2007, 356:1445-1454.Saravanan S, Velu $\mathrm{V}$, Kumarasamy N, Nandakumar S, Murugavel K, et al.: Coinfection of hepatitis B and hepatitis C virus in HIVinfected patients in South India. World J Gastroenterol 2007, 13:5015-5020.

[13]. Khakhkhar VM, Bhura PJ, Bhuva SP, Patel CP, Cholera MS. Sero prevalence of hepatitis B amongst pregnant women attending the antenatal clinic of a tertiary care hospital, Jamnagar (Gujarat). Natl J Med Res 2012; 2:362-5.

[14]. Madhava V, Burgess C, Drucker E. Epidemiology of chronic hepatitis C virus infection in sub-Saharan Africa. Lancet Infect Dis 2002; 2:293-302.

[15]. Mulu A, Kassu A, Tessema B, Yismaw G, Tiruneh M, Moges F, et al. Seroprevalence of syphilis and HIV1 during pregnancy in a teaching hospital in northwest Ethiopia. Jpn J Infect Dis 2007; 60:193-5.

[16]. Nelson, B. Mathers, B. Cowie, et al., "The epidemiology of viral hepatitis among people who inject drugs: results of global systematic reviews,” The Lancet, vol. 378, no. 9791, pp. 571-583, 2011.

[17]. Ndams IS, Joshua IA, Luka SA, Sadiq HO, Ayodele SB. Human immunodeficiency virus seroprevalence among pregnant women in Minna, Nigeria. Ann Niger Med 2010; 4:14-7.

[18]. Osotimehin B. Director General, National Action Committee for the Control of AIDS (NACA), Federal Ministry of Health, Nigeria. NACA Bulletin; July 2008.

[19]. Ogunro PS, Adekanle DA, Fadero FF, Ogungbamigbe TO, Oninla SO. Prevalence of anti-hepatitis C virus antibodies in pregnant women and their offspring in a tertiary hospital in Southwestern Nigeria. J Infect Dev Ctries $20071 ; 1: 333-6$.

[20]. Olokoba AB, Salawu FK, Danburam A, Olokoba LB, Midala JK, Badung LH, et al. Hepatitis B virus infection amongst pregnant women in North-eastern Nigeria-A call for action. Niger J Clin Pract 2011; 14:10-3. [21]. Ojo DA, Oyetunji IA. Sero prevalence of syphilis among pregnant women in Osogbo in Southwestern Nigeria. Asset Ser B 2007; 6:61-5.

[22]. Pirillo MF, Bassani L, Germinario EA, Mancini MG, Vyankandondera J, Okong P, et al. Seroprevalence of hepatitis B and C viruses among HIV-infected pregnant women in Uganda and Rwanda. J Med Virol 2007; 79:1797-801.

[23]. Population Reference Bureau. World Population Data Sheet, 2011. Available from: http://www.prb.org//publications/datasheets/2011/world-population-data-Sheet.aspx. [Last assessed on 2013 Sep $02]$.

[24]. Pineda JA, Romero-Gómez M, Díaz-García F, Girón-González JA, Montero JL, Torre-Cisneros J, et al. HIV coinfection shortens the survival of patients with hepatitis $\mathrm{C}$ virus-related decompensated cirrhosis. Hepatology 2005; 41:779-89.

[25]. Raghuraman S, Subramaniam T, Daniel D, Sridharan G, Abraham P. Occurrence of false positives during testing for antibodies to hepatitis C virus among volunteer blood donors in India. J Clin Microbiol 2003; 41:178890.

[26]. Schmid, G., (2004) Bulletin of World Health Organization. 82(6): 402-9.

[27]. Tessema B, Yismaw G, Kassu A, Amsalu A, Mulu A, Emmrich F, et al. Seroprevalence of HIV, HBV, HCV and syphilis infections among blood donors at Gondar University Teaching Hospital, Northwest Ethiopia: Declining trends over a period of five years. BMC Infect Dis 2010; 10:111.

[28]. UNAIDS. 2008 Report on Global AIDS Epidemic. Geneva, Switzerland: UNAIDS; 2008.

[29]. WHO - World Health Organization (2010) HIV/AIDS epidemic update Available from: aids.gov.br. 


\title{
Malaria Treatment at Community; Can Rapid Diagnostic Test Eliminate Stock-out of Artemisinin-Based Combination Therapy in South Sudan
}

\author{
Article by Dricile Ratib \\ PhD, Public health, Texila American University, Uganda \\ E-mail:dricileratib@yahoo.co.uk
}

\begin{abstract}
Malaria remains endemic in South Sudan, accounting for $20 \%$ of deaths and $30 \%$ of hospital admissions (Global Fund, 2015). The 2014 to 2021 South Sudan national malaria strategic plan aims to bring down the morbidity and mortality related to malaria by $80 \%$, but stock-out of drugs is a major challenge (National malaria control program [NMCP], 2017) ${ }^{l}$.

South Sudan received over fifty five million (55,585,832 USD) United states dollars from Global fund in 2015 for fighting malaria in addition to similar amounts from Department of International development (DFID) but this has not changed the ant-malaria stock out status(DFID, 2015). In the last quarter of 2014, 854 Community based distributors (CBDs) from two sub-recipients had stock out of Artemisinin based combination therapy (ACTs) (Global Fund, 2015) ${ }^{2}$.

This retrospective study re-analyzed the data used for training 240 community based drug distributors (CBDs) in April 2015 on the use of malaria rapid diagnostic test (RDT). Of those who passed the post test, 131 were given kits of RDT to practice the skills they had acquired and give ACTs only to the children 2-59 months who test positive for malaria.

The number of children assessed with fever were 1047, (534 males and 513 females); 1012 were done RDT and only 364(36\%) tested positive for plasmodium falciparum malaria. The iCCM programme in South Sudan treats all fever cases with ACTs. This one month RDT use therefore saved $64 \%$ of the ACTs that would have been irrationally used.
\end{abstract}

\section{Introduction}

\section{Problem statement}

The acute on chronic conflict in South Sudan has destroyed and retarded the health systems to fight malaria, a serious acute infectious illness spread by bites of infected female anopheles mosquito, and is the leading cause of morbidity and mortality in the country, which accounts for $20-40 \%$ of morbidity resulting in over $20 \%$ of deaths reported at health facilities and $30 \%$ of all hospital admissions $^{3}$. The 2009 malaria indicator survey showed that prevalence of infection in children Under 5 was $24.5 \%$ (95\% CI: 23.0-26.1) and in pregnant women was 9.9\% (95\% CI: 7.4-13.1). About two thirds (64\%) of children under five (5) and $46 \%$ of pregnant women were anemic (Eyobo et al $2014)^{4}$.

The ministry of health has developed national malaria control strategy 2015-2021 that lays down a framework for the prevention, diagnosis, treatment and control of malaria in the Country (WHO Afro $2017)^{5}$. The key interventions are information, education and behaviour change communication programmes; early detection with rapid diagnostic tests (RDTs), treatment with artemisinin-based combination therapy (ACT), indoor residual spraying (IRS), use of long-lasting insecticidal nets (LLINs) and intermittent preventive treatment (IPT) for pregnant women. The South Sudan MoH Malaria strategy is in line with the WHO Global Technical Strategy for Malaria (2016-2030) ${ }^{6}$,

\footnotetext{
${ }^{1}$ NMCP South Sudan -National malaria strategic plan 2014-2021

2 OIG_GF-OIG-15-016_Report_en.pdf

${ }^{3}$ World malaria report 2017

${ }^{4}$ Malaria indicator survey 2009, South Sudan: baseline results at household level

${ }^{5}$ south-sudan-national-malaria-strategic-plan-2014-2021-launched

${ }^{6}$ Global technical strategy for malaria 2016-2030
} 
health sector development plan 2012-16 (MoH- South Sudan 2012) ${ }^{7}$ and Action and Investment to defeat Malaria (2016-2030) strategy developed by the Roll Back Malaria (RBM) partnership (WHO, 2016) ${ }^{8}$.

The World health organization (WHO) recommends parasitological confirmation of malaria through quality assured diagnosis, in all settings before treatment is started (WHO 2010) ${ }^{9}$. Treatment solely on the basis of clinical suspicion should only be considered when a parasitological diagnosis is not accessible (WHO 2011) ${ }^{10}$. Prompt diagnostic confirmation of malaria can be achieved through good quality microscopy. Since this is not feasible in many rural settings across Africa, especially South Sudan, quality assured malaria Rapid Diagnostic Tests (RDTs) represent suitable alternatives for confirmation of malaria diagnosis prior to treatment at the health facilities (MoH- South Sudan National Malaria control program 2015) ${ }^{11}$.

However, the situation is not the same at the community level where integrated community case management of malaria takes place. Government of South Sudan through support from partners has been implementing a home management of malaria as part of the integrated community case management of malaria, pneumonia diarrhoea and malnutrition (iCCM) program in the country including the counties like Aweil centre and Aweil west of Northern Bahr el Ghazal state since 2010 which is shown to reduce child mortality by $40 \%$ (Population services international [PSI] 2012, Malaria Consortium $[\mathrm{MC}], 2012)^{12} \cdot{ }^{13}$ The program targets children between 2-59 months and treatment are conducted by community based distributors (CBDs). Treatment of malaria at community level by community based distributors (CBDs) in these areas has been solely based on clinical suspicion due to the inaccessibility of parasitological diagnosis leading to inclusion of significant proportion of febrile illnesses that are not necessarily malaria who needed to be assessed for other causes of fever and given appropriate treatment(WHO 2012) ${ }^{14}$. The result is chronic stock out of ACTs especially during the peak of rainy season when ACTs are needed most; hence the impact of the project is not being felt as it should due to the stock-outs constraints (Systems for improved access to pharmaceuticals and services [SIAPS]2016, 2015),${ }^{15}{ }^{16}$.There was need therefore to find out what proportion of the ACTs are being given to children with febrile illness who do not actually have malaria by reviewing and re-analyzing available RDT and ACT data from a pilot study done in Northern Bahr el Ghazal in 2015.

\section{Main objective}

The purpose of the study is to find out if the irrational use of ACTs for all children 2-59 months with febrile illness contributes to the chronic stock out of ACTs in former Northern Bahr al Ghazal state of South Sudan.

\section{Specific objectives}

- To find out the proportion of children 2-59 months with fever who tested positive for malaria with rapid diagnostics tests (RDTs) in Aweil Centre and Aweil West Counties in April 2015

- To find out the doses of ACTs given to children 2-59 months during the period when RDT was used in Aweil Centre and Aweil West Counties in April 2015

\footnotetext{
${ }^{7}$ Health-sector-development-plan-2012-2016.pd

${ }^{8}$ Malaria Policy Advisory Committee to the WHO: conclusions and recommendations of eighth biannual meeting (September 2015)

9 9789241599412_eng.pdf-parastological confirmation of malaria diagnosis

${ }^{10}$ world_malaria_report_2011/9789241564403_eng.pdf

${ }^{11}$ Approved-Printed-Version_SSD-MCM-Guidelines_2015.pdf

12 iCCM Program Brief Oct 2012_5__1

${ }^{13}$ Facilitator-Training-Manual-iCCM-South-Sudan_Malaria-Consortium_2012

${ }^{14}$ Training module on malaria control : case management

${ }^{15}$ Malaria-pmi-quarterly-updates-april-june-2015

16 pdf.usaid.gov/pdf_docs/PA00MW5Q.pdf
} 


\section{Methodology}

\section{Study area}

The malaria RDT field test was conducted in Aweil centre and Aweil west counties of former Northern Bahr el Ghazal state in April 2015. Northern Bahr el Ghazal was one of the 10 states of South Sudan. It had an area of $30,543 \mathrm{~km}^{2}$ and is part of the Bahr el Ghazal region (National Bureau of statistics [NBS], 2011)17. The state is susceptible to flooding which creates a contusive environment for mosquito breeding resulting in the state having high malaria incidences during the rainy season(Magda Armah Penn Amaah and Jemila M. Ebrahim, 2016 )18. Flooding commonly occurs in the later part of the rainy season, from July to December, and is known to cause issues with accessibility. The two counties covered by the operational research: Aweil centre and Aweil west are also flood-prone areas with silty soils and poor drainage system19 (Max Gibson and Eric Kramak 2016).

\section{Sampling method}

Two Payams were randomly selected one from each of the Counties, Aweil centre and Aweil west. All the 240 CBDs and their supervisors in the selected payams of Gomjuer east and Chel south were included in the malaria RDT field test. Selected CBDs had different education levels. A total of $46.7 \%$ were illiterate and $40 \%$ and $13.3 \%$ had reached elementary and high school level respectively. The majority $85 \%$ had at least one year ICCM experience.

The 240 CBDs and CBD supervisors participated in one day training on malaria RDT use. The main objective of the training was to test whether a minimal investment in training time and use of simple job aid could achieve satisfactory competency. Supplies used during the training included RDTs, gloves, alcohol swabs, lancets, sharps and non-sharps bins, and a copy of the job aid for each participant.

The training was facilitated by Ministry of health officials from the County health department (CHD) and technical team from health partner. The training had two sections the theoretical and practical part. The generic WHO malaria RDT job aid was simplified and used during the training (WHO 2010) $)^{20}$.

The facilitators started by reviewing patient history taking and physical examination. This was to ensure that only children with fever were tested for malaria with RDT. They then demonstrated step by step how to conduct malaria RDT starting with how to open the test packet, assemble the RDT items, conduct the test, interpret and record the results. The training materials were revised to be more pictorial with less writing to enable the CBDs who are illiterate to benefit too. The trainees then practiced on one another and were given assistance by the trainers who attended the trainings. A pre and post-test was administered together with a competency checklist to ensure that the competency of the trainees was confirmed before they could go and administer RDT on actual patients. Only the CBDs who passed the competency test were allowed to proceed to test children with fever and those found positive for malaria were given ACTs according to the iCCM guidelines (WHO and UNICEF $2012)^{21}$.

\footnotetext{
${ }^{17}$ key_indicators_for_northern_bahr_el_ghazal.pd

18 health-cluster-bulletin_24-august---06-sept-2016.pd

${ }^{19}$ Understanding flood resilience in rural South Sudan

${ }^{20}$ Generic_PfPan_training_manual_web.pdf

${ }^{21}$ WHO/UNICEF JOINT STATEMENT - Integrated Community Case Management: An equity-focused strategy to improve access to essential treatment services for children
} 


\section{Sample size and sampling design}

This was a retrospective cohort study. Two Payams were randomly selected one from Aweil Centre and another from Aweil West. All the children who presented with fever to the CBD from the selected payams were enrolled into the study. A total of 1047 children 2-59 months who had fever from the two payams of Chel South and Gumjur east of Aweil centre and Aweil west respectively were enrolled into the study. Of these 513 were females and 534 were males. Of these 996 were tested for malaria with RDT. And those found to be positive were give Artemisinin-based Combination Therapy for treatment of malaria by the community drug distributors.

\section{Research team}

The research team included the 131 community based drug distributors (CBDs) out of 240 CBDs who were trained and passed the post test well, (42 from Gumjur east and 89 from Chel South Payams) of Aweil west and Aweil centre respectively); 16 CBD supervisors half from each of the two Payams, two field officers one for each Payam, Monitoring and Evaluation officer and the researcher.

The function of the CBDs was to screen children 2-59 months for fever who were then assessed for danger signs like anemia, convulsions, severe acute malnutrition. Those with fever were done RDT while those with danger signs were referred and those with fever who were well outside the age bracket were reassured and sent back home. The CBD also recorded the results of the RDT tests. Those who tested positive were given ACT and those with fever, but tested negative were given amoxicillin according to the iCCM guidelines with suspicion that they could be having bacterial infection commonest in the area like streptococcus are responsive to amoxicillin. The function of the CBD supervisor was to oversee 10-15 CBDs weekly on bicycle to see if they were working and the records were well made in the patient register. He made corrections where necessary and summarized the results from his CBDs into caseload summary. The field officer rode on motor bike to supervise the CBD supervisors and collects the caseload summaries to be handed over to the $\mathrm{M}$ and $\mathrm{E}$ officer who then made entries into the data base made by the researcher.

\section{Research equipment and materials}

For the training of the CBDs and all the research team, standard WHO training materials on malaria rapid diagnostic tests were used (WHO 2010) ${ }^{22}$. 8Bicycles for CBD supervisors, 2motorbikes for field officer, and a vehicle hire for the researcher, desk top computer for $\mathrm{M}$ and $\mathrm{E}$ officer, a laptop for the researcher. The ministry of health, republic of South Sudan patient register was used to capture the patient information and CBD supervisor case load summary for the summarizing the data from 1015 CBDs.

\section{Data collection}

Since the data for the CBDs is being recorded in the ICCM registers, recorded in the iCCM registers, especially CBD patient registers designed by the ministry of health, the data collectors needed only the period of the data collection which was April 2015 for which the RDT pilot and training was conducted. The original purpose of the RDT pilot was to assess whether the CBDs some of whom were illiterate could be able to gain competency and skills during the training to be able to do the RDT tests. In this retrospective study, the focus is the RDT results and the ACTs used, hence different objectives and data actually required.

The hard copies of CBD patient registers are kept in the office of the implementing partner in Aweil state capital. The filling is stratified by Payam, hence this made it easier for the data collectors to locate the files for the CBDs from Chel south and Gumjur east payams for the period of April 2015. The data is then entered in to the data-base developed by the researcher and then analyzed.

\section{Quality assurance}

To ensure that the tests and treatments given by the CBDs are reliable, all the CBDs were trained $1^{\text {st }}$ for 6 days based on the ministry of health ICCM guidelines then for one additional day with focus

${ }^{22}$ Generic_PfPan_training_manual_web.pdf 
on RDT use making a total of one week training. Only those CBDs who pass the competence test were given RDT to test the children. A maximum of 15 CBDs were supervised by a CBD supervisor to ensure that the quality of supervision is good and enough time is taken by the CBD supervisor to check the RDT cassettes already used and compared with the results recorded by the CBD in the patient register. The ACT treatment is also checked for the storage conditions, expiry dates, and stock records and compared with ACTs issued out. The researcher did spot checks from sample CBD registers and $\mathrm{CBD}$ supervisor case load summery and compared this with the $\mathrm{M}$ and $\mathrm{E}$ data in soft copy for consistency.

\section{Data analysis}

Data analysis was done using statistical package for social scientists (SPSS). This is then compared for consistency with the data in the district health information system (DHIS) which is an access based software used by the ministry of health in South Sudan for data entry and analysis.

\section{Results}

The total number of children with fever assessed by the 131 community based drug distributors (CBDs) for a period of 1 month (April 2015) was 1047. Of these 534 were boys and 513 girls. 841 of the children were from Aweil Centre while 206 were from Aweil west. Not all the children were tested, only 1012 out of 1047 were tested with rapid diagnostic test (RDT); of these 364 (36\%) tested positive for falciparum malaria. All the children who tested positive for RDT were given ACT, 71 were infants given ACT infant while 349 were toddlers given ACT toddler. 25 children (20 from Aweil Centre and 5 from Aweil west who had fever were not tested for malaria, but were given ACTs (see table1) 


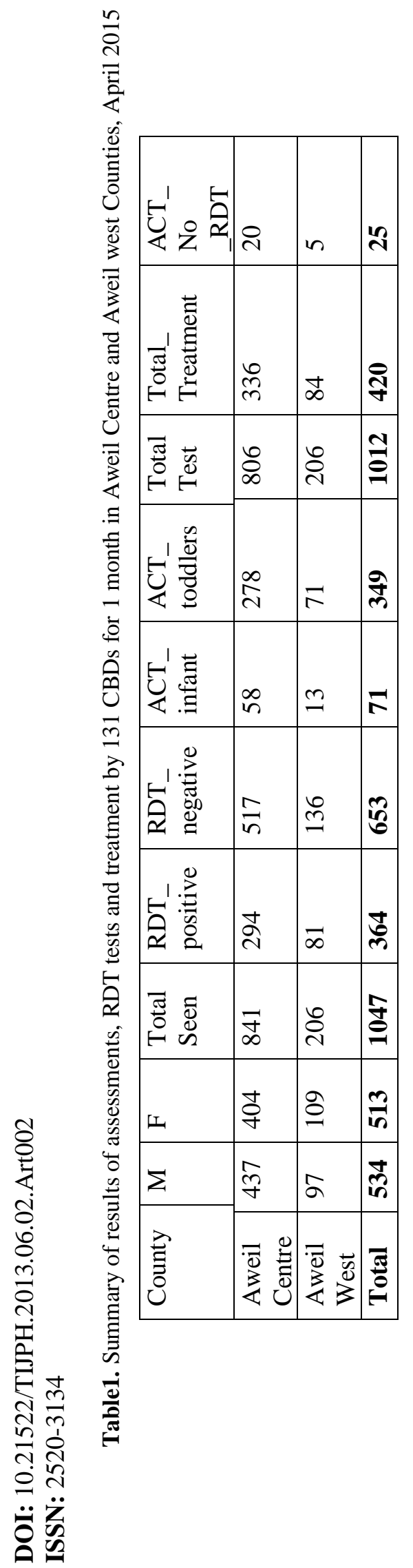


During the period $1^{\text {st }}$ to $30^{\text {th }}$ April 2015, 131 CBDs assessed 1047 children with fever. This gives a mean of 8children with fever cases per CBD. Since only $36 \%$ of these children assessed with fever tests positive for malaria with RDT, the mean number of ACT doses issued out per CBD is 3 doses per month (see table 2).

Table2. Mean malaria caseload for CBDs for the 1month period April 2015

\begin{tabular}{|l|l|l|l|l|l|}
\hline \multicolumn{7}{|l|}{ Descriptive statistics-CBD caseload } \\
\hline & N & Minimum & Maximum & Mean & Std. Deviation \\
\hline $\begin{array}{l}\text { No. of children tested per } \\
\text { CBD }\end{array}$ & 131 & 1.00 & 12.00 & 7.9924 & 3.03187 \\
\hline $\begin{array}{l}\text { ACT doses given per } \\
\text { CBD }\end{array}$ & 131 & .00 & 10.00 & 3.2061 & 2.73079 \\
\hline Valid N (list wise) & 131 & & & & \\
\hline
\end{tabular}

The number of boys and girls who suffered from malaria during the research period was 534 and 513 respectively. These constitute $51 \%$ and $49 \%$ with boys tending to have more illness than girls (See fig: 2 below).

\section{Percentage of children with fever by gender in Aweil Centre and Aweil West April 2015}

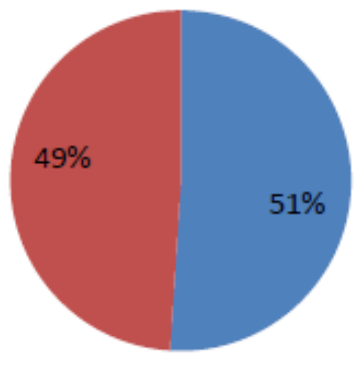

Figure 1. \% Distribution of children assessed with fever by gender-Aweil Centre and Aweil West Counties April 2015.

Over one thousand (1047) children were assessed with fever and 1012 tested with RDT for falciparum malaria, the most common species of plasmodium in the republic of South Sudan. Of those tested only $420(36 \%)$ tested positive for malaria and were given AC treatment (table 3). However, in the integrated community case management of malaria (iCCM), all children with fever are treated with ACT (MoH 2010). This means that if the for the month of April alone 2016, 627 doses of ACT would be lost to irrational use in the community through the community based treatment programme. Of the 627 ACTs saved, 505 (60\%) were from Aweil Centre and 122 (59\%) from Aweil West. The mean ACTs saved for the two counties in April 201 was $59.6 \%$ ( see fig 3 below).

Table 3. No. of ACTs saved through RDT use in aweil centre and aweil west april, 2015.

\begin{tabular}{|l|l|l|l|l|}
\hline County & Children with fever & ACT Treatments & ACTs saved & \% ACTs saved \\
\hline Aweil Centre & 841 & 336 & 505.0 & $\mathbf{6 0 . 0}$ \\
\hline Aweil West & 206 & 84 & 122.0 & $\mathbf{5 9 . 2}$ \\
\hline Total & $\mathbf{1 0 4 7}$ & $\mathbf{4 2 0}$ & $\mathbf{6 2 7 . 0}$ & $\mathbf{5 9 . 9}$ \\
\hline & & & & \\
\hline
\end{tabular}




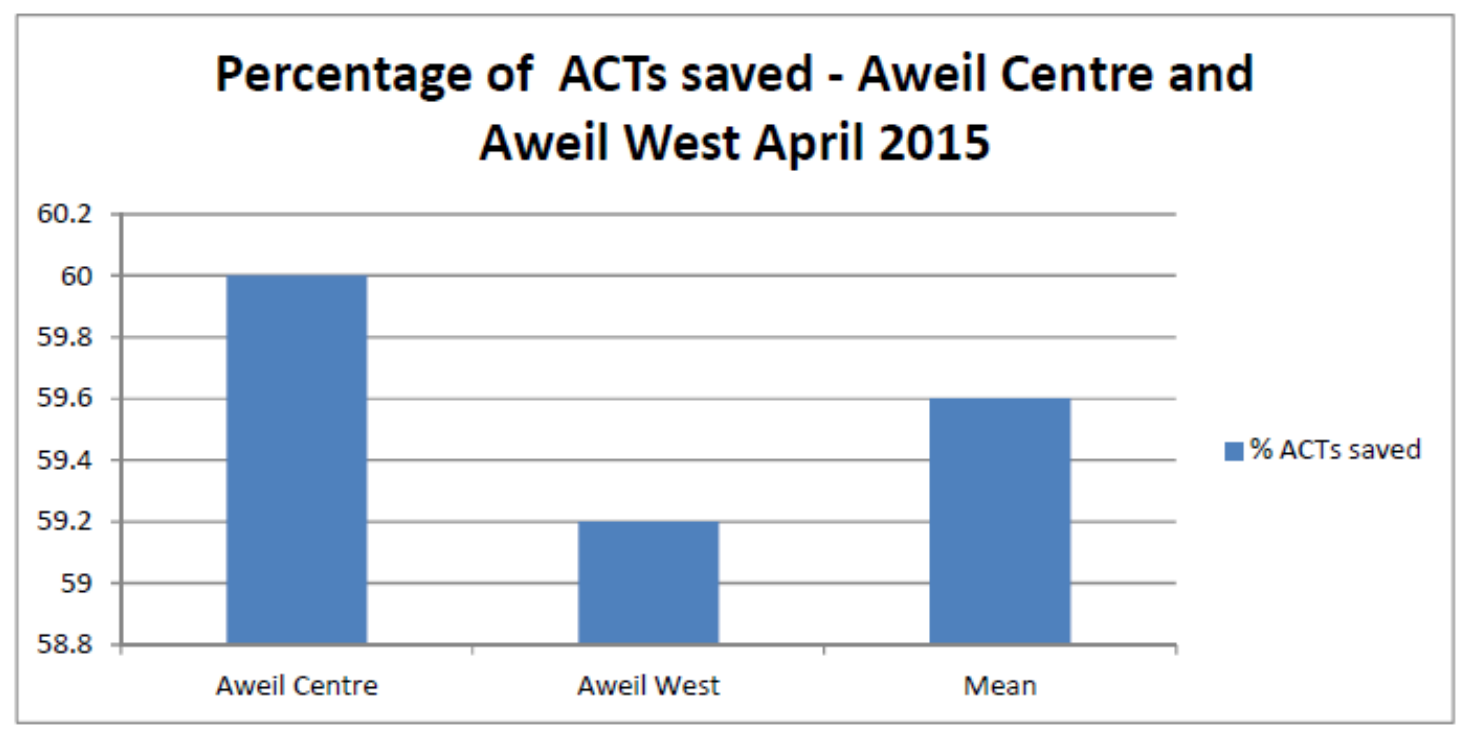

Figure 2. Mean ACTs saved from Aweil Centre and Aweil west Counties April 2015

\section{Discussion}

The ministry of health, UN agencies like WHO and UNICEF international non-governmental organizations and community based organizations among others have being trying hard to reduce morbidity and mortality related to malaria, especially among children, but this has not made significant impact as infant and young child mortality related to Malaria remains high especially during the rainy season partly due to ACT stock-outs. In 2017, 1.3 million people were infected in South Sudan and 220 died every week (ALIMA 2017) ${ }^{23}$

The findings of this retrospective study show that, only $36 \%$ of the fever cases being treated with ACT are actually caused by plasmodium falciparum. This result answers the research question in the objectives and is consistent with the study done in 2013 for the national malaria indicator survey which showed that $30 \%$ of all hospital admissions were due to Malaria (Eyobo B. M, 2014) ${ }^{24}$. This result is consistent with other similar study results from Tanzania which showed only $50 \%$ of fevers among children tested positive for malaria (Mubi et al 2011) 25 $^{25}$ and 58.6\% in Myamar (Ohnmar et al 2012). ${ }^{26}$ This has been partly attributed to frequent drug stock outs at all levels in the health care structure up to the community based programmes like iCCM(Dick, M., Farai, C., \&Joseph, N. $2011)^{27}$. Up to $27 \%$ of the drug stores, health facilities and pharmacies experience stock out of medicines in South Sudan (USAID, 2011). ${ }^{28}$

This study was done in April which is not the peak of malaria season; it is likely that the figures would be higher if the study was done in the months of August to November when the rains and subsequent flooding provides heavens for the breeding of mosquitos in Northern Bahr el Ghazal. The question now is what is the cause of 64\% of fever cases among children 6-59 months of age for which ACTs have been irrationally used?

The integrated community case management of malaria pneumonia and diarrhea in South Sudan and home based management malaria in the neighboring Uganda share one thing in common; they all suffer from chronic stock out of ACTs despite millions of dollars spent on procurement of ACTs

\footnotetext{
${ }^{23}$ ALIMA 2017, South-Sudan-mobile-clinics-respond-malaria-peak, para 4

${ }^{24}$ Malaria indicator survey 2009, South Sudan: baseline results at household level

${ }^{25}$ Malaria Rapid Testing by Community Health Workers Is Effective and Safe for Targeting Malaria Treatment: Randomised Cross-Over Trial in Tanzania.
}

\footnotetext{
${ }^{27}$ Pharmaceutical logistics assessment in South Sudan, Global health and technical assistance project

${ }^{28}$ Pharmaceutical logistics assessment in South Sudan, Global health and technical assistance project
} 
which are ideally enough to treat the $36 \%$ of the population with Malaria. Due to the frequent stock out of ACTs, some families in Uganda prefer indoor residual spraying (Uganda MoH, 2015). ${ }^{29}$

The challenge of drug stock out at facilities and with CBDs was also confirmed by the Global fund auditors that found that 854 community based drug distributors (CBDs) from two sub-recipients to population services international (PSI) had anti-malarial medicine stock outs in the last quarter of $2014 .^{30}$ Though only $36 \%$ of the tests were positive for malaria, the percentage could be higher because the RDT used was specific for plasmodium falciparum. Other species of plasmodium like plasmodium malariae, ovale and vivax among others would still be positive from a blood slide. A fever that tests negative with RDT was then referred to the health facility for further investigations and treatment. More research is therefore needed to confirm the diagnosis of febrile illness that test negative with RDT. Secondly the same research needs to be repeated during the peak of the rainy season when the malaria cases are very high.

\section{Conclusion}

Stock of medicines remains a big challenge to the integrated community based management of malaria, primarily due to irrational use of up to $64 \%$ of the available ACTs. Unfortunately the stock outs are likely to be during the peak of rainy season when the accessibility to health facilities is a challenge and malaria is also at its peak. This causes the morbidity and mortality due to malaria to remain high despite the concerted efforts from the Ministry of health, UN agencies, international organizations and the local communities to fight malaria. The solution will be to train all Community based distributors on use of RDTs and provide them with regular supplies. Include other preventive measures like indoor residual spraying, health education and long lasting insecticide treated net use if the morbidity and mortality due to malaria can be significantly reduced in South Sudan.

\section{References}

[1].ALIMA 2017, South Sudan: Mobile clinics respond to malaria peak. South-Sudan-mobile-clinics-respondmalaria-peak, para 4

[2].Armah, M. Amaah, P. and Ebrahim M.J. 2016. Health cluster bulletin \# 406 September 2016. South Sudun. health-cluster-bulletin_24-august---06-sept-2016.pd

[3].DFID, 2015. Annual review summary sheet. Integrated Community Case Management (ICCM) South Sudan. South-Sudan-ICCM-Integrated-Community-Case-Management-DFID-2015-review.pdf?x30250

[4].Dick, M., Farai, C., \&Joseph, N. 2011. Pharmaceutical logistics assessment in South Sudan, Global health and technical assistance project. s19289en.pdf

[5].Global fund 2015; Audit report for the Global Fund Grants to South Sudan. Office of the inspector general, 5th October Geneva 2015 OIG_GF-OIG-15-016_Report_en.pdf

[6].Malaria Journal201413:45. Doi.1475-2875-13-45

[7].Margaret B Eyobo, Adwok C Awur, Gregory Wani, Ahmed I Julla, Constantino D Remijo, Bakhit Sebit, Robert Azairwe, Othwonh Thabo, Edward Bepo, Richard L Lako, Lul Riek and Emmanuel Chanda, 2014. Malaria indicator survey 2009, South Sudan: baseline results at household level

[8].Marycelina Mubi, Annika Janson, Marian Warsame, Andreas Mårtensson, Karin Källander, Max G. Petzold, Billy Ngasala, Gloria Maganga, Lars L. Gustafsson, Amos Massele, Göran Tomson, Zul Premji, and Anders Björkman, 2011. Malaria Rapid Testing by Community Health Workers Is Effective and Safe for Targeting Malaria Treatment: Randomised Cross-Over Trial in Tanzania doi.org/10.1371/journal.pone.0019753.

[9].Max Gibson and Eric Kramak, 2016. Understanding flood resilience in rural South Sudan. id=77f24aa163aa-4224-a69f-b5aa50d449b0.

[10]. MC, 2012. Integrated Community Case Management (ICCM) for Malaria, Pneumonia, Diarrhoea \& Severe Acute Malnutrition. Facilitator-Training-Manual-iCCM-South-Sudan_Malaria-Consortium_2012.pdf

\footnotetext{
${ }^{29}$ Uganda malaria indicator survey 2014-2015

${ }^{30}$ OIG_GF-OIG-15-016_Report_en.pdf

SIAPS, 2016. Annual Report: Program Year 5 October 2015-September 2016 2015-2016. pdf.usaid.gov/pdf_docs/PA00MW5Q.pdf
} 
DOI: $10.21522 /$ TIJPH.2013.06.02.Art002

ISSN: $2520-3134$

[11]. MoH, 2010. Ntegrated Community Case Management of Childhood Malaria, Pneumonia and Diarrhoea: Implementation Guidelines.

[12]. MoH, 2015. Uganda malaria indicator survey 2014-15. MIS21.pdf.

[13]. MOH, Republic of South Sudan, 2012. Health sector development plan 2012-2016. health-sectordevelopment-plan-2012-2016.pdf.

[14]. NBS, 2011. 25th November 2010 Key Indicators for Northern Bahr El Ghazal (N.B.G) key_indicators_for_northern_bahr_el_ghazal.pdf.

[15]. NMCP, 2015. South Sudan Malaria Case Management Guidelines and Training Manual ApprovedPrinted-Version_SSD-MCM-Guidelines_2015.pdf.

[16]. Ohnmar, Tun-Min, San-Shwe, Than-Win and Virasakdi Chongsuvivatwong 2012. Effects of malaria volunteer training on coverage and timeliness of diagnosis: a cluster randomized controlled trial in Myanmar.

[17]. PSI, 2014. Integrated Community Case Management of Pneumonia, Malaria \& Diarrhea. iCCM_Program_Brief.pdf.

[18]. SIAPS, 2015. Systems for Improved Access to Pharmaceuticals and Services: Malaria Quarterly Updatemalaria-pmi-quarterly-updates-april-june-2015.

[19]. SIAPS, 2016. Annual Report: Program Year 5 October 2015-September 2016. PA00MW5Q.pdf.

[20]. Uganda Malaria indicator survey 2009. Uganda Bureau of statistics, Kampala Uganda.

[21]. UNICEF, 2012. WHO/UNICEF joint statement Integrated Community Case Management (iCCM). statement_child_services_access_whounicef.pdf.

[22]. USAID 2011, Pharmaceutical logistics assessment in South Sudan, Global health and technical assistance project.

[23]. WHO Afro, 2017. South Sudan national malaria strategy 2014-2015. south-sudan-national-malariastrategic-plan-2014-2021-launched.

[24]. WHO Malaria Policy Advisory Committee and Secretariat Malar J (2016) 15:117.

[25]. WHO Malaria Policy Advisory Committee and Secretariat, 2016. Malaria Policy Advisory Committee to the WHO: conclusions and recommendations of eighth biannual meeting (September 2015). Malaria Journal201615:117 doi.s12936-016-1169-x.

[26]. WHO, 2010. How to use rapid diagnostic test (RDT).generic_PfPan_training_manual_web.pdf

[27]. WHO, 2010. Parasitological confirmation of malaria diagnosis: WHO technical consultation, Geneva, 6-8 October 2009. Doi.9789241599412_eng.pdf.

[28]. WHO, 2011. WHO Global Malaria Programme: World malaria report 2011. Doi. 9789241564403_eng.pdf.

[29]. WHO, 2012. Training module on malaria control: case management guide for participants. Doi.9789241503976_eng.pdf.

[30]. WHO, 2015. Global technical strategy for malaria 2016-2030. 9789241564991_eng.pdf.

[31]. World health organization, 2017. World malaria report 2017. 9789241565523-eng.pdf. 


\title{
Family Planning Practices of Female Garment Workers
}

\author{
Article by Shazly Bari ${ }^{1}$, Irin Hossain ${ }^{2}$ \\ ${ }^{1,2}$ National Institute of Preventive and Social Medicine, Mohakhali, Dhaka \\ E-mail: irin.hossain@gmail.com ${ }^{l}$
}

\begin{abstract}
A cross sectional descriptive study was carried out among the garments workers with the objective to assess the family planning practices of female garment workers with structured questionnaire by face to face interview. The proportion of women seeking abortion was $75 \%$. The proportion of female workers were using family planning method was $85 \%$ and rest of workers were not using any type of method is 15\%. Among those 15\% who were using family planning method and apart from them $76.5 \%$ were taking OCP and $70 \%$ providing by Govt. source. There were also some garment workers who were concern about family planning method but due to long term use of oral contraceptive pills as contraceptive method leading to many chronic diseases. This study reflected family planning practices of female garment workers, for better standard. Further large scale studies needed to explore.
\end{abstract}

Keywords: Family planning practice, female garment workers.

\section{Introduction}

The female garment workers are not aware about taking any family planning method leading to unwanted and recurrent pregnancy which increases the risk of spontaneous abortion, low birth weight, prematurity and so on. Despite the significant expansion of health services in the last two decades in the countryside, the health status has remained poor in Bangladesh. One major reason of high maternal morbidity in Bangladesh is the lack of maternal knowledge about the need of antenatal care and preventive measures. As they are not conscious about receiving antenatal and postnatal care as well as vaccination so they are facing various gynaecological and obstetrical problems. The main objectives of this research were to identify knowledge and behavior of adolescents about menstruation, marriage, pregnancy, family planning etc and to specify different important matters like their functional behavior, if their health problem arises where they usually go, discussion about sexual matters with anyone, their willingness to know about reproductive health.

Among the contraceptive methods, sterilization, IUD, oral pills are the most widely used methods. The proportion of couples using these three methods in developing countries is much greater than corresponding proportion in developed countries which is about $81 \%$ and $43 \%$ respectively. In developed countries condoms are used widely because they are much aware of sexually transmitted diseases and it is a fact that condom prevents both pregnancy and sexually transmitted diseases. Sterilization is the most used method accounting for over one third of the world contraceptive use. China and India have almost half of the users of his method. In general, female sterilization is more common than male sterilization and this gap is widening. Oral pill is an important method in many countries but in contrast to China and India it is relatively insignificant [1]. In Bangladesh, during 1996-97 periods, among the different methods used 50\% was oral pill, $18.3 \%$ was female sterilization $14.9 \%$ was injectables, $9.4 \%$ was condoms, $4.3 \%$ was IUD, $2.7 \%$ was male sterilization, and $0.2 \%$ was implants. But in India $75.1 \%$ taken female sterilization as a method of choice oral pill. In Indonesia oral pill and injectables were methods of choice accounts respectively $28.2 \%$ and $38.6 \%$ [2]. Only $7 \%$ women had unmet need for family planning. 18\% discontinued use within 12 months mainly among the pills, condoms and traditional users.

Study shows the socioeconomic and geographical differentials in use of contraception in general terms, contraception for spacing varies more widely than for limitation of the family size. Urban, well-educated and wealthier respondents were much more like to use reversible methods to postpone the next birth than their rural, less educated and poorer counterparts [3]. The timing of female first 
marriages in relation to menarche shows an appreciable minority (28\%) of women age 45-49 reported that their first marriage occurred before menarche [4]. Traditionally, Bangladesh has been characterized by exceptionally early marriage for female and large age differences between husbands and wives. This situation is changing steadily. Female age at marriage has risen from about 16 years in the mid-1970s to about 18 years in 1989. About $60 \%$ of the Bangladeshi women were married by the time they were age 15 years. The median age of first marriage among the women 20-49 is 14 years. There has been slow but steady increase of first marital age among the women over past 25 years. The median age at first marriage increased from 13.3 among the women currently age 45-49 to 15.3 for those aged 20-24 years. Only one-half of the adolescents were aware of various family planning methods, and young people's knowledge about spacing methods, such as through the use of intrauterine devices (IUDs) or oral contraceptive pills, was very low. In India, high fertility rates, high rates of teenage pregnancy, high risk of STI/HIV, and poor nutritional status are the main health problems among the adolescent population. High fertility is related to early marriage [5].

\section{Methods}

\section{Study design and sample}

This study was conducted to assess the family planning practices of female garment workers at Meherun Apparels Ltd Malibag, Dhaka according to the following methodologies:

A semi structured questionnaire was used as research instrument. The questionnaire development: based on the specific objectives of the study, at first variables were identified. Data were collected by face to face interview, by asking them questions as per the written questionnaire at the factory. The study populations were interviewed one after another without disturbing their routine works. The interview was taken by the researcher herself at the site of the study.

\section{Analysis}

Collected data were analyzed after thorough checking, cleaning, editing and compiling by using the SPSS (Statistical package for social science, version 24 for windows) software the test statistics was used to analyze the data are descriptive statistics and inferential statistic according to the demand of the study with $95 \%$ confidence interval. Level of significance was set at 0.05 . Qualitative data were analyzed on the basis of themes.

\section{Result}

This was a cross sectional study, conducted among the female garment worker.

\section{Distribution of the respondents by history of unplanned or unwanted pregnancy $n=152$}

Out of the total 152 respondents who had children, majority (70\%) of them had no history of unplanned or unwanted pregnancy and less than one third (30\%) had history of unplanned or unwanted pregnancy.

Table 1. Distribution of the respondents by history of unplanned or unwanted pregnancy

\begin{tabular}{|l|l|l|l|}
\hline $\begin{array}{l}\text { History of unplanned } \\
\text { or unwanted } \\
\text { pregnancy }\end{array}$ & $\begin{array}{l}\text { History of } \\
\text { unplanned or } \\
\text { unwanted } \\
\text { pregnancy }\end{array}$ & Frequency & Percentage \\
\hline No & 152 & 106 & 70 \\
\hline Yes & & 46 & 30 \\
\hline Total & & 152 & 100.0 \\
\hline
\end{tabular}

\section{Distribution of the respondents by family planning practice $\mathbf{n}=\mathbf{2 0 0}$}

Out of the total 200 respondents most of them 170 (85\%) found to take contraceptive method and only $30(15 \%)$ did not practice contraceptive method. Out of the total 170 respondents who had history of taking contraceptive method more than half 90 (53\%) had started taking contraceptive 
method just after marriage, more than one third 60 (35\%) had started after first child birth and only more than one tenth $20(12 \%)$ had started after last child birth. Out of the total 200 respondents most of them $130(76.5 \%)$ took oral pills. Out of the total 130 respondents who use oral pill most of them $91(70 \%)$ got contraceptive pill from government source and $39(30 \%)$ got from non govt. source. Out of the total 99 respondents most of the respondents 90 (99\%) got government contraceptive pill by free of cost and only $1(1 \%)$ was not free.

Table 2. Distribution of the respondents by family planning practice

\begin{tabular}{|l|l|l|}
\hline $\begin{array}{l}\text { Practice of } \\
\text { contraceptive method }\end{array}$ & Frequency & Percentage \\
\hline Yes & 170 & 85 \\
\hline No & 30 & 15 \\
\hline Time of starting contraceptive method n= 170 \\
\hline After marriage & 90 & 53 \\
\hline After first child birth & 60 & 35 \\
\hline After last child birth & 20 & 12 \\
\hline Type of contraceptive use n= 170 \\
\hline Oral pills & 130 & 76.5 \\
\hline Condom & 15 & 8.8 \\
\hline Depo provera & 5 & 3 \\
\hline Copper T & 18 & 10.6 \\
\hline Norplant & 2 & 1.2 \\
\hline Source of getting contraceptive pill n= 130 \\
\hline Govt. & 91 & 70 \\
\hline Non-govt. & 39 & 30 \\
\hline Expense of Government oral pill \\
\hline Not free & 1 & 1 \\
\hline free & 90 & 99 \\
\hline
\end{tabular}

\section{Distribution of the respondents by problem in using oral pill and type of problem}

Out of the total 130 respondents who used oral pill half of the respondents 67 (51.6\%) had problem in using oral pill and $63(48.4 \%)$ had no problem in using oral pills. Out of the total 130 respondents who used oral pill majority $88(68 \%)$ had developed vertigo in using this method.

Table 3. Distribution of the respondents by problem in using oral pill and type of problem

\begin{tabular}{|l|l|l|}
\hline $\begin{array}{l}\text { Problem in using } \\
\text { this method n= 130 }\end{array}$ & Frequency & Percentage \\
\hline No & 63 & 48.4 \\
\hline Yes & 67 & 51.6 \\
\hline Types of problem n= 91 & 88 & 68 \\
\hline Vertigo & 8 & 6.15 \\
\hline Headache & 8 & 2.3 \\
\hline Nausea or vomiting & 3 & .76 \\
\hline Weight gain & 1 & 13.07 \\
\hline Weakness & 17 &
\end{tabular}

Distribution of the respondents by consultation about gap between children with husband $n=$ 152

Out of the total 152 respondents who had one child, two child or more, most of them $114(75 \%)$ talked about gap between two children and one forth 38 (25\%) did not consult with their husbands. 
Table 4. Distribution of the respondents by consultation about gap between children with husband

\begin{tabular}{|l|l|l|}
\hline $\begin{array}{l}\text { Consultation about } \\
\text { gap between } \\
\text { children with } \\
\text { husband }\end{array}$ & Frequency & Percentage \\
\hline No & 38 & 25 \\
\hline Yes & 114 & 75 \\
\hline Total & 152 & 100.0 \\
\hline
\end{tabular}

Distribution of the respondents by knowledge about emergency contraceptive $\mathbf{n}=\mathbf{2 0 0}$

Out of the total 200 respondents, majority 136 (68.0\%) had no knowledge about emergency contraceptive and 64 (32.0\%) had knowledge about emergency contraceptive.

Table 5. Distribution of the respondents by knowledge about emergency contraceptive

\begin{tabular}{|l|l|l|}
\hline $\begin{array}{l}\text { Knowledge about } \\
\text { emergency } \\
\text { contraceptive }\end{array}$ & Frequency & Percentage \\
\hline No & 136 & 68.0 \\
\hline Yes & 64 & 32.0 \\
\hline Total & 200 & 100.0 \\
\hline
\end{tabular}

\section{Discussion}

The study was carried out to describe the family planning practices of female garment workers in selected garment factory. The study was done to assess the family planning practices of female garment workers.

Out of the total 152 respondents who had children, majority (70\%) of them had no history of unplanned or unwanted pregnancy and less than one third (30\%) had history of unplanned or unwanted pregnancy. Most of them $170(85 \%)$ found to take contraceptive method and only 30 (15\%) did not practice contraceptive method. Out of the total 170 respondents who had history of taking contraceptive method more than half 90 (53\%) had started taking contraceptive method just after marriage, more than one third $60(35 \%)$ had started after first child birth and only more than one tenth $20(12 \%)$ had started after last child birth. most of them 130 (76.5\%) took oral pills.

Out of the total 130 respondents who use oral pill maximum of them 91 (70\%) got contraceptive pill from government source and 39 (30\%) got from non govt. source. Out of the total 99 respondents most of the respondents 90 (99\%) got government contraceptive pill by free of cost and only $1(1 \%)$ was not free. Out of the total 130 respondents who used oral pill half of the respondents $67(51.6 \%)$ had problem in using oral pill and $63(48.4 \%)$ had no problem in using oral pills. Out of the total130 respondents who used oral pill majority $88(68 \%)$ had developed vertigo in using this method. Out of the total 152 respondents who had one child, two child or more, most of them 114 (75\%) talked about gap between two children and one forth 38 (25\%) did not consult with their husbands. Majority 136 (68.0\%) had no knowledge about emergency contraceptive and $64(32.0 \%)$ had knowledge about emergency contraceptive. Out of the total 27 respondents, majority $12(40.74 \%)$ had taken ANC in upazila health complex, $6(22.22 \%)$ in private doctor and $9(33.33 \%)$ in other places.

\section{Conclusion}

The awareness of family planning as a way to reduce unwanted birth was found universal amongst eligible women in Bangladesh. However, not all women were equally aware about the family planning methods. Oral pills and condoms were widely known but the other methods such as injections, ligations, vasectomy and other methods were not well known.

\section{Acknowledgement}

I am extremely grateful to my respected teacher Assistant Professor Dr. Md. Shafiur Rahman my supervisor for his continuous support and scholarly guidance despite his busy schedules. Without his 
valuable advices, constructive suggestions, passion and whole-hearted co-operation, I could never have completed it in time.

I express my sincere gratitude to Prof. Manzurul Haque Khan, PhD, Program in charge MPH $(\mathrm{OEH})$

\section{References}

[1]. Acharya Dev Raj, Bhattarai Rabi, Pobalan Amuda, van Teijlingen, Edwin R, Chapman Glyn (2010) on Factors associated with teenage pregnancy in south asia in Health science Journal, vol 4, issue 1.

[2]. Candan Iltemir, Ozturk Turhan, Yuksel Onaron, Ilknur Gumus, Hilal Yuvaci, Elif Gozdemir (2010), on Adolescent Pregnancies: Maternal and Fetal Outcomes. The new Journal of Medicine; vol 27; pp 113-116.

[3]. Chabra, S on Perinatal outcome in Teenage Mothers. The journal of Obstetrics and Gynaecology of India, Feb 1991, vol 41(1), pp 30-32.

[4]. Prianka Mukhopadhyay, R. N. Chaudhuri and Bhaskar Paul on The Hospital based perinatal Outcomes and complications in Teenage Pregnancy in India, (2010); October, vol 28(5); pp 494-500.

[5]. Rahman MM, Akter S, Mondal MNI on Contraceptive Use among Married Women in Chuadanga District, Bangladesh. Meddle East Journal of Family Medicine (2008); Vol 6(2), pp 40-45. 


\title{
Awareness and Knowledge of Diabetic Retinopathy (DR) among Al-Batinah Population, Oman-A Pilot Study, 2018
}

\author{
Article by Gopi Suresh Vankudre ${ }^{1}$, Galal Ismail ${ }^{2}$, Shaikha Salim Al-Shumosi ${ }^{3}$ \\ ${ }^{1}$ Master of Optometry, College of Health Sciences, University of Buraimi \\ ${ }^{2}$ Ph. D, College of Health Sciences, University of Buraimi \\ ${ }^{3}$ B.Sc. College of Health Sciences, University of Buraimi \\ E-mail: gopi.v@uob.edu.om ${ }^{1}$
}

\begin{abstract}
Introduction: As per Oman government's health report (2013), Diabetes Mellitus (DM) prevalence in Omani population aged 18 and above was $12.3 \%$. Omani young adult and older population, are at a higher risk of being diabetic and developing diabetic retinopathy $(D R)$. There are limited studies conducted in AlBatinah region, to evaluate the community's, DR related awareness and knowledge. Evidences on community's condition related knowledge can further help in enhancing the eye health care system.

Aim: To evaluate DR related awareness and knowledge, among Al Batinah population in Oman.

Material and Methods: This cross-sectional questionnaire-based study involved 100, randomly selected Omani participants. A self-designed validated questionnaire was used to assess awareness and knowledge of DR, amongst Al-Batinah population. The survey-based responses were analysed using Statistical Package for Social Sciences (SPSS) version 21.

Results: All participants have heard of DR. Relative or friend was the most common knowledge (51\%) source. $81 \%$ of the study participants were aware that DM leads to ocular complications. $94 \%$ participants believed that the eye care visit can be avoided, if DM is under control. Controlled diet was the highly agreed DR prevention strategy among the participants (88\%). Agreement on the use of medication, laser and surgery as a part of the treatment, was observed to be $29 \%, 62 \%$, and $70 \%$ respectively.

Conclusion: Awareness about DR, among the participants was high. However, the condition related knowledge variations were observed.
\end{abstract}

Keywords: Awareness and Knowledge-Diabetic Retinopathy, Diabetic Eye Disease.

\section{Introduction}

Universally, Diabetes Mellitus (DM) prevalence is expected to grow at around 592 million by the year 2035, from 382 million reported in 2013. Diabetic Retinopathy (DR) is one of the leading causes of vision impairment or loss, especially in the 20-74 age group. The condition shows systemic as well as ocular involvement. The systemic complications such as 'cardiovascular, neural and renal' involvements are commonly observed (Al Zarea, 2016). Cataract, Glaucoma, retinopathy and macular edema are the ocular complications secondary to DM (Nei.nih.gov, 2018).

DM prevalence in Oman is on rise (Khandekar et al., R., 2003). As per the governmental report, in 2013, DM prevalence in Omani population is $12.3 \%$ among the age group of 18 and above. Out of the total diabetic population, $10 \%$ of the population is affected by visual impairment associated with DR. The country maintains, a National DM Register and follows World Health Organization's recommended managerial guidelines. Health promotion and provision of the treatment for DM and DR are provided through primary health centers (Khandekar, 2015).

Noncompliance with the regular checkup to screen the associated disease complication and or treatment, could lead to further irreversible sight-threatening ocular conditions. This can further negatively affect the vision-related quality of life and also create an economic burden to the individual and his family. Establishing the vision rehabilitative services are also recommended by the health program auditors 
(Khandekar, 2015). Hence, to ensure the program success, it is important that the community is aware of the condition and its severity causing a socioeconomic impact. Knowledge related to regular screening, preventive measures, available treatment options and visual rehabilitative services for patients with the sight-threatening condition, is also important.

Many people with early-onset DR do not complain of any symptoms (M'Kiunga et al., K., 2017). Retinopathy in these cases keeps developing to a higher complicated level (Al Zarea, 2016). Edema due to the accumulation of fluid in the retina post leakage can result in a decreasing central vision (Shetgar et al., 2015). Retinal detachment can also be observed as severe complication of diabetic eye disease. Edema is usually painless and can have no or few symptoms at an early stage. The symptoms could be the primarily blurred vision but must be dealt promptly to prevent irreversible degenerative changes (Al Rasheed, 2017).The complication of DR is exacerbated in those who do not receive guidelines for medical care, DM prevention, attention to the symptoms and the probable personal neglect. The effect of DR on physical performance and role constraints ability to perform daily activities, work efficacy, participation in social life and recreational activities. Hence, it is recommended that all individuals affected with DM to undergo periodic ocular examinations and prevent future complications (Webeye.ophth.uiowa.edu, 2017).

With the higher prevalence and increased diagnostic efficacies of health care systems countrywide, DM has taken one of the leadership positions for causing a public health challenge (Shetgar et al., 2015). It has estimated total prevalence of $10 \%$, increasing up to $30 \%$ in the elderly population. El Haddad (1998), found the prevalence of DR in $42.4 \%$ of the referred patients. Further, the author also discovered that DR was more prevalent in Omani male population compared to females.

The increasing prevalence of DR is posing a significant eye health challenge (Khandekar et al., 2003). Unfortunately, the eye disease burden causes a tremendous effect on the individual's quality of life, if not treated at an early stage (Webeye.ophth.uiowa.edu, 2017). Many patients report to the eye health facilities at an advanced stage of DR (Al Rasheed et al., 2017). Level of accessibility, affordability, and awareness were the attributes for the nonattendance to eye health centers at an early stage (Khandekar et al., 2003). Out of these, lack of awareness is considered as the most important factor (Webeye.ophth.uiowa.edu, 2017).

In summary, DR can lead to irreversible vision loss. Omani old as well as young population, are at a higher risk of DM and DR. Early diagnosis and timely management of the condition play a pivotal role. Awareness regarding the condition within the affected or at-risk population is one of the critical factors for its detection and reduction of the overall disease burden. There are limited studies conducted in Al-Batinah region, to evaluate the community's, DR related awareness and knowledge. Understanding this disease related educational level, could be crucial to design further health promotional activities and or to form the future eye health policies.

\section{Materials and methods}

\section{Materials}

A self-designed and validated questionnaire was used to evaluate the awareness and knowledge among the involved participants. The survey was prepared in English and further translated into Arabic. The translation was validated by Arabic language expert.

\section{Questionnaire design}

A questionnaire was designed through a thorough literature review. The first part of the survey obtained the demographic details of the participants as well as patient's current diabetic status. The second part of the questionnaire consists of questions collecting patient categorical or open-ended responses. The questions were focused on understanding the patient's awareness and knowledge about ocular effects of DM, the importance of eye examination, treatment and rehabilitative options available for the management of DR. Participant's awareness about DR is self-declared. The questionnaire was validated by the subject experts. Field investigator was trained to conduct the survey. Participant's responses were obtained through the questionnaire and were compared with the model answers. 


\section{Setting and design}

It was a cross-sectional, questionnaire-based, prospective study. The study proposal obtained the necessary permissions from the Research and Ethics Committee, College of Health Sciences, University of Buraimi. The study included participants with different age, gender, occupation, socioeconomic background and participants with and without DM or DR. Prior consent was obtained from all the interested participants eligible for the study.

\section{Participants}

The study involved 100 participants residing in Al Batinah Governorate aged 16 years and above. The study was conducted from September 2017 until December 2017. The participants were selected randomly from the concerned population, having different age group and socioeconomic profile.

\section{Methods}

This study included 100 randomly selected native, Al Batinah residents. Participants with different age, gender, occupation, socioeconomic background and with or without DM or DR, were included in the study. Non-willing participants, age less than 16 years, participants involved with eye care services and individuals residing outside Al-Batinah region were excluded. The self-designed questionnaire collected responses from participants on the same day.

\section{Data analysis}

Participant's responses were obtained using hard copies. The data was also stored in soft copy using Microsoft Excel 2013. Statistical Package for Social Sciences (SPSS) version 21 was used to perform the descriptive analysis.

\section{Results}

\section{Demographic profile of the involved participants}

Table 1 represents the demographic profile of the involved participants. Out of 100 samples, 33 were males and 67 were females. Most of the participants were between the age group of $16-35$ years and were graduates. Only 17 participants were related to medical field by education and or occupation. All participants were native and were residing in Al-Batinah region of Oman

Table 1. Demographic profile of the participants

\begin{tabular}{|l|l|l|}
\hline Participants profile & Categories & Numbers/Percentage \\
\hline Age in years & $16-25$ & 31.0 \\
\hline & $26-35$ & 36.0 \\
\hline & $36-45$ & 4.0 \\
\hline & $46-55$ & 16.0 \\
\hline & $56-65$ & 13.0 \\
\hline Gender & Female & 67.0 \\
\hline & Male & 33.0 \\
\hline \multicolumn{2}{|l}{} \\
\hline Education & Graduate & 44.0 \\
\hline & Secondary & 36.0 \\
\hline & Illiterate & 20.0 \\
\hline \multicolumn{2}{|l}{} \\
\hline Education related to Medical field \\
\hline & Medical \\
\hline
\end{tabular}


DOI: $10.21522 /$ TIJPH.2013.06.02.Art004

ISSN: $2520-3134$

\begin{tabular}{|c|c|c|}
\hline & Non-medical & 83.0 \\
\hline \multicolumn{3}{|l|}{ Occupation status } \\
\hline & Employed & 36.0 \\
\hline & Unemployed & 44.0 \\
\hline & Student & 20.0 \\
\hline \multicolumn{3}{|c|}{ Occupation-related to medical field } \\
\hline & Medical related & 17.0 \\
\hline & $\begin{array}{l}\text { Non-medical } \\
\text { related }\end{array}$ & 83.0 \\
\hline
\end{tabular}

\section{Participants diabetic profile and the source of information}

Awareness related to DR considered in the study is the self-declared. All participants have heard of DR. Relative or friend was the major information source for $51 \%$ of participants, followed by $22 \%$ who received information on DR from eye care professionals. Newspapers, were the least observed source of information (9\%). $16 \%$ and $1 \%$ of total participants had type 2 and type 1, DM respectively. The duration of diabetic in these participants ranged from 5 to 17 years. $93 \%$ had a family history of DM.

Table 2. Participant's diabetic profile and DR related source of information

\begin{tabular}{|c|c|c|}
\hline Profile & Category & Number/Percentage \\
\hline \multicolumn{3}{|c|}{ Heard of DR } \\
\hline & Yes & 100.0 \\
\hline \multicolumn{3}{|c|}{ If yes, the source of information } \\
\hline & Internet & 18.0 \\
\hline & Newspaper & 9.0 \\
\hline & Relatives & 51.0 \\
\hline & $\begin{array}{l}\text { Eye care } \\
\text { professional }\end{array}$ & 22.0 \\
\hline \multicolumn{3}{|c|}{ Do you have DM } \\
\hline & No & 83.0 \\
\hline & Yes & 17.0 \\
\hline \multicolumn{3}{|c|}{ Type of DM } \\
\hline & Type 1 & 1.0 \\
\hline & Type 2 & 16.0 \\
\hline \multicolumn{3}{|c|}{ Duration of DM in years } \\
\hline & 10 & 1.0 \\
\hline & 11 & 1.0 \\
\hline & 15 & 1.0 \\
\hline & 16 & 6.0 \\
\hline & 17 & 1.0 \\
\hline & 5 & 3.0 \\
\hline & 6 & 1.0 \\
\hline & 7 & 3.0 \\
\hline & Not applicable & 83.0 \\
\hline \multicolumn{3}{|c|}{ Family history of DM } \\
\hline & I don't know & 3.0 \\
\hline & No & 4.0 \\
\hline & Yes & 93.0 \\
\hline
\end{tabular}




\section{DM and eye health-knowledge related questions}

$81 \%$ of all the participants knew that DM could affect eyes and $49 \%$ stated that the vision can be affected. All involved participants did not know the ocular effects of DM apart from vision. Only $13 \%$ participants knew that both types of DM can affect vision. A high percentage (94\%) of participants knew that even controlled DM could affect the eye. The analysis showed that $59 \%$ of participants were aware that when the vision is affected, it would be hardly regained. A group representing $35 \%$ agreed for the level of ocular complications due to the condition as associated with the duration of DM (Refer to the Table 3).

Table 3. DM and eye health-knowledge related questions

\begin{tabular}{|c|c|c|}
\hline $\begin{array}{l}\text { DM and eye health- } \\
\text { Knowledge related questions }\end{array}$ & Categories & Number/Percent \\
\hline \multicolumn{3}{|l|}{ Does DM affect eye? } \\
\hline & I don't know & 19.0 \\
\hline & Yes & 81.0 \\
\hline \multicolumn{3}{|l|}{ Does DM affect vision? } \\
\hline & I don’t know & 26.0 \\
\hline & No & 25.0 \\
\hline & Yes & 49.0 \\
\hline \multicolumn{3}{|c|}{ What are the ocular effects of DM? } \\
\hline & I don't know & 51.0 \\
\hline & vision & 49.0 \\
\hline \multicolumn{3}{|c|}{ Which type of DM can affect the eye? } \\
\hline & Both & 13.0 \\
\hline & I don't know & 87.0 \\
\hline \multicolumn{3}{|c|}{ Can controlled DM, still affect eyes? } \\
\hline & I don't know & 6.0 \\
\hline & yes & 94.0 \\
\hline \multicolumn{3}{|c|}{ Can we regain vision completely, lost due to $\mathrm{DM}$} \\
\hline & I don't know & 37.0 \\
\hline & No & 59.0 \\
\hline & Yes & 4.0 \\
\hline \multicolumn{3}{|c|}{ Is the duration of DM related to the level ocular complications? } \\
\hline & I don't know & 43.0 \\
\hline & No & 22.0 \\
\hline & Yes & 35.0 \\
\hline
\end{tabular}


DOI: $10.21522 / \mathrm{TIJPH} .2013 .06 .02$.Art004

ISSN: $2520-3134$

\section{Prevention, treatment and other management related knowledge about DR}

Only 59\% felt the importance of ocular examination once an individual is affected by DM and out of them, $66.10 \%$ mentioned that they should visit the eye care practitioner only when the vision is affected. This contributes to $39 \%$ of the total study population. A high percentage of (94\%) participants believe that the eye care visit can be avoided if DM is under control.

Majority of the participants ( $88 \%$ ) agreed that the DR can be prevented with a managed diet. Agreement on the use of medication, laser and surgery as a part of the treatment, was observed to be $29 \%, 62 \%$, and $70 \%$ respectively. Only $14 \%$ population knew that visual rehabilitation can be used as a managerial option for the irreversible visual impairment occurred due to the condition. However, all of them did not know the type of available visual rehabilitation modes.

Table 4. Prevention, treatment and other management related knowledge about DR

\begin{tabular}{|c|c|c|}
\hline & Category & Percentage \\
\hline \multicolumn{3}{|c|}{ Knowledge related to the need for ocular examination } \\
\hline \multicolumn{3}{|c|}{ Is it important for a patient with DR to have an eye check-up? } \\
\hline & $\begin{array}{l}\text { I don't } \\
\text { know }\end{array}$ & 25.0 \\
\hline & No & 16.0 \\
\hline & Yes & 59.0 \\
\hline \multicolumn{3}{|c|}{ If yes, what should be the frequency of eye check-up? } \\
\hline & Annually & 20.0 \\
\hline & \begin{tabular}{|l|} 
Once vision \\
is affected
\end{tabular} & 39.0 \\
\hline \multicolumn{3}{|c|}{ Can we avoid eye examination if the DM is always under control? } \\
\hline & $\begin{array}{l}\text { I don't } \\
\text { know }\end{array}$ & 6.0 \\
\hline & Yes & 94.0 \\
\hline \multicolumn{3}{|c|}{ Knowledge related to the prevention/treatment of DR } \\
\hline \multicolumn{3}{|c|}{ Can a controlled diet help in preventing DR? } \\
\hline & \begin{tabular}{|l|} 
I don't \\
know
\end{tabular} & 12.0 \\
\hline & Yes & 88.0 \\
\hline \multicolumn{3}{|c|}{ Can medication help for treatment of DR? } \\
\hline & \begin{tabular}{|l|} 
I don't \\
know
\end{tabular} & 64.0 \\
\hline & No & 7.0 \\
\hline & Yes & 29.0 \\
\hline \multicolumn{3}{|l|}{ Can lasers help for treatment of DR? } \\
\hline & $\begin{array}{l}\text { I don't } \\
\text { know } \\
\end{array}$ & 37.0 \\
\hline & No & 1.0 \\
\hline & Yes & 62.0 \\
\hline \multicolumn{3}{|c|}{ Can ocular surgery help for the treatment of DR? } \\
\hline & \begin{tabular}{|l|} 
I don't \\
know
\end{tabular} & 30.0 \\
\hline & Yes & 70.0 \\
\hline
\end{tabular}




\begin{tabular}{|l|l|l|}
\hline $\begin{array}{l}\text { Are there visual rehabilitation modes of management for the } \\
\text { condition? }\end{array}$ & $\begin{array}{l}\text { I don't } \\
\text { know }\end{array}$ & 64.0 \\
\hline & No & 22.0 \\
\hline & Yes & 14.0 \\
\hline \multicolumn{3}{|l|}{ If yes, please mention which rehabilitation mode you know? } \\
\hline & $\begin{array}{l}\text { Provided } \\
\text { wrong } \\
\text { responses }\end{array}$ & 14.0 \\
\hline
\end{tabular}

\section{Discussion}

This study aimed to evaluate awareness and knowledge of DR among Al-Batinah population, Oman. The awareness regarding DR was self-declared. Majority of this study participants were females, contributing to $67 \%$, and men were $33 \%$. A study done by Al Zarea (2016), in Saudi Arabia, had a higher percentage of men $(57.17 \%)$ compared to females. This study has a higher population of young adults in contrast to the study done by Al Zarea (2016) which had the majority of the older population. Awareness and knowledge about DR could differ in different age or gender. This could be due to the higher experience or higher percentage of exposure to the disease in the older population. Also, the gender-wise difference could be observed in different regions probability due to contextual differences in availing health care facilities.

\section{Awareness and knowledge of DR}

The DR awareness in this study is defined as participants, having heard of DR. All the study population has heard of DR. This is higher than the other studies done by Martha et. Al. (2011), Anupama et. al. (2015), Alasiri and Bafaraj (2016), Rani et al. (2008) and Thapa R et al. (2012) which had awareness percentages of $83 \%, 45.3 \%, 61 \%, 37.04 \%$ and $37 \%$ respectively. Interestingly, in the study by Alasiri and Bafaraj (2016), Type 1 diabetic patients had a significantly higher awareness than Type 2. This is dissimilar to our findings which could be due to the smaller sample size of Type 1 diabetic participant in our study. The demographic awareness variation also exists which can be observed with lower awareness percentage (37\%) in a study done in Nepal (Thapa, 2012). In our study, participants were from different age groups, gender and with the different diabetic profile. Still, the higher awareness level reflects that in the study awareness is independent of the socioeconomic or diabetic health profile of the candidates.

\section{Knowledge related to DR}

Variations in knowledge regarding prevention, treatment and other managerial options of DR are observed in the study. For instance, controlling diet as a preventive measure of DR was found to be $88 \%$, whereas only $6 \%$ knew the importance of ocular examination even with the controlled status of DM. The knowledge variability could be multifactorial and can be explored separately. Khandekar et al. (2010), observed that the age, region and duration of DM as responsible factors for the knowledge level.

\section{Source of information}

In this study, relatives and friends were the most common knowledge source (51\%), whereas in a study done in Nepal by Thapa et al. (2012), stated physicians as the most common source with a similar percentage. Even lowest availed informative source in the later study was the radio. None of this study participant acquired information through the radio and very few receiving the information through newspapers (9\%). An appropriate platform needs to be identified while distributing DR related health information. 
DOI: $10.21522 /$ TIJPH.2013.06.02.Art004

ISSN: $2520-3134$

\section{Knowledge related ocular effects of DM}

In this study, the knowledge regarding ocular complications resulting from DM was $81 \%$ which was slightly higher than that of the study in Saudi Arabia (75.62\%) (Al Zarea, 2016), India (70.2\%) (Shetgar et al., 2015) and slightly lesser than observed in a study done in Kenya (83\%) (M' Kiunga et al., 2017). A study done by Kiran and Mendonca (2016) found that $37.4 \%$ of their study participants have heard of ocular complications of DM and only $29.5 \%$ knew that vision can be affected due to DM. Hence, a higher percentage of our participants were aware of ocular and visual complications due to DR compared to other studies.

In our study, even though, the percentage of the population knowing the risk of ocular complication in DM is high, none of the participants knew the type of associated complications and only $49 \%$ knew that the vision will be impaired. Moreover, only $35 \%$ population knew the relation between DM duration and the severity of ocular complications. This knowledge level is very low compared to a study done by Khandekar et al. (2010), in Oman, which was 72.9\%. This could also be due to the close-ended question approach used in the later study. Moreover, Kiran and Mendonca (2016), found that $29.5 \%$ of the study involving population, knew that increased blood sugar level can affect vision. In contrast, Prabhu et. al. (2015), observed higher awareness prevalence in diabetic population regarding ocular $(72.50 \%)$ and visual complications $(51 \%)$ compared to our study population. This emphasizes the need for further knowledge building exercises within the non-diabetic community.

\section{Knowledge related to the preventive, treatment and other managerial methods}

$59 \%$ felt the importance of ocular examination, once an individual is affected by DM and out of them, $66.10 \%$ stated that they should visit the eye care practitioner only when the vision is affected. This percentage contributes to $39 \%$ of the total study population. The felt need of ocular examination is lesser in our study compared to the study done in Saudi Arabia (68.79\%) (Al Zarea, 2016).

Alarmingly, we found that $94 \%$ of our study participants believe that the eye care visit can be avoided if DM is under control. Anupama et al. (2015) found that $25.3 \%$ of their study participants knew the risk factors of DR.

Majority of the participants (88\%) agreed that the DR can be prevented with a managed diet. Agreement on the use of medication, laser and surgery as a part of the treatment, was observed to be $29 \%, 62 \%$, and $70 \%$ respectively. Only $14 \%$ population knew that visual rehabilitation can be used as a managerial option for the irreversible visual impairment occurred due to the condition. However, all the study participants did not know the type of available visual rehabilitation modes.

In summary, the study has found higher awareness about DR, but the variation in, the knowledge about the condition, preventive, treatment and managerial modes is observed. Community awareness and knowledge regarding this condition are crucial to support and ensure the success of the national level diabetic program and to reduce the burden of DR. Educating the population about the importance of early diagnosis, need for regular follow-ups and available prevention and treatments plan related to DR can be important.

\section{Future directions}

Further studies can be repeated with the higher sample size and in different parts of Oman. Though this study has focused only on the evaluation of awareness and knowledge of the involved participants, it is also important to identify community attitude and practices towards the condition. Moreover, there is a need to evaluate the knowledge, attitude, and practices of the medical professionals and especially primary eye care professionals (Raghad \& Fadwa, 2017) regarding the condition. As effective DR, related health promotion or education is vital, community perception towards the availed material can be important to assess. This could help in designing future educational resources, activities or performing necessary modifications. 


\section{Conclusion}

There is higher awareness about DR among the study population. However, DR related knowledge variability was observed with respect to its ocular effects, prevention, treatment and other managerial modes. Hence, there is potential for conducting DR related health education and health promotional programs. Similar studies involving higher sample size, rural population, primary health care professionals and in different governorates can be useful.

\section{Acknowledgements}

We cannot/ express enough thanks to our College of Health Sciences faculty, academic and administrative staff from different departments of University of Buraimi for their continued support and encouragement during the study.

We would also like to acknowledge our study participants for their precious time and efforts spent for the study.

\section{References}

[1]. Alasiri, R. A., \& Bafaraj, A. G. (2016). Awareness of Diabetic Retinopathy among Diabetic Patients in King Abdulaziz University Hospital, Jeddah, Saudi Arabia.

[2]. Al Rasheed, R., \& Al Adel, F. (2017). Diabetic retinopathy: Knowledge, awareness and practices of physicians in primary-care centers in Riyadh, Saudi Arabia. Saudi Journal of Ophthalmology, 31(1), 2-6.

[3]. Al Zarea, B. (2016). Knowledge, Attitude and Practice of Diabetic Retinopathy amongst the Diabetic Patients of of AlJouf and Hail Province of Saudi Arabia. JOURNAL OF CLINICAL AND DIAGNOSTIC RESEARCH. http://dx.doi.org/10.7860/jcdr/2016/19568.7862.

[4]. Diabetic Retinopathy for Medical Students. EyeRounds.org - Ophthalmology. Available at: http://webeye.ophth.uiowa.edu/eyeforum/tutorials/Diabetic-Retinopathy-Med-Students/index.htm. Accessed October 14, 2017.

[5]. El Haddad, O. A., \& Saad, M. K. (1998). Prevalence and risk factors for diabetic retinopathy among Omani diabetics. British journal of ophthalmology, 82(8), 901-906.

[6]. Khandekar, R. B., \& Al-Lawati, J. A. (2015). Epidemiology of diabetic retinopathy in Oman: Two decades of research. Oman journal of ophthalmology, 8(1), 1.

[7]. Khandekar, R., Al Harby, S., Al Harthy, H., \& Al Lawatti, J. (2010). Knowledge, attitude and practice regarding eye complications and care among Omani persons with diabetes-A cross sectional study. Oman journal of ophthalmology, 3(2), 60.

[8]. Khandekar, R., Al Lawatii, J., Mohammed, A. J., \& Al Raisi, A. (2003). Diabetic retinopathy in Oman: a hospital based study. British journal of ophthalmology, 87(9), 1061-1064.

[9]. M'Kiunga, K., Thuo, K., Margaret, C. and Miriam, W. (2017). Long-Term Complications and their Associated Risk Factors among Diabetic Patients at the Kenyatta National Hospital, Kenya. The International Annals of Medicine, 1(9).

[10]. Nei.nih.gov. (2018). Facts about Diabetic Eye Disease | National Eye Institute. Nei.nih.gov. Retrieved 10 February 2018, from https://nei.nih.gov/health/diabetic/retinopathy

[11]. Prabhu, M., Kakhandaki, A., \& Chandra, K. R. (2015). A hospital based study on awareness of diabetic retinopathy in diabetic individuals based on knowledge, attitude and practices in a tier-2 city in South India. Indian Journal of Clinical and Experimental Ophthalmology, 1(3), 159-163.

[12]. Shetgar, A. C., Patil, B., Salagar, M. C., \& Nanditha, A. (2015). Assessment of awareness of diabetic retinopathy among diabetics: A Clinical Survey. Indian Journal of Clinical and Experimental Ophthalmology, 1(4), 260-263.

[13]. Srinivasan, S., Raman, R., Kulothungan, V., Swaminathan, G., \& Sharma, T. (2017). Influence of serum lipids on the incidence and progression of diabetic retinopathy and macular oedema: Sankara Nethralaya Diabetic Retinopathy Epidemiology and Molecular Genetics Study (SN-DREAMS II). Clinical \& experimental ophthalmology. 
DOI: $10.21522 / \mathrm{TIJPH} .2013 .06 .02$.Art004

ISSN: $2520-3134$

[14]. Thapa, R., Paudyal, G., Maharjan, N., \& Bernstein, P. S. (2012). Demographics and awareness of diabetic retinopathy among diabetic patients attending the vitreo-retinal service at a tertiary eye care center in Nepal. Nepalese Journal of Ophthalmology, 4(1), 10-16. 


\title{
Association between Socio-demographic Characteristics of Community Health Workers with Compliance to Quality Delivery of Integrated Community Case Management of Febrile Illness services in Nigeria
}

\author{
Article by Bright Orji ${ }^{1}$, William Brieger ${ }^{2}$, Lindiwe Innocentia ${ }^{3}$ \\ ${ }^{1,3}$ Texila American University \\ ${ }^{2}$ Public Health, the Johns Hopkins Bloomberg \\ Email: bright2orji@yahoo.com ${ }^{1}$
}

\begin{abstract}
The objective of the study was to investigate the association between community health workers (CHWs) socio-demographic characteristics with compliance to quality delivery of integrated community case management (iCCM) of malaria, diarrhea and simple respiratory infection. This was an implementation research study conducted in two local government areas of Akwa Ibom State, Nigeria with a total of 152 CHWs. The study used an observational data collected by the ministry of health and implementing agency in 2010. The observational data was re-analyzed using SPSS version 17 to examine the association between the dependent variable, quality improvement performance score and independent variable - socio-demographic characteristics of CHWs. $21 \%$ of the CHWs were male while $79 \%$ were female CHWs. The CHWs overall mean age was 36.8( \pm 8.7$)$ years. The CHWs were assigned to the following age groups: <36 years (53\%), and >36 years (47\%). $12.0 \%$ of the CHWs had primary education; $74.0 \%$ attained secondary school while $14.0 \%$ of the CHWs attained postsecondary school. $63.0 \%$ of the CHWs were unskilled while 37.0\% of the CHWs were skilled. Chisquare test result revealed that $81.5 \%(n=124)$ of the $152 \mathrm{CHWs}$ studied were compliant to quality improvement performance. Logistic regression analysis showed that socio-demographic characteristic associated with quality improvement performance was sex (OR 2.717, 95\% CI: 1.064-6.937, $p=0.037$ ). To introduce and sustain the impact on quality performance among CHWs requires training, supportive supervision and strong coordination.
\end{abstract}

Keyword: So-demographic characteristics, Community health workers, integrated community case management of malaria, pneumonia and diarrhea; quality improvement performance standards.

\section{Introduction}

Evidence based interventions to prevent malaria deaths are available. The World Malaria Report 2016 revealed that $74 \%$ of global suspected malaria cases were tested using RDTs with greater number of proportion taking place in the public health sector. Malaria treatment using ACTs increased from $29 \%$ in 2010 to $80 \%$ in 2015 representing almost a three-fold increase. These achievements were as results of countries engaging community health workers (CHWs) in order to mitigate the challenges associated with lack of human resource for health. Training CHWs to provide quality of malaria care and deploying them to work at the community under the supervision of the frontline health care workers has helped in taking essential life-saving interventions to the door-step of those who need them. This approach was made popular by the African Program for Onchocerciasis Control (APOC) that used community directed treatment with invermectin (CDTI). The approach helped to make substantial contributions to the control and treatment of Onchocerciasis (York KJ., et al., 2015). Therefore understanding the factors influencing CHWs contributions, and compliance to performance standards will help sustain the gains of their involvement in the delivery of quality of care.

In Ghana, Edgar Necochea et al (2015) demonstrated that application of provider performance quality improvement assessment to community-based health services in 2011-2014 among 61 community health programs (CHPs) resulted in well over 30\% improvement from baseline within one year of program implementation. In Zambia, provider performance of quality improvement standard was introduced to the lay workers on the delivery of PMTCT counseling and group education sessions. This excluded clinical services, and the study concluded that the PMTCT lay workers contributed to the increase of clients flow and work-load of the health workers by taking off the responsibility and freed 
up time for them to engage in other duties (Young MI Kim, et al 2013). Similarly, studies on taskshifting strategies that involved CHWs have reported high impact and impressive contributions of CHWs on taking responsibilities of counseling and health education sessions off the health workers (Born LJ , et al 2012; Morris MB., et al 2009). These evidences have continued to support active involvement and participation of CHWs in public health interventions as part of the key strategy to reduce the effect of critical shortages of health workers in the developing countries. In rural Nepal, female community health volunteers were able to provide satisfactory quality performance in maternal and child health services (Dilaram Acharya, et al, 2016). In another effort, community health volunteers in Malaysia were able to understand their roles, and commitment that led to high quality improvement of performance standards when they were engaged on early detection of Non-communicable diseases, improving knowledge to healthy behavior and life-style (Liang Chung HM.., et al 2017).

In one study in Nigeria, Orji B., et al shows that $97.6 \%$ of the female volunteer CHWs were adherent with malaria treatment protocol compared to $89.0 \%$ of the male. The authors concluded that women are more disposed to responding to volunteer job and may not be unconnected to their human nature especially given their societal roles and responsibilities in the family. Similarly, this finding was collaborated by Dilaram Acharya et al (2016) that reported that quality improvement performance of female community health volunteers are affected by some of their socio-demographic characteristics. Bagonza J., et al, 2014 in rural Uganda demonstrated that performance of female CHWs was high in the delivery of maternal and child services; and this collaborated an earlier work carried out by Alam $\mathrm{K}$, Tasneem S and Oliveras E in rural Bangladesh in 2012. Another study in Zambia, Hamer DH et al, 2012, found female CHWs more compliant than facility based health workers in following RDTs positive results to dispense ACTs according to treatment protocols. The authors concluded that female CHWs high performance is associated with the ease other women may have in seeking care from among their peers; and also male CHWs area distracted by their societal roles of providing the needs of their family members which might make them less effective to unpaid jobs.

However, there are studies that demonstrated that gender did not influence performance of CHWs. Example, one study in Zambia Harvey SA., et al, 2008 that trained CHWs on the use of RDT to test for malaria compared along the line of those that use job-aids, manufacturers manuals etc. concluded that gender was not statistically significant with quality performance in the delivery of malaria services. Especially when compared on the use of RDT to correctly test for malaria, result interpretations and appropriate dispensing of ACTs.

In another dimension the study found volunteers who were in age brackets older than 36 years more adherent with appropriate and correct treatment protocols compared with those younger than that age bracket. Similar findings have been reported else-where, in one study in the United States volunteers were highest in number with people between age bracket 35 - 44 years compared with those under 25 years (13\%) and 65 years or more (18\%) (Hayghe HV., 1991). Some studies have found that age of the CHWS is associated with their performance. In one study, Melvin Hsien et al 2017, demonstrated that older CHWs are more concerned with the delivery of altruistic services whereas the younger CHWs are easily distracted by career concern, spouse and peer pressure that make them not so effective. However, in Guinea-Bissau Lopez SC., et al 2014 found younger CHWs to deliver more quality performance in the management of diarrhea among under-five children. This findings collaborate the result of the work by Dilaram Acharya et al 2016 that reported age of the CHWs as not a predictor of knowledge and performance. Earlier work in urban slum of Dhaka by Alam K., et al 2012 has shown that attrition among younger CHWs may make them less effective in quality improvement of performance standards. Melvin Hsien et al 2017 has noted high attrition of younger CHWs from service, and opined that if this was not addressed it would lead to critical shortfall in the number of CHWs available for volunteer services.

Also, available evidence shows that generally education impacts on volunteerism. People with higher level of education are more likely to participate in volunteer job compared to those with lower education. Liang Chung ML., et al 2017, noted that education is a positive factor that could influence CHWs to perform much better and improve quality of services in the community where they serve. Similarly, Dilaram Acharya et al, 2016 opined that the higher educational level that the CHWs have, the more knowledge they have and complaint to guidelines and set of performance standards. The study 
in the US by Hayghe HV., (1991) shows that proportion of volunteers was more among people with college education compared to those with lower qualification. In Nigeria, Orji B. et al 2010 reported too that proportion of volunteers were more among those with higher education. However, education was not found to significantly impact compliance with treatment protocols.

The study also reported that proportion of people with jobs or vocations were more likely to volunteer their services than those without jobs. This is because vocations or jobs will support them to provide for their family members, and the opportunity to take unpaid jobs. This has been collaborated by study in Kuching district of Sarawak Malaysia where job occupations of the CHWs were not predictor of role performance and did not influence service outcome.

\section{Materials and methods}

An implementation research with measurement over time specifically designed to measure independent variable- CHWs socio-demographic characteristics and dependent variable - compliance with quality improvement of performance standards. Performance standard is defined as taking history/examination; conducting RDTs and appropriate management of febrile illness. One page checklist was developed by the project to monitor and measure the performance of the CHWs. The checklist has 37 performance criteria (PC) that was used to observe and measure CHW's knowledge, skills and competence in 3 sections: History taking and Examination; Conducting RDTs for Malaria; and Illness Management. Each section of the performance criteria has between 11 to 13 verifiable criteria. The checklist was used to train the CHWs, and also used to observe them while providing services at the community; each correctly performed criterion was scored 1 point. A score $\geq 80 \%$ was set as compliant based on implementing agency's participant's pass mark at trainings; while $\leq 80 \%$ is adjudged as non-compliant. Four rounds of assessments were conducted after the baseline at an interval of two months between project implementation periods June 2011 - March, 2012.

The study population was the $152 \mathrm{CHWs}$ selected by the communities. The CHWs were selected by the communities using agreed criteria. These criteria include residency in the community where they served, able to read and write, willingness to volunteer services, approved by spouse if married, atten d monthly meetings and submit reports. The community held - community meetings with men, women, youths and visitors residents in the community in attendance. In some communities there were people that volunteered their services and if more than the number required, the communities conducted voting exercise to select appropriate numbers of CHWs that will be able to serve the community. In some other communities, selection was based on previous experience especially communities that have had experience with onchocerciasis where CHWs were in existence. At the end, twenty-one percent of the CHWs were male, while seventy-nine were female. The mean age of the CHWs was 36.8( \pm 8.7$)$ with highest educational level as senior secondary school. The vocations of the CHWs include farming, trading, retirees, civil servants etc. The CHWs provided services to 2,206 over one year period. The CHWs records were audited at the end of twelve calendar months.

The study used purposive sampling technique because all the data elements were included. All the 152 trained CHWs were sampled to investigate the quality of improvement performance standards in the delivery of integrated community case management of malaria, pneumonia and diarrhea services.

\section{Data management}

The study focused on data that was used to answer research questions based on ascertaining the extent to which the socio demographic characteristics measured in sex, age, education and vocation impacts on the CHWs performance. Chi-square tests was conducted at 0.05 level of significance, and corresponding p-values reported to three decimal places with values less than (0.001) reported as $(<0.001)$. Statistical decision to reject the null hypothesis was based on the following:

- $P$-value less than or equal to the alpha level, reject the null hypothesis and accept the alternative hypothesis

- $P$-value greater than the alpha level, retain the null hypothesis and reject the alternative hypothesis. The research question of the study is: 
RQ1: To what extent does socio-demographic characteristic as measured by sex, age, education and vocations make a difference on CHWs' compliance to quality improvement of performance standards scores for integrated community case management of malaria, pneumonia and diarrhea?

Ho1: CHW's socio demographic characteristics (sex, age, educational levels and vocation) do not make a difference in quality performance scores for integrated community case management of malaria, pneumonia and diarrhea.

Ha1: CHW's socio demographic characteristics (sex, age, educational levels and vocation) do make a difference in quality performance scores for integrated community case management of malaria, pneumonia and diarrhea.

Chi-square test for association was conducted to ascertain the extent to which social demographic characteristic status as measured by sex, age, education and vocations. Logistic regression results is used to determine the level of significance and the decision to reject or retain the null hypothesis based on the stated alpha level of 0.05 .

\section{Results}

\section{Socio-demographic characteristics}

One hundred and fifty-two (152) CHWs were studied. $21 \%$ were male while $79 \%$ were female CHWs. The CHWs overall mean age was $36.8( \pm 8.7)$ years. The mean age for the male CHWs was 37.6 $( \pm 4.3)$ years while the mean age for the female CHWs was $36.6( \pm 9.5)$ years. The youngest age of the study CHWs was 30 years while the oldest age was 49 years old with a range of 30-49. The CHWs were assigned to the following age groups: $<36$ years, and $>36$ years. Eighty (80) or $53.0 \%$ of the CHWs were in the group < 36 years while seventy-two (72) or $47 \%$ of the CHWs were in the group of $>36$ years old. Eighteen (18) $12 \%$ of the CHWs had primary education. One hundred and thirteen (113) of the CHWs or $74.0 \%$ attained secondary school while twenty-one (21) or $14.0 \%$ attained postsecondary education. Ninety-six (96) or $63.0 \%$ of the CHWs were unskilled while 56 of the CHWs or $37.0 \%$ of the CHWs were skilled. Most of the CHWs were unskilled $n=96$. Table 2 below provides information about the occupation of the studied CHWs.

A Chi-square test analysis of independent and dependent variables revealed that in overall, a total of $81.5 \%(\mathrm{n}=124)$ of the CHWs were compliant to performance standards. These include $69.0 \%(\mathrm{n}=22)$ of the male and $85.0 \%(n=102)$ of the female CHWs. The result of the Chi-square test analysis indicated that sex was significantly associated with compliance to quality performance standards $(\mathrm{p}=0.035)$. Of those, $81.5 \%(n=124)$ studied CHWs were compliant to quality performance standards; $80.0 \%(n=64)$ were within the age brackets of $\leq 36$ years while $83.0 \%(n=60)$ were CHWs $>36$ years old. The result of the Chi-square test analysis shows that age was not significantly associated with compliance to quality performance standards $(\mathrm{p}=0.596)$. CHWs with primary educational level that were compliant included $72.0 \%(\mathrm{n}=13)$, secondary educational level $82 \%(\mathrm{n}=93)$ while post-secondary educational level $86.0 \%(\mathrm{n}=18)$. Educational level was not significantly associated with compliance to quality improvement of performance standards $(\mathrm{p}=0.515) .83 .0 \%$ of the unskilled CHWs was compliant to quality improvement performance standards $(n=80)$ compared $79 \%$ of the skilled CHWs $(n=44)$. CHWs vocation was not significantly associated with $\mathrm{CHW}$ 's compliance to quality improvement performance standards for integrated community case management of malaria, pneumonia and diarrhea $(\mathrm{p}=0.465)$.

The result of the logistic regression analysis showed Hosmer and Lemeshow (model of goodness fit test) fits the data $\left(\mathrm{X}^{2}=22.165 ; \mathrm{df}=6 ; P=0.001\right)$, and statistically significant which correctly explains the $8.20 \%$ (Nagelkerke $\mathrm{R}^{2}$ ) of the variance in compliance and correctly classified $81.6 \%$ of the performance. The CHWs' socio-demographic characteristic sex and compliance to quality improvement performance standards results in changes in quality of performance standards (defined as female and male by CHWs delivery of quality performance. The odds ratio for sex was (OR 2.717, 95\% CI: 1.064-6.937, $\mathrm{p}=0.037$ ); age measured by $\leq 36$ years old and $>36$ years old CHWs (OR 0.568, 95\% CI: $0.221-1.458, p=0.240$ ); Educational level measured by primary, secondary and post-secondary (OR 0.685, 95\% CI: 0.2671.761, $\mathrm{P}=0.433$ ); and vocation as measured by skilled and unskilled CHWs (OR 0.729, 95\% CI: 0.308 $1.728, \mathrm{p}=0.473)$. Sex predicted compliance among the female and male CHWs to quality improvement performance standards in Akwa Ibom State, Nigeria at a statistically significant level ( $\mathrm{c}<=0.05$ ). Therefore, the null hypothesis that CHW's socio demographic characteristics sex as measured by female 
and male do not make a difference in quality performance scores for integrated community case management of malaria, pneumonia and diarrhea could not be rejected.

\section{Discussions}

The socio-demographic characteristics sex of the CHWs alone varies with complaint to quality improvement performance. Female CHWs were found to be more complaint compared to their male counter-parts. This study's findings also indicated that as the rounds of measurement of quality improvement performance standards, and feedback provided to the CHWs increases, compliance to performance standards of the CHWs improves. Addressing the barriers that limits the extent of impact on compliance with performance standards may improve compliance rates, quality of iCCM services provided by $\mathrm{CHWs}$ and decrease high mortality and morbidity due to malaria, pneumonia and diarrhea. Female CHWs performance showed $85 \%$ compliance compared to male CHWs of $69 \%$. The more the length of services provided, the female CHWs improve their services. This result shows that female CHWs is 2.7 times more likely to provide quality integrated community case management of malaria, diarrhea and pneumonia than male counter-parts. This finding deferred with what was earlier reported in a study conducted in Zambia where CHWs gender was not statistically significant with quality service delivery of malaria services especially on the use of RDT to correctly test for malaria and dispense ACTs appropriately (Steven Harvey, Larissa Jennings and Chinyama et al, 2008). The report indicated that more women in the community are care givers of under-five children, and therefore peers with the female CHWs. It is easier for the female CHWs to bond with the community women, improve friendship, communication; and promote service utilization. The female CHWs could check for the expiry dates of the RDTs, collect adequate blood from the clients and provide correct interpretation of the results as well as dispense ACTs following RDTs results. These were areas that seem difficult for some of the male CHWs. This corroborates earlier study findings where the performance of female CHWs was high in the delivery of maternal and child health services in Uganda and Bangladesh that share similar characteristics with Nigeria (James Bagonza, Simon PS Kibira, and Elizeus Rutebemberwa, 2014; Alam K, Tasneem S, Oliveras E., 2012); and another study in rural Zambia that found CHWs more compliant than facility based health workers in dispensing ACTs following RDTs positive results (Davidson H. Hamer, Erin Twohig Brooks, Katherine Semrau et al, 2012). The authors attributed the reason for female CHWs high performance over the male to the comfort women may have in seeking care from women volunteer care givers as well as to the societal role of men that might affect level of performance. This role include men's social responsibility to their families i.e. for providing the needs of their families. This role might make male CHWs not to be effectively disposable to unpaid job.

Data analysis using the Chi-square test revealed that there was no association between age and compliance to quality improvement performance standards ( $\mathrm{p}$-value $=0.596$ ). Though the results showed that as service delivery improves during every round of assessments, more of the CHWs in the age brackets $>36$ performed better than the younger ones with $83 \%$ compared to $80 \%$. This corroborates other studies where best role performance was associated with CHWs from the age brackets of 35 to 44 years old. Melvin Hesien Liang Chung et al, 2017 explained that CHWs who are older appear more interested in "values function" especially in making more people happy. Logistic regression was conducted to further test for possible influence of age as a socio-demographic characteristics with compliance to quality improvement performance standards. The Hosmer and Lemeshow model explains $8.20 \%$ of the variance in compliance and correctly classified $81.6 \%$ of the performance cases while the odd ratio of age measured by $\leq 36$ years old and $>36$ years old CHWs (OR 0.568, 95\% CI: 0.221-1.458, $\mathrm{p}=0.240$ ). Therefore, there is no difference in compliance to the quality improvement performance among the CHWs. However, contrary to our study, younger CHWs have been found to more accurately provide correct management of diarrhea among children in Guinea-Bissau (Sergio C Lopez, Antonio J Cabral and Bruno de Sousa, 2014). This study's findings supports the results from an earlier study where the age of the CHWs was not a predictor on knowledge and performance even when ages of the CHWs varied from <35 years to >45 years old (Dilaram Acharya, Jitendra Kumar Singh, Samaj Adhikari and Varidmala Jain, 2016). In another study, Khurshid Alam and Elizabeth Oliveras 2014 reported that younger CHWs <25 years in the Urban slum of Dhaka were found to be more in attrition 
by leaving the slum compared to older ones hence had poor retention in the job and less effective in performance. This is because younger CHWs appear to be easily influenced by their peers; and distracted by either their spouse, career social than "value functions" (Melvin Hsien Liang Chung, Helmy Hazmi, and Whye Lian Cheah, 2017). Interestingly, the CHWs that participated in the intervention in Akwa Ibom State, Nigereia were more of female CHWs and large proportion of them were married. The project implementation report demonstrated that agreement with their spouse were sought by the community prior to selection, and this may have contributed to their stability in the job, and improved service utilization as observed. Also, the report emphasized the monthly community health workers' meetings with their supervisors which was used to track quality improvement efforts using tools based on set performance criteria and coordinate monthly reporting system among the CHWs. This approach may have strengthened coordination among CHWs, institutionalized process to improve quality improvement across all ages. However, another study showed increase in nonadherence to treatment protocol among cases of maternal death in 2002-2004 compared with 1999-2001 though this was not statistically significant but enough concern for quality of care.

This result demonstrates that educational level as sociodemographic characteristics of the CHWs does not affect or predict compliance with quality improvement standards. The performance of the CHWs with primary education may have been influenced by trainings and supportive supervision provided across CHWs with all levels of educational qualifications. This corroborates the results of an earlier study. Davidson H. Hamer et al, 2012 reported that trainings, supportive supervision and logistics provision were able to strengthen the capacity of CHWs to appropriately conduct RDTs, interpret results, and with good adherence to WHO treatment protocols providing evidence that CHWs can safely implement the new guidelines. One study in Guinea-Bissau demonstrated that CHWs were capable to understand theoretical concepts presented during training, and such knowledge contributed to their performance. The study also opined that the number of trainings attended by CHWs was compared with accuracy in carrying out diagnosis and treatment, the authors could not identify any trend. Besides, one of the statistical test conducted showed that CHWs with less training, and experience performed better with CHWs that had higher number of trainings. The authors concluded that selection of appropriate volunteers as CHWs, supportive supervision and continuous trainings should be given the same level of importance to the training itself (Sergio C Lopez, Antonio J Cabral, and Bruno de Sousa, 2014).

This conclusion supports public health practitioner's policy makers, program managers, service providers and communities in the development of interventions that in considering educational background as a factor and predictor of compliance to quality delivery of services, selection of appropriate persons as CHWs, supportive supervision and trainings should be given top priority. The findings may also assist stakeholders in modification of health program interventions that volunteers should not only be given to people with high level education but ensure that adequate training package is provided, and guidelines used in providing training to those that volunteered their services. This will help to boost their compliance with quality improvement performance. Public health providers and other personnel involved in the provision and facilitation of health care services in the community should focus also on interventions such as improving the educational level of volunteers with lower educational level in the form of adult education which could serve as an incentive to motivate their interest and improve their compliance with quality services delivery. According to Allen et al. (2014), community play an important role in community health because they provide both social and health support to their members through health education programs in the Parishes and routinely provide members with current information about different diseases.

This findings showed that vocation is not a predictor of compliance to quality improvement of performance standards for CHWs in Akwa Ibom state, Nigeria. This corroborates earlier study in Kuching district of Sarawak Malaysia where job occupations of the CHWs were not predictor of role performance and did not in any way influence service outcome. As noted earlier, the result of this study might have been influenced by the level of supportive supervision provided by the frontline health workers as well as the training of the CHWs. Supportive supervision has been identified as one of the critical component of the work of Community services. Melvin Hsien et al has noted that supervision of the CHWs will improve and impact positively on their performance. These features - training and supportive supervision of community directed interventions may have contributed to the performance 
of the CHWs across all levels of vocations - skilled and unskilled by ensuring compliance to performance standard especially the monthly meetings of the CHWs that was used to address gaps, and support the CHWs improve their performance.

\section{Conclusion}

Compliance to quality improvement of performance standards remains both a national and global public health concern due to increasing use of community health volunteers to support service delivery. This has been brought about by the critical challenges with poor availability of human resource for health. Also, the emergence of community approach in the delivery of iCCM to complement integrated management of childhood illness (IMCI) which is facility based has thrown up the challenges of dependence on the work of the CHWs alongside of quality service delivery. Therefore, lack of compliance with quality improvement of performance standards and socio-demographic characteristics, features of CDI organizational structures may continue to hinder efforts to improve best practices and quality improvement among the community health workers if not addressed. Future studies should focus on the impact of covariates such as income range, marital status, perceived community status, and previous experience with health work on compliance with quality improvement of performance standards.

\section{Reference}

[1]. Alam K., Tasneem S., Oliveras E. (2012). Retention of female volunteer community health workers in Dhaka urban slums: a case-control study. Health Policy Plan 27(6): 477-86. Doi: 1093/heapol/czr059.

[2]. Bagonza J., Kibira PS., Rutebemberwa E., (2014). Performance of health workers managing malaria, pneumonia and diarrhea under community case management program in central Uganda: a cross sectional study. Malaria Journal doi: 10.1186/1475-2875-13-367.

[3]. Born LJ, Wamulume C, Neroda KA, Quiterio N, Gigant MI, Morris M, Bolton-Moore C, Baird S, Sinkamba M, Tropp SM, Reid SE (2012). Evaluation of a task-shifting strategy involving peer education in HIV Care and treatment clinics in Lusaka, Zambia. Journal of Public Health in Africa.

[4]. Dilaram Acharya, Jitendra Kumar Singh, Samaj Adhikari, Varidmala Jain (2016). Association between sociodemographic characteristics of female community health volunteers and their knowledge and performance on maternal and child health services in Nepal. Journal of Multidisciplinary Healthcare 9:111-120.

[5]. Edgar Necochea, Vandana Tripathi, Young MI Kim, Nabeal Akran, Yoland Hyjazi, Maria da Luz Vaz, Emmanuel Otolorin, Tsigue Pleah, Tambudzai Rashidi, Dustan Bishanga (2015).

[6]. Hayghe HV. (1991). Volunteers in the US: Who donates time? Monthly Labor Review.

[7]. Hamer DH., Brooks ET., Semrau K., Pilingana P., MacLeod WB., Siazeele K., Sabin LL., Thea DM., Yeboah-Antwi (2012). Quality and safety of integrated community case management of malaria using rapid diagnostic tests and pneumonia by community health workers. Pathog Glob Health. 106(1): 32-39. doi: 10.1179/1364859411Y.0000000042Harvey S.A, Jennings L, Chinyama M, Masaninga F, Mulholland K, Bell DR, 2008. Improving community health worker use of malaria rapid diagnostic tests in Zambia: package instructions, job aid and job aid-plus-training. Malar J 7: 160.

[8]. Implementation of Standard-Based Management and Recognition approach to quality improvement in maternal, newborn, and child health programs in low-resource countries. International Journal of Gynecology and Obstetrics 130 S17-S24.

[9]. Lopes SC., Cabral A., de Sousa B., (2014). Community health workers: to train or to restrain? A longitudinal survey to assess the impact of training community health workers in the Bolama Region, Guinea-Bissau. Hum Resour Health. 12:8 doi: 10.1186/1478-4491-12-8.

[10]. York KJ, Kabole I., Mrisho M., Berry DM. Schmidt E., (2015). Factors Affecting Community Participation in the CDTI Program in Morogor, Tanzania. Journal of Nursing Scholarship vol. 47, pages 96-104.

[11]. Morris MB, Chapula BT, Chi BH, Mwanza J, Manda H, Bolton C, Pankratz DS, Stringner JS, Reid SE (2009). Use of task-shifting to rapidly scale-up HIV treatment services: experiences from Lusaka, Zambia. BMC Health Services Research.

[12]. Melvin Hsien Liang Chung, Helmy Hazmi, and Whye Lian Cheah (2017). Role Performance of Community Health Volunteers and its Associated Factors in Kuching District, Sarawak. Journal of Environmental and Public health ID 9610928. 
DOI: $10.21522 /$ TIJPH.2013.06.02.Art005

ISSN: $2520-3134$

[13]. Orji BC., Brieger WR., Otolorin EO., Nwadike J., Bassey EV., Nkanga M. (2010). Health System Strengthening through Community Referral in the Management of Febrile Illness in Nigeria, ASTMH annual Meeting, Georgia - Atlanta (Abstract \#1277.

[14]. Young MI Kim, Maureen Chilila, Hildah Shasulwe, Joseph Banda, Webby kanjipite, Supriya Sarkar, Eva Bazant, Cyndi Hiner, Maya Tholandi, Stephanie Reinhardt, Joyce Chongo Mulilo, and Adrienne Kols. (2013). Evaluation of quality improvement intervention of HIV (PMTCT) at Zambia defence force facilities. BMC Health Services Research 13:345.

Table 1. Socio demographic characteristics of the CHWs

\begin{tabular}{|c|c|c|c|}
\hline & \# of CHWs & $\%$ of CHWs & \\
\hline & & & P-value \\
\hline No. of Participants & $(\mathrm{N}=152)$ & $(\%=100)$ & \\
\hline \multicolumn{4}{|l|}{ Sex } \\
\hline Male & 32 & 21.0 & \\
\hline Female & 120 & 79.0 & \\
\hline \multicolumn{4}{|l|}{ Age } \\
\hline Mean age & $36.8 \pm 8.7$ & & \\
\hline Male mean age & $37.6 \pm 4.3$ & & 0.00 \\
\hline Female Mean age & $36.6 \pm 9.5$ & & \\
\hline$<=36$ & 80 & 53.0 & \\
\hline$>36$ & 72 & 47.0 & \\
\hline \multicolumn{4}{|l|}{ Educational Level } \\
\hline Primary & 18 & 12.0 & \\
\hline Secondary & 113 & 74.0 & \\
\hline Post-secondary & 21 & 14.0 & \\
\hline \multicolumn{4}{|l|}{ Occupation } \\
\hline Unskilled & 96 & 63.0 & \\
\hline Skilled & 56 & 37.0 & \\
\hline
\end{tabular}

Participants $=\mathrm{N}=152$

Complaints $(\mathrm{n}=124)$

Non-complaints $(=28)$

Table 2. Chi-square test analysis of independent and dependent variables

\begin{tabular}{|c|c|c|c|c|c|c|c|}
\hline $\begin{array}{l}\text { Socio- } \\
\text { characteristics }\end{array}$ & Compliant & $\%$ & $\begin{array}{l}\text { Non- } \\
\text { compli } \\
\text { ant }\end{array}$ & $\%$ & $\mathrm{X}^{2}$ & $\mathrm{Df}$ & p-value \\
\hline \multicolumn{8}{|l|}{ Age (years) } \\
\hline \multirow[t]{2}{*}{$<36$} & 64 & 80 & 16 & 20 & & & \\
\hline & & & & & 0.282 & 1 & 0.596 \\
\hline$>36$ & 60 & 83 & 12 & 17 & & & \\
\hline \multicolumn{8}{|l|}{ Sex } \\
\hline \multirow{2}{*}{ Male } & 22 & 69 & & 31 & & & \\
\hline & & & 10 & & & & \\
\hline Female & 102 & 85 & & 15 & 4.439 & 1 & 0.035 \\
\hline \multicolumn{8}{|c|}{ Educational level } \\
\hline Primary & 13 & 72 & 5 & 28 & & & \\
\hline Secondary & 93 & 82 & 20 & 18 & 1.327 & 2 & 0.515 \\
\hline $\begin{array}{l}\text { Post- } \\
\text { secondary }\end{array}$ & 18 & 86 & 3 & 14 & & & \\
\hline
\end{tabular}


Texila International Journal of Public Health Volume 6, Issue 2, Jun 2018

\begin{tabular}{|l|l|l|l|l|l|l|l|}
\hline Vocation & 80 & 83 & 16 & 17 & & & \\
\hline Unskilled & & & & & 0.534 & 1 & 0.465 \\
\hline Skilled & 44 & 79 & 12 & 21 & & & \\
\hline
\end{tabular}




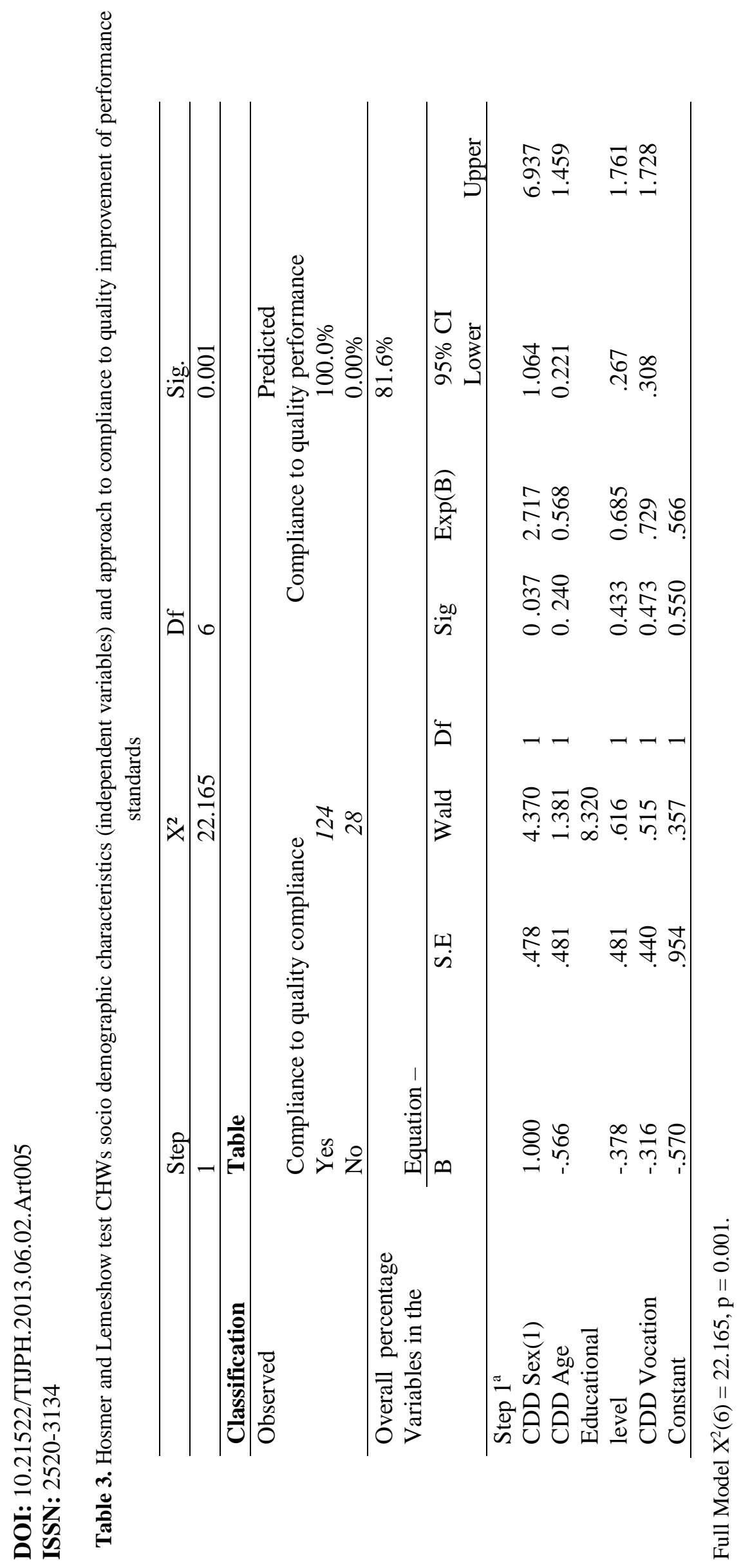




\title{
A Critical Review of the Articles "Rubella Outbreak Investigation, Gokwe North District, Midlands Province, Zimbabwe 2014
}

\author{
Article by D. Chirundu' ${ }^{1}$ P.N. Magande ${ }^{2,}$ A.N. Musiya ${ }^{3}$ \\ ${ }^{1,2,4}$ Kadoma City Health Department, Zimbabwe \\ ${ }^{3}$ University of Zimbabwe Dept. of Community Medicine, Zimbabwe \\ E-mail:dchirundu@me.com ${ }^{1}$,pmagande@gmail.com ${ }^{2,}$ drnyashaadrianmusiya@gmail.com ${ }^{3}$, \\ skhaemoyo@gmail.com ${ }^{4}$
}

Source: This review looks at the manuscript entitled "Rubella Outbreak Investigation, Gokwe North District, Midlands Province, Zimbabwe 2014- a case control study ' written by Donewell Bangure et. al. It was published in The Pan African Medical Journal Issue of September 2015. The Doi is 10.11604/pamj.2015.22.60.5939.

\begin{abstract}
This was an appraisal of a Rubella outbreak investigation carried out in Gokwe North District (Zimbabwe). The outbreak occurred from 24th June to 12 August 2014 at a primary school. The manuscript has an abstract that provided the stance and thesis. The introductory part covered the epidemiology of the disease. Methods section detailed the study design. Findings of the descriptive and analytical epidemiology investigations are presented in the results sections.

The article was published in the Pan African Medical Journal, a peer reviewed journal. This confers credence to the journal. It is tracked by HINARI, and Scopus, among others. The corresponding author is Donewell Bangure, a Zimbabwean epidemiologist. The manuscript was backed up by credible references from World Health Organization and other peer reviewed journals. However, wrong construction of the epidemic curve, may have led to erroneous conclusions.

Most of the information in the manuscript was objectively developed. However, some references were unpublished, and, some outdated. The manuscript was published in a peer reviewed journal and this makes it stable. There are three tables and one graph in the article. There are three well labelled tables and a graph in the manuscript. Information in the tables and graph is presented in a way that is comprehensible.
\end{abstract}

Keywords: Rubella, Gokwe North, Outbreak.

\section{Introduction}

This was an appraisal of a Rubella outbreak investigation carried out in Gokwe North District (Midlands Province) of Zimbabwe. In this review we will initially look at the literature review pertaining to the rubella outbreak investigation. We will then look at the article structure in terms of content and alignment. Under the article critique, we will give an overview of the authority, accuracy, currency, relevance, objectivity, stability and analysis of graphs or tables.

\section{Review of literature}

Rubella, is a mild febrile disease with a diffuse punctuate and maculopapular rash sometimes resembling that of measles (Heymann 2014 and Dimech et. al. 2015). It usually occurs in winter and spring. It is caused by the rubella virus, which can be found in the throat, blood, and stool of infected person. Transmission is by contact with nasopharyngeal secretions of infected people through droplet spread. Infected persons who exhibit no signs and symptoms may transmit rubella. According to the American Public Health Association (2014) 30\% to 50\% of rubella infections are not recognized as rubella disease. An increase in rubella incidence has been noted in unvaccinated adolescents and adults as well as in religious communities with no or low levels of vaccination. 
The incubation period, varies from 14-17 days, with a range of 14-21 days (Heyman 2014). Signs and symptoms of rubella includes fever, swollen glands that are usually found either in the neck or behind the ears, and, a rash that appears as either pink or light red spots. Other symptoms of rubella may include conjunctivitis and coryza. When rubella occurs in a pregnant woman, it may cause congenital rubella syndrome, resulting in malformations of the developing foetus (Axton et. al 1979; Kimberlin et. al 2015 and Chimhuya et. al. 2015). In areas where there is no routine rubella immunization like Cameroon and Central African Republic among others, rubella outbreaks are often confused and responded to as if they are measles outbreaks. (Chimhuya et. al. 2015; Axton et al.1979; Farra et. al.2016: and Mengouo et. al. 2017) This leads to waste of resources and provision of a false sense of security to the communities

\section{Article summary}

The article "Rubella Outbreak Investigation Gokwe North District Midlands province Zimbabwe 2014" by Bangure et. al. is based on a Rubella outbreak investigation. The outbreak occurred from $24^{\text {th }}$ of June to the $12^{\text {th }}$ of August 2014 at a primary school. The index case was a child of a relief teacher who had recently joined the school. The outbreak spread among the school pupils and ultimately infecting community members. The total number of people infected was 374 over three months. A case control study was done to identify factors associated with contracting the infection. Having a household contact, classmate contact, having more than three children in a household were significant risk factors ( $\mathrm{p}>0.05)$. Having suffered from rubella illness, and history of measles vaccination were protective but not statistically significant. Based on the shape of the epidemic curve the authors concluded that it was a propagated outbreak that spread from the school to the community. The recommendation was that a vaccine for rubella be routinely administered in Zimbabwe.

\section{Article structure}

This manuscript has an abstract that provided the stance and thesis as well as a brief overview of the main points. The article is an IMRAD outline of the outbreak investigation. Thus, there is an introduction, methods, results, discussion, and conclusion in that order.

The introduction gave a detailed background of rubella as well as the epidemiology of the disease. It also gave the details of the increase in the number of cases during the period and the index case. However, it is our opinion that the details of the index case were obtained as part of the investigation and as such it was more appropriate to be placed in results section.

Methods sections specified the study design. The definition of a case and the control as the terms applied to the investigation were clearly defined in this section. It is stated that simple random sampling was used, however, there is no elaboration on how the sample size was calculated.

Findings of the descriptive and analytical epidemiology components of the investigation are presented in the results sections. In descriptive epidemiology, "person characteristics" are presented in the demographic data. The epidemic timeline (time) is depicted by use of an epidemic curve. However, the "place attributes" are not well covered. Under the circumstances, we expected the attack rates by class, and/or village to depict the spatial distribution of cases. In analytical epidemiology, univariate, bivariate and multiple logistic regression analysis are soundly presented.

Under the discussion section, the statement "the epi-curve has several peaks typical of a propagated outbreak, suggestive of person to person transmission" is more of a conclusion than discussion. There is also inappropriate use of words like "quarantine" as the sick are isolated and those exposed and not exhibiting symptoms are quarantined (source). In the article sick pupils were said to have been "quarantined".

The conclusion was that primary school children aged 5-9 years were mostly affected. Nonetheless, there is nowhere in the results were attack rates by age are presented so that we get the basis of the conclusion. However, the recommendation to implement routine rubella vaccination is a sound recommendation.

The sentences were short, the readability was high, and, this makes the article easy to follow. 


\section{Article critique}

\section{Authority}

The journal in which the article is published Pan African Medical Journal (ISSN 1937-8688 (www.panaftrican-med-journal.com) is a peer reviewed journal that is published in partnership with the African Field Epidemiology Network (AFENET). This confers credence to the journal. It is tracked by HINARI, Scopus, DOAJ, Embase and PubMed Central. The numbers of manuscripts submitted to the journal an increased from 211 in 2010 to 2614 in 2017. Out of the 2614 manuscripts submitted in 2017, 994 were published. Manuscripts are submitted by authors from all geographical regions. This attests to the popularity of the Pan African Medical Journal and this gives it authority. Its affiliation to Field Epidemiology Training programs in Africa gives it further credence as this makes it a resource of first choice for African disease control specialists.

The corresponding author of the article is Donewell Bangure. He is a Zimbabwean public health expert formerly employed as an assistant field coordinator for the Zimbabwe field Epidemiology Training program but currently employed as an epidemiologist by CDC Africa. According to ResearchGate, he has published several articles on outbreak investigations, evaluation of surveillance systems, and, program evaluation. He is the holder of a master's in public health degree from the Zimbabwe Field Epidemiology Training Program.

\section{Accuracy}

The primary source of data for the manuscript was an outbreak investigation. It was backed up by references from credible sources like WHO (World Health Organization 2012). However, wrong construction of the epidemic curve, leading to misinterpretation of same may have led to inaccurate conclusions. The interval between the dates on the $x$-axis is supposed to be between a quarter to a third of the incubation period (Centres for Disease Control 2012).

\section{Currency}

The manuscript was accepted for publication on 26 May 2015 and published on 22 September 2015. This makes it relatively current work. The field work was done from June to August 2014. One compromise is that most the references were outdated- for example the article by Lawn et. al. was published in the year 2000. Some of the references are not published in peer reviewed journals for example the 2005 Rubella outbreak investigation by Mpeta et. al. and the 2004 outbreak by Muchedzi et. al.

\section{Relevance}

The Pan African Journal of Medicine is a journal of the African Field Epidemiology Training Programs. It is relevant in that it addresses relevant and pertinent issues of public health interest including communicable disease control in Africa and beyond.

\section{Objectivity}

To some extent, the information was objectively developed. Bias may hay have been introduced in the article by incorrect construction and interpretation of the epidemic curve. Terms are well explained and described. The sample size was mentioned but the assumptions and how it was calculated are not articulated.

\section{Stability}

The manuscript was published in a peer reviewed journal and this makes it stable. 
DOI: $10.21522 /$ TIJPH.2013.06.02.Art006

ISSN: $2520-3134$

\section{Analysis of graphs and tables}

There are three tables and one graph in the article. All tables are well labelled, and information is presented in a way that is easy to understand. However, in table 2 bivariate analysis, odds ratio as well as 95\% confidences intervals are included whilst $p$ - values are not absent.

Figure 1 is an epidemic curve depicting the epidemic timeline. The date of onset is shown on the $x$-axis and the number of case on the $y$-axis. The interval on the $x$-axis is one day. This is supposed to be a quarter to a third of the incubation period (WHO 2008 and CDC 2018). This defies standard epi-curve construction and makes correct interpretation of epi-curves impossible. Wrong interpretation in turn leads to incorrect conclusion on transmission dynamics.

There was need to present a spot map to depict the "place" of descriptive epidemiology.

\section{Recent advances related to the topic}

Bosma et. al. (1995) investigated the use of PCR for detection of virus RNA in clinical samples. Rubella virus RNA was detected in 12 pharyngeal swabs from patients with serologically confirmed rubella; these RT-PCR results were in complete agreement with virus isolation. Analysis of products of conception obtained after confirmed primary maternal rubella infection by RT-PCR gave $92 \%$ agreement (12 of 13 samples) with virus isolation. No false-positive results were obtained. PCR can therefore be used to establish the source of infection. Molecular investigations of Rubella is also being done in countries like Romania (Lazar et. al. 2016) In the case of Bangure et. al. they could have compared the PCR result from Gokwe and Masvingo to verify if the outbreaks were related (Bosma et. al).

Laboratory tests are essential for confirming sporadic cases and outbreak of rubella. Detection of rubella is often necessary to confirm rubella cases and to identify specimens to be used to characterize wild-type rubella viruses. Zhen Zhu as far back as 2007 showed that direct RT-PCR followed by hybridization was the most sensitive method; the replicon-based method was the least difficult to perform. Such methods can be used in confirming the cases where resources allow. All the recent advances show that molecular assays are important tools in the early diagnosis of rubella and congenital rubella syndrome. In the provision of molecular epidemiological information for tracking transmission pathways and in adding to the knowledge of rubella strain distribution worldwide. Another of African countries are also introducing Rubella vaccination. This is having a further effect of strengthening meascles vaccination (Wesolowski et. al. 2016).

\section{Conclusion}

This article summarized, reviewed and critiqued Donewell Bangure`s manuscript "Rubella Outbreak Investigation Gokwe North District Midlands province Zimbabwe 2014". The content, structures and limitations of the structure were analyzed. This contributed to literature and knowledge in that it is a documentation an outbreak investigation and audit of the response. Outbreaks are common in Africa and this manuscript can serve as a reference to other investigators.

\section{Acknowledgements}

We acknowledge the contribution of Prince Matambo and Patrick Makovere for typesetting this manuscript.

\section{References}

[1]. Axton et. al. (1979). Simultaneous Rubella and Measles Epidemics in an African Community. The Central African Journal of Medicine.

[2]. Bosma et. al. (1995) PCR for detection of rubella virus RNA in clinical samples. J. Clin. Microbiol. May 1995 vol. 33 no. 5 1075-1079.

[3]. Centres for Disease Control (2006). Principles of Epidemiology in Public Health Practice-US Department of Health and Human Services Updated May 2012. 
[4]. Chimhuya et. al. (2015). Trends of rubella incidence during a 5-year period of case-based surveillance in Zimbabwe. BMC Public Health.

[5]. Dimech et.al. (2016). Standardization of assays that detect anti-rubella virus IgG antibodies. Clin Microbiol Rev 29:163-174. doi:10.1128/CMR.00045-15.

[6]. Farra et. al. (2016). Epidemiology of primary rubella infection in the Central African Republic: data from measles surveillance 2007-2014 BMC Infectious Diseases.

[7]. Heymann, D. (2014). Control of Communicable Diseases Manual. American Public Health Association.

[8]. Kimberlin et. al. (2015) The Red Book- American Academy of Pediatrics 2015.

[9]. Lawn et. al (2000). Unseen blindness, unheard deafness and unrecorded death and disability: congenital rubella in Kumusi Ghana American J public Health.

[10]. Mengouo et. al. (2017) Epidemiology of Rubella Infection in Cameroon: a 7 -year experience of measles and rubella case-based surveillance 2008-2014. BMJ.

[11]. Mpeta T, Ndlovu et. al. Rubella Outbreak in Nkakezi, Insiza District, Matebeleland South Province (Unpublished). 2005. Google Scholar).

[12]. Lazar et. al. (2016) Epidemiological and molecular investigation of a rubella outbreak, Romania, 2011 to 2012. Euro Surveill. 2016; 21(38):pii=30345. DOI: http://dx.doi.org/10.2807/1560-7917.ES.2016.21.38.30345.

[13]. Wesolowski A et al. 2016 Introduction of rubella-containing-vaccine to Madagascar: implications for roll-out and local elimination. J. R. Soc. Interface 13: 20151101.http://dx.doi.org/10.1098/rsif.2015.1101.

[14]. World Health Organization (2008) Foodborne disease outbreaks: guidelines for investigation and control. World Health Organization.

[15]. World Health Organization (2012). Global measles and rubella strategic plan: 2012-2020. W.H.O.

[16]. World Health Organization (2012). Recommended surveillance standard of rubella and congenital rubella syndrome. World Health Organization.

[17]. Zhen Zhu (2007). Comparison of Four methods using throat Swabs to Confirm Rubella Virus Infection. J. Clin. Microbiology. 


\title{
Knowledge Intervention on Nutrition among the Primary School Students
}

\author{
Article by M.M Aktaruzzaman ${ }^{1}$, Shazly Bari², Irin Hossain ${ }^{3}$ \\ ${ }^{1} V B D C, D G H S$ \\ ${ }^{2,3}$ National Institute of Preventive and Social Medicine, Mohakhali, Dhaka \\ Email: irin.hossain@gmail.com
}

\begin{abstract}
This quasi experimental study was done among the students of class $V$ of 68 No. Islampur Primary School, Dhamrai, Dhaka to assess \& intervene knowledge on nutrition. Purposively 104 students of class $V$ were selected and interviewed with a structured, self-administered questionnaire. Then the respondents were taught with basic nutrition knowledge for 5 days and after completion of teaching, post intervention evaluation was done with same questionnaire. Then the answer scripts were evaluated to understand whether there were any changes in their knowledge on nutrition. As on the analysis it is clearly understood that there is huge difference and increase in percentage before and after the intervention. There was a satisfactory improve of knowledge after giving of intervention on nutrition. The primary objective was to assess the knowledge on nutrition to improve the health of the respondents. On the basis of the findings it may be concluded that the knowledge on nutrition is one of the major health concern, so creating awareness through intervention program on nutrition can reduce the malnutrition problem.
\end{abstract}

Keywords: Knowledge, nutrition.

\section{Introduction}

Life cannot be sustained without adequate nourishment. The word "nutrition" is often paired with the word "food". Nutrition is a science that encompasses all the interactions that occur between living organisms and food. The biological importance of food is dictated by the nutrients it contains [1]. Common belief is that acquiring nutritional knowledge will itself lead to improved dietary practices. Nutritional knowledge can be gained by means of nutrition education. Nutrition education can be defined as "the process of helping individuals to develop the knowledge, skills and motivation needed to make appropriate food choices throughout the life" [2]. The health habits established affects the quality of life. By practicing wellness, healthy life can be achieved. 'Good habits for proper life management [3] includes Choosing and eating nutritious food, exercising regularly, having adequate sleep, learning to handle stress, avoiding harmful substances. Children who are overweight or obese are more likely to be overweight or obese in adulthood, and they are more likely to develop cardiovascular disease as well as Type II Diabetes Mellitus during childhood [4]. Though diet is incredibly complex, nutrition knowledge has been shown to correlate with healthier food choices [5]. Adolescents are future parents. Particularly women play a significant role in the development of their offspring [6]. So if they have better nutritional knowledge and awareness on nutrition they improve the nutritional status of family members and good health can be maintained. Despite the fact that adolescence is a window of opportunity to break the intergenerational cycle of malnutrition, adolescents are the neglected age groups. Hence information regarding the nutritional status of adolescents is lacking making creating and implementing intervention programs difficult. Adolescents constitute $20 \%$ of the world population and are estimated to be 1.13 billion by the year 2025 [7]. About $25 \%$ of the Ethiopian populations are adolescent. Adolescence is a period of rapid growth and development by which up to $45 \%$ of skeletal growth takes place and 15 to $25 \%$ of adult height is achieved [8]. In addition to the increased nutritional requirements during 
adolescence period, poor dietary diversity and dietary inadequacies are more likely threats among adolescents due to their erratic eating pattern and having specific psychosocial factors [7].

Malnutrition passes from generation to generation, because adolescent girls that enter pregnancy with poor nutrient store are more likely to give birth to low birth weight or intrauterine growth restricted baby that is more vulnerable to metabolic disorders later in life [9]. So adolescence period is a unique opportunity to break a range of vicious cycles of structural problems that are passed from one generation to the next, such as poverty, gender discrimination, violence, poor health, and nutrition [7].

\section{Background}

A cross sectional study was conducted, to determine changes in nutrition knowledge, attitude and practice of 8-year-old school children after receiving a nutrition education package. A total of 418 school children from urban and rural areas participated in this study. The intervention group consisted of 237 children while 181 children who did not receive the nutrition education package acted as controls. The nutrition education program that was conducted for 3 weeks comprised of a video viewing session and a comic reading session followed by exercise questions as reinforcement for each session, and also classroom activities. Knowledge, attitude and practice questionnaires were distributed to the children before pre-intervention and after post intervention receiving the nutrition education program. A follow-up visit was conducted six months after the program had elapsed. The results obtained indicated that the nutrition knowledge score increased significantly in the intervention group from $48.3 \pm 13.2$ at pre-test to $54.6 \pm 16.2$ in post-test and 55.0 \pm 14.3 in follow-up test $(\mathrm{p}<0.05)$. The nutrition attitude score also increased significantly from $68.7 \pm 15.5$ at pre-intervention to $72.6 \pm 15.0$ and $74.7 \pm 15.8$ during post-test and followup test respectively $(\mathrm{p}<0.05)$. However, the nutrition practice score had no significant improvement in both groups throughout the study period. There were no significant changes in the control group in knowledge, attitude and practice scores at pre, post and follow-up tests. In conclusion, this study showed that a good nutrition education program had a positive impact whereby better nutrition knowledge; attitude and healthy eating habits in children were seen. It is hoped that the improvements would be sustained throughout their lives [10]. A cluster-randomized controlled-trial examining the effect of a school-based comprehensive intervention on nutrition knowledge, eating habits, and behaviors among low socioeconomic status (LSES) school-aged children was performed. LSES school-aged children (47 years) and their mothers were recruited from 11 schools, located in one town. The intervention was implemented on three levels: children, mothers, and teachers. The intervention (IArm) included nutrition classes for children, mothers, and teachers and physical activity (PA) classes for children; the control (C Arm) received PA only. Interventions were conducted by professional personnel, who were trained during in a two-day session to deliver the specific program in schools. Family data were obtained by parental interviews. Food knowledge observations, packed lunch records, and anthropometric measurements were obtained in school at baseline, six months, and at the end of the school year. Of 258 children enrolled, 220 (87.6\%) completed the six-month program. Only children in the I Arm improved their nutrition knowledge and eating-habits and increased food variety and fruit and vegetable consumption, quality score of packed lunches ( $p<0.001$ for all), habitual water drinking increased $(p=0.02)$, and decreased sweet-drink consumption $(\mathrm{p}=0.05)$. A school-based comprehensive nutrition intervention targeting LSES population improved eating habits, nutritional knowledge, and healthier packed lunches [11].

A randomized educational controlled trial was carried out on 221 primary school age children selected by cluster sampling in the elementary schools of Shiraz-Iran. The intervention consisted of 6 nutrition education sessions carried out through one year for children, using active learning methods. Mothers' education was carried out in person in both lecture and question-answer sessions also via sending text messages and pamphlets. Weight, height and waist circumference (WC) of children were measured before and after the intervention. Also a 168-item food frequency questionnaire was completed. Two separate nutrition knowledge questionnaires were filled up by children and their mothers. Data were analyzed using SPSS version 16. Results: 171 children (83 in the case and 88 in the control group), aged 9.5-10.5 
years, completed the study. Anthropometric and nutritional knowledge of the participants in both the intervention and control groups was significantly increased. Weight, height, WC and nutritional knowledge increased significantly more in the intervention group compared to the controls. Consumption of fruits and vegetables decreased in the intervention group while plain sugar and fast foods intake increased among the controls. There were no significant differences between the changes in the intake of any of the food groups in the two groups. Conclusions: In conclusion, the designed nutrition education program could increase students' nutritional knowledge, and lead to a non-significant change towards reducing the consumption of unhealthy foods such as fast foods, sweets and salty snacks.

Nutritional status of today reflects a healthy and productive generation in future. Especially for primary school children, nutritional condition is a critical factor for optimum growth and it should neither be inadequate nor is excessive malnutrition usually the result of a combination of inadequate dietary intake and infection. In children, malnutrition is synonymous with growth failure. Malnourished children are shorter and lighter in weight than they should be for their age. With the high incidence of poverty and HIV/ AIDS, prevalence of malnutrition is also high. Malnutrition needs to be viewed as an indication of inadequate provision of some of the most basic of all human rights. It is also a reflection of inadequate investment and progress in a range of issues related to human capital development and has a significant influence on the future economic development of a country. Study showed that majority (93.6\%) of the school children were suffering from underweight (BMI) and very few (6.4\%) of them had normal BMI. Similar findings had found in the study done by Adhikary $M$ et al. among primary school children in one Upazila (sub district) where it was found that more than two third children were underweight. According to WHO $48 \%$ of children were malnourished and $10 \%$ of them were severely malnourished. In case of WAZ, more than two thirds (79.10\%) were normal. In case of HAZ, almost majority (80\%) were normal and in case of WHZ, more than half $(55.50 \%)$ were normal range. Previous study found that more than $54 \%$ of preschool-age children, equivalent to more than 9.5 million children, were stunted, $56 \%$ were underweight and more than $17 \%$ were wasted [12].

\section{Methods}

\section{Study design and sample}

The study was quasi-experimental study. This study was conducted for a period from $12^{\text {th }}$ February, 2017 to $9^{\text {th }}$ March, 2017 in 68 no. Islampur Primary School, Dhamrai, Dhaka. The target population of this research was Class V students. Non cooperative, ill students were excluded from the study. The ultimate sample size for the study was 104 which were selected by purposive sampling. Each sample was collected from selected school. A structured questionnaire was used to collect data. Method of data collection was Self-administered method by the respondents. Permission was taken from the ethical review committee of NIPSOM and Headmaster of 68 No. Islampur Primary School, Dhamrai Dhaka. All participants were treated equally. All participants of the study were informed about the research and consent was taken. Before going to the process of data collection, pretesting was carried out on 10 students in 68 No. Islampur Primary School, Dhamrai, Dhaka to finalize to procedure and to evaluate the effectiveness of the research instrument. Modifications were made as necessary and the research instrument was finalized. Data was collected by Self-administered method by the respondents who fulfilled the selection criteria. The data were collected by a prepared pre-tested questionnaire. The analysis were include description of the study population by their socio-demographic characteristics at first instance using certain descriptive statistics, frequency distribution tables on frequencies, percentages, mean, median \& SD. In order to find out association between two or more variables Chi-Square test and Fisher's exact test were performed to see the statistical significance. Graphical software was used for creation of charts by using Microsoft Excel. 
DOI: $10.21522 /$ TIJPH.2013.06.02.Art007

ISSN: $2520-3134$

\section{Analysis}

Collected data were checked-rechecked, edited, coded and recorded for quality management. Data were analyzed with SPSS 22. To assess or measure the objectives, for descriptive statistics-frequency, percentage, mean, median, standard deviation (SD) were used for socio-demographic factors. For test of significance, Chi-square test was done to see the relation between (dependent variable) and associated factors (independent variable). For all statistical test used in this study, statistically significant level set as $\mathrm{p} \leq .05$.

\section{Result}

This quasi-experimental study was carried out on 104 students in 68 no. Islampur Primary School, Dhamrai, Dhaka. The main purpose of the study was to assess \& intervene the knowledge on nutrition among the primary school students. Participation of this study who were selected purposively and each participant was provided with a consent form. After completion of data analysis, the results were organized in the tabular form and figures as necessary respectively. There is difference in the percentage before and after intervention. On an average $70 \%$ of people are got awareness of their food habits after the intervention. The tables and figures are described below. The findings of the study are presented in the subsequent pages.

\section{A. Distribution of respondents by knowledge on components of food pre and post intervention $(\mathbf{n}=104)$}

Table-1 shows that before intervention $62.1 \%$ respondents know carbohydrate, $69.9 \%$ know protein, 43.7\% know fat, $73.8 \%$ know vitamin and $4.9 \%$ don't know as the components of food and after intervention $97.1 \%$ know carbohydrate, $97.1 \%$ know protein, $90.3 \%$ know fat, $91.3 \%$ know vitamin as the components of food.

Table 1. Distribution of respondents by knowledge on components of food pre and post intervention $(n=104)$

\begin{tabular}{|l|l|l|l|l|}
\hline \multirow{2}{*}{$\begin{array}{l}\text { Components of } \\
\text { food }\end{array}$} & \multicolumn{2}{l|}{ Before intervention } & \multicolumn{2}{l|}{ After intervention } \\
\cline { 2 - 5 } & Frequency & Percentage & Frequency & Percentage \\
\hline Carbohydrate & 64 & $62.1 \%$ & 100 & $97.1 \%$ \\
\hline Protein & 72 & $69.9 \%$ & 100 & $97.1 \%$ \\
\hline Fat & 45 & $43.7 \%$ & 93 & $90.3 \%$ \\
\hline Vitamin & 76 & $73.8 \%$ & 94 & $91.3 \%$ \\
\hline Don`t know & 4 & $4.9 \%$ & 0 & $0.0 \%$ \\
\hline
\end{tabular}

\section{B. Distribution of respondents by knowledge on examples and function of carbohydrate, protein and fat pre and post intervention $(n=104)$}

Table-2 shows that before intervention $85.6 \%$ respondents know rice, $23.1 \%$ know fish-meat, $74.0 \%$ know bread, $75.0 \%$ know potato and $2.9 \%$ don't know as the examples of carbohydrate and after intervention $96.2 \%$ respondents know rice, $11.5 \%$ know fish-meat, 92.3\% know bread, 96.2\% know potato and $0.0 \%$ don't know as the examples of carbohydrate.Table- 2 shows that before intervention $26.9 \%$ respondents know improves intelligence, $65.4 \%$ know body building, $46.2 \%$ know prevent disease, $20.2 \%$ know provide energy and 9.6\% don't know as the functions of carbohydrate and after intervention $29.4 \%$ respondents know improves intelligence, $49.0 \%$ know body building, $43.1 \%$ know prevent disease, $52.9 \%$ know provide energy and $1.0 \%$ don't know as the functions of carbohydrate. Table-2 shows that before intervention $65.4 \%$ respondents know fish, 51.0\% know vegetables, $65.4 \%$ know meat, $27.9 \%$ know fruits and $1.9 \%$ don't know as the examples of protein rich food and after intervention $37.6 \%$ respondents know fish, $13.5 \%$ know vegetables, $37.6 \%$ know meat, $11.4 \%$ know fruits and $0.0 \%$ don't know as the examples of protein rich food. Table- 2 shows that before intervention 
43.3\% respondents know body building, $44.2 \%$ know disease prevention, 37.5\% know provide calorie, $44.2 \%$ know prevent muscle decay and $7.7 \%$ don't know as the functions of protein and after intervention $70.2 \%$ respondents know body building, 53.8\% know disease prevention, $43.3 \%$ know provide calorie, $44.2 \%$ know prevent muscle decay and $0.0 \%$ don't know as the functions of protein. Table- 2 shows that before intervention $79.8 \%$ respondents know meat, $22.1 \%$ know fruits, $42.3 \%$ know fish, $23.1 \%$ know vegetables and $8.7 \%$ don't know as the examples of fat and after intervention $89.4 \%$ respondents know meat, $12.5 \%$ know fruits, $64.4 \%$ know fish, $18.3 \%$ know vegetables and $1.0 \%$ don't know as the examples of fat. Table- 2 shows that before intervention $46.2 \%$ respondents know body building, $28.8 \%$ know prevent disease, $33.7 \%$ know provide calorie, $28.8 \%$ know improve intelligence and $11.5 \%$ don't know as the functions of fat and after intervention $46.2 \%$ respondents know body building, $30.8 \%$ know prevent disease, $52.9 \%$ know provide calorie, $38.5 \%$ know improve intelligence and $4.8 \%$ don't know as the functions of fat.

Table 2. Distribution of respondents by knowledge on examples and function of carbohydrate, protein and fat pre and post intervention $(\mathrm{n}=104)$ :

\begin{tabular}{|c|c|c|c|c|}
\hline \multirow{2}{*}{$\begin{array}{l}\text { Examples of } \\
\text { carbohydrate }\end{array}$} & \multicolumn{2}{|c|}{ Before intervention } & \multicolumn{2}{|c|}{ After intervention } \\
\hline & Frequency & Percentage & Frequency & Percentage \\
\hline Rice & 89 & $85.6 \%$ & 100 & $96.2 \%$ \\
\hline Fish-meat & 24 & $23.1 \%$ & 12 & $11.5 \%$ \\
\hline Bread & 77 & $74.0 \%$ & 96 & $92.3 \%$ \\
\hline Potato & 78 & $75.0 \%$ & 100 & $96.2 \%$ \\
\hline Don`t know & 3 & $2.9 \%$ & 0 & $0.0 \%$ \\
\hline \multicolumn{5}{|c|}{ Functions of carbohydrate } \\
\hline $\begin{array}{l}\text { Improves } \\
\text { intelligence }\end{array}$ & 28 & $26.9 \%$ & 30 & $29.4 \%$ \\
\hline Body building & 68 & $65.4 \%$ & 50 & $49.0 \%$ \\
\hline Prevent disease & 48 & $46.2 \%$ & 44 & $43.1 \%$ \\
\hline Provides energy & 21 & $20.2 \%$ & 54 & $52.9 \%$ \\
\hline Don`t know & 10 & $9.6 \%$ & 1 & $1.0 \%$ \\
\hline \multicolumn{5}{|c|}{ Examples of protein food } \\
\hline Fish & 68 & $65.4 \%$ & 89 & $37.6 \%$ \\
\hline Vegetables & 53 & $51.0 \%$ & 32 & $13.5 \%$ \\
\hline Meat & 68 & $65.4 \%$ & 89 & $37.6 \%$ \\
\hline Fruits & 29 & $27.9 \%$ & 27 & $11.4 \%$ \\
\hline Don`t know & 2 & $1.9 \%$ & 0 & $0.0 \%$ \\
\hline \multicolumn{5}{|c|}{ Functions of protein } \\
\hline Body building & 45 & $43.3 \%$ & 73 & $70.2 \%$ \\
\hline $\begin{array}{l}\text { Disease } \\
\text { prevention }\end{array}$ & 46 & $44.2 \%$ & 56 & $53.8 \%$ \\
\hline Provide calorie & 39 & $37.5 \%$ & 45 & $43.3 \%$ \\
\hline $\begin{array}{l}\text { Prevent muscle } \\
\text { decay }\end{array}$ & 46 & $44.2 \%$ & 46 & $44.2 \%$ \\
\hline Don`t know & 8 & $7.7 \%$ & 0 & $0.0 \%$ \\
\hline \multicolumn{5}{|l|}{ Examples of fat } \\
\hline Meat & 83 & $79.8 \%$ & 93 & $89.4 \%$ \\
\hline Fruits & 23 & $22.1 \%$ & 13 & $12.5 \%$ \\
\hline Fish & 44 & $42.3 \%$ & 67 & $64.4 \%$ \\
\hline
\end{tabular}


DOI: $10.21522 /$ TIJPH.2013.06.02.Art007

ISSN: $2520-3134$

\begin{tabular}{|l|l|l|l|l|}
\hline Vegetables & 24 & $23.1 \%$ & 19 & $18.3 \%$ \\
\hline Don`t know & 9 & $8.7 \%$ & 1 & $1.0 \%$ \\
\hline Functions of fat & \multicolumn{5}{|l|}{} \\
\hline Body building & 48 & $46.2 \%$ & 48 & $46.2 \%$ \\
\hline Prevent disease & 30 & $28.8 \%$ & 32 & $30.8 \%$ \\
\hline Provide calorie & 35 & $33.7 \%$ & 55 & $52.9 \%$ \\
\hline $\begin{array}{l}\text { Improve } \\
\text { intelligence }\end{array}$ & 30 & $28.8 \%$ & 40 & $38.5 \%$ \\
\hline Don`t know & 12 & $11.5 \%$ & 5 & $4.8 \%$ \\
\hline
\end{tabular}

\section{Distribution of respondents by knowledge on examples and deficiency disease of vitamin $\mathrm{A}$ and vitamin $\mathrm{C}$ rich food pre and post intervention $(n=104)$}

Table-3 shows that before intervention $96.2 \%$ respondents know green vegetables, $16.3 \%$ know yellow vegetables, $57.7 \%$ know fruits, $7.7 \%$ know mola-dhela fish and $1.9 \%$ don't know as the examples of vitamin A rich food and after intervention 90.4\% respondents know green vegetables, $22.1 \%$ know yellow vegetables, $64.4 \%$ know fruits, $38.5 \%$ know mola-dhela fish and $1.0 \%$ don't know as the examples of vitamin A rich food. Table-3 shows that before intervention $91.3 \%$ respondents know night blindness, $47.1 \%$ know oral ulcer, $7.7 \%$ know weight gain, $19.2 \%$ know kidney disease and $1.9 \%$ don't know as diseases due to deficiency of vitamin A and after intervention $92.3 \%$ respondents know night blindness, $34.6 \%$ know oral ulcer, $10.6 \%$ know weight gain, $8.7 \%$ know kidney disease and $0.0 \%$ don't know as diseases due to deficiency of vitamin A. Table-3 shows that before intervention 59.6\% respondents know green vegetables, 36.5\% know sour fruits, 36.5\% know sweet fruits, $8.7 \%$ know yellow fruits and 7.7\% don't know as the examples of vitamin $\mathrm{C}$ rich foods and after intervention $54.8 \%$ respondents know green vegetables, 50.0\% know sour fruits, $33.7 \%$ know sweet fruits, $10.6 \%$ know yellow fruits and 5.8\% don't know as the examples of vitamin $\mathrm{C}$ rich foods. Table-3 shows that before intervention $69.2 \%$ respondents know oral ulcer, $24.0 \%$ know leg ulcer, $18.3 \%$ know weight gain, 29.8\% know common cold a5.8nd \% don't know as the diseases of due to vitamin $\mathrm{C}$ deficiency and after intervention $83.7 \%$ respondents know oral ulcer, $21.2 \%$ know leg ulcer, $9.6 \%$ know weight gain, 38.5\% know common cold and $1.0 \%$ don't know as the diseases of due to vitamin $\mathrm{C}$ deficiency.

Table 3. Distribution of respondents by knowledge on examples and deficiency disease of vitamin A and vitamin $\mathrm{C}$ rich food pre and post intervention $(\mathrm{n}=104)$

\begin{tabular}{|c|c|c|c|c|}
\hline \multirow{2}{*}{$\begin{array}{l}\text { Examples of } \\
\text { vitamin A rich } \\
\text { food }\end{array}$} & \multicolumn{2}{|c|}{ Before intervention } & \multicolumn{2}{|c|}{ After intervention } \\
\hline & Frequency & Percentage & Frequency & Percentage \\
\hline Green vegetables & 100 & $96.2 \%$ & 94 & $90.4 \%$ \\
\hline Yellow vegetables & 17 & $16.3 \%$ & 23 & $22.1 \%$ \\
\hline Fruits & 60 & $57.7 \%$ & 67 & $64.4 \%$ \\
\hline Mola-dhela fish & 8 & $7.7 \%$ & 40 & $38.5 \%$ \\
\hline Don`t know & 2 & $1.9 \%$ & 1 & $1.0 \%$ \\
\hline \multicolumn{5}{|c|}{ Diseases due to deficiency of vitamin A } \\
\hline Night blindness & 95 & $91.3 \%$ & 96 & $92.3 \%$ \\
\hline Oral ulcer & 49 & $47.1 \%$ & 36 & $34.6 \%$ \\
\hline Weight gain & 8 & $7.7 \%$ & 11 & $10.6 \%$ \\
\hline Kidney disease & 20 & $19.2 \%$ & 9 & $8.7 \%$ \\
\hline Don`t know & 2 & $1.9 \%$ & 0 & $0.0 \%$ \\
\hline \multicolumn{5}{|c|}{ Examples of vitamin $\mathrm{C}$ rich foods } \\
\hline Green vegetables & 62 & $59.6 \%$ & 57 & $54.8 \%$ \\
\hline Sour fruits & 38 & $36.5 \%$ & 52 & $50.0 \%$ \\
\hline
\end{tabular}


Texila International Journal of Public Health Volume 6, Issue 2, Jun 2018

\begin{tabular}{|l|l|l|l|l|}
\hline Sweet fruits & 38 & $36.5 \%$ & 35 & $33.7 \%$ \\
\hline Yellow fruits & 9 & $8.7 \%$ & 11 & $10.6 \%$ \\
\hline Don`t know & 8 & $7.7 \%$ & 6 & $5.8 \%$ \\
\hline \multicolumn{5}{|l|}{ Diseases due to deficiency of vitamin C } \\
\hline Oral ulcer & 72 & $69.2 \%$ & 87 & $83.7 \%$ \\
\hline Leg ulcer & 25 & $24.0 \%$ & 22 & $21.2 \%$ \\
\hline Weight gain & 19 & $18.3 \%$ & 10 & $9.6 \%$ \\
\hline Common cold & 31 & $29.8 \%$ & 40 & $38.5 \%$ \\
\hline Don`t know & 6 & $5.8 \%$ & 1 & $1.0 \%$ \\
\hline
\end{tabular}

\section{Distribution of respondents by knowledge on sources and deficiency disease of iodine and iron pre and post intervention $(n=104)$}

Table-4 shows that before intervention $44.2 \%$ respondents know sea-fish, $34.6 \%$ know body fruits, $50.0 \%$ know table salt, $27.9 \%$ know vegetables and $14.4 \%$ don't know as the sources of iodine and after intervention $79.8 \%$ respondents know sea-fish, $8.7 \%$ know body fruits, $78.8 \%$ know table salt, $10.6 \%$ know vegetables and $2.9 \%$ don't know as the sources of iodine. Table- 4 shows that before intervention $32.7 \%$ respondents know autism, 46.2\% know eye problem, 34.6\% know kidney problem, 51.0\% know goiter and $11.5 \%$ don't know as the diseases due to deficiency of iodine and after intervention $74.0 \%$ respondents know autism, 19.2\% know eye problem, 11.5\% know kidney problem, $69.2 \%$ know goiter and $1.0 \%$ don't know as the diseases due to deficiency of iodine. Table- 4 shows that before intervention $50.0 \%$ respondents know fish, meat, liver, $44.2 \%$ know lal shak, $32.7 \%$ know green banana, $41.3 \%$ know kochu shak and $21.2 \%$ don't know as the source of iron and after $54.8 \%$ respondents know fish, meat, liver, $44.2 \%$ know lal shak, $48.1 \%$ know green banana, 52.9\% know kochu shak and 12.5 as the source of iron. Table- 4 shows that before intervention $48.5 \%$ respondents know cancer, $56.3 \%$ know anemia, $29.1 \%$ know oral ulcer, $38.8 \%$ know eye problem and $9.7 \%$ don't know as the diseases of due to deficiency of iron and after intervention $31.7 \%$ respondents know cancer, $80.8 \%$ know anemia, $18.3 \%$ know oral ulcer, $11.5 \%$ know eye problem and $2.9 \%$ don't know as the diseases of due to deficiency of iron.

Table 4. Distribution of respondents by knowledge on sources and deficiency disease of iodine and iron pre and post intervention $(n=104)$

\begin{tabular}{|l|l|l|l|l|}
\hline \multirow{2}{*}{ Sources of iodine } & \multicolumn{3}{|l|}{ Before intervention } & \multicolumn{2}{l|}{ After intervention } \\
\cline { 2 - 5 } & Frequency & Percentage & Frequency & Percentage \\
\hline Sea fish & 46 & $44.2 \%$ & 83 & $79.8 \%$ \\
\hline Fruits & 36 & $34.6 \%$ & 9 & $8.7 \%$ \\
\hline Table salt & 52 & $50.0 \%$ & 82 & $78.8 \%$ \\
\hline Vegetables & 29 & $27.9 \%$ & 11 & $10.6 \%$ \\
\hline Don`t know & 15 & $14.4 \%$ & 3 & $2.9 \%$ \\
\hline Diseases due to deficiency iodine \\
\hline Autism & 34 & $32.7 \%$ & 77 & $74.0 \%$ \\
\hline Eye problem & 48 & $46.2 \%$ & 20 & $19.2 \%$ \\
\hline Kidney problem & 36 & $34.6 \%$ & 12 & $11.5 \%$ \\
\hline Goiter & 53 & $51.0 \%$ & 72 & $69.2 \%$ \\
\hline Don`t know & 12 & $11.5 \%$ & 1 & $1.0 \%$ \\
\hline Sources of iron & \multicolumn{5}{|l|}{} \\
\hline Fish, meat, liver & 52 & $50.0 \%$ & 57 & $54.8 \%$ \\
\hline Lal shak & 46 & $44.2 \%$ & 46 & $44.2 \%$ \\
\hline Green banana & 34 & $32.7 \%$ & 50 & $48.1 \%$ \\
\hline
\end{tabular}


DOI: $10.21522 /$ TIJPH.2013.06.02.Art007

ISSN: $2520-3134$

\begin{tabular}{|l|l|l|l|l|}
\hline Kochu shak & 43 & $41.3 \%$ & 55 & $52.9 \%$ \\
\hline Don`t know & 22 & $21.2 \%$ & 13 & $12.5 \%$ \\
\hline Diseases due to deficiency of iron \\
\hline Cancer & 50 & $48.5 \%$ & 33 & $31.7 \%$ \\
\hline Anemia & 58 & $56.3 \%$ & 84 & $80.8 \%$ \\
\hline Oral ulcer & 30 & $29.1 \%$ & 19 & $18.3 \%$ \\
\hline Eye problem & 40 & $38.8 \%$ & 12 & $11.5 \%$ \\
\hline Don`t know & 10 & $9.7 \%$ & 3 & $2.9 \%$ \\
\hline
\end{tabular}

E. Distribution of respondents by knowledge on daily water requirement, ideal food, its example; balanced diet and fiber rich food and its benefit pre and post intervention ( $n=104)$

Table-5 shows that before intervention $27.9 \%$ respondents know two liter, $25.0 \%$ know three liter, $15.4 \%$ know four liter, $45.2 \%$ know five liter and $19.2 \%$ don't know as daily water requirement of a 70 $\mathrm{kg}$ man and after intervention 3.9\% respondents know two liter, $83.5 \%$ know three liter, $6.8 \%$ know four liter, $7.8 \%$ know five liter and $1.0 \%$ don't know as daily water requirement of a $70 \mathrm{~kg}$ man. Table-5 shows that before intervention $70.9 \%$ respondents know food contains 5 components, $13 \%$ know food contains only carbohydrate, $21.4 \%$ know food contains only protein, $40.8 \%$ know food contains carbohydrate \& protein and $7.8 \%$ don't know about the ideal food and after intervention $87.5 \%$ respondents know food contains 5 components, $6.7 \%$ know food contains only carbohydrate, $8.7 \%$ know food contains only protein, $7.7 \%$ know food contains carbohydrate \& protein and $3.8 \%$ don't know about the ideal food. Table-5 shows that before intervention $79.8 \%$ respondents know rice, $74.0 \%$ know milk, 46.2\% know meat, $78.8 \%$ know egg and $2.9 \%$ don't know as examples of ideal food and after intervention $14.4 \%$ respondents know rice, $96.2 \%$ know milk, $19.2 \%$ know meat, $95.2 \%$ know egg and $0.0 \%$ don't know as examples of ideal food. Table-5 shows that before intervention $43.3 \%$ respondents know carbohydrate(50-55\%), 30.8\% know vitamin, 27.9\% know protein (15-20\%), 19.2\% know fat(30$35 \%$ ) and $30.8 \%$ don't know as the ratio of balanced diet and after intervention $83.7 \%$ respondents know carbohydrate(50-55\%), 38.5\% know vitamin, $70.2 \%$ know protein (15-20\%), 63.5\% know fat(30-35\%) and $5.8 \%$ don't know as the ratio of balanced diet. Table-5 shows that before intervention 57.3\% respondents know vegetables, $40.8 \%$ know fruit, $19.4 \%$ know milk, 55.3\% know fish-meat and $6.8 \%$ don't know as the examples of fiber rich foods and after intervention $82.7 \%$ respondents know vegetables, $76.9 \%$ know fruit, $8.7 \%$ know milk, $32.7 \%$ know fish-meat and $1.0 \%$ don't know as the examples of fiber rich foods. Table-5 shows that before intervention $32.7 \%$ respondents know prevent constipation, $62.5 \%$ know improve vision, $21.2 \%$ know prevent colon cancer, $21.2 \%$ know prevent hemorrhoid and 19\% don't know as the benefits of fiber rich foods and after intervention $81.7 \%$ respondents know prevent constipation, 30.8\% know improve vision, 70.2\% know prevent colon cancer, $70.2 \%$ know prevent hemorrhoid and $1.9 \%$ don't know as the benefits of fiber rich foods.

Table 5. Distribution of respondents by knowledge on daily water requirement, ideal food, its example; balanced diet and fiber rich food and its benefit pre and post intervention $(n=104)$

\begin{tabular}{|l|l|l|l|l|}
\hline \multirow{2}{*}{$\begin{array}{l}\text { Daily water } \\
\text { requirement }\end{array}$} & \multicolumn{2}{l|}{ Before intervention } & After intervention \\
\cline { 2 - 5 } & Frequency & Percentage & Frequency & Percentage \\
\hline Two Liter & 29 & $27.9 \%$ & 4 & $3.9 \%$ \\
\hline Three liter & 26 & $25.0 \%$ & 86 & $83.5 \%$ \\
\hline Four liter & 16 & $15.4 \%$ & 7 & $6.8 \%$ \\
\hline Five liter & 47 & $45.2 \%$ & 8 & $7.8 \%$ \\
\hline Don`t know & 20 & $19.2 \%$ & 1 & $1.0 \%$ \\
\hline Ideal food & \multicolumn{5}{|l}{} \\
\hline $\begin{array}{l}\text { Food contain 5 } \\
\text { components }\end{array}$ & 73 & $70.9 \%$ & 91 & $87.5 \%$ \\
\hline
\end{tabular}




\begin{tabular}{|c|c|c|c|c|}
\hline $\begin{array}{l}\text { Food contains } \\
\text { only } \\
\text { carbohydrate }\end{array}$ & 13 & $12.6 \%$ & 7 & $6.7 \%$ \\
\hline $\begin{array}{l}\text { Food contains } \\
\text { only protein }\end{array}$ & 22 & $21.4 \%$ & 9 & $8.7 \%$ \\
\hline $\begin{array}{l}\text { Food contains } \\
\text { carbohydrate \& } \\
\text { protein }\end{array}$ & 42 & $40.8 \%$ & 8 & $7.7 \%$ \\
\hline Don`t know & 8 & $7.8 \%$ & 4 & $3.8 \%$ \\
\hline \multicolumn{5}{|c|}{ Examples of ideal food } \\
\hline Rice & 83 & $79.8 \%$ & 15 & $14.4 \%$ \\
\hline Milk & 77 & $74.0 \%$ & 100 & $96.2 \%$ \\
\hline Meat & 48 & $46.2 \%$ & 20 & $19.2 \%$ \\
\hline Egg & 82 & $78.8 \%$ & 99 & $95.2 \%$ \\
\hline Don`t know & 3 & $2.9 \%$ & 0 & $0.0 \%$ \\
\hline \multicolumn{5}{|l|}{ Balanced diet } \\
\hline $\begin{array}{l}\text { Carbohydrate } \\
(50-55 \%)\end{array}$ & 45 & $43.3 \%$ & 83 & $83.7 \%$ \\
\hline Vitamin & 32 & $30.8 \%$ & 40 & $38.5 \%$ \\
\hline $\begin{array}{l}\text { Protein }(15- \\
20 \%)\end{array}$ & 29 & $27.9 \%$ & 73 & $70.2 \%$ \\
\hline Fat $(30-35 \%)$ & 20 & $19.2 \%$ & 66 & $63.5 \%$ \\
\hline Don`t know & 32 & $30.8 \%$ & 6 & $5.8 \%$ \\
\hline \multicolumn{5}{|c|}{ Examples of fiber rich foods } \\
\hline Vegetables & 58 & $57.3 \%$ & 86 & $82.7 \%$ \\
\hline Fruit & 42 & $40.8 \%$ & 80 & $76.9 \%$ \\
\hline Milk & 20 & $19.4 \%$ & 9 & $8.7 \%$ \\
\hline Fish-meat & 57 & $55.3 \%$ & 34 & $32.7 \%$ \\
\hline Don`t know & 7 & $6.8 \%$ & 1 & $1.0 \%$ \\
\hline \multicolumn{5}{|c|}{ Benefits of fiber rich food } \\
\hline $\begin{array}{l}\text { Prevent } \\
\text { constipation }\end{array}$ & 34 & $32.7 \%$ & 85 & $81.7 \%$ \\
\hline Improve vision & 65 & $62.5 \%$ & 32 & $30.8 \%$ \\
\hline $\begin{array}{l}\text { Prevent colon } \\
\text { cancer }\end{array}$ & 22 & $21.2 \%$ & 73 & $70.2 \%$ \\
\hline $\begin{array}{l}\text { Prevent } \\
\text { hemorrhoids }\end{array}$ & 22 & $21.2 \%$ & 73 & $70.2 \%$ \\
\hline Don`t know & 19 & $18.3 \%$ & 2 & $1.9 \%$ \\
\hline
\end{tabular}

\section{F. Distribution of respondents by knowledge on examples of fast food and its hazard pre and post intervention $(\mathbf{n}=104)$}

Table- 6 shows that before intervention $83.5 \%$ respondents know burger, $17.5 \%$ know rice, $51.5 \%$ know hotdog, 70.9\% know pizza and 3.9\% don't know as the examples of fast food and after intervention 96.2\% respondents know burger, $4.8 \%$ know rice, $85.6 \%$ know hotdog, 99.2\% know pizza and $0.0 \%$ don't know as the examples of fast food. Table-6 shows that before intervention $78.8 \%$ respondents know weight gain, 30.8\% know cancer, 29.8\% know high blood pressure, 33.7\% know sleep disturbance and $5.8 \%$ don't know as hazards of fast food and after intervention $82.7 \%$ respondents know weight gain, 
DOI: $10.21522 /$ TIJPH.2013.06.02.Art007

ISSN: $2520-3134$

27.9\% know cancer, $43.3 \%$ know high blood pressure, 30.8\% know sleep disturbance and 4.8\% don't know as hazards of fast food.

Table 6. Distribution of respondents by knowledge on examples of fast food and its hazard pre and post intervention $(n=104)$

\begin{tabular}{|l|l|l|l|l|}
\hline \multirow{2}{*}{$\begin{array}{l}\text { Examples of fast } \\
\text { food }\end{array}$} & \multicolumn{2}{|l|}{ Before intervention } & \multicolumn{2}{l|}{ After intervention } \\
\cline { 2 - 5 } & Frequency & Percentage & Frequency & Percentage \\
\hline Burger & 86 & $83.5 \%$ & 100 & $96.2 \%$ \\
\hline Rice & 18 & $17.5 \%$ & 5 & $4.8 \%$ \\
\hline Hotdog & 53 & $51.5 \%$ & 89 & $85.6 \%$ \\
\hline Pizza & 73 & $70.9 \%$ & 98 & $99.2 \%$ \\
\hline Don`t know & 4 & $3.9 \%$ & 0 & $0.0 \%$ \\
\hline Hazards of fast food & 82 & $78.8 \%$ & 86 & $82.7 \%$ \\
\hline Weight gain & 32 & $30.8 \%$ & 29 & $27.9 \%$ \\
\hline Cancer & 31 & $29.8 \%$ & 45 & $43.3 \%$ \\
\hline $\begin{array}{l}\text { High blood } \\
\text { pressure }\end{array}$ & 35 & $33.7 \%$ & 32 & $30.8 \%$ \\
\hline Sleep disturbance & 6 & $5.8 \%$ & 5 & $4.8 \%$ \\
\hline Don`t know & 6 &
\end{tabular}

G. Distribution of respondents by knowledge on keeping the quality of vegetables by washing and foods which improves defense mechanism pre and post intervention $(n=104)$

Table-7 shows that before intervention $47.1 \%$ respondents know washing before cutting, $34.6 \%$ know washing after cutting, $57.7 \%$ know washing before \& after cutting, 5.8\% know cutting without washing of vegetables and $6.7 \%$ don't know as to keep the quality of vegetables and after intervention $87.5 \%$ respondents know washing before cutting, $10.6 \%$ know washing after cutting, $22.1 \%$ know washing before \& after cutting, $2.9 \%$ know cutting without washing of vegetables and $1.0 \%$ don't know as to keep the quality of vegetables. Table-7 shows that before intervention $76.0 \%$ respondents know vegetables, $61.5 \%$ know fruits, $48.1 \%$ know milk, $37.1 \%$ know fish-meat and $7.7 \%$ don't know as the foods improving the defense mechanism of the body and after intervention $79.8 \%$ respondents know vegetables, 53.8\% know fruits, $48.1 \%$ know milk, $43.1 \%$ know fish-meat and $3.8 \%$ don't know as the foods improving the defense mechanism of the body.

Table 7. Distribution of respondents by knowledge on keeping the quality of vegetables by washing and foods which improves defense mechanism pre and post intervention $(n=104)$

\begin{tabular}{|l|l|l|l|l|}
\hline \multirow{2}{*}{$\begin{array}{l}\text { Keeping the quality of } \\
\text { vegetables }\end{array}$} & \multicolumn{2}{l|}{ Before intervention } & \multicolumn{2}{l|}{ After intervention } \\
\cline { 2 - 5 } & Frequency & Percentage & Frequency & Percentage \\
\hline Washing before cutting & 49 & $47.1 \%$ & 91 & $87.5 \%$ \\
\hline Washing after cutting & 36 & $34.6 \%$ & 11 & $10.6 \%$ \\
\hline $\begin{array}{l}\text { Washing before \& after } \\
\text { cutting }\end{array}$ & 60 & $57.7 \%$ & 23 & $22.1 \%$ \\
\hline Cutting without washing & 6 & $5.8 \%$ & 3 & $2.9 \%$ \\
\hline Don`t know & 7 & $6.7 \%$ & 1 & $1.0 \%$ \\
\hline Foods improving defense mechanism \\
\hline Vegetables & 79 & $76.0 \%$ & 83 & $79.8 \%$ \\
\hline
\end{tabular}


Texila International Journal of Public Health Volume 6, Issue 2, Jun 2018

\begin{tabular}{|l|l|l|l|l|}
\hline Fruits & 64 & $61.5 \%$ & 56 & $53.8 \%$ \\
\hline Milk & 50 & $48.1 \%$ & 50 & $48.1 \%$ \\
\hline Fish-meat & 39 & $37.5 \%$ & 43 & $41.3 \%$ \\
\hline Don`t know & 8 & $7.7 \%$ & 4 & $3.8 \%$ \\
\hline
\end{tabular}

\section{Discussion}

The study KNOWLEDGE INTERVENTION ON NUTRITION AMONG THE PRIMARY SCHOOL STUDENTS was conducted at the 68 No. Islampur Govt. Primary School, Dhamrai, Dhaka from $26^{\text {th }}$ February, 2017 to $2^{\text {nd }}$ march, 2017. The sample was of 104 students of class V of 68 No. Islampur Govt. Primary School. They were asked a questionnaire with 25 questions about the knowledge on nutrition and then the intervention of knowledge on nutrition was given to improve their knowledge on nutrition. After completion of the intervention, post intervention evaluation was done by the same questionnaire. In this study 104 respondents were participated. Among the respondents before intervention $75.0 \%$ and after intervention $96.2 \%$ knew potato as carbohydrate. $20.2 \%$ knew the functions of carbohydrate before intervention and after intervention 52.9\% knew. Functions of protein knew $43.3 \%$ before intervention and $70.2 \%$ after intervention. Before intervention $33.7 \%$ knew the functions of fat and after intervention $52.9 \%$. Mola-dhela fish is a source of vitamin A knew 7.7\% before intervention after intervention 38.5\% knew. Before intervention $69.2 \%$ knew oral ulcer is caused by vitamin $\mathrm{C}$ deficiency and after intervention $83.7 \%$ knew. Before intervention $44.2 \%$ knew sea fish, $50.0 \%$ knew table salt and after intervention $79.8 \%$ knew sea fish and $78.8 \%$ knew as the source of iodine. $32.7 \%$ knew autism and $51.0 \%$ knew goiter before intervention and $74.0 \%$ knew autism and $69.2 \%$ knew goiter after intervention as the disease caused by iodine deficiency. Before intervention $56.3 \%$ knew anemia caused by iron deficiency and 80.8\% knew after intervention. 70.9\% respondents knew there are 5 components of food before intervention and after intervention $87.5 \%$. Before intervention $74.0 \%$ respondents knew milk as a ideal food but after intervention $96.2 \%$ knew milk as an ideal food. About fiber rich food before intervention $32.7 \%$ respondents knew it prevents constipation, $21.2 \%$ knew it prevents colon cancer and after intervention $81.7 \%$ knew it prevents constipation, $70.2 \%$ respondents knew it prevents colon cancer. $25.0 \%$ respondents knew that a healthy man requires 3 liter water daily before intervention but after intervention $83.5 \%$ respondents knew that a healthy man requires at least 3 liter water daily. Before intervention $47.1 \%$ knew that vegetables should washed before cutting but after intervention $87.5 \%$ knew the correct procedure to keep the quality of vegetables. From the above information we may conclude that the respondents were eager to receive knowledge on nutrition. We see a radical improvement on knowledge among the respondents after giving intervention in short period of time.

\section{Conclusion}

The present study showed that the nutrition education intervention conducted over a period of 5 days has a positive impact on nutrition knowledge. Nutrition Education Intervention Improves Nutrition among 68 No. Islampur Govt. Primary school students. The implementation period of the intervention, its concept, content, and presentation strategies and support from teachers and schools are the major factors that have contributed to the outcomes of the intervention. The provision of necessary nutrition knowledge and skills to children in promoting healthy dietary behaviors is integral to long-term health and nutrition of children as dietary behaviors established during childhood may well extend into adolescence and adulthood. It is equally important to address the factors within the child's familial environment such as increasing parental awareness on ways to make healthful foods more available and accessible at homes for their children, encouraging breakfast consumption, avoiding excessive control of children's food intake and modeling of healthy food behaviors. As parents provide both genetic and eating environments further studies are imperative to understand their influences on children's dietary behaviors. Besides parental influence, there is also an increasing concern on the impact of food marketing through television a marketing strategy on dietary intake of children. More studies are urgently needed to understand the 
relationship between food marketing and health and nutrition of children. Nevertheless, concerted efforts from various segments of the society such as the family, school, community, media, government and food industry is crucial to create an environment that facilitates children to establish healthy eating behavior.

\section{Acknowledgement}

First of all we would like to thank Almighty Allah for helping and supporting us to complete this concurrent field practice report. We wish to express our sincere thanks to Professor and Head (Course in charge), Prof. Dr. Jahanara Begum, Department of Health Education, National Institute of Preventive and Social Medicine (NIPSOM), Mohakhali, Dhaka, for her individual supports and kind suggestion and sustained encouragement throughout the course of this research work and report writing. We are grateful to Prof. Dr. Kazi Jahangir Hossain PhD Associate Professor Department of Health Education, National Institute of Preventive and Social Medicine (NIPSOM), Mohakhali, Dhaka, for his expert supervision kind suggestion to prepare research plan, teaching, Preparing Questionnaire, Sample collection techniques, guidance, kind advice, cooperation, continuous supervision, constant support and encouragement during my thesis work. We wish to express our sincere thanks to Dr. Hafiza Sultana Associate professor Department of Health Education, Dr. MD. Mahmudul Hasan Medical Officer, Dr.Shazly Bari, Medical Officer, Department of Health Education, National Institute of Preventive and Social Medicine (NIPSOM), Mohakhali, Dhaka for their friendly cooperation valuable suggestion .We are also thankful to Headmaster and other teachers and students of 68 no. Islampur Govt. Primary School, Dhamrai, Dhaka, where we conducted our field practice. We also express our special thanks to all students of MPH (HE\&HE) course for our good cooperation to carry out concurrent field practice. Finally we express our gratitude to the respondents, participate in our study and help us to conduct our field practice. We would also like to thank Prof. Dr. Baizid Khoorshid Riaz, Director, National Institute of Preventive and Social Medicine (NIPSOM), Mohakhali, Dhaka, for his kind approval and valuable support to complete this concurrent field practice.

\section{Reference}

[1].Clasnoff. I. J. 1994, "Family Medical and Health Guide".

[2].(CDC) Centers for Disease Control and Prevention. 2012. Childhood overweight and obesity. Accessed 05 March 2013.

[3].Crockett S.J. and L.S. Sims. 1995. Environmental influences on children's eating. J Nutr Educ. 27(5):235.

[4].Delisle, H. Chandra-Mouli, V. and de Benoist, B. (2014) "Should Adolescents be Specifically Targeted for Nutrition in Developing Countries: To Address Which Problems, and How? World Health Organization/International Nutrition Foundation for Developing Countries".

[5].Gracey, D., Stanley, N., Burke, V., Corti, B. \& Beilin, L.J. 1996, 'Nutritional knowledge, beliefs and behaviours in teenage school students', Health Education Research, v.11, n.2, pp.187-203.

[6].Gupta. K., et al., 1992,"Food and Nutrition", Jaypee Brothers.

[7].Guilloteau, P. Zabielski, R. Hammon, H. M. and Metges, C. C. (2009) "Adverse effects of nutritional programming during prenatal and early postnatal life, some aspects of regulation and potential prevention and treatments," Journal of Physiology and Pharmacology, vol. 60, supplement 3, pp. 17-35.

[8].Ruzita AT, Wan Azdie MAB, Ismail MN (2007) 'The Effectiveness of Nutrition Education Programme for Primary School Children, Mal J Nutr, 13(1), pp. 45-54.

[9].Stang, J. and Story, M. (2005) “Adolescent growth and development," in Guidelines for Adolescent Nutrition Services, J. Stang and M. Story, Eds., chapter 1, pp. 1-8, Center for Leadership, Education and Training in Maternal and Child Nutrition, Division of Epidemiology and Community Health, School of Public Health, University of Minnesota, Minneapolis, Minn, USA.

[10]. Smolin. L. A., \& Grovenor. M. B., 1997, "Nutrition Science and Applications".

[11]. Sreedevi.V., 1997,’Nutrition Education”, Discovery publishing House 
Texila International Journal of Public Health Volume 6, Issue 2, Jun 2018

[12]. Shriqui V., Entin A., Fraser D., Novack Y., Bilenko N., Vardi H., Shahar D.R. Development and validation of food frequency questionnaire for children age 5-6 using multiple methods. Int. J. Child. Health Nutr. 2013; 2:367376. 


\title{
Barriers to HIV Testing among Adolescents and Young Adults in Harare City, Zimbabwe
}

\author{
Article by Notion Gombe ${ }^{1,2}$, Nicholas Midzi ${ }^{3}$ \\ ${ }^{1}$ Public Health, Texila American University, Guyana, South America \\ ${ }^{2}$ Department of Community Medicine, University of Zimbabwe \\ ${ }^{3}$ Department of Medical Microbiology, University of Zimbabwe \\ E-mail: ntgombe@gmail.com ${ }^{1}$, midzinicholas@gmail.com ${ }^{3}$
}

\begin{abstract}
The HIV prevalence in the Zimbabwean population aged 15-49 years remains high (15.2\%). Most adolescents do not know their HIV status despite knowing a place to get tested. We determined barriers to HIV testing and counseling (HCT) among sexually active adolescents and young adults in Harare City

We conducted a cross-sectional study among sexually active adolescents and young adults. Data were collected using a pretested self-administered questionnaire. Information was collected on individual characteristics, HIV testing acceptance, risk behaviors and reasons for having never been tested. Epi-Info 7 was used to analyze data. Chi-square tests and logistic regression models were used to assess independent determinants for not testing for HIV. Statistical significance was set at $p<0.01$.

A total of 427 adolescents and young adults were recruited. The majority (56.9\%) were female. Of these, 186(43.6\%) had never tested for HIV. Participants listed not knowing where to get tested (60.8\%), low risk perception (29\%), never having been offered a test(21.5\%), fear of a positive result(16.1\%), being embarrassed (10.2\%), parents who will not allow (7.5\%), failure to afford consultation fees(5.9\%), and being worried about health worker confidentiality (5.9\%) as reasons for not having been tested. In multivariate analysis being afraid of a positive result [aOR=0.07; 95\%CI (0.01-0.30)] and being male [aOR=0.43; 95\%CI (0.23-0.80)] were independently associated with never having had an HIV test.

Barriers to HIV testing identified in this study can be easily resolved by applying innovative approaches tailored to increase access to and acceptance of HIV-testing services among the adolescent and young adult populations.
\end{abstract}

Keywords: Adolescents, HIV Testing, Correlates, Barriers, Harare City.

\section{Introduction}

HIV Counseling and Testing (HCT) facilitates early diagnosis for HIV positive persons which helps reduce the risk of further transmission, provides access to care and treatment, while motivating people who test HIV negative to maintain their negative status (Day et al. 2003:665; Peltzer, Matseke, Mzolo, \& Majaja, 2009:2; Subramanian, Gupte, Mathai, Boopathi, \& Dorairaj, 2008:26). This suggests that HCT is vital for both knowledge of one's HIV status and HIV prevention. However, there are still people who have no knowledge of their HIV status.

In Zimbabwe according to the Zimbabwe Demographic Health Survey (2010/11) the HIV prevalence rate for the young people between the ages of 15-24 is 5, 5\%. According to the World Bank indicators the prevalence of HIV in males and females aged 15-24 in Zimbabwe is 4.8\% and 7.0\% respectively showing that women are disproportionately affected.

As adolescents and young adults are a key population, many barriers arise because of their vulnerability on a personal, social and policy level. The vulnerability of adolescents from key populations is profoundly compounded by severe social stigma and harsh, poorly informed, legal, and policy regulations and law enforcement practices that criminalize their behaviors and foster discrimination and 
DOI: $10.21522 /$ TIJPH.2013.06.02.Art008

ISSN: $2520-3134$

violence (Idele et al., 2014). These factors hinder access to critically needed health services and other HIV prevention, treatment, protection, care, and support interventions.

In Zimbabwe literature on barriers to testing among HCT non-users is limited. However studies have been done elsewhere. Peltzer et. al (2013) in a South African cross-sectional population-based household survey identified self-perceived adolescent barriers to HIV testing such as stigma attitudes and discrimination; a low perception of HIV risk; (Govindasamy et al., 2015) In addition other studies found the fear of knowing and living with a sero positive status; having never been offered testing before; and administrative complications as barriers to adolescent HIV testing (Idele et al., 2014; Baral et al., n.d.). Adolescence provides a window of opportunity in which to intervene early and these barriers need to be addressed when coming up with service delivery models for this key population.

This study sought to determine barriers to HCT among sexually active adolescents and young adults in Harare City.

\section{Methods}

A cross-sectional study was conducted in Harare City and the study participants comprised of adolescents and young adults aged 13-24 years. For purposes of this study a resident of Harare City was classified as someone who has lived in Harare for at least three months. All those who fell within the required age range (13-24 years), able to speak and read English or Shona were eligible to participate. Conversely men and women who fell outside the 13-24 years age range and visitors to Harare metropolitan province were excluded from participating in the study. Adolescents under age 16 who met the inclusion criteria but whose parents did not provide consent were to be excluded. Assuming an error risk of 1.96 and a proportion (P), of those tested for HIV (52.2\%) from a previous study conducted by Pelzer et al (2013) in South Africa and margin of error of 5\%, we obtained a minimum sample size of 422 after factoring in $10 \%$ attrition rate.

Data were collected using a pretested self-administered questionnaire. Information was collected on individual characteristics, HIV testing acceptance, risk behaviors and reasons for having never been tested. Check codes, and legal values were used to reduce errors of data collection and entry. Data were cleaned for errors and inconsistencies before analysis. Data were analyzed using Epi Info 7 statistical package to generate means, frequencies, proportions, prevalence odds ratios (POR), and their corresponding 95\% confidence intervals (CI). PORs excluding the null value (1) in the $95 \%$ confidence interval were considered statistically significant. We conducted stratified analysis to check for effect modification and to control for confounding. Factors associated with ever being HIV-tested were determined using multivariate logistic regression.

To ensure protection of study participants, permission was sought from Harare City Council institutional review board and the Medical Research Council of Zimbabwe (Application number: MRCZ/A/2216). Further, informed written consent was obtained from adolescents age 16 and older and adolescent assent and parental/guardian consent was obtained for those aged $13-15$ years. Consent was obtained after explaining the purpose of the study, and assuring confidentiality. Confidentiality was maintained throughout the study by not including the participants' names from the questionnaires. In addition the questionnaire was self-administered owing to the sensitive nature of the questions.

\section{Results}

\section{Sample characteristics}

Socio demographic characteristics of study participants are reported in Table 1. Of the 427 participants enrolled into this study, 186 had never tested for HIV. Of these 186 participants, the majority (79\%) had attained secondary education and the least $(3.8 \%)$ were those who had never been to school. Students comprised $68.8 \%$ of the population followed by those not employed at $23.7 \%$. High density dwellers accounted for $50.5 \%$ of the study population compared to $49.5 \%$ from the low density suburbs. Majority $(81.2 \%)$ of participants were single. 


\section{Barriers to HIV testing}

Reasons for not testing for HIV are reported in Table 2. Of the total respondents $(n=427), 43.6 \%$ $(\mathrm{n}=186)$ reported never having had an HIV test (Table 2). The most common reason given for not having been tested was not knowing where to get tested $(60.8 \%)$. Other reasons given by the participants included perceiving oneself not to be at risk $(29.0 \%)$ and having not been offered the test $(21.5 \%)$, being afraid of a positive result and being embarrassed were reported by both sexes in almost identical proportions. The list reported reasons were inability to pay fees and being worried about confidentiality reported by $5.9 \%$ respectively.

\section{Bivariate analysis}

Table 3 shows bivariate analysis of barriers to HIV testing in Harare City. A number of factors were associated with ever being tested for HIV in this population of adolescents and young adults. Participants who reported fearing a positive result $[\mathrm{OR}=0.07 ; \mathrm{p}<0.001$ ), having parents who would not allow them to test $(\mathrm{OR}=0.06 ; \mathrm{p}<0.001)$, having attained only primary education $[\mathrm{OR}=0.53 ; \mathrm{p}=0.028)$, being aged less than 18 years $[\mathrm{OR}=0.32 ; \mathrm{p}<0.001$ ), being worried about confidentiality $[\mathrm{OR}=0.07 ; \mathrm{p}=0.001$ ) and perceiving oneself not to be at risk of contracting HIV [OR=0.01; $\mathrm{p}<0.001$ ) were less likely to be tested for HIV.

\section{Multivariate analysis}

Table 4 shows multivariate analysis of barriers to HIV testing in Harare City. After controlling for confounding, independent barriers for HIV testing and counseling among adolescents and young adults in Harare City were; being afraid of a positive result(Adjusted $\mathrm{OR}=0.07 ; \mathrm{P}<0.001$ ) and being male (Adjusted $\mathrm{OR}=0.43 ; \mathrm{p}=0.008$ ).

\section{Discussion}

The current study sought to determine barriers to HIV testing and counseling among adolescents and young adults in Harare City, Zimbabwe. This information is critical, as promotion of HCT is the first step to getting medical care and treatment that can improve health, save lives, and prevent the spread of HIV (Bekker \& Hosek, 2015). HCT provides an entry point to prevention, care, treatment and support. It contributes to reduction of the stigma and discrimination that surrounds HIV and AIDS.

The barriers to HIV testing observed in this study were varying and are consistent with what was observed in similar studies. Consistent with what was reported by Lopez et al (2005) in a study on barriers and facilitators to adolescent HIV testing never having been offered a test was one of the major reasons for not having been tested. Not knowing where to get tested was the major reason for not having been tested given by participants in this study. This finding is consistent with a study that found the majority of non-testers to be unaware of HIV testing sites (Choi et al. 2006:40). Other notable reasons reported in this study include, perceiving oneself not to be at risk, being afraid of a positive result and being embarrassed reported by both sexes in almost identical proportions. Not knowing where to get tested had the highest combined proportion of about $61 \%$ followed by perceiving oneself not to be at risk reported by $29 \%$ of the participants. The least reported reasons were inability to pay fees and being worried about confidentiality reported by $5.9 \%$ respectively.

Perceiving oneself not to be at risk may be attributed to that most participants $(58.6 \%)$ reported not being involved in a sexual relationship with their partners (boyfriend/girlfriend) and this may have negatively affected uptake of HIV testing in this population. However this result must be taken with caution considering that most of the participants were school going children and as such their answers may reflect social desirability bias. In a similar study among Hispanics adults in the United States showed that the most common barrier to not being tested for HIV was considering oneself not to be at risk (Lopez-Quintero, Shtarkshall, \& Neumark, 2005; Kabiru, Beguy, Crichton, \& Zulu, 2011; Njagi \& Maharaj, 2006). 
DOI: $10.21522 /$ TIJPH.2013.06.02.Art008

ISSN: $2520-3134$

In another study focusing on reasons for not taking an HIV-test among untested men who have sex with men (MSM), results showed that fear of a positive test result and the perceived consequences thereof, were reported as the most important reasons for not taking an HIV-test among at-risk respondents (Mikolajczak, Hospers, \& Kok, 2006). This is supported by other studies in Ethiopia, South Africa and Thailand, (Addis et al., 20103; Strauss, Rhodes, \& George, 2015; Musumari et al., 2016).

Our study had some limitations. Data on HIV testing were self-reported hence social desirability may have influenced some of the responses from study participants. Furthermore recall bias may not be ruled out completely. However, participants were requested to provide written informed consent only after they were fully aware of the study details and they were assured of confidentiality hence bias may be unlikely.

\section{Conclusion}

In this study several barriers of HCT have been identified, which can guide interventions to improve HCT uptake. The most common reason given for not having been tested was not knowing where to get tested. Other reasons given by the participants included low risk perception and having not been offered the test, being afraid of a positive result and being embarrassed reported by both sexes in almost identical proportions. The least reported reasons were inability to pay fees and being worried about confidentiality reported by $5.9 \%$ respectively.

Overall, the major barriers to HIV testing in the current study seem to be more personal than structural. For instance, fear of getting an HIV positive result, being embarrassed and perceived lack of confidentiality by health workers were all considered as the biggest barriers to HIV testing in this study. These findings are consistent with those found in a systematic review of barriers to HIV testing in Europe (Deblonde et al. 2010:429) where the majority of barriers was perceived to be more personal than health care related.

\section{Tables}

Table 1. Socio-demographic characteristics of adolescents and young adults, harare, zimbabwe, 2017

\begin{tabular}{|l|l|l|l|}
\hline Variable & Tested for HIV n (\%) & $\begin{array}{l}\text { Never tested for } \\
\text { HIV n }(\%)\end{array}$ & Total sample n (\%) \\
\hline Sex & & & \\
\hline Male & $94(39.0)$ & $90(48.4 \%)$ & $184(43.09)$ \\
\hline Female & $147(61.0)$ & $96(51.6)$ & $243(56.91)$ \\
\hline Age-group & & & \\
\hline $13-<18$ & $91(37.8)$ & $121(65.1)$ & $212(49.65)$ \\
\hline $18-<23$ & $117(48.6)$ & $60(32.3)$ & $177(41.45)$ \\
\hline $23-<24$ & $19(7.9)$ & $2(1.1)$ & $21(4.92)$ \\
\hline $24+$ & $14(5.8)$ & $3(1.6)$ & $17(3.98)$ \\
\hline $\begin{array}{l}\text { Level of } \\
\text { education }\end{array}$ & & & $19(4.45)$ \\
\hline $\begin{array}{l}\text { Never been to } \\
\text { school }\end{array}$ & $12(5.0)$ & $7(3.8)$ & $35(8.20)$ \\
\hline Primary & $11(4.6)$ & $24(12.9)$ & $353(82.67)$ \\
\hline Secondary & $206(85.5)$ & $147(79.0)$ & $20(4.68)$ \\
\hline Tertiary & $12(5.0)$ & $8(4.3)$ & $169(39.58)$ \\
\hline Occupation & & & $19(4.45)$ \\
\hline Not employed & $125(51.9)$ & $44(23.7)$ & $18(4.77)$ \\
\hline $\begin{array}{l}\text { Informally } \\
\text { employed }\end{array}$ & $10(4.2)$ & $9(4.8)$ & \\
\hline Formally & $13(5.4)$ & $5(2.7)$ & \\
\hline
\end{tabular}


Texila International Journal of Public Health Volume 6, Issue 2, Jun 2018

\begin{tabular}{|l|l|l|l|}
\hline employed & & & \\
\hline Student & $93(38.6)$ & $128(68.8)$ & $221(51.76)$ \\
\hline Area of residence & & & \\
\hline High density & $188(78.0)$ & $94(50.5)$ & $282(66.04)$ \\
\hline Low density & $53(22.0)$ & $92(49.5)$ & $145(33.96)$ \\
\hline Marital status & & & \\
\hline Single & $170(70.5)$ & $151(81.2)$ & $321(75.18)$ \\
\hline Married & $71(29.5)$ & $35(18.8)$ & $106(24.82)$ \\
\hline
\end{tabular}

Table 2. Reasons reported for having never been tested for HIV among adolescents and young adults in Harare City, Zimbabwe $(\mathrm{n}=186)$

\begin{tabular}{|l|l|l|l|}
\hline & Male $(\mathrm{n}=90)$ & $\begin{array}{l}\text { Female } \\
(\mathrm{n}=96)\end{array}$ & Total (\%) \\
\hline $\begin{array}{l}\text { I do not know where I can get } \\
\text { tested }\end{array}$ & 57 & 56 & $113(60.8)$ \\
\hline I am not at risk & 27 & 27 & $54(29.0)$ \\
\hline Never offered an HIV test & 20 & 20 & $40(21.5)$ \\
\hline I am afraid of a positive result & 16 & 14 & $30(16.1)$ \\
\hline I am embarrassed & 10 & 9 & $19(10.2)$ \\
\hline My parent will not allow me & 5 & 9 & $14(7.5)$ \\
\hline Cannot afford fees & 2 & 9 & $11(5.9)$ \\
\hline $\begin{array}{l}\text { I am worried about } \\
\text { confidentiality }\end{array}$ & 6 & 5 & $11(5.9)$ \\
\hline
\end{tabular}

Table 3. Bivariate analysis of factors associated with never tested for HIV in adolescents and young adults, harare city, zimbabwe, 2017

\begin{tabular}{|c|c|c|c|}
\hline Variable & $\begin{array}{l}\text { Never tested } \\
\text { for HIV } \\
n=186\end{array}$ & POR(95\%CI) & p-value \\
\hline \multicolumn{4}{|l|}{ I am not at risk } \\
\hline $\begin{array}{l}\text { Yes } \\
\text { No }\end{array}$ & $\begin{array}{l}53 \\
133\end{array}$ & $0.01(0.00-0.08)$ & $<0.001$ \\
\hline \multicolumn{4}{|c|}{ My parents will not allow me to get tested } \\
\hline $\begin{array}{l}\text { Yes } \\
\text { No }\end{array}$ & $\begin{array}{l}13 \\
173\end{array}$ & $0.06(0.01-0.43)$ & $<0.001$ \\
\hline \multicolumn{4}{|c|}{ Fear of a positive result } \\
\hline $\begin{array}{l}\text { Yes } \\
\text { No }\end{array}$ & $\begin{array}{l}27 \\
159 \\
\end{array}$ & $0.07(0.02-0.25)$ & $<0.001$ \\
\hline \multicolumn{4}{|c|}{ I am worried about confidentiality } \\
\hline $\begin{array}{l}\text { Yes } \\
\text { No }\end{array}$ & $\begin{array}{l}10 \\
176\end{array}$ & $0.07(0.01-0.58)$ & 0.001 \\
\hline \multicolumn{4}{|l|}{ Age } \\
\hline $\begin{array}{l}<18 \\
>18 \\
\end{array}$ & $\begin{array}{l}121 \\
65\end{array}$ & $0.33(0.22-0.49)$ & $<0.001$ \\
\hline \multicolumn{4}{|l|}{ Education level } \\
\hline $\begin{array}{l}\text { Primary and below } \\
\text { Above primary }\end{array}$ & $\begin{array}{l}31 \\
155 \\
\end{array}$ & $0.53(0.30-0.94)$ & 0.028 \\
\hline
\end{tabular}


DOI: $10.21522 /$ TIJPH.2013.06.02.Art008

ISSN: $2520-3134$

Table 4 Multivariable model of predictors of HCT in adolescents and young adults, Harare City, Zimbabwe, 2017

\begin{tabular}{|l|l|l|l|}
\hline Term & $\mathrm{aOR}^{1}$ & $95 \% \mathrm{CI}^{2}$ & $\mathrm{p}$-value \\
\hline $\begin{array}{l}\text { Being afraid of a positive } \\
\text { result }\end{array}$ & 0.07 & $0.01-0.30$ & $<0.001$ \\
\hline Sex(Male) & 0.43 & $0.23-0.80$ & 0.008 \\
\hline
\end{tabular}

\section{References}

[1]. Addis, Z., Yalew, A., Shiferaw, Y., Alemu, A., Birhan, W., Mathewose, B., \& Tachebele, B. (2013). Knowledge, attitude and practice towards voluntary counseling and testing among university students in North West Ethiopia: a cross sectional study. BMC Public Health, 13, 714. https://doi.org/10.1186/1471-2458-13-714

[2]. Baral SD, Poteat T, Strömdahl S, Wirtz AL, Guadamuz TE, Beyrer C. Worldwide burden of HIV in transgender women: a systematic review and meta-analysis. Lancet Infect Dis. 2013; 113(3):214-22. Publisher Full Text

[3]. Bekker, L.-G., \& Hosek, S. (2015). HIV and adolescents: focus on young key populations. Journal of the International AIDS Society, 18(2Suppl 1). https://doi.org/10.7448/IAS.18.2.20076

[4]. CDC. Revised Recommendations for HIV Testing of Adults, Adolescents, and Pregnant Women in Health$\begin{array}{llllll}\text { Care } & \text { Settings. (2006). } & \text { Retrieved } & \text { February } & \text { 7, 2018, } & \text { from }\end{array}$ https://www.cdc.gov/mmwr/preview/mmwrhtml/rr5514a1.htm

[5]. Choi, K. H., Lui, H., Guo, Y., Han, L., \& Mandel, J. S. (2006). Lack of HIV testing and awareness of HIV infection among men who have sex with men, Beijing, China. AIDS Education and men who have never tested for HIV. Sexually Transmitted Diseases, 38(5), 419e428. http://dx.doi.org/10.1097/OLQ.0b013e31820369dd.

[6]. Day, J. H., Miyamura, K., Grant, A. D., Leeuw, A., Munsamy, J.,Baggaley, R., et al. (2003). Attitudes to HIV voluntary counselling and testing among mineworkers in South Africa:will availability of antiretroviral therapy encourage testing? AIDS Care, 15, 665e672. http://dx.doi.org/10.1080/0954012030001595140.

[7]. Deblonde, J., De Koker, P., Hamers, F. F., Fontaine, J., Luchters, S., \& Temmerman, M. (2010). Barriers to HIV testing in Europe: a systematic review. European Journal of Public Health, 20(4), 422e432. http://dx.doi.org/10.1093/eurpub/ckp231.

[8]. Govindasamy, D., Ferrand, R. A., Wilmore, S. M., Ford, N., Ahmed, S., Afnan-Holmes, H., \& Kranzer, K. (2015). Uptake and yield of HIV testing and counselling among children and adolescents in sub-Saharan Africa: a systematic review. Journal of the International AIDS Society, 18(1), 20182. http://doi.org/10.7448/IAS.18.1.20182

[9]. Idele, P., Gillespie, A., Porth, T., Suzuki, C., Mahy, M., Kasedde, S., \& Luo, C. (2014). Epidemiology of HIV and AIDS among adolescents: current status, inequities, and data gaps. Journal of Acquired Immune Deficiency Syndromes (1999), 66 Suppl 2, S144-153. https://doi.org/10.1097/QAI.0000000000000176

[10]. Kabiru, C. W., Beguy, D., Crichton, J., \& Zulu, E. M. (2011). HIV/AIDS among youth in urban informal (slum) settlements in Kenya: what are the correlates of and motivations for HIV testing? BMC Public Health, 11, 685. https://doi.org/10.1186/1471-2458-11-685

[11]. Lopez-Quintero, C., Shtarkshall, R., \& Neumark, Y. D. (2005). Barriers to HIV-testing among Hispanics in the United States: analysis of the National Health Interview Survey, 2000. AIDS Patient Care and STDs, 19(10), 672683. https://doi.org/10.1089/apc.2005.19.672

[12]. Mikolajczak, J., Hospers, H. J., \& Kok, G. (2006). Reasons for not taking an HIV-test among untested men who have sex with men: an Internet study. AIDS and Behavior, 10(4), 431-435. https://doi.org/10.1007/s10461-0069068-8

[13]. MOHCC- Zimbabwe National Guidelines for HIV Testing and Counselling in Children and Adolescents (2014). Retrieved January 13, 2018, from https://aidsfree.usaid.gov/sites/default/files/hts_zimbabwe_2014.pdf

[14]. Musumari, P. M., Tangmunkongvorakul, A., Srithanaviboonchai, K., Yungyuankul, S., Techasrivichien, T., Suguimoto, S. P., ... Chariyalertsak, S. (2016). Prevalence and Correlates of HIV Testing among Young People

1 aOR is adjusted odds ratio

2 95\% $\mathrm{Cl}$ is $95 \%$ confidence interval 
Enrolled in Non-Formal Education Centers in Urban Chiang Mai, Thailand: A Cross-Sectional Study. PLOS ONE, 11(4), e0153452. https://doi.org/10.1371/journal.pone.0153452

[15]. Njagi, F., \& Maharaj, P. (2006). Access to voluntary counselling and testing services: Perspectives of young people. South African Review of Sociology, 37(2), 113-127. https://doi.org/10.1080/21528586.2006.10419150

[16]. Peltzer, K., Matseke, G., Mzolo, T., \& Majaja, M. (2009).Determinants of knowledge of HIV status in South Africa: results from a population-based HIV survey. BioMedCentral Public Health, 9, 174. http://dx.doi.org/10.1186/1471-2458-9-174.

[17]. Strauss, M., Rhodes, B., \& George, G. (2015). A qualitative analysis of the barriers and facilitators of HIV counselling and testing perceived by adolescents in South Africa. BMC Health Services Research, 15(1), 250. https://doi.org/10.1186/s12913-015-0922-0

[18]. Subramanian, Y., Gupte, M. D., Mathai, A. K., Boopathi, K., \& Dorairaj, V. S. (2008). Perception of HIV among attendees at an TD clinic in India. AIDS Care, 20(1), 26e34. http://dx.doi.org/10.1080/09540120701427480. 


\title{
Erectile Dysfunction among Diabetic Patients at Parirenyatwa Group of Hospitals in Zimbabwe
}

\author{
Article by Pasipanodya Ian Machingura ${ }^{1}$, Vasco Chikwasha ${ }^{2}$ \\ ${ }^{1}$ Department of Medical Laboratory Sciences, University of Zimbabwe College of Health \\ Sciences \\ ${ }^{2}$ Department of Community Medicine, University of Zimbabwe College of Health Sciences \\ E-mail: imachingura@yahoo.co.uk $k^{1}$
}

\begin{abstract}
Erectile dysfunction is a major problem amongst diabetes mellitus patients. However sexual problems are not usually discussed with doctors due to embarrassment and lack of understanding of the condition thus the patients suffer silently. The study sought to determinate the prevalence of erectile dysfunction and associated factors amongst male diabetes mellitus patients attending the outpatient clinic at Parirenyatwa group of hospitals.

Adult male diabetic patients who consented to participate in the study had a questionnaire administered on them to collect demographic data and an International Index of Erectile Function (IIEF5) Questionnaire administered on them by a male medical doctor. Anthropometric measurements were conducted and samples were collected for laboratory investigations.

The prevalence of erectile dysfunction was $73.9 \%$. Erectile dysfunction was associated with higher age $(p=0.009)$, higher systolic blood pressure $(p=0.009)$ and being on hypertensive drugs $(p=0.007)$. The proportion of diabetic patients with higher glycosylated haemoglobin was higher among patients with erectile dysfunction ( $p=0.020$ ).

This study shows high prevalence of erectile dysfunction in diabetes mellitus patients attending Parirenyatwa outpatient clinic. Erectile dysfunction was associated with higher age, higher systolic blood pressure and being on antihypertensive drugs. This study shows the need of consistent screening of erectile dysfunction among diabetic patients for early detection, treatment and prevention. There is also need for a large national study to confirm this prevalence and the associated factors.
\end{abstract}

Keywords: erectile dysfunction, diabetes mellitus.

\section{Introduction}

Erectile dysfunction has been identified to be a major problem amongst diabetes mellitus patients (Mutagaywa et al. 2014). Erectile dysfunction has been defined as the inability to achieve and maintain an erection which is sufficient to permit satisfactory sexual intercourse (Mutagaywa et al. 2014) (Hackett 2009). The causes of erectile dysfunction are classified into organic or psychogenic. Organic causes of sexual dysfunction are drug induced, traumatic/post-surgical, vascular, endocrine induced and neurological. Whilst psychogenic causes include relationship problems, performance anxiety and depression (Mutagaywa et al. 2014).

The main risk factors of erectile dysfunction amongst diabetes mellitus patients are neuropathy, vascular insufficiency, poor glycaemic control, hypertension, low testosterone levels and life style which include smoking, alcohol and inactivity. The prevalence of erectile dysfunction increases with age (Mutagaywa et al. 2014). Sexual problems are not usually discussed with doctors due to embarrassment and lack of understanding of the condition thus the patients suffer silently. The clinicians and the patients all have difficulty bringing up sexual matters (Malavige et al. 2014).

The prevalence of erectile dysfunction among diabetes mellitus patients ranges from 35 to $90 \%$ compared to $26 \%$ in the general population. In a study carried out on diabetic patients attending diabetic clinic at Muhimbili National Hospital Tanzania between May and December 2011 the prevalence of 
DOI: $10.21522 /$ TIJPH.2013.06.02.Art009

ISSN: $2520-3134$

erectile dysfunction was reported to be $55.1 \%$ of which $12.8 \%$ had mild dysfunction, $11.5 \%$ moderate and 27.5\% severe dysfunction (Mutagaywa et al. 2014). The prevalence of erectile dysfunction and its associated factors in Zimbabwe to our knowledge has not been studied. Thus the study sought to determinate the prevalence of erectile dysfunction and associated factors amongst male diabetes mellitus patients attending the outpatient clinic at Parirenyatwa group of hospitals.

\section{Materials and methods}

The main study, Clinical Biochemical Genetic and Biochemical characteristics associated with the development on nephropathy was a cross sectional study in which 348 patients with diabetes mellitus 18 years and above monitored at Parirenyatwa outpatient clinic were recruited between 23 October 2013 and 09 July 2014. The study was ethically approved by the Joint Research Ethics Committee for the University of Zimbabwe College of Health Sciences and Parirenyatwa Group of Hospitals and the Medical Research Council of Zimbabwe.

All diabetic patients monitored at Parirenyatwa Group of hospitals outpatient clinic were given information on the study. All patients who agreed to participate in the study were asked to give written consent. Information on demography, anthropometric measurements and clinical data and laboratory samples were collected as part of the main study. The male participants had an International Index of Erectile Function (IIEF-5) Questionnaire administered on them by a male medical doctor. Erectile dysfunction scores of 22 to 25 were classified as no erectile dysfunction where as a score of 21 and below were classified as erectile dysfunction (Shi et al. 2014) (Binmoammar et al. 2016).

The body mass index was calculated by dividing weight by the square of the height. A sphygmomanometer was used to measure blood pressure. Neuropathy was diagnosed by the medical doctor using history of neuropathy symptoms, pin prick sensation, vibration perception using a 128 tuning folk, assessment of ankle reflexes and temperature sensation.

The Mindray analyser was calibrated and control samples were analysed before study samples were analysed for total cholesterol, triglycerides, high density lipoprotein cholesterol and glycosylated haemoglobin.

\section{Data analysis}

The STATA version 13 was used for statistical analysis, Descriptive statistic was used. Chi squared was carried out for categorical data and the Student $t$ test for dichotomous and continuous variables in bivariate analysis. Multivariate logistic regression was carried out for adjusted odds predictors of erectile dysfunction. A p value of less than 0.05 were considered statistical significant.

\section{Results}

Out of the 348 diabetes mellitus patients recruited into the study 94 were male. Of the 94 male patients who responded 5.3\% [5/94] could not respond to the questions in the questionnaire due to the fact they were not married or widowed. In this study 73.4\% [69/94] had International Index of Erectile Function (IIEF-5) Questionnaire administered on them. Amongst the 69 diabetic patients 51/69 had erectile dysfunction giving a prevalence of $73.9 \%$. Among the 69 patients, there was one current smoker and 5 patients who indicated they drink alcohol. Of the 5 patients who indicated they drink alcohol 3 had erectile dysfunction. 
Table 1. To show factors associated with erectile dysfunction

\begin{tabular}{|c|c|c|c|}
\hline Characteristics & $\begin{array}{l}\text { Erectile } \\
\text { dysfunction } n= \\
51\end{array}$ & $\begin{array}{l}\text { No erectile } \\
\text { dysfunction } n= \\
18\end{array}$ & p Value \\
\hline Age/Years & $60.4 \pm 14.5$ & $49.6 \pm 15.3$ & 0.009 \\
\hline Body mass index $/ \mathrm{Kg} / \mathrm{m}^{2}$ & $24.5 \pm 4.7$ & $25.1 \pm 4.9$ & 0.677 \\
\hline $\begin{array}{l}\text { Systolic blood } \\
\text { pressure/mmHg }\end{array}$ & $155.6 \pm 25.5$ & $138.6 \pm 13.5$ & 0.009 \\
\hline $\begin{array}{l}\text { Diastolic blood } \\
\text { pressure/mmHg }\end{array}$ & $83.8 \pm 11.9$ & $78.2 \pm 11.3$ & 0.083 \\
\hline $\begin{array}{l}\text { On hypertensive drugs } \\
\text { Yes } \\
\text { No }\end{array}$ & $\begin{array}{l}40 \\
11\end{array}$ & $\begin{array}{l}8 \\
10\end{array}$ & 0.007 \\
\hline $\begin{array}{l}\text { Neuropathy } \\
\text { Yes } \\
\text { No }\end{array}$ & $\begin{array}{l}23 \\
28\end{array}$ & $\begin{array}{l}7 \\
11\end{array}$ & 0.648 \\
\hline $\begin{array}{l}\text { History of myocardial } \\
\text { infarction } \\
\text { Yes } \\
\text { No }\end{array}$ & $\begin{array}{l}4 \\
47\end{array}$ & $\begin{array}{l}0 \\
18\end{array}$ & 0.566 \\
\hline Total cholesterol $/ \mathrm{mmol} / \mathrm{L}$ & $4.3 \pm 1.5$ & $4.3 \pm 1.5$ & 0.942 \\
\hline Triglycerides/mmol/L & $1.1(0.7-1.6)$ & $1.1(0.6-1.8)$ & 0.633 \\
\hline $\begin{array}{l}\text { High density lipoprotein } \\
\text { cholesterol/mmol/L }\end{array}$ & $1.1 \quad \pm 0.4$ & $1.1 \pm 0.4$ & 0.672 \\
\hline $\begin{array}{l}\text { Glycosylated } \\
\text { haemoglobin/\% }\end{array}$ & $8.4(6.8-11.1)$ & $6.6(5.7-9.0)$ & 0.116 \\
\hline $\begin{array}{l}\text { Glycosylated } \\
\text { haemoglobin } \geq 7 \%\end{array}$ & $38[74.5 \%]$ & $8[44.4 \%]$ & 0.020 \\
\hline
\end{tabular}

Erectile dysfunction was associated with higher age, higher systolic blood pressure and being on hypertensive drugs. The proportion of diabetic patients with higher glycosylated haemoglobin (glycosylated haemoglobin $\geq 7 \%$ ) was higher among patients with erectile dysfunction.

\section{Discussion}

It is important to note that diabetes mellitus has been associated with sexual dysfunction in both men and women. However among the women the evidence of the association of diabetes mellitus and sexual dysfunction is less conclusive even though most studies have reported higher prevalence of female sexual dysfunction in diabetic women when compared with non-diabetic women. In men diabetes mellitus is an established risk factor for sexual dysfunction with a documented threefold increase in risk of erectile dysfunction in diabetes mellitus men comparing to non-diabetes mellitus men (Esposito, Maiorino, and Bellastella 2014). In this study the prevalence of erectile dysfunction was high and more than $55.1 \%$ reported at Muhimbili National Hospital [2011] (Mutagaywa et al. 2014), 56.4\% reported in Benin City Nigeria [2004] (Unadike, Eregie, and Ohwovoriole 2008), 57\% reported in city of Bobo Dioulasso Burkina Fasso [2012] (Kambou et al. 2014) but lower than 95\% reported at Steve Biko Academic Hospital Diabetic Clinic South Africa (Kemp and Rheeder 2015). Similar to this study, a study in diabetic patients in five hospitals in Northern Ethiopia reported a prevalence of 69.9\% (Seid et al. 2017). Furthermore, the prevalence of erectile dysfunction among patients with diabetes mellitus was within the reported prevalence of 35 to $90 \%$ (Binmoammar et al. 2016). Difference in prevalence of erectile dysfunction has been attributed to difference in composition of study population (Mutagaywa et al. 2014), 
sexual disorders are considered personal and private that most patients will not readily discuss them (Unadike, Eregie, and Ohwovoriole 2008). Studies from high income countries report lower prevalence of erectile dysfunction than that in developing countries, this is attributed to the fact that in developed countries diabetes mellitus is detected early and glucose is well controlled hence preventing the development of diabetic complications (Mutagaywa et al. 2014).

The prevalence of erectile dysfunction increases with age. In this study higher age was associated with erectile dysfunction similarly in a study at Muhimbili National Hospital [2011] age was also associated with erectile dysfunction (Mutagaywa et al. 2014).

Hypertension has been associated with the development of erectile dysfunction (Esposito, Maiorino, and Bellastella 2014). In this study being on antihypertensive drugs which is caused by having high blood pressure as well as higher systolic blood pressure were associated with erectile dysfunction. The etiology of erectile dysfunction in hypertensive males is reported to be multifactorial and may be caused by vascular disease, decreased heart capacity, medication and/or other factors such as heavy smoking, psychological issues, obesity and physical inactivity (Salman et al. 2016). Erectile dysfunction has been associated with use of $\beta$-blockers, thiazide diuretics, metformin, antidepressants, statins, fibrates and the drugs used for neuropathic pain such as pregabalin, gabapentin and opiate analgesics (Hackett 2016).

The proportion of diabetic patients with higher glycosylated haemoglobin (glycosylated haemoglobin $\geq 7 \%$ ) was higher among patients with erectile dysfunction compared to patients without erectile dysfunction. However it has been reported that it is not clear whether hyperglycaemia is a risk factor for the development of erectile dysfunction. Some studies have observed association between poor glycaemic control as expressed by elevated levels of glycosylated haemoglobin whist other studied did not report any association (Esposito, Maiorino, and Bellastella 2014). Further research is required to clarify causal link between prolonged hyperglycaemia and erectile dysfunction (Binmoammar et al. 2016).

Erectile dysfunction is a treatable complication of diabetes mellitus with reported success rate of treatment of $95 \%$ (Seid et al. 2017). However erectile dysfunction is reported to be one of most neglected complication of diabetes mellitus (Mofid et al. 2009). Pathophysiology of erectile dysfunction is multifactorial. Normally biological and psychological factors work synchronously leading to an erection. Psychological arousal causes biological cascade that involves parasympathetic activation and consequent nitric oxide release from local endothelial cells. Nitric oxide mediates smooth muscle and vascular relaxation causing increased arterial flow to the penile corpora cavernosa. The increasing blood flow impedes venous return via compression of penile venules, thus maintaining an erection. Erectile dysfunction develop in diabetes mellitus patients due to an interplay of neuropathy, vasculopathy, hypogonadism, endothelial dysfunction and psychological factors (Hackett 2016).

\section{Conclusion}

This study shows high prevalence of erectile dysfunction in diabetes mellitus patients attending Parirenyatwa outpatient clinic. Erectile dysfunction was associated with higher age, higher systolic blood pressure and being on antihypertensive drugs. This study shows the need of consistent screening of erectile dysfunction among diabetic patients for early detection, treatment and prevention. There is also need for a large national study to confirm this prevalence and the associated factors.

\section{References}

[1].Binmoammar, Turki A, Sondus Hassounah, Saad Alsaad, Salman Rawaf, and Azeem Majeed. 2016. "The Impact of Poor Glycaemic Control on the Prevalence of Erectile Dysfunction in Men with Type 2 Diabetes Mellitus: A Systematic Review.” JRSM Open 7 (3): 205427041562260. doi: 10.1177/2054270415622602.

[2].Esposito, Katherine, Maria Ida Maiorino, and Giuseppe Bellastella. 2014. "Diabetes and Sexual Dysfunction: Current Perspectives." Diabetes, Metabolic Syndrome and Obesity: Targets and Therapy, March, 95. doi:10.2147/DMSO.S36455.

[3].Hackett, G. 2009. "The Burden and Extent of Comorbid Conditions in Patients with Erectile Dysfunction." International Journal of Clinical Practice 63 (8): 1205-13. doi:10.1111/j.1742-1241.2009.02088.x. 
[4].Hackett, Geoffrey Ian. 2016. "Erectile Dysfunction, Diabetes and Cardiovascular Risk." British Journal of Diabetes 16 (2): 52. doi:10.15277/bjd.2016.076.

[5].Kambou, Timothée, Cyprien Zaré, Abdoul Karim Paré, Adama Ouattara, Youombèviel Ludovic Somé, and Bakary Gustave Sanon. 2014. "Erectile Dysfunction among Diabetic Men in Two Medical Centers in Burkina Faso: Epidemiological, Diagnosis and Therapeutic Aspects." Advances in Sexual Medicine 04 (01): 1-5. doi:10.4236/asm.2014.41001.

[6].Kemp, T, and P Rheeder. 2015. "The Prevalence and Associations of Erectile Dysfunction in a South African Male Diabetic Urban Population.” Journal of Endocrinology, Metabolism and Diabetes of South Africa 20 (3): 134 39. doi:10.1080/16089677.2015.1090185.

[7].Malavige, L. S., S. D. Jayaratne, S. T. Kathriarachchi, S. Sivayogan, P. Ranasinghe, and J. C. Levy. 2014. "Erectile Dysfunction Is a Strong Predictor of Poor Quality of Life in Men with Type 2 Diabetes Mellitus." Diabetic Medicine 31 (6): 699-706. doi:10.1111/dme.12412.

[8].Mofid, Alireza, SeyedAhmad Seyedalinaghi, Saeed Zandieh, Tahereh Yazdani, and Sara Jam. 2009. "Prevalence and Risk Factors of Erectile Dysfunction in Iranian Diabetic Men.” Acta Medica Iranica 47 (4): 309-14.

[9].Mutagaywa, Reuben Kato, Janeth Lutale, Aboud Muhsin, and Benjamin Anathory Kamala. 2014. "Prevalence of Erectile Dysfunction and Associated Factors among Diabetic Men Attending Diabetic Clinic at Muhimbili National Hospital in Dar-Es-Salaam, Tanzania." Pan African Medical Journal 17. doi:10.11604/pamj.2014.17.227.2695.

[10]. Salman, Muhammad, Naureen Shehzadi, Muhammad T Khan, Muhammad Islam, Sohail Amjad, Omer Afzal, Sibghat Mansoor, et al. 2016. "Erectile Dysfunction: Prevalence, Risk Factors and Involvement of Antihypertensive Drugs Intervention.” Tropical Journal of Pharmaceutical Research 15 (4): 869. doi:10.4314/tjpr.v15i4.29.

[11]. Seid, Awole, Hadgu Gerensea, Shambel Tarko, Yosef Zenebe, and Rahel Mezemir. 2017. "Prevalence and Determinants of Erectile Dysfunction among Diabetic Patients Attending in Hospitals of Central and Northwestern Zone of Tigray, Northern Ethiopia: A Cross-Sectional Study." BMC Endocrine Disorders 17 (1). doi: 10.1186/s12902-017-0167-5.

[12]. Shi, M-D, J-K Chao, M-C Ma, S-K Chiang, and I-C Chao. 2014. "The Connection between Type 2 Diabetes and Erectile Dysfunction in Taiwanese Aboriginal Males." International Journal of Impotence Research 26 (6): 235 40. doi:10.1038/ijir.2014.26.

[13]. Unadike, B. C., A. Eregie, and A. E. Ohwovoriole. 2008. "Prevalence and Types of Sexual Dysfunction among Males with Diabetes in Nigeria." Mera: Diabetes International, 18-20. 


\title{
Strengthening Malaria Service Delivery through Measurement of Quality Improvement of Performance Standards in Nigeria: evaluation of Community Health Workers Performance
}

\author{
Article by Bright Orji ${ }^{1}$, William Brieger ${ }^{2}$, Lindiwe Innocentia ${ }^{3}$ \\ 1,3 Texila American University \\ ${ }^{2}$ Public Health, the Johns Hopkins Bloomberg \\ E-mail:bright2orji@yahoo.com ${ }^{1}$
}

\begin{abstract}
This study monitored quality improvement performance standards of Community Health Workers $(\mathrm{CHWs})$ who were providing integrated community case management of malaria, pneumonia and diarrhea (iCCM) in two selected LGAs. One hundred and fifty-two trained CHWs providing iCCM services in Akwa Ibom State, Nigeria were monitored and assessed using one page tool on quality improvement performance standards. The tool has 37 performance criteria (PC) to measure CHWs' knowledge, skills and competence in 3 sections: History taking and Examination; Conducting RDTs for Malaria; and Illness Management. Trained assessors observed CHWs providing services. Each correctly performed criterion was scored 1 point. Four rounds of assessments were conducted at an interval of two months from June 2011 - March, 2012 as part of the efforts to strengthen services provided by CHWs. The result shows that during Round 1 CHWs achieved an average of $19(52.2 \%)$ performance standards. This rose to $25(67.5 \%)$ in Round 2; 28 $(75.6 \%)$ in 3 and $30(81.1 \%)$ in round 4 and $(p=0.00)$. Therefore, the number of $C H W$ s that scored $>=80$ increased from 79 in round-1 to 124 in round-4. PC that needed to be strengthened the most included reinforcement on checking RDT expiry date, recording results, and safe disposing of sharps. Providing feedback in-between rounds of assessments contributed to CHWs improved performance during the subsequent round. The feedback mechanism provides the platform for addressing the barriers that limits the CHWs extent of achieving performance standards for malaria improved service delivery
\end{abstract}

Keywords: Measurement, Quality improvement performance standards, community health workers, integrated community case management of malaria, pneumonia and diarrhea.

\section{Introduction}

Globally, the number of malaria cases has been in the decline. In 2016, the number of malaria cases declined to 216 million from 237 million cases in 2010 (WMR, 2017). Estimated incidence of malaria cases dropped from 63 cases to 76 cases per 1000 per population at risk of the disease between 2010 and 2016. Similarly, global malaria deaths dropped between the same periods. Estimated annual malaria deaths in 2016 was 445,000. In Nigeria, percent of persons with suspected malaria receiving a diagnostic test (RDT and/or microscopy) increased from $17 \%$ in 2012 to $39 \%$ in 2016. In 2015, $41 \%$ of children under-five years of age that reported fever, only $13 \%$ were tested using RDTs while $38 \%$ of them received ACTs the recommended medicine for malaria treatment (MIC, 2015).

The increase in number of people receiving malaria care in Nigeria has over-stretched the health system; resulting in poor availability of infrastructures, equipment, supplies and heavy workload for the few standing health workers. These may have compromised quality of care provided by the available service providers (Adrienne Kols, Young-Mi Kim, Eva Bazant, Edgar Necochea, Joseph Banda and Stacie Stender, 2015). One study in Nigeria reported quality of care in a hospital to be $38.8 \%$ and described this as suboptimal and totally unacceptable (Ariba AJ., Thanni LO., Adebayo EO; 2007) while another study showed increase in non-adherence to treatment protocol among cases of maternal death in 2002-2004 compared with 1999-2001 though this was not statistically significant but enough concern for quality of 
care. One of the reasons for poor quality of care was the shortage of human resource for health. Therefore, engagement of CHWs as part of the efforts in the implementation of task shifting policy to address the challenges of poor availability of human resource for health becomes inevitable. Various studies have shown that trained CHWs can use RDTs as a component of home management of malaria but only few studies have monitored and assessed quality of services provided by the CHWs.

This has prompted focus on CHWs performance assessment using evidence-based standards for maternal, newborn and child health care. The standards are developed from evidence-based practices and includes practical perspective on technical areas as well as emphases clients' centered care. Clients' centered care are services that recognizes and respects patients' rights and human dignity including cultural orientations (Necochea E., Tripathi V., MI-Kim Y., Akran N., Hyjazi Y., Luz vaz M., Otolorin EO., Pleah T., Rashidi T., Bishanga D., 2015). Implementation of evidence interventions and client's centered care to reduce maternal death in Nigeria has been very tasking. Some of the reasons given for this include poor documentation, and gaps in the measurement of quality of care that might have hindered the delivery of quality care by the service providers (Kabo I., Otolorin EO., Williams E., et al, 2016). In one study, Kinney et al opine that if quality of care cannot be measured, identification of quality gaps will be challenged and therefore affect the ability to reduce the gaps. On the other hand, poor documentation will lead to poor quality data that is critical for decision-making to address health challenges and improve malaria service delivery among countries on the pathway to malaria elimination.

There has been increasing national and international attention to the need to improve the quality of malaria services. In 2010 and 2011 World Health Organization adopted "counting out malaria" as a theme for the years' world malaria day; in an effort to draw attention to quality of malaria services and the need for strong health information, monitoring and evaluation system.

Kabo et al, 2016 has noted that maternal and newborn health outcomes in Nigeria can be improved through monitoring and measurement of quality improvement performance standards.

In Bauchi State, Nigeria (Kabo I., Otolorin EO., Williams E., et al, 2016) demonstrated that application of provider performance quality improvement assessment to maternal and newborn health services in 20102014 among 23 secondary health facilities resulted in well over $82 \%$ achievement of performance standards from baseline within four years of program implementation. While service providers compliance to quality improvement performance standard improved over time from 8\% (2010) baseline to $92 \%$ (2013) leading to the decline of maternal mortality rate from 4113/100,000 live births in 2010 to 704 in 2014.

There are only very few studies in Nigeria on the quality performance of community health workers. However, studies in other seven countries that shared similar characteristics with Nigeria such as Bangladesh, India, Nepal, Pakistan, the Philippines and Tanzania that involved CHWs have reported high impact and quality performance and contributions on diagnosis and treatment of pneumonia that reduced risk of death by $36 \%$ in children in addition to $24 \%$ overall risk of deaths in children living in those countries (Perry HB., Zulliger R., Rogers MM., 2014). These evidences have continued to support active involvement and participation of CHWs in public health interventions as part of the key strategy to reduce the effect of critical shortages of health workers in the developing countries.

This current effort monitored and measured the CHWs achievement of performance standards in providing quality management of febrile illnesses in two selected LGAs, in Nigeria. The study will answer the research question what is the effect of regular monitoring and measurement of quality improvement performance of CHWs providing integrated community case management of malaria, pneumonia and diarrhea? Study objective - The study will investigate the CHWs achievement of performance standards in the delivery of integrated community case management (iCCM) of malaria, diarrhea and simple respiratory infection in Akwa Ibom State, Nigeria. The project will specifically. Describe the effect of regular quality assessments on CHW's performance. 


\section{Method}

The study was measurement over time implementation research to monitor and strengthen quality improvement performance of the CHWs providing integrated community case management of malaria, pneumonia and diarrhea (iCCM) in Akwa Ibom State, Nigeria. Standards used in this study include taking history/examination; conducting RDTs and appropriate management of febrile illness.

152 CHWs selected by the communities were studied. The selection criteria used by the community included persons living in the community where they served, ability to read and write, agreed to volunteer services, if married must have support of spouse, willingness to attend monthly meetings and submit reports. In some other communities, criteria included previous experience especially community with onchocerciasis experience with active CHWs. Community meetings were held, and usually included men, women, youths and visitors residents in the community. The CHWs were mainly farmers, traders, retirees, civil servants etc.

Total of two thousand, two hundred and six clients were reached by the CHWs during the project implementation period June 2011 - March, 2012.

\section{Tool and data management}

The study used purposive sampling technique because all the 152 CHWs were studied for quality improvement of performance standards in the delivery of iCCM.

The state ministry of health partnered with implementing agency and developed one page tool for quality performance standards - monitoring the quality of services provided by the CHWs in two selected LGAs of Akwa Ibom State, Nigeria. The tool has 37 performance criteria (PC) that measured CHW knowledge, skills and competence in 3 sections: History taking and Examination; Conducting RDTs for Malaria; and Illness Management. Each section of the performance criteria has between 11 to 13 verifiable criteria. The tool was used to observe the CHWss while providing services at the community; each correctly performed criterion was scored 1 point.

Four rounds of assessments were conducted after the baseline at an interval of two months between project implementation periods June 2011 - March, 2012. The results of the previous assessments was used to provide feedback to the CHWs before the next round of evaluation. The post-evaluation data collected during the iCCM project were re-analyzed using SPSS version 21.0 series for Windows.

In the analysis, descriptive statistics such as mean, mode, median, standard deviation percentage, as well as graphic illustrations were used in characterizing the data of the CHWs socio demographic characteristics. These characteristics include the CHWs' sex, age, education and vocations. Also, CHWs improvement in the delivery of quality services (defined as taking history/examination, conducting RDTs and appropriate management of febrile illness) was measured in percentages (\%). A score $\geq 80 \%$ was set as quality improved service delivery based on Jhpiego's participant's pass mark at trainings; while $\leq 80 \%$ is adjudged as non-quality improved services using the round-4 endline assessment.

The CHWs meet monthly to share challenges, success stories, replenish stock of medicines and get feedback on their performance. The supervising health worker used the opportunity to administer the supervisory checklist to monitor and assess the performance of the CHW based on their bi-monthly reports and provide support and feedback on areas that needed improvement.

The tool was administered quarterly in collaboration with the Local government staff who also provided supportive supervision to the CHWs; and three rounds of supervision visits were provided

\section{Results}

The sample size for the study was $152 \mathrm{CHWs}$. The $152 \mathrm{CHWs}$ worked through the end of the project. There was no attrition, and performance of the CHWs were measured at the interval of two to three months. Of the 152 CHWs provided iCCM services during the period under review Table 1 shows the sociodemographic characteristics of the CHWs. 
DOI: $10.21522 / \mathrm{TIJPH} .2013 .06 .02 . A r t 010$

ISSN: $2520-3134$

One hundred and fifty-two (152) CHWs were studied. $21 \%$ were male while $79 \%$ were female CHWs. The CHWs overall mean age was 36.8 years with a standard deviation of \pm 8.7 years. The mean age for the male CHWs was 37.6 years with standard deviation of \pm 4.3 while the mean age for the female CHWs was 36.6 years with standard deviation of \pm 9.5 . The youngest age of the study CHWs was 30 years while the oldest age was 49 years old with a range of 30-49. The CHWs were assigned to the following age groups: $<36$ years, and $>36$ years. The mean age of the CHWs was used as the cut-off point for the grouping. The result shows that eighty (80) or $53.0 \%$ of the CHWs were in the group < 36 years while seventy-two (72) or $47 \%$ of the CHWs were in the group of $>36$ years old.

Education was also analyzed based on the CHWs' educational level ranging from primary to secondary and post- secondary education. Eighteen (18) of the CHWs who had primary education represents $12.0 \%$ of the total number of $152 \mathrm{CHWs}$ that participated in the project. One hundred and thirteen (113) of the CHWs or $74.0 \%$ attained secondary school while twenty-one (21) or $14.0 \%$ of the CHWs attained postsecondary school. Table 1 below provides information about the educational level of the study CHWs.

Occupation was analyzed based on the CHWs' principal work or business ranging from unskilled to skilled. Those trained on the work or business that they do such as fashion designers, health care workers, retired teachers, and soldiers were classified as skilled. While those that are not trained in the work or business that they are involved in are classified as unskilled; and these include petty traders, subsistence farmers, housewives etc. Ninety-six (96) or $63.0 \%$ of the CHWs were unskilled while 56 of the CHWs or $37.0 \%$ of the CHWs were skilled. Most of the CHWs were unskilled $n=96$. Table 1 below provides information about the occupation of the study CHWs.

On the measurement of quality improvement of performance standards disaggregated by rounds. The result shows that during Round $1 \mathrm{CHWs}$ achieved an average of $19(52.2 \%)$ performance standards. This rose to $25(67.5 \%)$ in Round 2; $28(75.6 \%)$ in 3 and $30(81.1 \%)$ in round 4 and $(\mathrm{p}=0.00)$. Therefore, the number of CHWs that scored $>=80$ increased from 79 in round- 1 to 124 in round- 4 . Some of the performance criteria that needed most improvement included reinforcement on checking RDT expiry date, entering results on records, and safe disposing of sharps.

Efforts to improve access to quality case management of febrile illness in Nigeria included the engagement of CDDs to use Rapid Diagnostic tests as a component of home management of malaria (iCCM) and dispense ACTs when the RDTs result is positive and manage pneumonia and diarrhea when negative. It also included effort to monitor and measure the performance of CDDs in providing quality management of febrile illnesses through regular assessments. Four rounds of assessments were conducted among the same cohorts of CHWs, and effects of the measurement recorded and provided in figure- 2 below:

The effect of the regular assessments of the CHWs performance was more on illness management which rose from $45.5 \%$ in round- 1 to $89.1 \%$ in round- 4 . This was followed by history taking and examination increasing from $46.2 \%$ in round- 1 to $80.1 \%$ in round- 4 . Conducting RDT for malaria showed slow but continuous increase from $61.5 \%$ in round- 1 to $69.2 \%$ in round- 2 and $76.9 \%$ in round-3 but decreased in round-4 to $72.7 \%$. Performance criteria that needed most improvement included checking signs and symptoms to distinguish among the illnesses in the history taking \& examination thematic area. While CHWs need reinforcement on checking RDT expiry dates, entering RDT results on records and safe disposal of sharps in the Conducting RDT for malaria thematic area; On illness management thematic area CHWs require improvement on counseling for illness preventive measures i.e. reinforcing messages on the use of Long Lasting Insecticide Treated Nets (LLINs) among children under-five years of age and pregnant women; and use of Sulfadoxine-pyrimethamine in prevention of malaria during pregnancy. At the end of each round of assessment, feedback was provided to the CHWs to improve their services before the subsequent round. Feedback provided in between rounds has the effects of helping CHWs improve their performance; and plan for subsequent assessments and feedback sessions as can be seen in figure- 2 . 


\section{Discussions}

Discussions centered essentially on the measurement of quality improvement of performance standards. The effects of regular monitoring and measurement of CHWs performance, and how this may have strengthened malaria service delivery was measured. The results of the regular monitoring and measurement of performance standards showed that performance was increasing over time. It was also observed that the CHWs remain the same cohorts, none of them dropped. Though this study did not investigate the reason for that.

The use of one page assessment tool to periodically (two to three months apart) assess and observe CHWs while providing services and using the results to provide feedback in-between rounds of assessments strengthened service delivery by the CHWs during the subsequent round. The feedback mechanism provides the platform for addressing the barriers that limits the CHWs extent of achieving performance standards for improved service delivery. The essence is that the high performing CHWs are engaged to ensure that they continue with quality service delivery while those with areas to improve upon are mentored. So, that promoting interactions between mentors and mentees may improve CHWs achievement of performance standard for quality of iCCM services delivery; thereby decreases high mortality and morbidity due to malaria, pneumonia and diarrhea.

The CHWs achieved performance was observed in each of the three thematic areas - namely history taking and examination; conducting RDTs and illness management. The tools identified sections in the thematic areas that needed more work to improve over time. Example, the sections needed most improvement included checking signs and symptoms to distinguish among the illnesses. CHWs demonstrate eagerness and zeal in the performance of their duties and appear to neglect to check for signs and symptoms to distinguish illness as well as take note of the expiry date of the rapid diagnostic test kits. This is largely due to myths and misconception that every fever is caused by malaria; leading to first treating malaria before investigating other febrile illness only when the treatment of malaria fails. So, the introduction of rapid diagnostic test kits remains innovative in distinguishing malaria from other febrile illness that causes fever.

Also, CHWs needed reinforcement on checking RDT expiry date, entering results on record books, safe disposing of sharps, and counseling on preventive measures. In this anxiety to treat, it was also not unusual to forget checking for expiry date of the RDT first prior to conducting the test; and re-enforcement on preventive measures to maintain good health and fitness. Also, CHWs were under performing in recording RDTs and treatment results. It has been observed that poor documentation of data will limit the ability to improve quality services. This is because if data is not recorded, it cannot be measured and, when it cannot be measured obviously it cannot be improved (Kinney MV., Kerber KJ., Black RE. et al, 2010). This current work recorded improvement in entering results of RDTs in rounds two and three but dropped in round four. Interestingly, the results can be used to plan for additional quarterly assessments and feedback sessions that will strengthen service delivery and improve performance across the thematic areas.

The measurement of quality improvement of performance standards among CHWs and using the results to provide feedback will lead to an increased compliance and adherence to performance standards. Feedback provided in between rounds has the effects of helping CHWs improve their performance; and plan for subsequent assessments and feedback sessions. These findings collaborate the result of an earlier work in Nigeria that monitored and measured quality improvement performance standards among health workers in 23 health facilities in Bauchi State, Nigeria. Results showed that quality of maternal and newborn health services improved in-between rounds and with each assessment (Kabo I., Otolorin EO., Williams E., et al, 2016). The findings also validates the report of another work in Ghana where the monitoring and measurement of provider performance among community-based health services in 2011 - 2014 across 61 community health programs led to over $30 \%$ achievement of performance standards (Necochea E., Tripathi V., and MI Kim Y., et al 2015). CHWs have the potentials to deliver quality management of febrile illness in the current efforts to reduce annual maternal and child deaths while contributing to the achievement of target number 3 of the Sustainable Development Goals (SDGs). In conclusions, CHWs supervisors and 
DOI: $10.21522 /$ TIJPH.2013.06.02.Art010

ISSN: $2520-3134$

program managers can use this tool and approach to enhance the quality of services provided by the CHWs and improve their performance through trainings and supervision.

\section{Reference}

[1]. Alam K., Tasneem S., Oliveras E. (2012). Retention of female volunteer community health workers in Dhaka urban slums: a case-control study. Health Policy Plan 27(6): 477-86. Doi: 1093/heapol/czr059.

[2]. Adrienne Kols, Young-Mi Kim, Eva Bazant, Edgar Necochea, Joseph Banda and Stacie Stender, (2015). A Standards-based approach to quality improvement for HIV services at Zambia Defence force facilities: results and lessons learned. AIDS 29(Suppl 2): S145 - S153.

[3]. Ariba AJ., Thanni LO., Adebayo EO. (2007). Patients' perception of quality of emergency care in a Nigerian teaching hospital: The influence of patient-provider interactions. Nigeria Postgraduate. Medical Journal 14(4):296301.

[4]. Bagonza J., Kibira PS., Rutebemberwa E., (2014). Performance of health workers managing malaria, pneumonia and diarrhea under community case management program in central Uganda: a cross sectional study. Malaria Journal doi: 10.1186/1475-2875-13-367.

[5]. Edgar Necochea, Vandana Tripathi, Young MI Kim, Nabeal Akran, Yoland Hyjazi, Maria da Luz Vaz, Emmanuel Otolorin, Tsigue Pleah, Tambudzai Rashidi, Dustan Bishanga (2015). Implementation of Standard-Based Management and Recognition approach to quality improvement in maternal, newborn, and child health programs in low-resource countries. International Journal of Gynecology and Obstetrics 130 S17-S24.

[6]. Hamer DH., Brooks ET., Semrau K., Pilingana P., MacLeod WB., Siazeele K., Sabin LL., Thea DM., YeboahAntwi (2012). Quality and safety of integrated community case management of malaria using rapid diagnostic tests and pneumonia by community health workers. Pathog Glob Health. 106(1): 32-39. doi: $10.1179 / 1364859411$ Y.0000000042.

[7]. Harvey S.A, Jennings L, Chinyama M, Masaninga F, Mulholland K, Bell DR, (2008). Improving community health worker use of malaria rapid diagnostic tests in Zambia: package instructions, job aid and job aid-plus-training. Malar J 7: 160.

[8]. Ibrahim Kabo, Emmanuel Otolorin, Emma Williams, Nosa Orobaton, Hannatu Abdullahi, Habib Sadauki, Masduk Abdulkarim, Dele Abegunde. (2016). monitoring maternal and newborn health outcomes in Bauchi State, Nigeria: an evaluation of a standards-based quality improvement intervention. International Journal for Quality in Health Care 28(5), 566-572.

[9]. Kinney MV., Kerber KJ., Black RE, Cohen B., Nkrumah F., Coovadia H., Nampala PM., Lawn JE. (2010) on behalf of the Science in Action: Saving the lives of Africa's mothers, newborns, and children working group. PLoS Med. https://doi.org/10.1371/journal.pmed. 1000294.

[10]. Lopes SC., Cabral A., de Sousa B., (2014). Community health workers: to train or to restrain? A longitudinal survey to assess the impact of training community health workers in the Bolama Region, Guinea-Bissau. Hum Resour Health. 12:8 doi: 10.1186/1478-4491-12-8.

[11]. National Population Commission (NPC), Malaria indicator survey (MIS), 2015.

[12]. Perry HB, Zulliger R., Rogers MM. (2014). Community health workers in low-, middle-, and high-income countries: an overview of their history, recent evolution, and recent effectiveness Annu Rev Public Health. 2014; 35:399-421. doi: 10.1146/annurev-publhealth-032013-182354.

[13]. Young MI Kim, Maureen Chilila, Hildah Shasulwe, Joseph Banda, Webby kanjipite, Supriya Sarkar, Eva Bazant, Cyndi Hiner, Maya Tholandi, Stephanie Reinhardt, Joyce Chongo Mulilo, and Adrienne Kols. (2013). Evaluation of quality improvement intervention of HIV (PMTCT) at Zambia defence force facilities. BMC Health Services Research $13: 345$.

[14]. World Health Organization - World Malaria Report, 2017. 
Table 1. Socio demographic characteristics of the CHWs

\begin{tabular}{|c|c|c|c|}
\hline & \# of CHWs & $\%$ of CHWs & P-value \\
\hline No. of Participants & $(\mathrm{N}=152)$ & $(\%=100)$ & \\
\hline \multicolumn{4}{|l|}{ Sex } \\
\hline Male & 32 & 21.0 & \\
\hline Female & 120 & 79.0 & \\
\hline \multicolumn{4}{|l|}{ Age } \\
\hline Mean age & $36.8 \pm 8.7$ & & \\
\hline Male mean age & $37.6 \pm 4.3$ & & 0.00 \\
\hline Female Mean age & $36.6 \pm 9.5$ & & \\
\hline$<=36$ & 80 & 53.0 & \\
\hline$>36$ & 72 & 47.0 & \\
\hline \multicolumn{4}{|l|}{ Educational Level } \\
\hline Primary & 18 & 12.0 & \\
\hline Secondary & 113 & 74.0 & \\
\hline Post-secondary & 21 & 14.0 & \\
\hline \multicolumn{4}{|l|}{ Occupation } \\
\hline Unskilled & 96 & 63.0 & \\
\hline Skilled & 56 & 37.0 & \\
\hline
\end{tabular}

Table 2. Measurement of quality improvement standards disaggregated by rounds of assessments and performance score

\begin{tabular}{|l|l|l|l|}
\hline $\begin{array}{l}\text { Total \# of } \\
\text { performance score } \\
=37\end{array}$ & $\begin{array}{l}\text { \# performance } \\
\text { criteria \% } \\
\text { Scored }\end{array}$ & \\
\hline Round-1 & 19 & 52.2 & P-value \\
\hline Round-2 & 25 & 67.5 & \\
\hline Round-3 & 28 & 75.6 & \\
\hline & 30 & 81.1 & 0.00 \\
\hline
\end{tabular}


DOI: $10.21522 /$ TIJPH.2013.06.02.Art010

ISSN: $2520-3134$

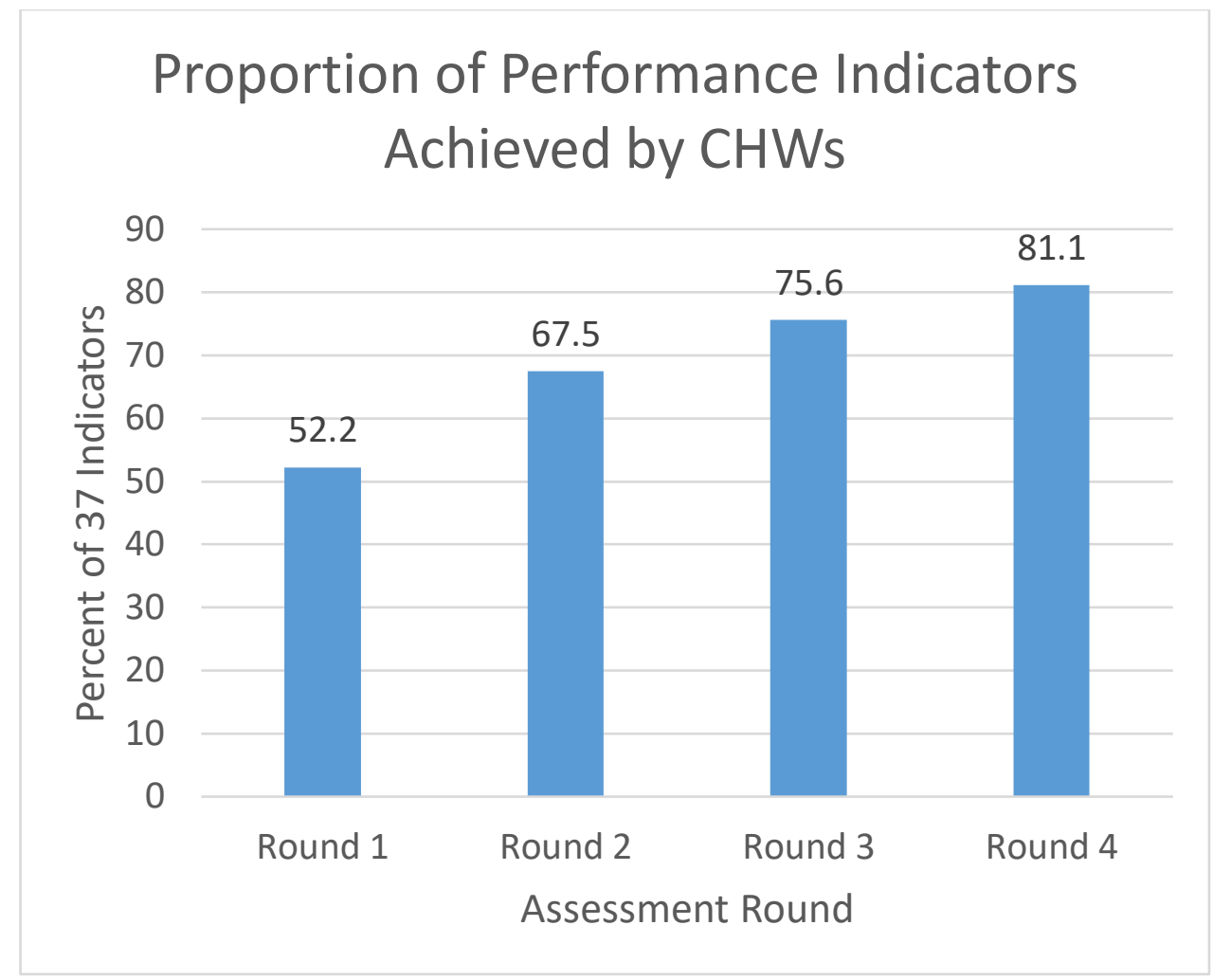

Figure 1. Proportion of performance indicators achieved by community health workers

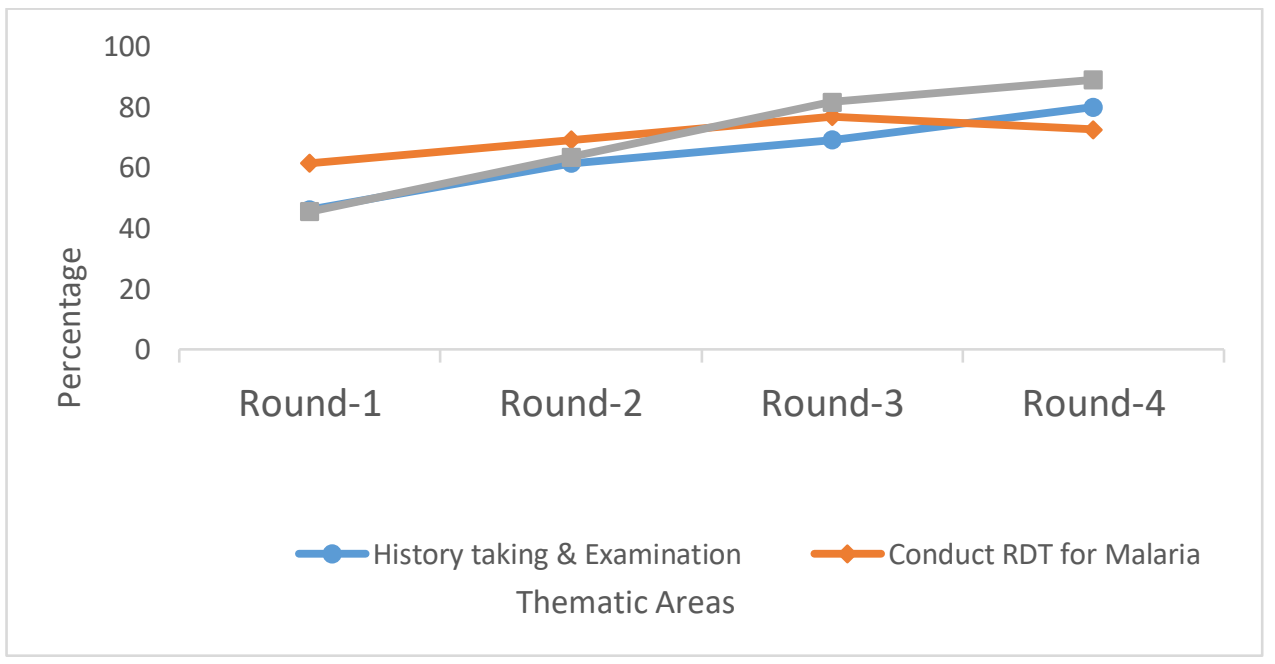

Figure 2. Community health workers performance by treatment sections 


\title{
Assessment of Effect of Labour Strikes on Access to Service Delivery in Secondary Health Institutions in Cross River State, Nigeria
}

Article by Samson Olusegun Aturaka ${ }^{1}$, Amosu AM$^{2}$, Robert J. Chiegil ${ }^{2}$, Felix Sanni ${ }^{3}$, Musa Orenyi ${ }^{4}$, Margaret Dakwat ${ }^{5}$, Abiodun Olaiya Paul ${ }^{6}$, Opeyemi Joseph ${ }^{7}$

${ }^{1}$ Texila American University, Department of Public Health, Guyana, South Amarica

${ }^{2}$ Department of Public Health, School of Allied Public and Allied Health, Babcock University, Ilishan Remo, Ogun State, Nigeria

${ }^{3}$ Department of Chemistry, Federal University of Agriculture, Abeokuta, Ogun State, Nigeria

${ }^{4}$ Department of Supply Chain Management and Operations, Axios Foundation Nigeria, Central Medical Store, EDP Compound Calabar, Nigeria

${ }^{5}$ Fhi 360 Department of Health system strengthening and Laboratory services, Country office, Abuja Nigeria

${ }^{6}$ Fhi 360 Department of Health system strengthening and Laboratory services, Country office, Abuja Nigeria

${ }^{7}$ Fhi360 AHNi, Benue State Office, Department of Health System Strengthening and Laboratory Services, Makurdi, Nigeria

${ }^{8}$ Fhi360, Cross River State Office, Department of Health System Strengthening and Laboratory Services, Calabar, Nigeria

E-mail:segunhydd@yahoo.com (S.O.Aturaka)

\begin{abstract}
Frequent labour crisis leading to strikes is common in a developing country like Nigeria. This crosssectional descriptive study was carried out to assess the effect of labour strikes on access to service delivery in secondary Health Institutions in Cross River State, Nigeria. The 508 respondents were drawn from the outpatient, laboratory and pharmacy departments, Ante-Natal and Post-Natal and ART clinics of the 7 secondary health institutions spread across 3 senatorial districts in the state between January and February 2018. Data were collected with a semi structured, closed-and open-ended questionnaire. Raw data were entered EpiData ${ }^{\mathrm{TM}}$ and exported for analysis using the SPSS software version 20. The data were cleaned and validated for use. Frequency tables were produced and associations between categorical variables were determined using chi square test at a significance level of $P<0.05$.

The age range of most repondents was 25 - 45 with the peak value of 198 (39\%) recorded for age group 25-34 years. The results showed that though many people did not know the reasons why health workers embark on incessant strikes, they did not support strikes. Seven factors were highlighted as the major causes of regular strikes in Nigerian health institutions and the knowledge of respondents about all these factors were tested. Overall, the accessibility of patients to healthcare during labour strikes was approximately $8 \%$ which was not a pleasant experience for the patients. Conclusively, labour strike has serious effects on access to service delivery in secondary health institutions in Cross River State, Nigeria.
\end{abstract}

Keywords: Labour Strikes, Access to Service Delivery, Secondary Health Institutions, Healthcare Workers and patients' educational level

\section{Introduction}

In a developing country like Nigeria, frequent labour crisis leading to strikes is common. The health sector is not an exception to this trend. It is a multi-disciplinary sector comprising of many professionals like doctors, medical laboratory scientists, nurses and pharmacists to mention a few. Nigeria masses have suffered from frequent healthcare workers' strikes from 2012 to date from 2013 - 2015 witnessing several health worker's strikes involving all health professionals. Frequent healthcare workers' strikes 
result from the closure of public healthcare institutions preventing Nigerians' access to quality health services (Olerebe, 2016).

There are so many reasons health professionals go on strike. The main underlying causes of industrial action Nigeria include career stagnation, perceived discriminatory policies and demoralization from working in systems with poor infrastructure, manpower shortages and poor personal remuneration (Ogunbanjo, 2009). However, in recent times, there has been a divided opinion on true underlying factors responsible for the causes of industrial action (Botero, 2014).

From year 2012 to date, the Nigerian health system has experienced several labour strikes involving different health professional unions/associations like Nigerian Medical Association (NMA), National Association of Resident Doctors (NARD), Joint Health Workers Union of Nigeria (JOHESU) and National Union of Allied Health Professionals (NUAHP) to mention a few. These strikes have adversely impacted on the healthcare system, leading to several avoidable deaths, complications and outgoing medical tourism, as the wealthy seek health services abroad (Adebimpe, 2010). The outcome of these strikes is worst when they occur to periods of national health emergencies such as the recent suspected cases of Monkey pox disease outbreak of some part of the country, Ebola viral disease outbreak, Lassa fever or cholera outbreaks or even man-made emergencies like Militant killing and Boko Haram suicide bombings with mass casualties (Oleribe, 2016)

Strike is a strategy used by a group of employees to force the employer to meet their demands. Generally, strikes are discussed in terms of the economic nature of the events. A third-party involvement may ultimately pressurize the employees and employer to settle a strike. Frequent strikes by the health workers would affect the role and responsibilities for professionals in the health sector and ultimately leads to poor service delivery, low quality of care and client dissatisfaction.

Labour strikes is an aberration in the healthcare system, it impacts negatively on patients accessing healthcare delivery and discourages many patients from accessing health institution. Frequent health worker strikes reduce uptake of service delivery which might invariably result in the poor healthcare quality.

\section{Materials and methods}

Health care service in Cross River State is tiered into: Primary, Secondary and Tertiary. The State has 1114 primary health centres, 12 General Hospitals and 1 tertiary health institution. A cross-sectional descriptive survey approach was used to execute this study between January and February 2018. A pretested semi structured questionnaire with both closed-and open-ended questions was used to collect data for this study. Multistage sampling technique was employed in selecting 508 respondents. Using the sample size calculation formula for population less than ten thousand, (Olawuyi, 1996) sample size of 500 was calculated. Multistage sampling methods were employed from state ministry of health totaling 12 General hospitals. In stage one, 2 out of the 3 senatorial districts were selected by simple random sampling employing simple ballot in the two selected geopolitical zones. In stage two, 7 out of 9 secondary health facilities were selected from the 2 senatorial districts (Southern and Northern senatorial districts) by simple random sampling. In Stage three, questionnaires were distributed systematically to patients attending the following service delivery points: outpatient department, laboratory department, pharmacy department and ART clinic based on their client load. These were consenting patients above 18 years old attending the outpatient, laboratory and pharmacy departments, Ante-Natal, Post-Natal and ART clinics of the 7 secondary health institutions spread across 3 senatorial districts in the Cross River state, Nigeria, between January and February 2018. Data collected were cleaned and validated for use. Simple frequency tables were produced and associations between categorical variables were determined using Chi square test at a significance level of $\mathrm{P}<0.05$. Age, Gender, educational qualification, occupation and attendance at the facility were re-coded for the Chisquare analysis. Recoding of variables saw all participants grouped into male and female, graduates and non-graduates, married and single (with widows classified as singles) and attendance at the facility grouped into $<1$ year, $1-5$ years, $6-10$ years, $11-15$ years and $>15$ years. 


\section{Results}

\section{Demographics}

There were $265(52.2 \%)$ males and 243 (47.8\%) females with male: female ratio of 1.1:1. The most frequent age group was 25 - 34 with $198(39.0 \%)$ respondents followed by 125 (24.6\%) seen for age range $35-44$. There were $92(18.1 \%)$ participants in $18-24$ age group, $75(14.8 \%)$ for $45-54$ while the least value of $18(3.5 \%)$ was seen for 55 years and above. Majority of respondents $(466 ; 87.8 \%)$ were Christians, 49 (9.6\%) Muslims and $13(2.3 \%)$ were traditional religion worshippers. Also, 83 (16.3\%) of the respondents did not have formal education, 220 (43.3\%) were non-graduates while 205 (40.4\%) were University/college graduates. Most of the respondents, $199(39.2 \%)$ were self-employed followed by $153(30.1 \%)$ who were gainfully employed while $142(28.0 \%)$ and $14(2.7 \%)$ were unemployed and retired respectively. The age range of repondents was $25-45$ years (Table 1).

Table 1. Socio-demographic characteristics of study participants

\begin{tabular}{|c|c|c|}
\hline Parameter & Frequency & Percentage \\
\hline $\begin{array}{l}\text { Gender } \\
\text { Male } \\
\text { Female }\end{array}$ & $\begin{array}{l}265 \\
243\end{array}$ & $\begin{array}{l}52.2 \\
47.8\end{array}$ \\
\hline $\begin{array}{l}\text { Marital status } \\
\text { Single } \\
\text { Married }\end{array}$ & $\begin{array}{l}248 \\
260\end{array}$ & $\begin{array}{l}48.8 \\
51.2\end{array}$ \\
\hline $\begin{array}{l}\text { Religion } \\
\text { Christianity } \\
\text { Islam } \\
\text { Traditional }\end{array}$ & $\begin{array}{l}446 \\
49 \\
13\end{array}$ & $\begin{array}{l}87.8 \\
9.6 \\
2.6\end{array}$ \\
\hline $\begin{array}{l}\text { Level of education } \\
\text { No formal education } \\
\text { Non-graduate } \\
\text { Graduate }\end{array}$ & $\begin{array}{l}83 \\
220 \\
205\end{array}$ & $\begin{array}{l}16.3 \\
43.3 \\
40.4\end{array}$ \\
\hline $\begin{array}{l}\text { Employment status } \\
\text { Unemployed } \\
\text { Employed } \\
\text { Self employed } \\
\text { Retired }\end{array}$ & $\begin{array}{l}142 \\
153 \\
199 \\
14\end{array}$ & $\begin{array}{l}28.0 \\
30.1 \\
39.2 \\
2.7\end{array}$ \\
\hline
\end{tabular}


DOI: $10.21522 /$ TIJPH.2013.06.02.Art011

ISSN: $2520-3134$

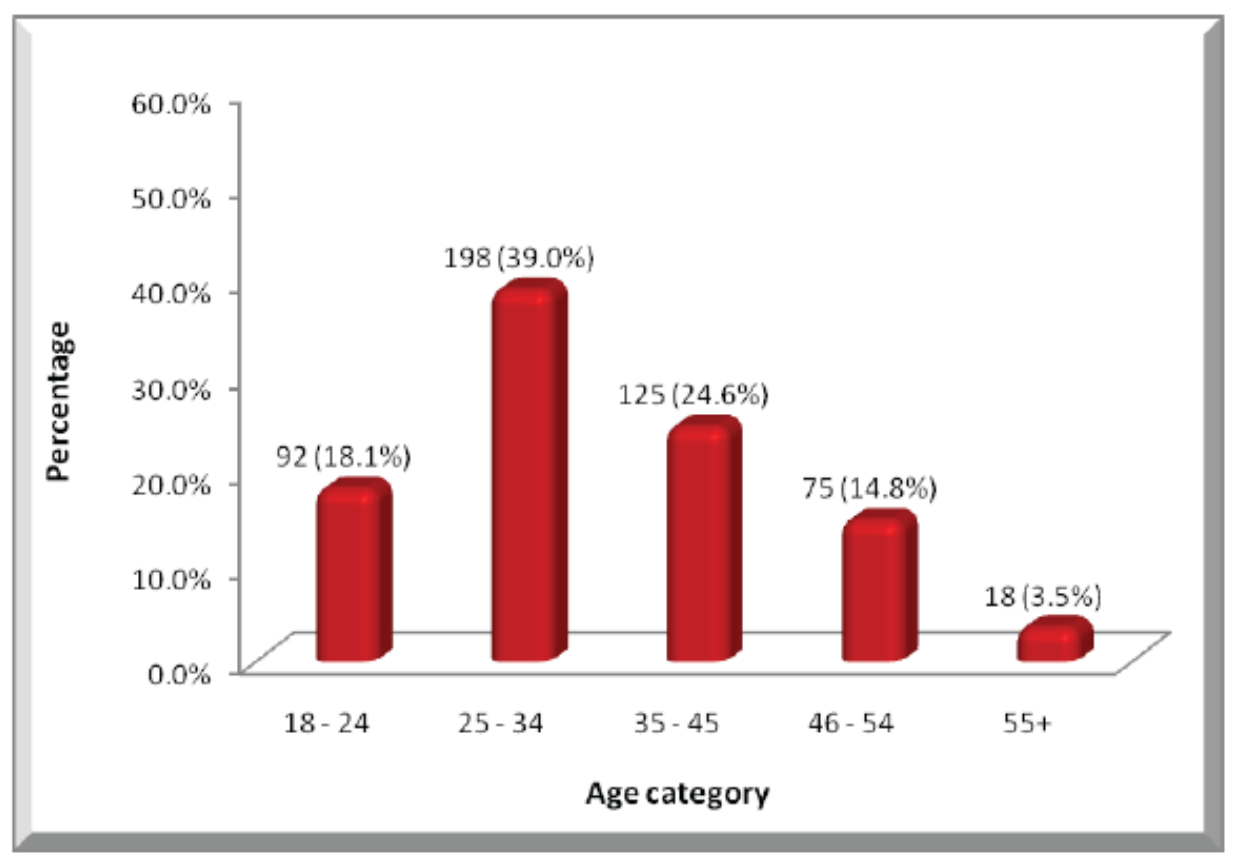

Figure 1. Age category of respondents

The age range of most repondents was 25 - 45 with the peak value of 198 (39\%) recorded for age group 25 - 34 years followed by $125(24.6 \%)$ for $35-45,92(18.1 \%)$ was seen for $18-24$ years, 75 $(14.8 \%)$ for $46-54$ while the least value of $18(3.5 \%)$ was seen for 55 years and above age group.

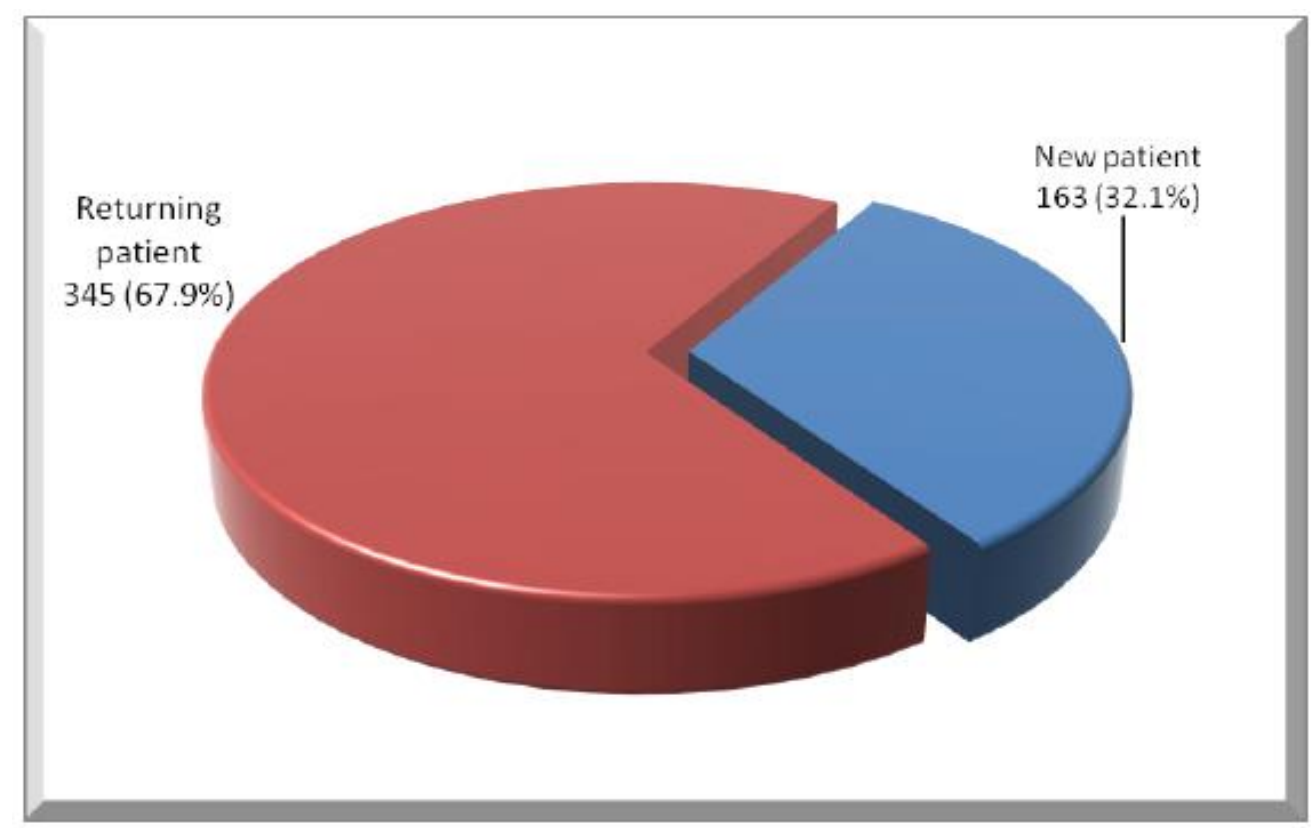

Figure 2. Patient's attendance status

More than half of the respondents were returning patients in their respective healthcare institutions, $345(67.9 \%)$ while $163(32.1 \%)$ were new patients at the time of interview.

About $87(17.1 \%)$ were in the hospital for the first time during while $421(82.9 \%)$ have been visited the hospital more than once before the day of interview. 


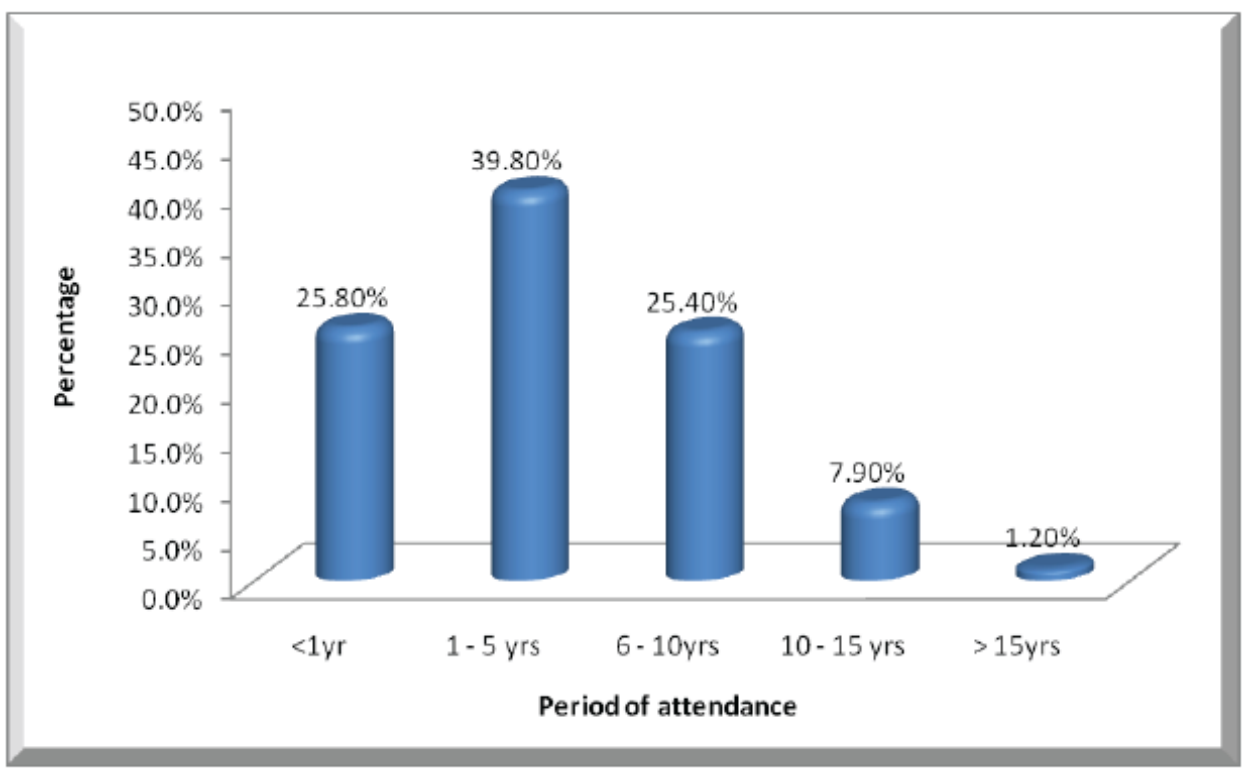

Figure 3. Period of hospital attendance

Approximately $40 \%$ of the respondents have been attending their respective hospitals for $1-5$ years, $25.8 \%$ have been attending for less than a year, $25.4 \%$ for $6-10$ years while $7.9 \%$ and $1.2 \%$ have been attending the hospital for $10-15$ years and more than 15 years respectively.

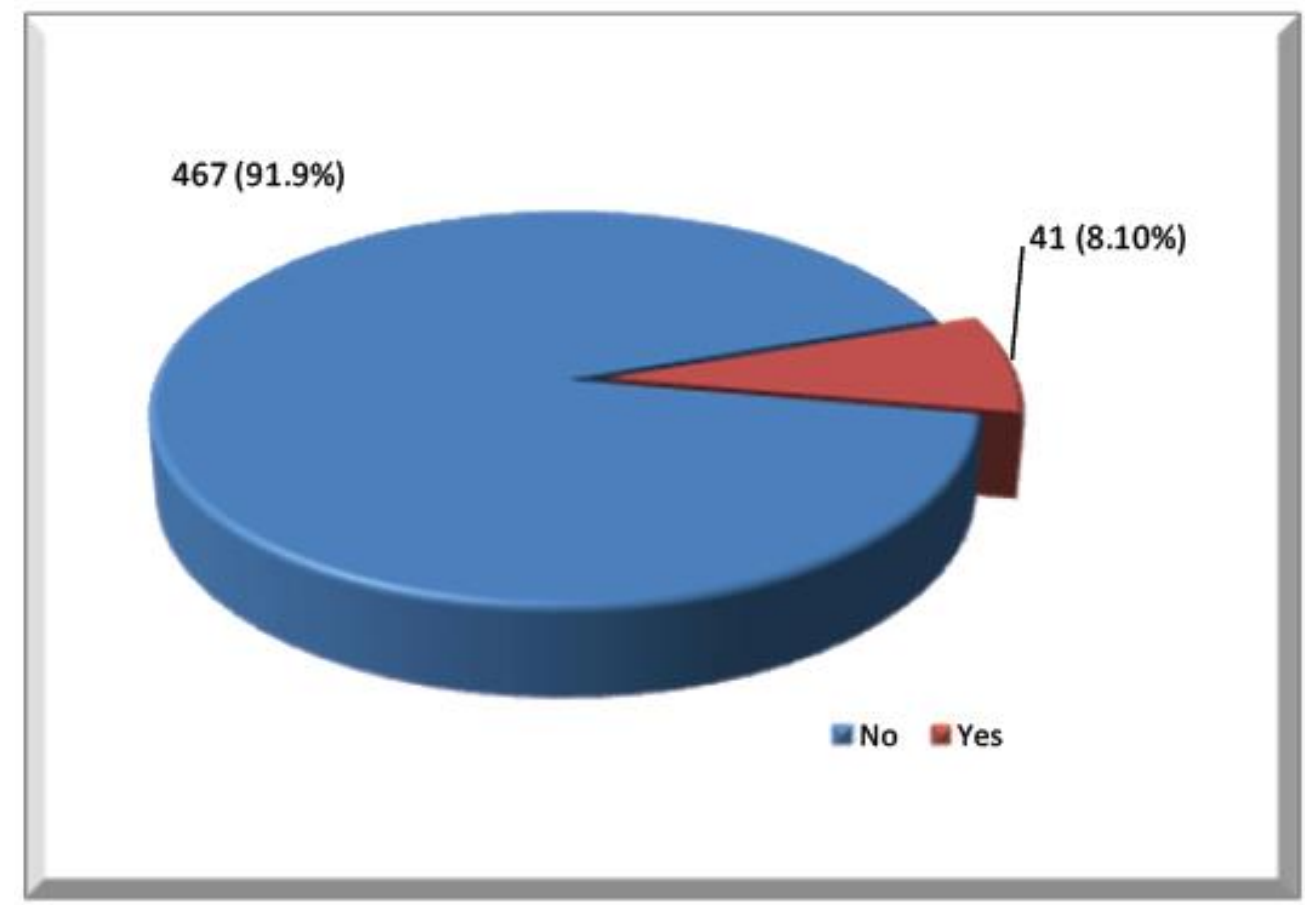

Figure 4. Do you support strike in our health institutions?

467 (91.9\%) respondents did not support strikes while just 41 (8.1\%) did. 
DOI: $10.21522 /$ TIJPH.2013.06.02.Art011

ISSN: $2520-3134$

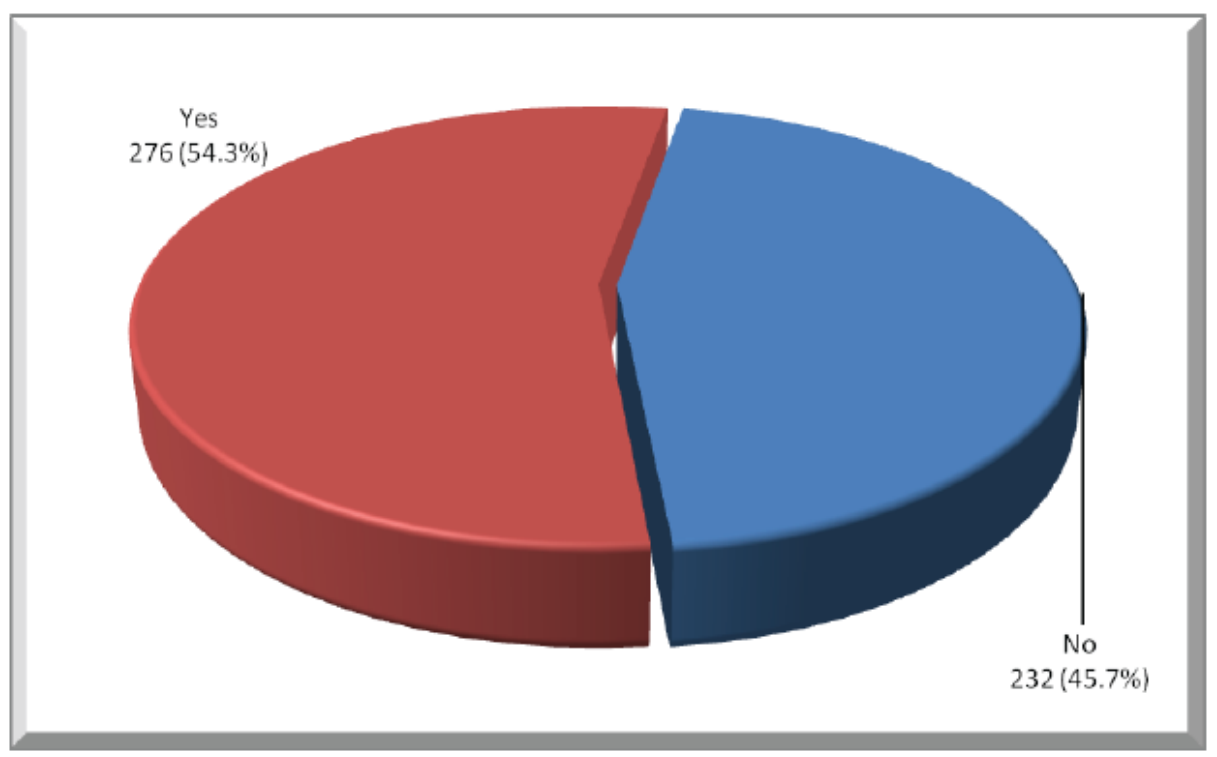

Figure 5. Do you know the reason for frequents strikes?

$276(54.3 \%)$ respondents knew the reasons for frequent labour strikes while $232(45.7 \%)$ said no

Table 2. Highlights of the major causes of strike

\begin{tabular}{llll}
\hline Parameter & Yes & No & Not sure \\
\hline $\begin{array}{l}\text { Bad Leadership/Management } \\
\begin{array}{l}\text { Inter-professional } \\
\text { disagreements }\end{array}\end{array}$ & $379(74.6 \%)$ & $88(19.5 \%)$ & $30(5.9 \%)$ \\
$\begin{array}{l}\text { Demand for higher } \\
\text { salary/wages }\end{array}$ & $312(61.4 \%)$ & $162(31.9 \%)$ & $34(6.7 \%)$ \\
$\begin{array}{l}\text { Inadequate funding of health } \\
\text { institutions }\end{array}$ & $450(88.6 \%)$ & $44(8.7 \%)$ & $14(2.8 \%)$ \\
$\begin{array}{l}\text { Inadequate tools/poor working } \\
\text { conditions }\end{array}$ & $356(70.1 \%)$ & $118(23.2 \%)$ & $34(6.7 \%)$ \\
$\begin{array}{l}\text { Failure to fulfill promises by } \\
\text { Government }\end{array}$ & $384(75.6 \%)$ & $99(19.5 \%)$ & $25(4.9 \%)$ \\
\begin{tabular}{l} 
Poor infrastructure \\
\hline
\end{tabular} & $359(70.7 \%)$ & $119(23.4 \%)$ & $30(5.9 \%)$ \\
\hline
\end{tabular}

$379(74.6 \%)$ accepted that bad leadership or bad hospital management is one of the causes of regular health workers' strikes, $88(19.5 \%)$ and 30 (5.9\%) said no and unsure respectively. On whether interprofessional disagreements are one of the factors that warrant health workers' strikes, $312(61.4 \%)$ said yes, $162(31.9 \%)$ said no while 14 (2.8\%) were not sure. Many of the respondents, $411(80.9 \%)$ were fully aware that demand for higher salaries is one of the major causes of strike while 44 (8.7\%) said no and $14(2.8 \%)$ were not sure. Inadequate funding of health institutions is one of the reasons why health workers embark on strikes, when tested, $411(80.9 \%)$ of the patients said yes, $76(15.0 \%)$ said no and $21(4.1 \%)$ were unsure. $356(70.1 \%)$ of the respondents were aware that inadequate tools/poor working conditions is one of the common bone of contention between government and health workers, which usually result to strikes. Yet 118 (23.2\%) were ignorant of this while $34(6.7 \%)$ were unsure. Failure by Government to fulfill promises made for health workers is another cause of regular strikes in health institutions, $384(75.6 \%)$ respondents were aware of this while $99(19.5 \%)$ said no and $25(4.9 \%)$ were not sure. $359(70.7 \%)$ said poor infrastructure in health institutions is one of the causes of strikes while $110(23.4 \%)$ said no and $30(3.5 \%)$ couldn't give specific answer. 


\section{Patients' access to healthcare services during strike}

Majority of the respondents (92.3\%) were unable to gain access to hospitals during strikes. Likewise, 94.5\% reported that no health worker was available to attend to them. $96.3 \%$ did not have access to laboratory services, $89.8 \%$ could not secure service in hospital pharmacies, $93.3 \%$ could not receive treatments because doctors and nurses were not available and $89.8 \%$ were unhappy attending hospitals during strikes. In overall, patient's access to healthcare services in government health institutions during strike is just $7.9 \%$. The chi square $\mathrm{P}$ value $<0.005$ negates the initial hypothesis that strike does not affect patients' access to health care services (Table 3 ).

Table 3. Access to healthcare during strike $(P=0.000)$

\begin{tabular}{|c|c|c|}
\hline Parameter & Yes & No \\
\hline $\begin{array}{l}\text { Were you able to gain access to the } \\
\text { hospital? }\end{array}$ & $39(7.7 \%)$ & $469(92.3 \%)$ \\
\hline Did health workers attend to you? & $28(5.5 \%)$ & $480(94.5 \%)$ \\
\hline $\begin{array}{l}\text { Did you meet a laboratory staff and being } \\
\text { attended to? }\end{array}$ & $19(3.7 \%)$ & $489(96.3 \%)$ \\
\hline $\begin{array}{l}\text { Do you meet a pharmacy staff and you were } \\
\text { you attended? }\end{array}$ & $52(10.2 \%)$ & $456(89.8 \%)$ \\
\hline Did you see any Doctor/Nurse working? & $34(6.7 \%)$ & $474(93.3 \%)$ \\
\hline Were you able to carry out laboratory tests? & $47(9.3 \%)$ & $461(90.7 \%)$ \\
\hline Were you able to collect all your drugs? & $52(10.2 \%)$ & $456(89.8 \%)$ \\
\hline $\begin{array}{l}\text { Will you be happy to come to this health } \\
\text { facility during strikes? }\end{array}$ & $52(10.2 \%)$ & $456(89.8 \%)$ \\
\hline Overall & $7.9 \%$ & $92.1 \%$ \\
\hline
\end{tabular}

Table 4. Awareness of causes of labour strikes with level of education $(\mathrm{P}=0.000)$

\begin{tabular}{l|lll}
\hline $\begin{array}{l}\text { Aware of reasons } \\
\text { for frequent } \\
\text { strikes }\end{array}$ & \multicolumn{3}{|l}{ Level of Education $(\%)$} \\
\cline { 2 - 4 } & $\begin{array}{l}\text { No formal } \\
\text { education }\end{array}$ & Non-graduate & Graduate \\
\hline Yes & $38(45.8 \%)$ & $97(44.1 \%)$ & $141(68.8 \%)$ \\
No & $45(54.2 \%)$ & $123(55.9 \%)$ & $64(31.2 \%)$ \\
Total & $83(100.0 \%)$ & $220(100.0 \%)$ & $\begin{array}{l}205 \\
(100.0 \%)\end{array}$ \\
\hline
\end{tabular}

Awareness of the causes of industrial actions is higher among graduates, $68.8 \%$ than $44.1 \%$ and $45.8 \%$ recorded for non-graduates and the group with no formal education respectively. The percentage of those that have no knowledge of causes of strikes is higher among non-graduates (55.9\%) than among group with no formal education $(52.2 \%)$ but the value seen for graduates is below thirty two percent $(31.2 \%)$. 
DOI: $10.21522 /$ TIJPH.2013.06.02.Art011

ISSN: $2520-3134$

Table 5. Awareness of causes of labour strikes with age $(\mathrm{P}=0.000)$

\begin{tabular}{|c|c|c|c|c|c|}
\hline \multirow{2}{*}{$\begin{array}{l}\text { Aware of } \\
\text { reasons for } \\
\text { frequent } \\
\text { strikes }\end{array}$} & \multicolumn{5}{|c|}{ Age Category (\%) } \\
\hline & $18-24$ & $25-34$ & $35-44$ & $45-54$ & $55+$ \\
\hline Yes & $36(39.1 \%)$ & $99(50.0 \%)$ & $75(60.0 \%)$ & $55(73.3 \%)$ & $11(61.1 \%)$ \\
\hline No & $56(60.9 \%)$ & $99(50.0 \%)$ & $50(40.0 \%)$ & $20(26.7 \%)$ & $7(38.9 \%)$ \\
\hline Total & $92(100.0 \%)$ & $198(100.0 \%)$ & $125(100.0 \%)$ & $75100.0 \%$ ) & $18(100.0 \%)$ \\
\hline
\end{tabular}

Percentage awareness was $39.1 \%$ among $18-24$ years age group, for $25-34$, the percentage increased to $50 \%$, higher percentage was seen for $35-45$ with $60 \%$, for $45-54$, it was $73.3 \%$ while the percentage dropped to $61.1 \%$ for group of over 55 years of age but still higher than the younger age group of $10-34$ years old.

Table 5b. Pairwise comparison of age based on awareness of causes of strike

\begin{tabular}{lllll}
\hline Age Category 1 & Age Category 2 & Mean diff. & Std. Error & P value \\
\hline $18-24$ & $25-34$ & -0.109 & 0.062 & 0.079 \\
& $35-44$ & $-0.209^{*}$ & 0.067 & 0.002 \\
& $45-54$ & $-0.342^{*}$ & 0.076 & 0.000 \\
& $55+$ & -0.220 & 0.126 & 0.082 \\
\hline $25-34$ & $35-44$ & -0.100 & 0.056 & 0.074 \\
& $45-54$ & $-0.233^{*}$ & 0.066 & 0.000 \\
& $55+$ & -0.111 & 0.120 & 0.357 \\
\hline $35-44$ & $45-54$ & -0.133 & 0.071 & 0.063 \\
& $55+$ & -0.011 & 0.123 & 0.928 \\
\hline $45-54$ & $55+$ & 0.122 & 0.128 & 0.342 \\
\hline
\end{tabular}

The mean difference is significant at the 0.05 level.

There is no statistical difference in the level of awareness of the causes of strike between age groups $18-24$ and $25-34,18-24$ and 55+, $25-34$ and $35-44,25-34$ and 55+, $35-44$ and 55+, $45-54$ and 55+ $(\mathrm{P}>0.05)$. However, the level of awareness is higher among $35-44$ and $45-54$ than among 18 -24 . Likewise, awareness level is higher among $45-54$ than $25-34(\mathrm{P}<0.05)$. In overall, the highest level of awareness is seen for $45-54$ age group while the least awareness is seen for $18-24$ age group.

Table 6. Awareness of causes of labour strike with support for strike $(P=0.004)$

\begin{tabular}{l|ll}
\hline Do you support strikes? & \multicolumn{2}{|l}{$\begin{array}{l}\text { Do you know the reason for frequents } \\
\text { strikes? (\%) }\end{array}$} \\
\cline { 2 - 3 } & Yes & No \\
\hline \multirow{2}{*}{ Yes } & $31(11.2 \%)$ & $10(4.3 \%)$ \\
No & $245(88.8 \%)$ & $222(95.7 \%)$ \\
Total & $\mathbf{2 7 6 ( 1 0 0 . 0 \% )}$ & $\mathbf{2 3 2}(\mathbf{1 0 0 . 0 \% )}$ \\
\hline
\end{tabular}


$88.8 \%$ of those who know the reasons for frequent labour strikes in health institutions do not support strike while $11.2 \%$ support strike. (95.7\%) do not know the reasons for strikes and yet did not support strikes while $4.3 \%$ of those who do not know the reasons for strike support strikes.

Table 7. Access to healthcare/service delivery during labour strike $(\mathrm{P}=0.000)$

\begin{tabular}{|c|c|c|}
\hline Parameter & Yes & No \\
\hline Were you able to gain access to the hospital? & $39(7.7 \%)$ & $469(92.3 \%)$ \\
\hline Did health workers attend to you? & $28(5.5 \%)$ & $480(94.5 \%)$ \\
\hline $\begin{array}{l}\text { Did you meet a laboratory staff and being } \\
\text { attended to? }\end{array}$ & $19(3.7 \%)$ & $489(96.3 \%)$ \\
\hline $\begin{array}{l}\text { Do you meet a pharmacy staff and you were } \\
\text { you attended? }\end{array}$ & $52(10.2 \%)$ & $456(89.8 \%)$ \\
\hline Did you see any Doctor/Nurse working? & $34(6.7 \%)$ & $474(93.3 \%)$ \\
\hline Were you able to carry out laboratory tests? & $47(9.3 \%)$ & $461(90.7 \%)$ \\
\hline Were you able to collect all your drugs? & $52(10.2 \%)$ & $456(89.8 \%)$ \\
\hline $\begin{array}{l}\text { Will you be happy to come to this health } \\
\text { facility during strikes? }\end{array}$ & $52(10.2 \%)$ & $456(89.8 \%)$ \\
\hline Overall & $7.9 \%$ & $92.1 \%$ \\
\hline
\end{tabular}

$92.3 \%$ were not able to gain access to hospitals during strikes while only $7.7 \%$ could. Only $5.5 \%$ said health workers attended to them during strikes while $94.5 \%$ were not attended to. $96.3 \%$ could not see staff to attend to their needs in laboratories while only $3.7 \%$ were able to gain attention. Only $10.2 \%$ said they met pharmacy staff and were attended to while $89.8 \%$ did not meet them. $6.7 \%$ saw Doctors/Nurses working during strikes while $93.3 \%$ did not. Only $9.3 \%$ could carry out laboratory tests while $90.7 \%$ could not. $10.2 \%$ could collect all their drugs while $89.8 \%$ could not. $10.2 \%$ will be happy coming to health institutions during strikes while $89.8 \%$ will not.

Table 8. Effect of access to service delivery during laboour strikes $(\mathrm{P}=0.000)$

\begin{tabular}{lll}
\hline Parameter & Yes & No \\
\hline $\begin{array}{l}\text { Do you go to private hospital during } \\
\text { strikes? }\end{array}$ & $384(75.6 \%)$ & $124(24.4 \%)$ \\
$\begin{array}{l}\text { Do you spend more money? } \\
\begin{array}{l}\text { Do you agree that there is disruption in } \\
\text { patients care? }\end{array}\end{array}$ & $375(73.8 \%)$ & $133(26.2 \%)$ \\
$\begin{array}{l}\text { Do you agree that there is high rate of } \\
\text { referral of patients to private hospitals } \\
\text { during strike? }\end{array}$ & $339(66.7 \%)$ & $169(33.3 \%)$ \\
\hline
\end{tabular}

$384(75.6 \%)$ do go to private hospitals for treatment during strikes while only 124 (24.4\%) do not. $374(73.8 \%)$ spend more money during strike wile $133(26.2 \%)$ do not. $399(66.7 \%)$ said there is disruption in patients' care during strike while 169 (33.3\%) said no. 397 (78.1\%) said there is high rate of referral during strikes while 111 (21.9\%) said no. 
DOI: $10.21522 /$ TIJPH.2013.06.02.Art011

ISSN: $2520-3134$

\section{Discussion}

Access to healthcare/service delivery during strike revealed a vital finding from the present study in that all the variables agreed to the fact that strike has effect on access to service delivery with all parameters having less than $10.5 \%$. This finding is a pointer to the poor health care quality during strikes (Ogunbanjo et al, 2009) and it also lay credence to the fact that many lives are lost during strikes action as hospital gates are under lock and key with few health workers attending to emergencies (Adebimpe et al, 2010). Health worker abandoned their duty post leading to sudden disruption in service delivery with many in-patients not completing their medication before discharged with no access to drugs and laboratory services for monitoring of their health conditions during strikes. Retention and adherence to drugs are very low since patients could not continue with medication as they could not have access to the pharmacy or laboratory to monitor their health condition. Low access to service delivery in government health institution sent many patients to private hospitals, traditional birth attendants and herbalist alike, it also encouraged medical tourism outside the country by the rich and people in government who can afford cost (Safiya, 2015). Hence, it is evidence from the outcome of the study $(10.2 \%)$ that patients are not happy coming to health facility during strikes. This is evidently clear that patients are not satisfy and unhappy during strike actions to access health institutions during strike knowing fully well that there will be no service delivery or at best only skeletal services. This study focused mainly on secondary health institutions in Cross River State which is not enough to generalize it to Nigeria. Subsequent study will need to focus on the whole health institution in Nigeria which include primary health care and tertiary health institutions.

\section{Conclusion}

Health care workers especially facility staff in in essential services like accidents and emergency section, laboratory and pharmacy sections need to demonstrate favourable attitude towards a looming strike by making sure that patients have access to services delivery and there is access to health commodities especially drugs and laboratory services during strike to improve quality of care in our health institution. In conclusion, labour strike has serious effects on access to service delivery in secondary health institutions and all effort should be in place to reduce the effect on service delivery.

\section{References}

[1]. Adebimpe WO, Owolade OA, Adebimpe MA. (2010). Health worker's perception of the use of strikes as a tool for dispute resolution in Lagos State, Nigeria SocSci Public Policy. 2010; 2: 19-23.

[2]. Adesina, J.O (2003). Labour Policies of a Neo-Fuhrer State: the Nigerian Case, Annals of the Social Science Academy 14(15):49-66.

[3]. Adeyemi, T.O. (2009). Principals' Management of Conflicts in Public Secondary Schools in Ondo State, Nigeria: A Critical Survey. Education Research and Review, 4 (9): 418-426.

[4]. Botero JC, Djankov S, La Porta R, López de Silanes F, Shleifer A. (2004). The Regulation of Labor. The Quarterly Journal of Economics. 2004; 119(4):1339-82. doi: 10.1162/0033553042476215. http://qje.oxfordjournals.org/content/119/4/1339.full.pdf+html.

[5]. Bloomsbury, G. (2002). A strategy for Industrial relations in Great Britain, Britain Journal of Industrial Relations 10(20):12-20.

[6]. Chima, O (2010). Nigerian Health Watch. Patients suffer as Nigerian healthcare workers continue strikes; who cares? Wednesday, 25 August 2010.

[7]. Dauda, Y.A (2007). Employment of Independent Arbitrators in the Management of Trade Disputes and Industrial Crisis in Nigeria. Nigerian Journal of Labour Law and Industrial Relations, 1(1):26-44.

[8]. Davies A, Rotimi A.D., Adenike A.O, Asa A, Adedapo A, Muktar G, Jacob K.O, Oluwafemi O, and Alexander I.(2017), Health workforce and governance: the crisis in Nigeria, Hum Resour Health. 2017; 15: 32.

[9]. Encyclopedia of the Nations. Nigeria-working conditions [Online]. (n.d); http://www.nationsencyclopedia.com/economies/Africa/Nigeria-WORKING-

CONDITIONS.html\#ixzz3Q0J8zoCc. Accessed 10 Apr 2015.

[10]. Fajana, S. (2000). Industrial Relations in Nigeria: Theory and Features 2ed, Lagos: Labofin\& Co.

[11]. Fashoyin, T. (1992). Industrial Relations in Nigeria, $2^{\text {nd }}$ Edition, Ikeja: Longman Ltd. 
Texila International Journal of Public Health Volume 6, Issue 2, Jun 2018

[12]. Fashoyin T. (2008). Management of disputes in the public service, southern African Journal of Industrial Relations 50(40):578-594.

[13]. George Padmore (2015). The voice of coloured labour; speeches and reports of colonial delegates to the World Trade Union Conference, Manchester, PANAF Services Ltd. 1945; Available from https://www.marxists.org/archive/padmore/1945/labour-congress/. Accessed 10 Apr 2015.

[14]. IBM Corp. IBM SPSS Statistics for Windows, Version 20.0. Armonk: IBM Corp; 2012.

[15]. Keating NL, Green DC, Koa AC, Gazmararian JU, Wu VY and Cleary PD (2002): How are patients' specific ambulatory care experiences related to trust, satisfaction and considering changing physicians, Gen Intern Med 17 (1): $29-39$.

[16]. Lauritsen JM. (2015) editor. EpiData data entry, data management and basic statistical analysis system. Odense Denmark, EpiData Association, 2000-2008. Http://www.epidata.dk. Accessed 13 Apr 2015.

[17]. Ogunbanjo G.A. and Knapp van Bogaert D. (2009), Doctors and strike action: can this be morally justifiable? S AfrFamPract. 2009; 51(4):306-8. doi: 10.1080/20786204.2009.10873869.

[18]. Olawuyi, J.F (1996).Choosing the study subjects and sampling. In biostatistics, a foundation course in health sciences. First edition. Yotson consult publishers Ibadan, 110-118.

[19]. Oleribe OO, Ezieme IP, Oladipo O, Akinola EP, Udofia D, Taylor-Robinson SD. Industrial action by healthcare workers in Nigeria in 2013-2015: an inquiry into causes, consequences and control-a cross-sectional descriptive study. Hum Resour Health. 2016; 14(1):46. doi: 10.1186/s12960-016-0142-7. [PMC free article][PubMed][Cross Ref].

[20]. Otobo, D. (2000). Industrial Relations Theory and Controversies. Lagos: Malthouse Press.

[21]. Orr, R. D., N. Pang, E. D. Pellegrino, and M. Siegler. (1997). "Use of the Hippocratic Oath: A Review of Twentieth-Century Practice and a Content Analysis of Oaths Administered in Medical Schools in the U.S. and Canada in 1993." The Journal of Clinical Ethics 8 (Winter): 377-388.

[22]. Rennie S. (2009). An epidemic of health care worker strikes. Lagos: Global consult.

[23]. Safiya I. Dantiye (2015), Strike: Nigerians at the mercy of health workers, doctors.

[24]. safiyadantiye@ dailytrust.com | Publish Date: Jan 2, 2015 4:00AM.

[25]. Stelfox HT, Ghandi TK, Orav EJ, and Gustafson ML (2005): The relation of patient satisfaction with complaints against physicians and malpractice law suits. Am J Med 118 (10): 1126 - 33.

[26]. Stuart, K. (2010). Professionalism and healthcare strikes. South African, Journal of Bioethics and Law 3(1):14-2. 


\title{
Consistent Condom Use in HIV/AIDS Patients Receiving Antiretroviral Therapy in Northwestern Ethiopia: Implication to Reduce Transmission and Multiple Infections - A Critical Review of Article
}

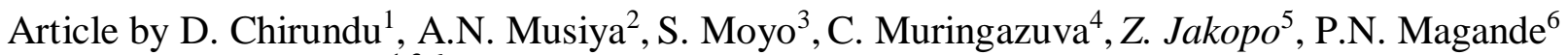 \\ 1,3,6 Kadoma City Health Department, Zimbabwe \\ ${ }^{2}$ Department of Community Medicine, University of Zimbabwe, Zimbabwe \\ ${ }^{4}$ Zimbabwe Defence Forces $H Q$, Zimbabwe \\ ${ }^{5}$ Kadoma General Hospital, Zimbabwe \\ ${ }^{6}$ Kadoma City Health Department, Zimbabwe \\ E-mail:dchirundu@me.com ${ }^{1}$,drnyashaadrianmusiya@gmail.com ${ }^{2}$,skhaemoyo@gmail.com ${ }^{3}$, \\ muringac@gmail.com ${ }^{4}$,jzorodzai@gmail.com ${ }^{5}$,pmagande@gmail.com ${ }^{6}$
}

Source: Zewdneh Shewamene et. al. 2015, "Consistent condom use in HIV/AIDS patients receiving antiretroviral therapy in northwestern Ethiopia: implication to reduce transmission and multiple infections" HIV/AIDS- Research and Palliative Care, 2015:7 119-124 downloaded 10 August 2015 http://www.dovepress.com/articles.php?article_id=21307

\begin{abstract}
Introduction: This is a critical review of an article by Zewdneh Shewamene published in the July 2015. The central theme is that consistent condom use among HIV patients is important in preventing transmission of HIV.

Article summary: The premise of the authors is that consistent condom use among HIV infected is critical for interrupting transmission of HIV and acquisition of resistant strains of HIV. Among the 317 respondents, condoms awareness was 96.2\%. Independent factors for consistent use were, male sex (AOR=6.87; $p=0.001)$, urban residency, $(A O R=4.65 ; p=0.001)$, a higher education attainment $(A O R=8.98 ; p=0.001)$, and prolonged duration on $A R T(A O R=3.91 ; p=0.001)$. The conclusion was that some HIV infected people were not using condoms.

Article critique: The article maybe considered as objective, and unbiased due to the peer review process. The journal that published it is indexed on PubMed, and, Embase, among others. That the article was published in a journal for those with an interest in HIV and palliative care makes it relevant for HIV programming particularly in Africa where HIV burden is high. The objectives are well spelt, and the methodology is easy to follow. Only verbal consent was obtained from the respondents contrary to the dictates of the Belmont report that requires written informed consent.

Conclusion: The articles contributed to literature and can provide a basis of improving future studies of a similar nature. However, it is suggested that measurement of condom use should be serial and be recoded to a dichotomous variable in analysis.
\end{abstract}

Keyword: Condoms, Ethiopia, HIV.

\section{Introduction}

This is a critical review of an article entitled "Consistent condom use in HIV/AIDS patients receiving antiretroviral therapy in northwestern Ethiopia: implication to reduce transmission and multiple infections" published in the July 2015 issue of the HIV/AIDS- Research and Palliative Care journal. The corresponding author is Zewdneh Shewamene. This review will firstly give an overview of the article. Secondly the article structure will be reviewed on the presentation of the content, the alignment and format of the article. Thirdly 
DOI: $10.21522 /$ TIJPH.2013.06.02.Art012

ISSN: $2520-3134$

the article will be critiqued looking at the authority, accuracy, currency, relevance, objectivity and coverage. Tables will also be looked at before judging the article's accessibility and credibility.

The central theme of the article is that consistent condom use among HIV/AIDS patients is an important method of preventing transmission and acquiring of infections. This includes sexually transmitted infections including HIV, and reinfection with resistant strains of HIV. It is against this background that the frequency and determinant factors of consistent condom use were investigated among attendees of a university Antiretroviral Therapy clinic in Ethiopia. This is generally a well thought and presented article. It is very relevant to Sub-Saharan Africa which accounts for almost $67 \%$ of the global total of new HIV infections (UNAIDS 2017). Under such circumstances correct and consistent condom use is a feasible method of preventing reinfection (Population Action International 2002).

\section{Article summary}

The background of HIV globally and in Ethiopia is proffered. An elaboration is done on availability of free condoms in the country. The premise of the authors is that consistent condom use among HIV infected is critical as it prevents transmission of HIV to uninfected partners, acquisition of resistant strains of HIV, and, impacts on community HIV prevalence.

The study was a hospital based analytical cross-sectional study that had 317 randomly selected respondents. Data were collected using a pretested questionnaire. The dependent variable was consistent use of condom in every sexual encounter in the six months prior to the study. Independent variables included socio-demographic variables and general awareness regarding condoms. Data analysis was done using SPSS. The study was funded and approved by the University of Gondar in Ethiopia. Verbal consent was obtained from participants.

Among the 317 respondents, $49.8 \%$ were males and 50.2\% (159) were females. Condom awareness was 96.2\%. Independent factors for consistent condom use were, male sex (AOR=6.87; $\mathrm{p}=0.001$ ), urban residency, $(\mathrm{AOR}=4.65 ; \mathrm{p}=0.001)$, a higher education attainment $(\mathrm{AOR}=8.98 ; \mathrm{p}=0.001)$, and prolonged duration on $\mathrm{ART}(\mathrm{AOR}=3.91 ; \mathrm{p}=0.001)$.

The authors concluded that some HIV infected people were not using condoms. However, in the discussion the "implication to reduce transmission and multiple infections" as alluded to in the title was not articulated. The article nevertheless, is well presented, has 13 subheadings, ensuring wide coverage of issues. There are citations throughout the article that allows the reader to evaluate findings and thesis against other works.

\section{Article structure}

The article has an abstract. In the main body there is the introduction that covered the literature review, objectives and rationale of the study. Under the methodology, subheadings of study area, study design and sampling, data collection procedures are covered. The dependent and independent variables are well defined under the data collection section. Data analysis is also another subheading within the methodology. Ethics section is also included. Under the results section, there are 3 subheadings covering study population characteristics, general condom awareness and the determinants of consistent condom use which are presented as tables. Recommendations and conclusions form the last part of the main body. There is a section on acknowledgements, author contributions and disclosure. The structure is therefore coherent and allows the articulation of pertinent issues in detail and depth.

\section{Article critique}

\section{Authority}

The article was published by an international peer reviewed open access journal that focuses on research in HIV, "The Journal of HIV/AIDS Research and Palliative care (ISSN 1179-1373)" This may be considered to be an objective, unbiased publication due to the peer review process. It is indexed on PubMed, 
Embase, Directory of Open Access Journal and the OAlster Open Initiative. These are all credible databases. The journal is also a member of the Committee on publication ethics.

The corresponding author was a member of the faculty of pharmacology at University of Gondor in Ethiopia. He holds a master's degree in Pharmacology and is currently study for his $\mathrm{PhD}$ with University of Western Sydney Australia. He has published 27 peer reviewed articles in a variety of journals. The project under review was funded by the University of Gondor; this affords it further credence.

\section{Accuracy}

The article is based on field work that was done from April to May 2013. It is backed up by a reference list that is cited in text and can be easily followed by reader. The peer review process, editorial processing and referencing, all contributed to the accuracy of the study. Under the author contribution it is indicated that "All authors reviewed and approved the final manuscript prior to submission and agree to be accountable for all aspects of the work." This is a further attestation that the authors stand by the accuracy of their work.

\section{Currency}

The article was published in July 2015. However, its date of submission was not reported. Data were collected between April and May 2013. All these factors make the article relatively current.

\section{Relevance}

This article was published in a peer reviewed journal for those with an interest in HIV and palliative care. It was written to inform both researchers and those in HIV programming. It is very relevant for HIV programming particularly in Africa which is burdened with a high prevalence of HIV. Under the circumstances condoms are a recommended intervention (Lurie et. al. 2008). In the developed world (and some parts of Africa) it can be used for programming in men who have sex with men. However, looking at the title and the content, the articles falls short of articulating the "implication to reduce transmission and multiple infections".

\section{Objectivity}

The objectives are clear and well spelt out. The methodology is easy to follow, and the study can be repeated in other settings. Clear methodology and objectives reduces bias and facilitates repeatability. However, the outcome variable consistent condom use was a dichotomous yes/ no. Given that the condom use is a continuous phenomenon, one would argue that this dichotomous measurement of condom use is not a sensitive way to measure condom use. When several response alternatives are provided to a condom frequency question, a researcher can gain reasonable insight into how often one uses condoms (Noar et. al 2006).

The recall period in the study was six months. Whilst a longer recall period may provide a better representation of the sexual behavior, little research has demonstrated the accuracy of recall periods of more than 3 months (Sheeran et. al. 1994 and Schroder et. al. 2003). This may introduce recall bias. It would also have made the article more specific to indicate if the intercourse was vaginal sex or anal sex or it was man having sex with man.

Whilst ethical clearance was obtained from the University, it is not clear if it were ordinary university authorities or a university ethical review board. Only verbal consent was obtained from the respondents contrary to the dictates of the Belmont report, that requires written informed consent (The National Commission for the Protection of Human Subjects of Biomedical and Behavioral Research (1978) and William et. al. 2008) ${ }^{1}$. The respondents were clients seeking care at a hospital. It is a known that there is a difference among those who seek care and those who do not. This may affect programming as people with a shorter duration or not on ART are not likely to use condoms consistently (Alene et. al. 2014). Nevertheless, the article can be deemed objective. The references cited were published between 1997 and 2011. However, citation of later publications would have made it more objective. 
DOI: $10.21522 / \mathrm{TIJPH} .2013 .06 .02 . A r t 012$

ISSN: $2520-3134$

\section{Stability}

The paper is stable since it was published in a peer reviewed journal. Other researchers and program managers can depend on it for guidance.

\section{Analysis of tables}

There were no graphs in the article. However, there are 3 tables that are adequately labelled and abbreviations appearing in them are explained e.g. AOR.

\section{Recent advances related to the topic}

Condom use is documented as one of the measures that can prevent sexual transmission of HIV (UNAIDS 2003; UNFPA 2002 and Cohen et. al 1999) ${ }^{1}$. In 2007, the Global Alliance on Condom use identified social and cultural, legal/policy, economic/financial and structural barriers as barriers to condom use (Drezin et. al 2007 and Daly et. al 2009). According to UNAIDS (2006) condoms if used correctly and consistently, can reduce the risk of sexual transmission by 80-90 percent. So far, condoms are the only product that can effectively protect against HIV and other sexually transmitted infections (Population Action International 2002). With the improved access to ART some infected people now have suppressed viral loads. With the subsequent improvement in health-related quality of life some of the HIV infected people are engaging in sexual risky behavior, and, this calls for accelerated condom promotion in this subpopulation (Stole et. al.2001 and Pedraza et. al. 1999).

Nonetheless, several studies in different geographical locations have reported low condom use among the HIV infected. Moazen et. al, (2017) reported a consistent condom use rate of $16.7 \%$ in a study carried out in Iran. In a study carried out in Zimbabwe (2016), Chirundu reported a 37\% and 52\% consistent condom use among males and females on ART respectively. Perceptions that condoms reduce pleasure; perception that there is no need for condoms in long term unions all militated against consistent condom use. Macharia et. al. (2017) also reported reduced sexual pleasure and non-disclosure of HIV status as barriers to condom use among the HIV infected. Furthermore, Goncalves et. al. in a system review published in 2017 concluded that behavioural interventions alone may not be adequate to promote consistent condom use among the HIV infected.

Nakaie et. al. (2014) in a study done in Cambodia, reported that the patient's formal education, gender, type of partner (regular or casual) or number of sexual partners were not significantly associated with consistent condom use but the "ability to ask a partner to use condom at every sexual intercourse" was a predictor. In an Italian study among the HIV infected, the prevalence of condom use was 44\%. Less income, lower education and having one child were negatively associated with condom use. Alene et. al (2014) in a study done in Ethiopia found out that those who had a higher level of education and have been on ART for longer periods were more likely to report condom use. Lurie et. al. (2008) in a study among the HIV infected patients in South Africa found predictors of consistent condom being regular partners, urban residence, and higher education levels disclosure and younger age.

In Zimbabwe McClellan et. al. (2010). Reported low condom use was among HIV-positive, aboveaverage educated women. Less than half reported ever-use of condoms, being a younger woman, being currently married, living with current husband/partner, religion, longer duration since HIV diagnosis (years), disclosure of HIV status to current husband/partners, and greater number of sexual partners in the past year predicted consistent condom use.

Canto et. al (2015) in a study carried out in the Dominican Republic found no association between alcohol consumption and unprotected use. This is contrary to previous reports (Kalichman S.C. 2000. and Crepaz N. \& Marks G. 2002).

\section{Conclusion}

This was a critical review of Zewdneh Shewamene's article "Consistent condom use in HIV/AIDS patients receiving antiretroviral therapy in northwestern Ethiopia: implication to reduce transmission and 
multiple infections". The content, structure and limitations of the study were analyzed and and suggestions made. The article has contributed to literature and can provide a basis of improving future studies of a similar nature. However, it is suggested that measurement of condom use should be serial and be recoded to a dichotomous variable in analysis. It is also suggested that the recall period be 3 months or less as recommended by other studies. Condoms may be used for vaginal or anal sex and it would give the reader more clarity if same is specified. A study on condom use among HIV infected in the general population not seeking care is also recommended.

\section{Acknowledgements}

We acknowledge the contribution of Prince Matambo and Patrick Makovere for typesetting this manuscript.

\section{References}

[1]. Alene et. al. (2014). Consistent condom use among sexually active HIV-positive women in Amhara region, Ethiopia. Open Access Journal of Contraception 2014:5 85-90.

[2]. Canto et. al. (2015) Substance Use and Condom Use among the HIV Population at Clínica de Familia La Romana, Dominican Republic. JGH Vol. V Issue I.

[3]. Chirundu Daniel (2016). Condom Use among HIV infected clients seeking care at Rimuka Integrated HIV and Tuberculosis Site, Kadoma, Zimbabwe 2015. South American Journal of Public Health Special Edition.

[4]. Cohen D et. al. (1999) Condom Skills, Education and Sexually Transmitted Disease Re-infection. Journal of Sex Research, 28 (1), 139-144.

[5]. Crepaz N. and Marks G. (2002). Towards an understanding of sexual risk behavior in people living with HIV: a review of social, psycho- logical, and medical findings. AIDS, 16(2), 135-49.

[6]. Daly et. al. (2009), Callie Long and Mary Ann Torres. Barriers to condoms - Implementing and documenting advocacy strategies. International Council of AIDS Service Organizations (ICASO).

[7]. Drezin et. al. (2007). Barriers to Condom Access: setting an advocacy agenda. International Council of AIDS Service Organizations (ICASO).

[8]. Haddad et. al. (2018) Factors associated with condom use among men and women living with HIV in Lilongwe, Malawi: a cross sectional study BMJ Sex Reprod Health2018; 44:42-53.

[9]. Kalichman S.C. (2000). HIV transmission risk behaviors of men and women living with HIV-AIDS: prevalence, predictors, and emerging clinical interventions. Clinical Psychology Science and Practice, 7, 32-47.

[10]. Lurie et. al. (2008) Sexual Behavior and Reproductive Health among HIV-Infected Patients in Urban and Rural South Africa; J Acquir Immune Defic Syndr.

[11]. Macharia et al. (2017) Barriers of Condom Use among HIV Positive Women at Thika Level 5 Hospital, Kenya J AIDS Clin Res 2017, 8:8 DOI: 10.4172/2155-6113.1000722.

[12]. McClellan et. al. (2010). Fertility desires and condom use among HIV-positive women at an antiretroviral rollout program in Zimbabwe. Afr J Reprod Health: 27-35.

[13]. Noar et. al. (2006) Condom Use Measurement in 56 Studies of Sexual Behavior: Review and Recommendation: Archives of Sexual Behavior.

[14]. Naomi Nakaie et. al. (2014) Family planning practice and predictors of risk of inconsistent condom use among HIV-positive women on anti-retroviral therapy in Cambodia: BMC Public Health 2014, 14:170

[15]. Population Action International. (2002) Condoms count. Meeting the need in the era of HIV/AIDS. The PAI report card.

[16]. Pedraza MA et. al. (1999) Heterosexual transmission of HIV-1 is associated with high plasma viral load levels and a positive viral isolation in the infected partner. J Acquir. Immune Defic Syndr 21: 120 - 125.

[17]. Schroder, K. E. et. al. (2003). Methodological challenges in research on sexual risk behavior: I. Item content, scaling, and data analytical options. Annals of Behavioural Medicine, 26, 76-103.

[18]. Sheeran, P., \& Abraham, C. (1994). Measurement of condom use in 72 studies of HIV-preventive behaviour: a critical review. Patient Education and Counseling, 24(3), 199-216. DOI: 10.1016/0738-3991(94)90065-5. 
DOI: $10.21522 / \mathrm{TIJPH} .2013 .06 .02 . A r t 012$

ISSN: $2520-3134$

[19]. Stole IG et.al. (2001) Increase in sexually transmitted infections among homosexual men in Amsterdam in relation to HAART. Sex Transm Infect 77: $184-186$.

[20]. The National Commission for the Protection of Human Subjects of Biomedical and Behavioral Research. (1978)

The Belmont report: Ethical Principles and Guidelines for the Protection of Human Subjects of Research. . U.S. Government Printing Office.

[21]. Williams et. al. (2008) The Declaration of Helsinki and Public health. Bulletin of the World Health Organization 2008; 86: 650-651 A Guide to Research Ethics. University of Minnesota Centre for Bioethics

[22]. UNAIDS (2003). Condoms for HIV Prevention: An Analysis of the Scientific Literature. (Discussion Paper). UNAIDS.

[23]. UNAIDS (2006). Report on the global AIDS Epidemic UNAIDS.

[24]. UNAIDS (2017), 2017 UNAIDA Data. UNAIDS.

[25]. UNFPA 2002. Condom Programming for HIV Prevention. HIV Prevention NOW. Programme Briefs. No. 6. New York: UNFPA. 2002.

[26]. Younge (2008). Condom Use at last sex as a proxy for other measures of condom use: Is it Good Enough? Adolescence 2008: (172): 927-931). 


\title{
Perception of Refractive Error among Adolescents - A Pilot Study
}

\author{
Article by Janitha Plackal Ayyappan ${ }^{1}$, Galal Ismail ${ }^{2}$, Kalyani Mohanraj ${ }^{3}$ \\ ${ }^{1}$ University of Buraimi Oman \\ E-mail: janitha.a@uob.edu.om ${ }^{1}$
}

\begin{abstract}
Background: Several studies reported about the prevalence of refractive error among children as well as various age group. Hardly any study reported about the perception of refractive error among adolescents. The purpose of the study was to examine the level perception regard to refractive error in adolescents, rural region of India.

Objectives: The aim of the study to find the level of perception of refractive error among adolescents, Andhra Pradesh, India.

Materials and Methods: A purposive sampling method was applied to choose 50 subjects aged between 16 years to 18 years from the rural population of Andhra Pradesh were considered for analysis. A selfdesigned questionnaire with open-ended and closed-ended questions was designed to gather the participants' demographic data such as gender, age, majors, socioeconomic status of the parent, as well as their perception toward refractive error was analysed using a Statistical Package for Social Science (SPSS 10.0.5) (SPSS Inc. Chicago, USA).

Results: A total of 50 participants' $(n=50)$ responded to a five-point Likert's scale comprising of 11test items. Out of the 11 test item, 5 item mean score found between 4.06-4.42 with SD $\pm 0.9-1.3$ showed consistently high responses as "strongly agree". Whereas, four-item mean score ranges from 3.18- 3.86 with $S D \pm 1.3-1.53$ reflected as "agree". Furthermore, 2 test items mean score 4.18-4.36 with SD \pm 1.5-1.6 found the responses as "Neutral". However, there is no test item mean score as "disagree" and "strongly disagree" reported by the participant.

Conclusion: perception of refractive error among adolescents found to be poor in this study.
\end{abstract}

Keyword: Perception, Refractive Error, Adolescents, Refractive Correction and Methods.

\section{Introduction}

Refractive error is considered as one of the central concern of visual impairment. This has a considerable impact on various levels of the age group, socioeconomic status and society (Chia et al. 2004). According to (WHO- 2013) worldwide, 285 million people are suffering due to visual impairment and 85 million people are considered to be blind. The figures of 2010 suggestive of eighty percent impairment related to visual can be preventable. Interestingly; on an average of ninety percent of people with visual impairment are living in developing countries. The recent reports suggest $43 \%$ of visual disability is due to the refractive error (Pascolini \& Mariotti 2012). The consequence of the imperfect optical system in the eye ends up with so-called refractive error, in which condition parallel light rays from infinity while passing through the optical component of the eye focus either short of the retina or beyond instead of the retina (Williams et al. 2015). The uncorrected refractive error can lead to visual impairment, and this has a negative impact on all age groups; children, adolescents, adults and the elderly. The consequences of visual impairment can lead to lack of employment opportunity, financial burden and poor quality of life (Gomez-Salazar et al. 2017). However; the extent of refractive error is not precisely known in all the ages, especially prevalence and perception of refractive error in adolescents of the rural region. Likewise; caring for eyes of adolescents found to be the more challenging task when it comes to their academic front and future perspectives. This scenario will be worse due to the current overexposure to electronic devices such as smartphones, TV, computer and video games (LLK Lin; et al. 1983-2000). The most exciting phenomena found among these 
DOI: $10.21522 / \mathrm{TIJPH} .2013 .06 .02 . A r t 013$

ISSN: $2520-3134$

adolescents; never complaints about visual fatigue or more or less they perceived to be asymptomatic in this age group. Moreover, when it comes to the rural region, the lack of eye care facility also another primary concern. Hence it is essential to investigate the perception of refractive error and their method of corrective option among adolescents.

\section{Method}

The study was conducted in Government Junior College, Palasa. It is a Higher Secondary School, located in the Palasa, a municipal in the district of Srikakulam, Andhra Pradesh, India. It is a school for both boys and girls having 700 scholars enrolled currently.

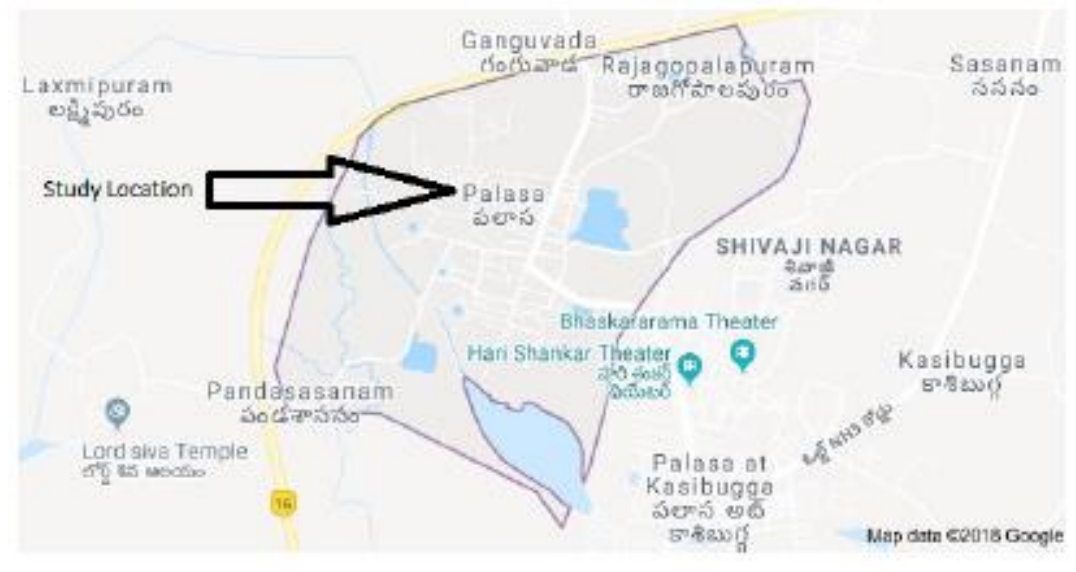

Figure 1. Location of the study

It is a quantitative, cross-sectional, prospective, questionnaire-based pilot study conducted to ensure the level of perception of refractive error among adolescents. A self-designed and validated questionnaire was used to collect the data. The survey was designed from a literature review. However, there were only few literature reviews available about the perception of the refractive error when it comes to the adolescent age group. The survey questions consist of two major components; The first part of the questionnaire consists of demographic details of the participants which includes biophysical data, socioeconomic status, educational status of parents and history of using spectacles for visual error correction among parents and siblings and any other close relatives; While the second part of the questionnaire comprised of questions related to the perception of refractive error. And both open-ended and closed-end items were included for the study. The inclusion criteria for the study was considered as the students who studied in higher secondary school with age ranging between 16 to 18 years; both genders, students who enrolled in different majors like, Maths, biology, Physics (MPC), biology, physics and chemistry (BPC), history, economics and civics (HEC) and commerce, economics and civics (CVC). Also, socioeconomic background of parents, with and without refractive error were included. Total 50 sample was taken for the pilot test. Participants' age above 18years were excluded from the study and participants who are not willing to participate in the survey also exempted from the pilot test. Before conducting a pilot test, the content validation of the questionnaire was tested. Content validation was done by subject experts. To test the internal consistency in the questionnaire tested using a, Cronbach's alpha test has applied the questionnaire. And it showed as 0.815, which is found to be highly consistent the test item Javali, S. B., Gudaganavar, N. V., \& Raj, S. M. (2011). The required permission was obtained from the school authorities before the start of the Pilot test. Likewise, the purpose of the study was explained to the subjects along with informed consent were obtained. The research protocol adhered to the provision of the Declaration of Helsinki for research involving human beings. However, participating in the study were purely involuntary nature. Also, confidentiality was assured to the participants by explaining that, details which were collected will be kept as confidential and it will be used only for research and educational purpose. Furthermore, also ensured that participants could withdraw from the study any point of time between the duration. 


\section{Sampling}

A total of $\mathrm{N}=50$ sample were considered for pilot test. Purposive sampling was done. All students fulfilling the inclusion criteria were added to the study till the required number achieved.

\section{Data management and analysis}

After collecting the completed questionnaire from the respondents, data entered in Microsoft XL spreadsheet after ensuring completeness of the filled forms. The analysis was done using the Statistical

Package for Social Science (SPSS 10.0.5) (SPSS Inc. Chicago, USA). The descriptive statistics used to identify the questionnaire based response related to perception. 


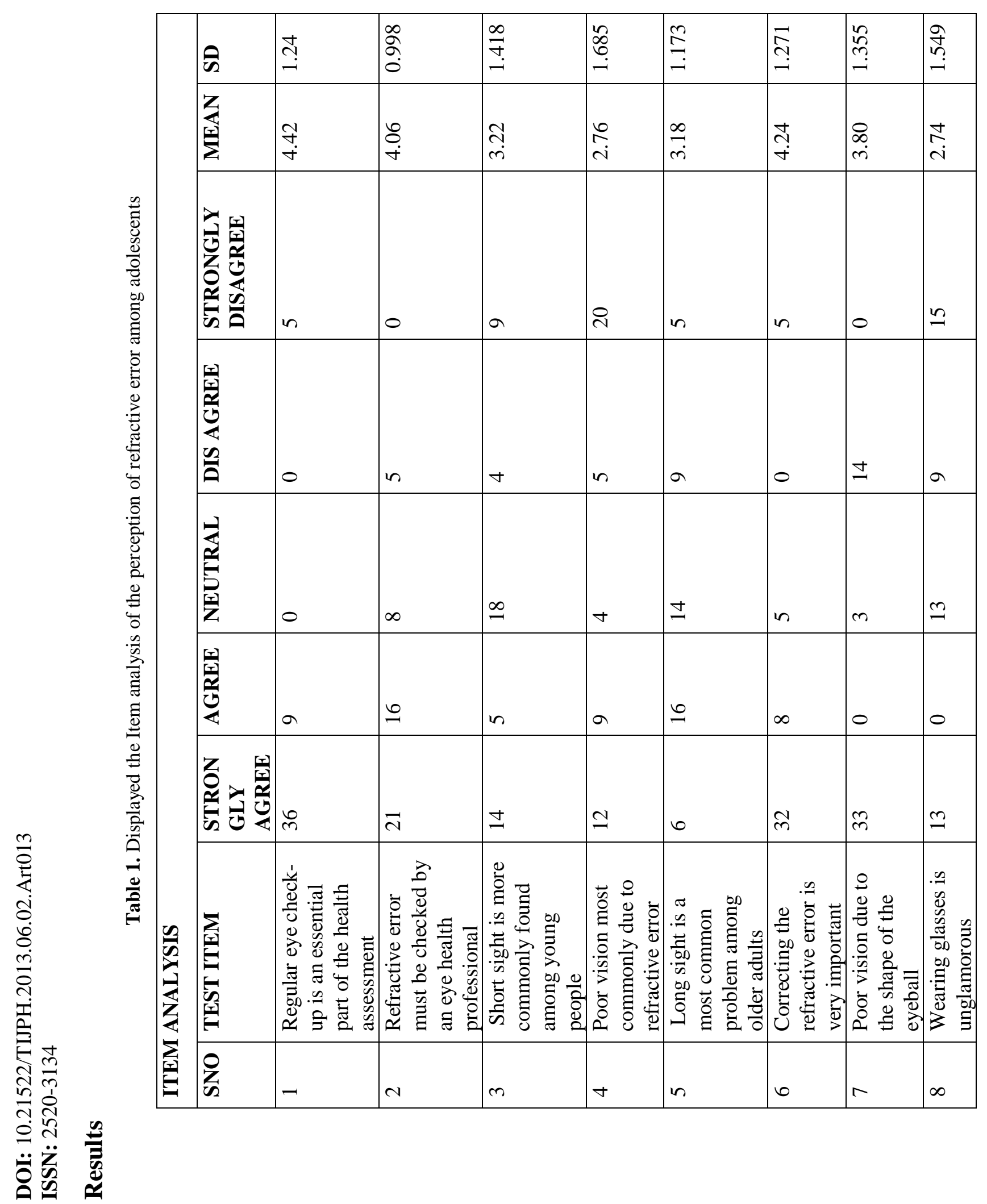




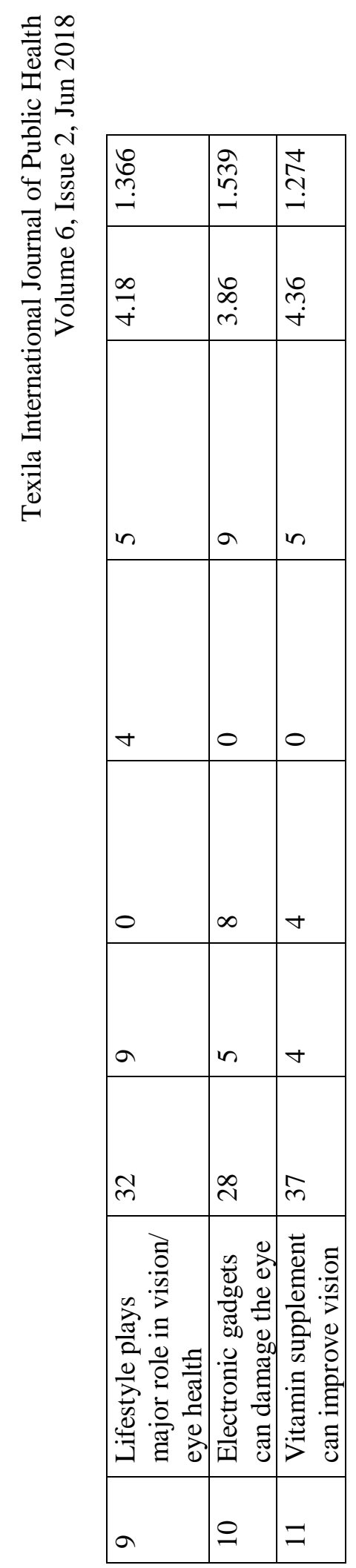


DOI: $10.21522 / \mathrm{TIJPH} .2013 .06 .02 . A r t 013$

ISSN: $2520-3134$

A total of 50 participants' $(\mathrm{n}=50)$ responded to a five-point Likert's scale comprising of 11 test items. For analysis, numerical values were considered as 5, 4, 3,2 \&1 with a statistical limit ranges from the mean score of 4.01-5 (Strongly agree), 3.01-4 (Agree),2.01-3(Neutral), 2.00(Disagree) and 0.01 until 1.0 (Strongly disagree). Out of the 11 test item, 5 item mean score found between $4.06-4.42$ with SD \pm 0.9 1.3 showed consistently high responses as "strongly agree". This includes regular eye check up with professionals and the following correction in the same regard as perceived as very important. Also, vitamin supplements and lifestyle were strongly perceived to influence vision. Whereas, four-item mean score ranges from 3.18- 3.86 with SD $\pm 1.3-1.53$ reflected as "agree". Furthermore, 2 test items mean score 4.184.36 with $\mathrm{SD} \pm 1.5-1.6$ found the responses as "Neutral". However, there is no test item mean score as "disagree" and "strongly disagree" reported by the participant.

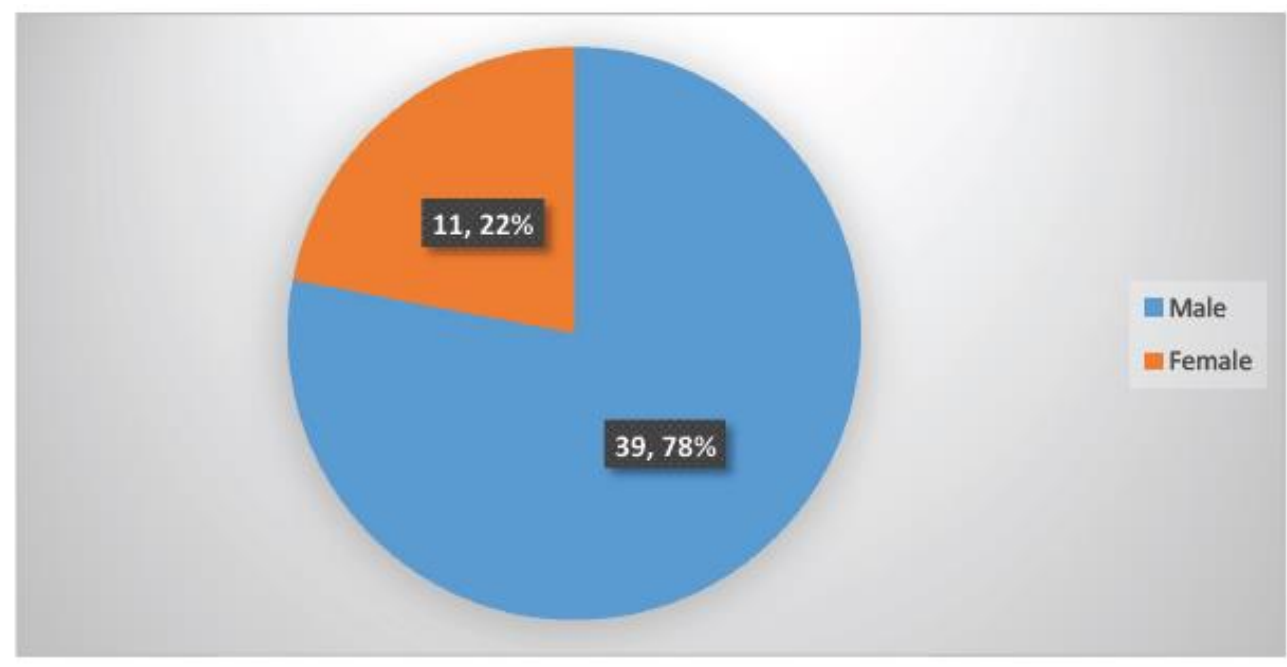

Figure 2. Shows the demographic signature of participants

The demographic signature showed 11 male participants (22\%) and 39 female participants (78\%) were responded out of 50

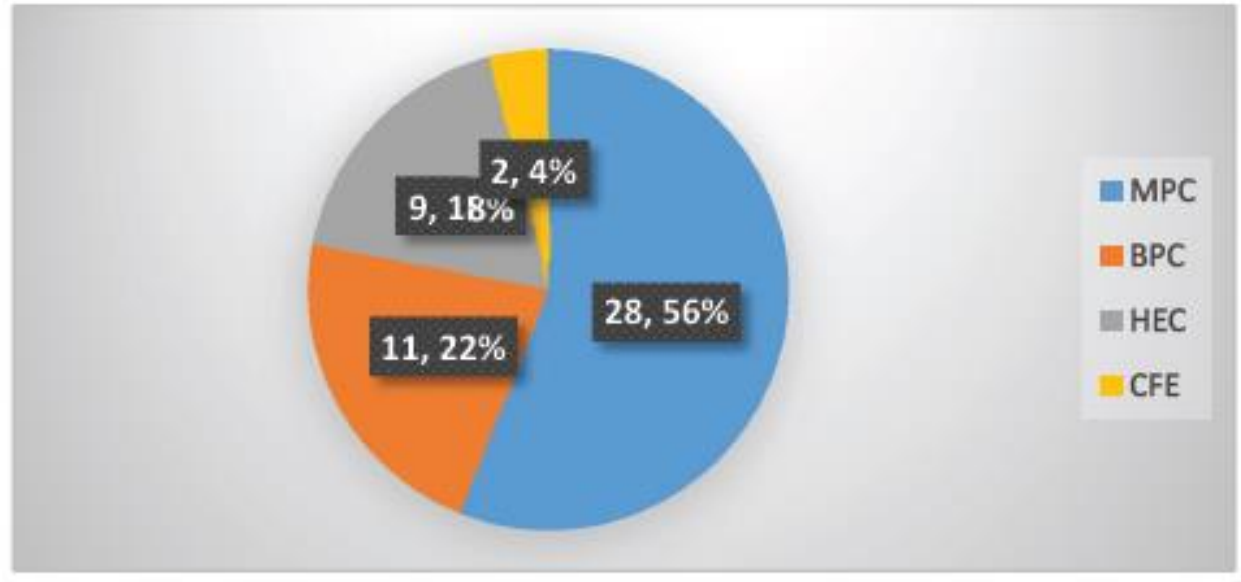

Figure 3. Demonstrates the distribution of adolescents enrolled in various majors

Figure-2 reveals the sharing of participants who part of the study among multiple majors. A 28 (56\%) of the adolescents who participated in the survey belonged to Maths, physics and chemistry (MPC) domain. While $11(22 \%)$ subjects were from biology, physics and chemistry discipline. And $9(18 \%)$ of study subjects are from the subject areas of history, economics and civics (HEC). Furthermore, 2(4\%) of the adolescents were enrolled in commerce, economics and civics (CEC). 


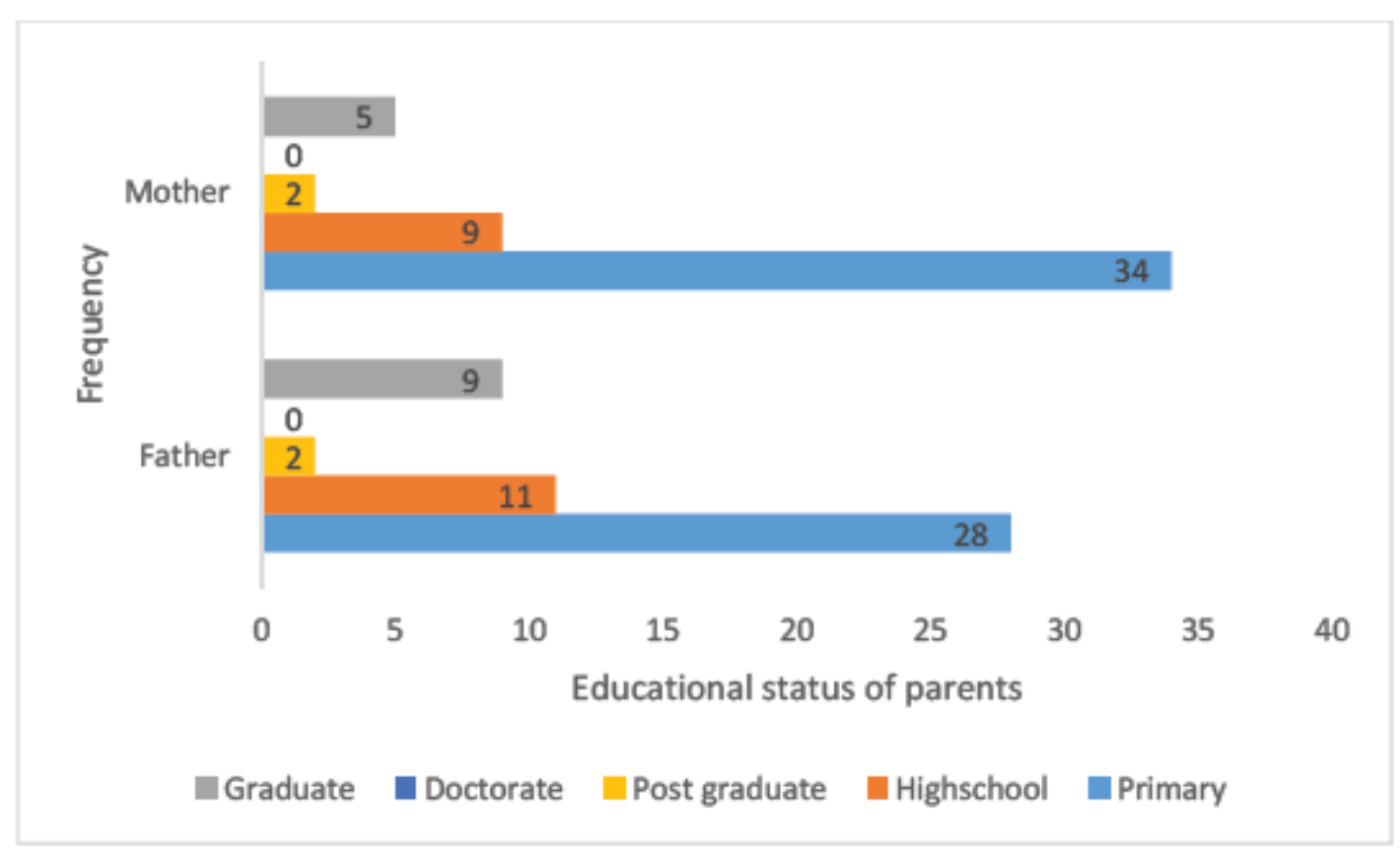

Figure 4. Exhibits the distribution of educational status of parents

Figure-3 demonstrates the literacy status of the parents; overall literacy found high among maternal side in comparison with a paternal side. Interestingly $34(68 \%)$ mothers had an education up to a primary level in contrast with fathers $28(59.5 \%)$. Although, 11(22\%) of a father having high school level literacy when compared to mothers $9(18 \%)$. While; $9(18 \%)$ of fathers having the graduate level of education about mothers $5(10 \%)$. Moreover, equal level $2(4 \%)$ of postgraduate training found among parents. And none of the parent's qualification not met up to the doctoral degree.

\section{Discussion}

To the best of our knowledge, hardly any studies reported about the perception of refractive error among adolescents, especially from the rural population, in India. By obtaining the perception from participants doesn't mean that adolescent's population have the high level of perception about spectacle wear and public health education is adequate. The present study gives an idea that $72 \%$ of respondent "strongly agree" that eye examination is an integral part of eye health. Likewise, $74 \%$ of subjects strongly agree that vitamin intake can play the crucial role in vision correction and AGARWAL, R., \& DHOBLE P. (2013) supported this, argues that the most common cause of poor vision is due to nutritional deficiency showed up to $68 \%$. The difference in the perception level of vitamin in taking from the current study is due to sample size probably attributed to the variation in the percentage. Interestingly $64 \%$ of the respondents "Strongly agree" vision correction and lifestyle plays the major role in eye health. Furthermore, $42 \%$ of the respondents "strongly agree" that vision correction should have done by an eye expert. AKS. M. R. (2013) supported this finding, reported that. $31.6 \%$ of the participants prefer to get eye examined by an ophthalmologist. While $66 \%$ of the participants expressed as "strongly agree" poor vision can lead to the shape of the eyeball. Similarly, $56 \%$ of the study subjects replied as" strongly agree "when it comes to an excessive use of electronic devices. Which can have negative impact on the visual system. And this observation was strongly supported by a study on ("Electronic gadgets and its effect on the eye", 2018) documented that electronic devices uses can cause the effect of UV rays in the eye, which leads to eye strain, redness, decrease vision and dry eye. Also, the fixation ability of the eye also will be declined due to excessive use of electronic gadgets. On the other hand, $28 \%$ of the subjects in the current study responded as "agree" that myopia more commonly seen in the youth population. This finding is in favour of a study conducted by the researchers 
DOI: $10.21522 / \mathrm{TIJPH} .2013 .06 .02 . A r t 013$

ISSN: $2520-3134$

argues that Castanon Holguin AM et al. (2007) and Congdon $\mathbf{N}$ et al. (2008) reported in a study that approximately 605 of Chinese students have myopia

And $32 \%$ of the participants perceived as "agree" that hyperopia is more common among geriatric population. However, $40 \%$ of the participants expressed as "strongly disagree" Low vision can lead to refractive correction issues. And in the present study, 30\% of the participants responded as "strongly disagree" wearing glass not because any cosmetic blemish and most of the contestant instead prefer to wear spectacle. Whereas in a study conducted by Parag Dhoble et al. (|2013) reported that $32 \%$ respondents expressed as glass were cosmetically unacceptable and it causes social stigma in comparison with the present study. And another study was done by SheetalSavur (2011). Mentioned that $51 \%$ of respondents felt that spectacles were is a cosmetic blemish.

\section{Conclusion}

To summarise, our so far finding suggests that, perception related to refractive error among adolescents from the rural background with a deprived district of Andhra Pradesh found to be poor. Moreover, a majority of the participants not known the fact that poor vision can have a significant impact on vision correction due to the influence of socioeconomic background and educational status of participants. To further comments on this extensive study should be conducted for further correlation with large sample size. Our finding suggestive of there is high needs for health education requirement when it comes to the perception of refractive error among adolescents especially the deprived districts of India.

\section{Limitations of the study}

The smaller sample size was considered for analysis. A lack of data related to a perception of refractive error for the references.

\section{Acknowledgement}

My sincere gratitude to the students who willing to share the information and the teaching and nonteaching staff of the Palasa Govt Junior college, Srikakulam district, Andhra Pradesh, India.

\section{References}

[1]. AGARWAL, R., \& DHOBLE, P. (2013). Study of the knowledge, attitude and practices of refractive error with emphasis on spectacle usages in students of rural central India. Journal of biomedical and pharmaceutical research, 2(3).

[2]. AK, S. M. R. (2013). Awareness and attitude toward refractive error correction methods: a population-based study in Mashhad. Journal of patient safety \& quality improvement, 1(1), 23-29.

[3]. Chia, E. M., Wang, J. J., Rochtchina, E., Smith, W., Cumming, R. R., \& Mitchell, P. (2004). Impact of bilateral visual impairment on health-related quality of life: the Blue Mountains Eye Study. Investigative Ophthalmology \& Visual Science, 45(1), 71-76.

[4]. Congdon, N., Wang, Y., Song, Y., Choi, K., Zhang, M., Zhou, Z. ... \& Wu, B. (2008). Visual disability, visual function, and myopia among rural Chinese secondary school children: the Xichang Pediatric Refractive Error Study (X-PRES)—report 1. Investigative ophthalmology \& visual science, 49(7), 2888-2894.

[5]. Dhoble, P., Agarwal, R., Patel, C., Anand, G., Sharma, J., \& Sabde, Y. (2013). Study to assess the psychosocial aspects of refractive errors and effectiveness of health education in correcting stigmas related to spectacle use in highschool students of rural India.

[6]. Electronic gadgets and its effect on the eye. (2018). Retrieved from http://www.medimanage.com/my-health-atwork/more-articles/electronic-gadgets-and-its-effect-on-the-eye.aspx.

[7]. Gomez-Salazar, F., Campos-Romero, A., Gomez-Campaña, H., Cruz-Zamudio, C., Chaidez-Felix, M., LeonSicairos, N. ... \& Martinez-Garcia, J. J. (2017). Refractive errors among children, adolescents and adults attending eye clinics in Mexico. International journal of ophthalmology, 10(5), 796.

[8]. He, M., Huang, W., Zheng, Y., Huang, L., \& Ellwein, L. B. (2007). Refractive error and visual impairment in school children in rural southern China. Ophthalmology, 114(2), 374-382. 
[9]. Javali, S. B., Gudaganavar, N. V., \& Raj, S. M. (2011). Effect of varying sample size in estimation of coefficients of internal consistency.

[10]. Kevin M. Sullivan, a. (2018). OpenEpi - Toolkit Shell for Developing New Applications. Retrieved from http://www.openepi.com/SampleSize/SSPropor.htm.

[11]. LLK Lin, YF Shih, CK Hsiao, CJ Chen (1983 to 2000).Prevalence of myopia in Taiwanese schoolchildren: " Annals Academy of Medicine Singapore 33, no. 1 (2004): 27-33.

[12]. Pascolini, D., \& Mariotti, S. P. (2012). Global estimates of visual impairment: 2010. British Journal of Ophthalmology, 96(5), 614-618.

[13]. SheetalSavur (2011). The perceptions regarding refractive errors and their psychosocial impact on youth in Dakshina Kannada. Journal of Clinical and Diagnostic Research. 2011 August, Vol-5(4): 746-748746 746J.

[14]. Williams, K. M., Verhoeven, V. J., Cumberland, P., Bertelsen, G., Wolfram, C., Buitendijk, G. H., \& Höhn, R. (2015). Prevalence of refractive error in Europe: the European eye epidemiology (E3) Consortium. European journal of epidemiology, 30(4), 305-315.

[15]. World Health Organization. (2013). Universal eye health: a global action plan 2014-2019. 


\title{
Awareness and Preventions of Malaria in Pregnant Women: A Study of
} Mile Four Hospital, Nigeria

\author{
Article by Mgbe Chinenye $\mathrm{G}^{1}$, Mgbe Emeka Kevin ${ }^{2}$, Rita Uzoamaka Nwali ${ }^{3}$ \\ ${ }^{1}$ Ph.D, Enugu State University Teaching Hospital \\ ${ }^{2} M B B S, f W A C S$, University of Nigeria Teaching Hospital Ituku \\ ${ }^{3}$ B.sc, Department of Public Health, National Open University of Nigeria \\ E-mail: chinenyemgbe@yahoo.com ${ }^{1}$, champlinks2001@yahoo.com ${ }^{2}$
}

\begin{abstract}
This cross sectional study was conducted at the maternity unit of Mile Four Hospital in Abakaliki Ebonyi State. The aim was to determine the degree of awareness and practice of malaria prevention strategies among antenatal attendees in Mile Four Hospital in Abakaliki Ebonyi State. Semistructured questionnaires were administered to one thousand five hundred and sixteen pregnant women in the antenatal clinic. The findings revealed among other things that pregnant women attending antenatal clinic in Mile Four Hospital Abakaliki in Ebonyi State are aware of malaria preventive measures and are utilizing malaria preventive measures to prevent themselves. The study recommended among other things that, awareness campaign should be drawn to rural areas so that Pregnant women should be educate on high risk involve in malaria infestation for total eradication of miscarriage, low birth weight, still birth and maternal death.
\end{abstract}

Keywords: Awareness, Malaria, Prevention, pregnant women.

\section{Introduction}

Malaria is a mosquito- borne diseases of humans and other animals cause by parasitic protozoan of the genus plasmodium. It is transmitted through the bite of an infected anopheles mosquito. According to (WHO), an estimated 214 million new cases occurred word wide in 205 and 438,000 malaria deaths with the African region accounting for most global cases of malaria (88\%). Malaria in pregnancy is an immense public health problem.

Currently, it is estimated that each year more 125 million women become pregnant in malaria epidemic areas in the word with 30 million of this in sub-sahara Africa, and that 75, 000- 200, 000 infants deaths are attributed to malaria infection in pregnancy, report show that the burden of malaria in pregnancy in Nigeria is high. $100 \%$ of women who had no prophylaxis is experienced attacks of malaria, with $76 \%$ experiencing two more attacks. Ahmed et al; (2010). 51\% pregnant women surveyed using aremsa staining were positive for malaria infection (Chukwuocha et al.; 2001). Pregnant women are more likely than non- pregnant women to become infected with plasmodium falciparum and once infected, there is a tendency towards increased severity of disease caused in part by the transient depression of cells mediated immunity that occurs during pregnancy. Under conditions of high transmission, there is increased plasmodium falciparum parasite density in placenta and peripheral blood, which is higher in first, compared to later pregnancies. This epidemiological pattern for plasmodium falciparum has been recognized for several years, with higher density in early pregnancy, which increases in untreated, and then decreased as gestation progresses in stable high transmission areas, almost primigravidae if unprotected, are likely to be infected in early pregnancy and approximately, half of these would remain so by the time of delivery if untreated. In multigravidea, especially in those with high parities, parasites are significantly reduced due to the acquisition of parity-specific immunity.

This potential fetal infection must be prevented but when they develop, they require prompt diagnosis and treatment. The most harmful effect on the mother is caused by plasmodium falciparum. In areas of high transmission, severe anaemia is common and associated with high mortality, where as 
ISSN: $2520-3134$

in areas of low transmission or in epidemics, pregnant women are at risk of high severe cerebral malaria and death (David Sinclair, 2012).

Millions of pregnant women are exposed to malaria and thousands die every year as direct or indirect consequences. (WHO, 2010). It further stated that in all endemic areas, babies born to mothers infected with malaria parasites have a low birth weight and also at increased risk of death in infancy. Therefore, it is essential to treat pregnant women, who are infected with plasmodium parasites effectively (Bugvi et al.; 2015). Unfortunately, a cheap, safe and effective drug such as chloroquine has globally lost its efficacy against malaria parasites (plasmodium falciparum). Malaria is highly endemic in Nigeria and possesses a major challenge to human development (Williams, 2016).

It is both the cause and consequences of under-developed and also remains one of the leading cause of morbidity and mortality in the country David Sinclair (2012). It accounts for about $60 \%$ of all clinic attendance in the country (WHO, 2010). The most vulnerable groups are children below five years of age and pregnant women primigraividae. in Nigeria, the situation of antenatal care ascertained during the baseline data collection for monitoring and revaluating roll back malaria (RBM) showed that on the average, $68.6 \%$ of pregnant women in the current pregnancy were receiving care and mostly in rural health centre (White et al.; 2014)

Furthermore, malaria is responsible for $25 \%$ of infant mortality and $30 \%$ of all childhood death and that is why Nigeria is a signatory to the Abuja declaration that set as one of the Abuja targets that $60 \%$ of pregnant women should receive intermittent preventive treatment drug during pregnancy by end of 2005 (WHO, 2010). Despite the effective launching of the roll back malaria since year 2001 in most African countries, pregnant women and their unborn babies continue to face disproportionate high burden of the disease. Pregnant women have a higher risk than the non - pregnant ones to be infected with malaria and they are at increased risk of adverse events such as anaemia, risk of miscarriage, still birth, preterm delivery, total growth, restriction and even death.

Preventing severe anaemia caused by malaria in pregnancy will head to fewer pregnant women requiring blood transfusion thereby reducing the risk of transfusion related infections especially HIV and Hepatitis B. adequate control of malaria in pregnancy will improve survival of mother and reduce prenatal mortality.

Malaria which is described as a febrile illness (WHO, 2003) can affect everyone, but pregnant women are known to have high risk for the disease with grievous consequences, malaria during pregnancy is accountable for an approximately $11 \%$ of maternal morbidity in Nigeria (United States Embassy in Nigeria, 2011) despite the awareness and high development World health organization (2013) observed that they was lack of adequate knowledge of malaria especially in regions where the prevalence of the disease is high.

Knowledge is one of the important elements in any effort targeted towards the reduction of disease burden such as malaria (Minnesota Health Acrim Team, 2010) (Ducarme et al.; 2008) reported that the failure to establish the level of knowledge of community members regarding malaria appeared to be responsible for the mobility of intervention programmes to achieve suitable control. Consequently every women is expected to possess an appreciable level of knowledge of the cause, breeding sources, mode of transmission, consequences and prevention for successful eradicative of the disease in any given community. This is because women have been recognized as the closest members of the family responsible for health care of the children and other members of the family. It is therefore necessary for women to posses' adequate knowledge about disease including malaria in order to protect members from the scourge of the disease.

Most Ebonyi people including women and highly involve in agricultural activities, which encourage the breeding of mosquitoes and consequently malaria infection is not an over statement to state that malaria has numerous negative outcomes which may include financial involvement translating into poor standard of living, hospital visitations as well as low productivity and loss of income (Kayentao et al.; 2005) sequel to this, the Ebonyi state in collaboration with Roll Back Malaria (RBM) in February 2011 took positive steps to reduce the spread of malaria in the state.

The action involved house distribution of Insecticide Treated Net (ITN) to mothers. However, after the distribution of the nets, a casual discussion with some of recipients revealed that the act of 


\section{Texila International Journal of Public Health}

Volume 6, Issue 2, Jun 2018

distributing the net was seen as a political programmes, and nets where seen as a gift from politician rather that a malaria prevention venture. A few of discussants also indicated they would keep the nets until rainy season before using them. The observation made on then women tend to suggest a possible gap in malaria knowledge

However, malaria in pregnancy is an obstetric social and medical problem requiring multidisciplinary and multidimensional solution (WHO, 2013) malaria the most dangerous human parasitic disease, is both preventable and treatable but continues to kill inappropriately, especially children and pregnant women. In all malaria evidence areas, infection by any human plasmodium specie during pregnancy is detrimental to the mother and the foetus.

Finally, malaria is still a public health concern particularly in sub-Sahara Africa and other parts of the developing world, (Bhatia et al.; 2013).

\section{Statement of the problem}

According to the world health organization (WHO, 2010) a quarter of all malaria cases in Africa occurs in Nigeria. This magnitude of occurrence in this part of the world correlates with poverty, ignorant and social deprivations in the community. The problems of malaria in pregnancy possess a substantial risk to the mother, her fetus and the neonates. It significantly contributes to anaemia in pregnancy as the parasitmia appear greater in the second trimester and may persist into the early postpartum period, increasing the low birth weight and is associated with preterm deliveries, still birth and perinatal mortality in Nigeria .(Centre for Disease and Prevention, 2009).

A researcher during his research in Federal Teaching Hospital Abakaliki observed that the pregnant women attending antenatal in that hospital, were always falling sick and as much come to the clinic before their appointment dates. Moreover, malaria in pregnancy was the worst occurring medical diagnosis in the medical records department of the hospital. The situation mentioned above raised the researcher's curiosity on the awareness and utilization of malaria preventive measures to pregnant women, attending antenatal clinic in order to join the way forward to provide a better pregnancy outcome, improve the survival of the mother and reduce prenatal mortality.

\section{Purpose of the study}

The broad purpose of the study is to determine the degree of awareness and practice of malaria prevention strategies among antenatal attendees in Mile Four Hospital in Abakaliki Ebonyi State.

\section{Research questions}

1. What are the challenges in the awareness of malaria preventive measures to pregnant women, attending antenatal clinic in Mile Four Hospital, Abakaliki in Ebonyi State?

2. What are the challenges of utilization of malaria preventive measures to pregnant women, attending antenatal clinic in Mile Four Hospital, Abakaliki in Ebonyi State?

\section{Significance of the study}

The study will create awareness on the causes, prevention, treatment and implication of malaria in pregnancy among the clients, public health students, communities and the society at large thereby reducing the financial burden and mortality resulting from malaria in pregnancy in the state and beyond.

It will provide information on adequate protection from mosquito bite especially during pregnancy to prevent malaria attack and its advance effects. It will also form basic for reference to other researchers who might work on the subject matter as well as mile four hospital management to design strategies for reducing malaria among their pregnant clients.

The findings will also help to improve the epidemiological data of the state ministry of health and consequently, help in further intervention plan in malaria prevention in the state. Furthermore, the data so generated will attract the attention of donor agencies as it will serve as assessment of the intervention strategies on the ground. 
DOI: $10.21522 /$ TIJPH.2013.06.02.Art014

ISSN: $2520-3134$

\section{Limitation of the study}

This study was adversely affected by a number of factors. The researcher faced with time constraints, due to the fact that this type of study requires long period of time to gather data. It was not at the disposal of the researcher as the some project audience falsified data and out rightly refused to participate in the study. Other limitations include, lack of fund and difficulty in volunteering information. However, these constraints did not stop the success of the study.

\section{Literature review}

\section{Concept of malaria}

Malaria, a life threaten parasitic disease has been known since time immemorial. Previously, it was thought that "miasma" (bad air gas from swamps) causes malaria this and a host of others are the misconceptions that many theorists have about malaria.

Malaria is a life threatening parasite disease transmitted by the female anopheles mosquitoes. Malaria is the most highly prevalent tropical disease, with high morbidity and mortality as well as high economic and social impact (WHO, 2001).

According to (WHO, 2003) malaria remains one of the most important threat to the health of pregnant women and their new born. In fact, its control is one of the most challenging in Africa where 45 countries including Nigeria are endemic for malaria and about 588 million people are at risk (WHO, 2003). The protection of women living in malaria endemic countries has been of peculiar interest to many National Malaria Control Programmes because of their reduced immunity.

This is not unconnected to the fact that malaria during pregnancy presents a unique problem. Pregnant women are at high risk of developing severe and fatal malaria because normal immune responses are reduced during pregnancy.

Today, approximately $40 \%$ of the world's population mostly those living in the world's poorest countries. Is at risk of malaria, on the average, each Nigeria suffers at least two or more attacks every year and while millions recover, hundreds or thousands are not so lucky. This single disease accounts for about $60 \%$ of outpatient visits, $30 \%$ hospitalizes, $25 \%$ of death in children under one year old, and $11 \%$ of maternal death a heavy burden of Nigerian families, communities, health system and workforce (WHO, 2013).

Although, malaria control efforts have helped reduce the global malaria burden, most malaria endemic countries are now meeting whose target for malaria control. Nigeria is amongst the five most malaria endemic countries in Africa alongside the Democratic Republic of Congo, Ethiopia, Kenya and Tanzania. Together, they account for more than half of the continents burden. While interventions have helped reduced malaria cases and death, less than $50 \%$ of people at risk have access to insecticide treated nets (ITN) last year, the number of ITNs distributed to national malaria control programme has also improved but the race is far from over to ensure that the country will meet WHO'S target of $80 \%$ coverage for the four main malaria treatments: ITNs, artemisinni - based combination therapies, indoor insecticides spraying programmes and treatment of pregnant women.

Desai et al; (2015) has declared malaria as being burdensome over several decades and still remains a burden especially for population in the endemic areas of the world. The authors noted that; "unfortunately, Africa is a known centre for malaria but tropical Africa that is, sub-Sahara seems to be at the receiving end of the malaria burden. infact, you can imagine the number of deaths recorded yearly from the under-five and even pregnant women.

\section{Life cycle of malaria parasite in nigeria}

The malaria parasite, plasmodium is very small single cell blood organism or protozoan. It lives as a parasite in other organisms, namely man and mosquito. The plasmodium parasite is dependent on a single species of mosquito, anopheles, which is the only species capable of serving as the host of it (Ducarme, 2008).

Diagram of life cycle of plasmodium vivax in man and the mosquito 


\section{Texila International Journal of Public Health \\ Volume 6, Issue 2, Jun 2018}

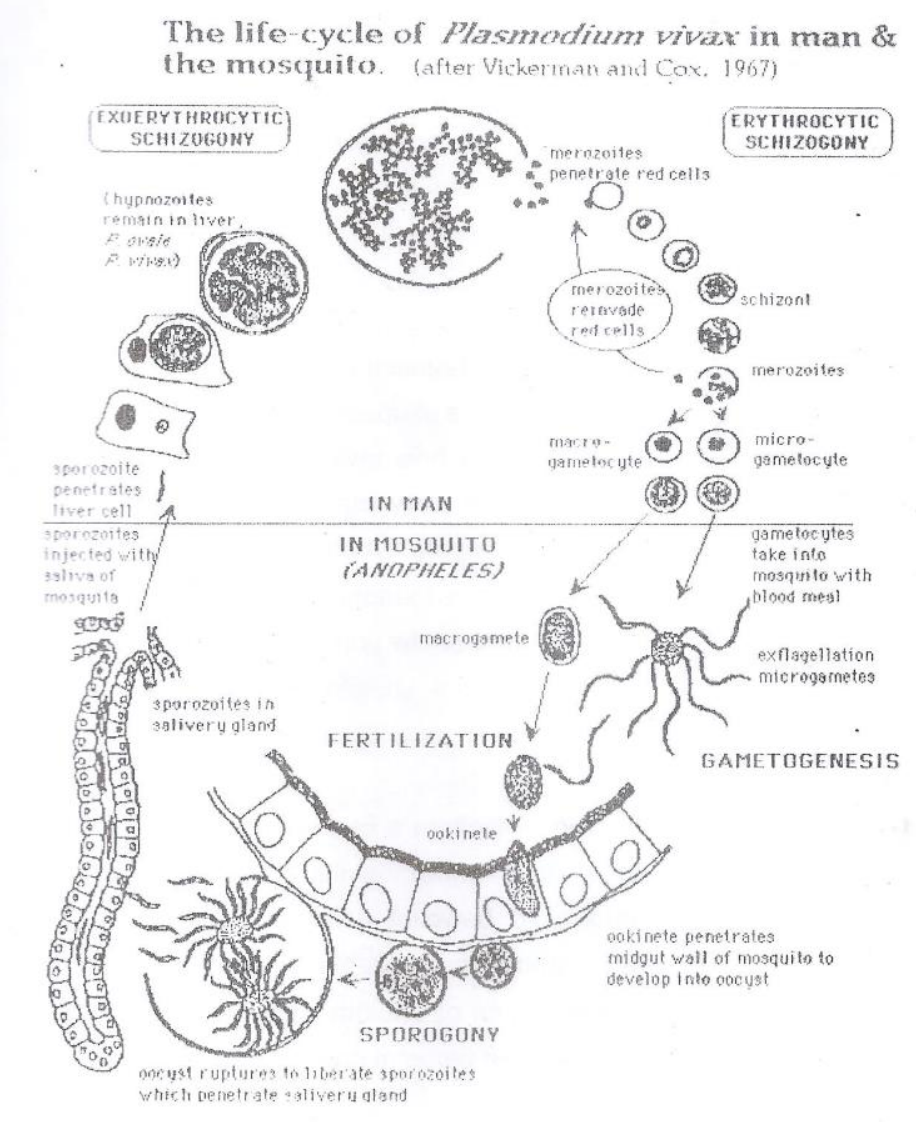

Animation: Lifecycle of a malaria parasite from mosquito to blood stages

The different stages of the parasite Life cycle from the diagram:

a. Mosquito infected with malaria parasite bites human, passing cell called "sporozoites" into the human blood stream.

b. Sporozoites travel to deliver

c. Merozoites enters the blood stream and infect Red Blood Cells

d. In Red Blood Cell merozoites grow and divide to produce more merozoites, eventually causing the Red Blood Cell rupture.

\section{Methodology}

\section{Research design}

The study employed a cross sectional research design to ascertain the extent of awareness and utilization of malaria preventive measures to pregnant women, attending antenatal clinic.

A structured interviewer- self-administered survey questionnaire was used to the selected staff and women attending to antenatal at Mile Four Hospital

\section{Area of the study}

The study was conducted in antenatal section of Mile Four Hospital Abakaliki Ebonyi State. The Hospital is located along old Abakaliki Enugu Road, Ebonyi State. 
DOI: $10.21522 /$ TIJPH.2013.06.02.Art014

ISSN: $2520-3134$

\section{Population of the study}

The study population includes all the staff of antenatal section and pregnant women attending antenatal in Mile Four Hospital Abakaliki. A simple random sample of one thousand five hundred and sixteen $(1,516)$.

Table 1.Total number of staff in Antenatal section and pregnant women attending Antenatal in Mile Four Hospital, Abakaliki

Source: (survey, 2016).

\begin{tabular}{|l|l|l|}
\hline Grade Level & Total & Percentage \\
\hline Senior Cadre & 45 & $3 \%$ \\
\hline Junior Cadre & 51 & $4 \%$ \\
\hline Women attending Antenatal: & & \\
\hline Zero Months - 5 Months & 870 & $57 \%$ \\
\hline 7 Months - 9 Months & 550 & $36 \%$ \\
\hline Total & 1,516 & $100 \%$ \\
\hline
\end{tabular}

\section{Sampling technique}

The simple random sampling technique was used in this study. A situation where respondent were randomly selected so that every members of the population is equal and has independent chance of being selected in the sample to study.

\section{Instrument of data collection}

The major instrument that the researcher used for collection of data was structured questionnaires to elicit and generate information concerning the topic investigated. The researcher visited Mile Four Hospital to distribute the questionnaire personally. Respondents were given four options of strongly agree (SA), agree (A), strongly disagree (SD) and disagree (D) to ascertain the degree of acceptance or rejection of the views expressed by the questionnaire.

\section{Tests for validity}

Validity is defined as the degree to which a measuring instrument measures what it is designed to measure given that every measuring instrument is designed for a specific measurement (Asika, 1991). It also refers to the authentic nature of the measuring instrument in being capable of eliciting the necessary information applicable to the study. In order to ascertain the validity of the instrument, it was subjected to face validation and content validity. The structured questionnaire was vetted by the project supervisor and other experts in the field understudy. Corrections were effected; the instrument was fine tuned to measure exactly what it intends to measure. The researcher was guided strictly by the corrections and adjustment made. Hence, the instrument was considered appropriate for the study.

\section{Method of data analysis}

The data collected for the study were first arranged in table containing the number of respondents and the corresponding percentages of the responses. This was done for easy understanding of the analysis of the tables. The hypotheses formulated for the study were tested using $\mathrm{Z}$ statistics.

$\mathrm{Z}$-value is a test statistic for Z-tests that measure the difference between an observed statistic and its hypothesized population parameter in units of the standard deviation.

The formular is given as:

$$
Z=\frac{\pi-\mu}{\mathbf{S} / \sqrt{\mathbf{n}}}
$$

Where $\mathrm{Z}=\mathrm{Z}$-value 
$\pi=$ Mean Sample

$\mathrm{S}=$ Sample standard deviate

$\mathrm{n}=$ Number of the Respondents

\section{Results}

These deals with the presentation of data collected from Mile Four Hospital Abakaliki, the respondent were grouped into two which includes: Senior and Junior Cadres. For proper analysis, the data was presented with the aid of table percentage. Table below details the questionnaire distributed to the respondents.

Table 2. Number of questionnaire distributed and number of questionnaire returned

\begin{tabular}{|l|l|l|l|}
\hline Staff Grade level & $\begin{array}{l}\text { Number of } \\
\text { distributed }\end{array}$ & Number of returned & \% returned \\
\hline Senior Cadre & 45 & 45 & $12 \%$ \\
\hline Junior Cadre & 51 & 51 & $13 \%$ \\
\hline Zero - 5Months & 154 & 148 & 37 \\
\hline 6-9 Months & 150 & 144 & 36 \\
\hline Total & 400 & 388 & 98 \\
\hline
\end{tabular}

Source: Field survey november, 2015.

The above table 2 shows that four hundred questionnaires were distributed to the respondents, out of the 400 questionnaires, 45 representing $12 \%$ were administered to the senior staff, 51 questionnaires representing $13 \%$ were also distributed to junior staff, and the entire questionnaire were returned completely. Moreover, 154 questionnaires were also distributed to Pregnant Women attending antenatal from 0-5 months and 150 questionnaires were also distributed to Pregnant Women attending antenatal from 6- 9 months and 148 and 144 were returned respectively. Therefore, out of 400 questionnaires distributed to the staff and pregnant women, 388 questionnaires representing 98\% of the total questionnaires were returned.

Question: Mosquitoes bite causes malaria

Table 3. Responds on whether mosquitoes bite causes malaria

\begin{tabular}{|l|l|l|}
\hline Responses & $\begin{array}{l}\text { No of } \\
\text { Respondents }\end{array}$ & \% of Respondents \\
\hline Strongly Agreed & 215 & $55 \%$ \\
\hline Agreed & 154 & $40 \%$ \\
\hline Strongly Disagreed & 13 & $3 \%$ \\
\hline Disagreed & 6 & $2 \%$ \\
\hline Total & 388 & 100 \\
\hline
\end{tabular}

Source: Field survey november, 2015.

From the above table, 215 respondents representing 55\% strongly agreed that Mosquitoes bite causes malaria, whereas 154 respondents representing $40 \%$ agreed that Mosquitoes bite causes malaria. However, 13 respondents representing 3\% strongly disagreed also 6 respondent representing $2 \%$ disagreed Mosquitoes bite causes malaria

Question: Poor environmental sanitation causes malaria

Table 4. Response on whether Poor environmental sanitation causes malaria

\begin{tabular}{|l|l|l|}
\hline Responses & $\begin{array}{l}\text { No of } \\
\text { Respondent }\end{array}$ & $\begin{array}{l}\text { \% of } \\
\text { Respondent }\end{array}$ \\
\hline Strongly agreed & 236 & $61 \%$ \\
\hline Agreed & 92 & $24 \%$ \\
\hline Strongly & 33 & $8 \%$ \\
\hline
\end{tabular}


DOI: $10.21522 /$ TIJPH.2013.06.02.Art014

ISSN: $2520-3134$

\section{Source: field survey November, 2015}

\begin{tabular}{|l|l|l|}
\hline disagreed & & \\
\hline Agreed & 27 & $7 \%$ \\
\hline Total & 388 & $100 \%$ \\
\hline
\end{tabular}

Based on analysis presented on the above table 4, 236 respondent representing $61 \%$ strongly agreed that Poor environmental sanitation causes malaria, while 92 respondents representing $24 \%$ agreed that Poor environmental sanitation causes malaria, while 33 respondents representing $8 \%$ strongly disagreed and 27 respondents representing $7 \%$ disagreed also. Therefore, it can be denoting from the table that according to majority of respondents that poor environmental sanitation causes malaria.

Question: Poor nutrition system causes malaria

Table 5. Responses on whether Poor nutrition system causes malaria.

\begin{tabular}{|l|l|l|}
\hline $\begin{array}{l}\text { Respondent } \\
\text { response }\end{array}$ & frequency & percentage \\
\hline Strongly agreed & 118 & $30 \%$ \\
\hline Agreed & 193 & $50 \%$ \\
\hline $\begin{array}{l}\text { Strongly } \\
\text { Disagreed }\end{array}$ & 33 & $9 \%$ \\
\hline Disagreed & 44 & $11 \%$ \\
\hline Total & 388 & $100 \%$ \\
\hline
\end{tabular}

Source: Field survey november, 2015

From the above table, 118 of respondents representing 30\% strongly agreed that Poor nutrition system causes malaria, where 193 respondents representing 50\% agreed that Poor nutrition system causes malaria. However 33 respondents representing 9\% strongly disagreed that poor nutrition system causes malaria and 44 respondents representing $11 \%$ disagreed that. Poor nutrition system causes malaria this shows that greater percent of the respondents agreed that Poor nutrition system causes malaria.

Question: Poor drainage system causes malaria

Table 6. Response: on whether poor drainage system causes malaria

\begin{tabular}{|l|l|l|}
\hline $\begin{array}{l}\text { Respondent } \\
\text { response }\end{array}$ & frequency & percentage \\
\hline Strongly Agreed & 274 & $71 \%$ \\
\hline Agreed & 85 & $22 \%$ \\
\hline $\begin{array}{l}\text { Strongly } \\
\text { Disagreed }\end{array}$ & 29 & $7 \%$ \\
\hline Disagreed & - & - \\
\hline Total & 388 & $100 \%$ \\
\hline
\end{tabular}

Source: Field survey November, 2015

The table above indicates that 274 respondents representing $71 \%$ strongly agreed that Poor drainage system causes malaria, 85 respondents representing $22 \%$ agreed that Poor drainage system causes malaria, while 29 respondents representing 7\% strongly disagreed that Poor drainage system causes malaria. 
Question: Malaria can be prevented by avoiding mosquito bite

Table 7. Response on whether Malaria can be prevented by avoiding mosquito bite

\begin{tabular}{|l|l|l|}
\hline $\begin{array}{l}\text { Respondent } \\
\text { response }\end{array}$ & frequency & percentage \\
\hline Strongly Agreed & 268 & 69 \\
\hline Agreed & 94 & 24 \\
\hline $\begin{array}{l}\text { Strongly } \\
\text { Disagreed }\end{array}$ & 14 & 4 \\
\hline Disagreed & 12 & 3 \\
\hline Total & 388 & $100 \%$ \\
\hline
\end{tabular}

Source: Field survey November, 2015

The details of table 7 above shows that 248 respondents representing $69 \%$ are of the view that Malaria can be prevented by avoiding mosquito bite, 94 respondents representing $24 \%$ of the respondents maintained that. Malaria can be prevented by avoiding mosquito bite. Furthermore, 14 respondents representing $4 \%$ and the remaining 12 respondents representing $3 \%$ are of the view that Malaria can be prevented by avoiding mosquito bite. It can be seen from the above analysis that. Malaria can be prevented by avoiding mosquito bite.

Question: Malaria can be prevented by the use of intermittent preventive therapy (IPT)

Table 8. response on if Malaria can be prevented by the use of intermittent preventive therapy (IPT)

\begin{tabular}{|l|l|l|}
\hline $\begin{array}{l}\text { Respondent } \\
\text { response }\end{array}$ & frequency & percentage \\
\hline Strongly Agreed & 236 & 61 \\
\hline Agreed & 108 & 28 \\
\hline $\begin{array}{l}\text { Strongly } \\
\text { Disagreed }\end{array}$ & 34 & 9 \\
\hline Disagreed & 10 & 3 \\
\hline Total & 388 & $100 \%$ \\
\hline
\end{tabular}

Source: Field survey november, 2015.

The above table details the respondents view of whether Malaria can be prevented by the use of intermittent preventive therapy (IPT), 236 respondents representing 61\% strongly agreed and 108 respondents representing 28\% also agreed, whereas 34 respondents representing 9\% strongly disagreed that Malaria can be prevented intermittent preventive therapy (IPT) and 10 of the respondents disagreed that Malaria can be prevented by the use of intermittent preventive therapy (IPT).

Question: Malaria can be prevented by the use of insecticide treated mosquito nets

Table 9. Response on if malaria can be prevented by the use of insecticide treated mosquito nets

\begin{tabular}{|l|l|l|}
\hline $\begin{array}{l}\text { Respondent } \\
\text { response }\end{array}$ & frequency & percentage \\
\hline Strongly Agreed & 226 & $58 \%$ \\
\hline Agreed & 150 & $39 \%$ \\
\hline $\begin{array}{l}\text { Strongly } \\
\text { Disagreed }\end{array}$ & - & - \\
\hline Disagreed & 12 & $3 \%$ \\
\hline Total & 388 & $100 \%$ \\
\hline
\end{tabular}

Source: Field survey November, 2015 
DOI: $10.21522 /$ TIJPH.2013.06.02.Art014

ISSN: $2520-3134$

It can be seen from the above table that 226 respondents representing $61 \%$ are of the view that Malaria can be prevented by the use of insecticide treated mosquito nets, 150 respondents representing 39\% also agreed. Meanwhile, 12 of the respondents representing 3\% strongly disagreed that Malaria can be prevented by the use of insecticide treated mosquito nets

Question: Malaria can be prevented by health education and creation of awareness

Table 10. Responses on if malaria can be prevented by health education and creation of awareness

\begin{tabular}{|l|l|l|}
\hline $\begin{array}{l}\text { Respondent } \\
\text { response }\end{array}$ & frequency & percentage \\
\hline Strongly Agreed & 247 & $64 \%$ \\
\hline Agreed & 141 & $36 \%$ \\
\hline $\begin{array}{l}\text { Strongly } \\
\text { Disagreed }\end{array}$ & - & - \\
\hline Disagreed & - & - \\
\hline Total & 388 & $100 \%$ \\
\hline
\end{tabular}

Source: Field survey November, 2015

The above table disclosed that 247 respondents representing $64 \%$ are of the strongly agreed that Malaria can be prevented by Health Education and creation of awareness, 141 respondents representing 36\% are of the view that: Malaria can be prevented by Health Education and creation of awareness. From the above analysis it can be deduced that Malaria can be prevented by Health Education and creation of awareness.

Question: Malaria can be prevented through environmental sanitation

Table 11. Responses on if malaria can be prevented through environmental sanitation

\begin{tabular}{|l|l|l|}
\hline $\begin{array}{l}\text { Respondent } \\
\text { response }\end{array}$ & frequency & percentage \\
\hline Strongly Agreed & 220 & $57 \%$ \\
\hline Agreed & 114 & $29 \%$ \\
\hline $\begin{array}{l}\text { Strongly } \\
\text { Disagreed }\end{array}$ & 44 & $11 \%$ \\
\hline Disagreed & 10 & $3 \%$ \\
\hline Total & 388 & $100 \%$ \\
\hline
\end{tabular}

Source: Field survey November, 2015.

The above table shows that 220 of respondents representing $57 \%$ stated that Malaria can be prevented through Environmental sanitation. 114respondents representing 29\% also agreed. While 44 respondents representing $11 \%$ strongly disagreed that Malaria can be prevented through Environmental sanitation, also $10(3 \%)$ are of the view that Malaria cannot be prevented through Environmental sanitation.

Question: Malaria can be prevented with the use of insecticide treated net

Table 12. Responses on whether Malaria can be prevented with the use of insecticide treated net

\begin{tabular}{|l|l|l|}
\hline $\begin{array}{l}\text { Respondent } \\
\text { response }\end{array}$ & frequency & percentage \\
\hline Strongly Agreed & 229 & $59 \%$ \\
\hline Agreed & 67 & $17 \%$ \\
\hline Strongly Disagreed & 35 & $9 \%$ \\
\hline Disagreed & 57 & $15 \%$ \\
\hline Total & 388 & $100 \%$ \\
\hline
\end{tabular}

Source: Field survey November, 2015 


\section{Texila International Journal of Public Health \\ Volume 6, Issue 2, Jun 2018}

From the above table 12, it can be deduced, 229 Respondents representing 59\% strongly agreed that Malaria can be prevented with the use of insecticide treated net, while 67 Respondents representing $17 \%$ also agreed. Whereas 35 of the respondents representing $9 \%$ strongly disagreed and 57 Respondents representing $15 \%$ disagreed that Malaria can be prevented with the use of insecticide treated net.

Question: Majority of pregnant women use the hospital regularly for antenatal appointments and check-up.

Table 13. Responses on if Majority of pregnant women use the hospital regularly antenatal appointments and check-up

\begin{tabular}{|l|l|l|}
\hline $\begin{array}{l}\text { Respondent } \\
\text { response }\end{array}$ & frequency & percentage \\
\hline Strongly Agreed & 135 & $35 \%$ \\
\hline Agreed & 88 & $23 \%$ \\
\hline $\begin{array}{l}\text { Strongly } \\
\text { Disagreed }\end{array}$ & 79 & $20 \%$ \\
\hline Disagreed & 86 & $22 \%$ \\
\hline Total & 388 & $100 \%$ \\
\hline
\end{tabular}

Source: Field survey november, 2015.

It could be noticed from the above table that 135 out of 388 respondents were of the view that Majority of pregnant women use the hospital regularly for antenatal appointments and check-up, while 88 , representing $23 \%$ agreed, that Majority of pregnant women use the hospital regularly for antenatal appointments and check-up. 79 respondents representing 20\% strongly disagreed and 86 respondents maintained that Majority of pregnant women use the hospital regularly for antenatal appointments and check-up.

Question: Majority of pregnant women use hospital every time they sick

Table 14. Responses on whether majority of pregnant women use hospital every time they sick

\begin{tabular}{|l|l|l|}
\hline $\begin{array}{l}\text { Respondent } \\
\text { response }\end{array}$ & frequency & percentage \\
\hline Strongly Agreed & 177 & $46 \%$ \\
\hline Agreed & 144 & $37 \%$ \\
\hline $\begin{array}{l}\text { Strongly } \\
\text { Disagreed }\end{array}$ & 37 & $10 \%$ \\
\hline Disagreed & 30 & $7 \%$ \\
\hline Total & 388 & $100 \%$ \\
\hline
\end{tabular}

Source: Field survey november, 2015.

The above table shows that 177 of respondents representing $46 \%$ stated that Majority of pregnant women use hospital every time they sick. 144respondents representing 37\% also agreed. While 37 respondents representing 10\% strongly disagreed that Majority of pregnant women use hospital every time they sick, also $30(7 \%)$ are of the view that Majority of pregnant women use hospital every time they sick. 
DOI: $10.21522 /$ TIJPH.2013.06.02.Art014

ISSN: 2520-3134

Question: Majority of pregnant women do not use the hospital at all

Table 15. Responses on whether majority of pregnant women do not use the hospital at all

\begin{tabular}{|l|l|l|}
\hline $\begin{array}{l}\text { Respondent } \\
\text { response }\end{array}$ & frequency & percentage \\
\hline Strongly Agreed & 137 & $35 \%$ \\
\hline Agreed & 140 & $36 \%$ \\
\hline $\begin{array}{l}\text { Strongly } \\
\text { Disagreed }\end{array}$ & 61 & $16 \%$ \\
\hline Disagreed & 50 & $13 \%$ \\
\hline Total & 388 & $100 \%$ \\
\hline
\end{tabular}

Source: Field survey november, 2015

The above table shows that 137 of respondents representing 35\% stated that Majority of pregnant women do not use the hospital at all, 140 respondents representing 36\% also agreed. While 61 respondents representing $16 \%$ strongly disagreed that Majority of pregnant women do not use the hospital at all, also 50 and $13 \%$ are of the view that Majority of pregnant women do not use the hospital at all.

Question: Majority of pregnant women are unaware of the hospital and resource available before them.

Table16. Responses on whether majority of pregnant women are unaware of the hospital and resource available before them

\begin{tabular}{|l|l|l|}
\hline $\begin{array}{l}\text { Respondent } \\
\text { response }\end{array}$ & frequency & percentage \\
\hline Strongly Agreed & 200 & $52 \%$ \\
\hline Agreed & 118 & $30 \%$ \\
\hline $\begin{array}{l}\text { Strongly } \\
\text { Disagreed }\end{array}$ & 40 & $10 \%$ \\
\hline Disagreed & 30 & $8 \%$ \\
\hline Total & 388 & $100 \%$ \\
\hline
\end{tabular}

Source: Field survey november, 2015.

The above table shows that 200 of respondents representing 52\% stated that Majority of pregnant women are unaware of the hospital and resource available before them. 118respondents representing $30 \%$ also agreed. While 40 respondents representing $10 \%$ strongly disagreed that Majority of pregnant women are unaware of the hospital and resource available before them, also $30(8 \%)$ are of the view that Majority of pregnant women are unaware of the hospital and resource available before them.

\section{Test of hypotheses}

\section{Test of stated hypotheses}

The benchmark was also used as the population mean for this study. Stated hypotheses were statistically tested with the Z-statistic at $5 \%$ level of significance on a one-tailed test.

\section{Test of hypothesis one (Ho1)}

In other to test the hypothesis $\mathrm{Ho}_{1}$ : Pregnant women, attending antenatal clinic in Mile Four Hospital, Abakaliki in Ebonyi State were awared of malaria preventive measures. Therefore, there was a need to ascertain if pregnant women are aware of whether Malaria can be prevented by avoiding mosquito bite. 


\section{Texila International Journal of Public Health \\ Volume 6, Issue 2, Jun 2018}

Computed $\mathbf{Z}$ value of 37.5 is greater than the critical value $\left(Z_{0.05}\right)$ of 1.64 . The null hypothesis one $\left(\mathrm{Ha}_{1}\right)$ is therefore rejected to conclude that Pregnant women, attending antenatal clinic in Mile Four Hospital, Abakaliki in Ebonyi State are not aware of malaria preventive measures of malaria.

\section{Test of hypothesis two (Ho2)}

In the quest determine if pregnant women attending antenatal clinic in Mile Four Hospital, Abakaliki in Ebonyi State are utilizing malaria preventive measures to prevent themselves. The data in table 12 were used to compute the sample mean score and standard deviation for test of hypothesis one.

Computed $\mathrm{Z}$ value of -20.93is less than the critical value $\left(\mathrm{Z}_{0.05}\right)$ of 1.64 . The null hypothesis one $\left(\mathrm{Ho}_{1}\right)$ is therefore accepted to conclude that Pregnant women attending antenatal clinic in Mile Four Hospital, Abakaliki in Ebonyi State are utilizing malaria preventive measures to prevent themselves.

Table 19. Summaries of results of tested hypotheses

\begin{tabular}{|l|l|l|l|l|}
\hline Hypothesis & $\mathbf{Z}_{0.0}$ & $\mathbf{Z}$ & Comparison & Decision and Conclusion \\
\hline $\mathrm{Ha}_{1}$ & 1.64 & 37.5 & $37.5>1.64$ & $\begin{array}{l}\text { Reject } \mathrm{Ho}_{1} \text { and accept } \mathrm{Ho}_{1} \\
\text { that Pregnant women, } \\
\text { attending antenatal clinic in } \\
\text { Mile Four Hospital, } \\
\text { Abakaliki in Ebonyi State } \\
\text { are aware of malaria } \\
\text { preventive measures. }\end{array}$ \\
\hline $\mathrm{Ho}_{2}$ & 1.64 & - & $-20.93<$ & $\begin{array}{l}\text { Reject } \mathrm{Ho}_{2} \text { and accept } \mathrm{Ha}_{2} \\
\text { that Pregnant women } \\
\text { attending antenatal clinic in } \\
\text { Mile Four Hospital, } \\
\text { Abakaliki in Ebonyi State } \\
\text { are utilizing malaria } \\
\text { preventive measures to } \\
\text { prevent themselves. }\end{array}$ \\
\hline
\end{tabular}

Source: Researcher's computation (2016).

\section{Conclusion}

Based on the statistical analysis as presented on the tables above the summary can state as follows:

1. Pregnant women, attending antenatal clinic in Mile Four Hospital, Abakaliki in Ebonyi State are aware of malaria preventive measures.

2. Pregnant women attending antenatal clinic in Mile Four Hospital, Abakaliki in Ebonyi State are utilizing malaria preventive measures to prevent themselves.

\section{Analyses of the findings}

For purpose of analysis and easy presentation of the data, the data was presented with the aid of table percentage.

Table 2 disclosed that four hundred questionnaires were distributed to the respondents, out of the 400 questionnaires, 45 representing $12 \%$ were administered to the senior staffs and above, 51 questionnaires representing $13 \%$ were also distributed to junior staffs, and the entire questionnaire were returned completely. Moreover 154 questionnaires were also distributed to Pregnant Women attending antenatal from 0-5 months and 150 questionnaires were also distributed to Pregnant Women attending antenatal from 6- 9 months and 148 and 144 were returned respectively. Therefore, out of 400 questionnaires distributed, 388 questionnaires representing $98 \%$ of the total questionnaires were returned. Therefore, the returned questionnaire was used for the purpose of the study

In the quest to ascertain whether pregnant women are aware of the implications of mosquitoes bite to malaria infections. It was discovered from table 3, that 215 respondents representing 58\% strongly agreed that Mosquitoes bite causes malaria, whereas 134 respondents representing 36\% agreed that 
DOI: $10.21522 /$ TIJPH.2013.06.02.Art014

ISSN: $2520-3134$

Mosquitoes bite causes malaria. However, 13 respondents representing 4\% strongly disagreed also 6 respondent representing 2\% disagreed Mosquitoes bite causes malaria. Based on the above analysis, it can be seen that pregnant women are aware that mosquito bite causes malaria.

In other to ascertain the views of pregnant women on whether poor environmental sanitation causes malaria, table 4 detailed that. 236 respondent representing $61 \%$ strongly agreed that Poor environmental sanitation causes malaria, while 92 respondents representing $24 \%$ agreed that Poor environmental sanitation causes malaria, while 33 respondents representing $8 \%$ strongly disagreed and 27 respondents representing $7 \%$ disagreed also. Therefore, it can be denote from the table that most of respondents that poor environmental sanitation causes malaria.

There was a need know to if pregnant women were aware that poor nutrition system could cause malaria. Table 5 stated that, 118 of respondents representing 30\% strongly agreed that Poor nutrition system causes malaria, where 193 respondents representing 50\% agreed that Poor nutrition system causes malaria. However 33 respondents representing 9\% strongly disagreed that poor nutrition system causes malaria and 44 respondents representing $11 \%$ disagreed that. Poor nutrition system causes malaria this shows that greater percentage of the respondents agreed that Poor nutrition system causes malaria.

The process of the investigation, it was important to ascertain if poor drainage system causes malaria. Table 6 indicated that 274 respondents representing 71 percent strongly agreed that Poor drainage system causes malaria, 85 respondents representing 22 percent agreed that Poor drainage system causes malaria, while 29 respondents representing 7 percent strongly disagreed that Poor drainage system causes malaria. It can be denotes from the above that pregnant women are aware that Poor drainage causes malaria.

On the process of the investigation, the researcher tends to know if pregnant women were aware that Malaria can be prevented by avoiding mosquito bite. Table 7 showed that 248 respondents representing $69 \%$ are of the view that Malaria can be prevented by avoiding mosquito bite, 94 respondents representing $24 \%$ of the respondents maintained that. Malaria can be prevented by avoiding mosquito bite. Furthermore, 14 respondents representing $4 \%$ and the remaining 12 respondents representing 3 percent are of the view that Malaria can be prevented by avoiding mosquito bite. It can be seen from the above analysis that, malaria can be prevented by avoiding mosquito bites

In order to know if pregnant women are aware that malaria can be prevented by the use of intermittent preventive therapy (IPT). The above table 8 detailed that the respondents view of whether Malaria can be prevented by the use of intermittent preventive therapy (IPT), 236 respondents representing $61 \%$ strongly agreed and 108 respondents representing $28 \%$ also agreed, whereas 34 respondents representing 9\% strongly disagreed that Malaria can be prevented by the use of intermittent preventive therapy (IPT) and 10 of the respondents disagreed that Malaria can be prevented by the use of intermittent preventive therapy (IPT). The above is an indication that pregnant women are aware that malaria can be prevented by the use of intermittent preventive therapy (IPT).

The researcher tends to know if the pregnant women are aware that malaria can be prevented by the use of insecticide treated mosquito nets. Table 9 indicated that 226 respondents representing $61 \%$ are of the view that malaria can be prevented by the use of insecticide treated mosquito nets, 150 respondents representing 39\% also agreed. Meanwhile, 12 of the respondents representing 3\% strongly disagreed that malaria can be prevented by the use of insecticide treated mosquito nets.

The need aroused to ascertain if malaria can be prevented by Health Education and creation of awareness. Table 10 disclosed that 247 respondents representing $64 \%$ are of the strongly agreed that Malaria can be prevented by Health Education and creation of awareness, 141 respondents representing 36\% are of the view that: Malaria can be prevented by Health Education and creation of awareness. From the above analysis it can be deduced that Malaria can be prevented by Health Education and creation of awareness.

The researcher wanted to know if pregnant women were aware of Environmental sanitation as a preventive measure of Malaria. Table 11 showed that 220 of respondents representing $57 \%$ stated that Malaria can be prevented through Environmental sanitation. 114respondents representing 29\% also agreed. While 44 respondents representing $11 \%$ strongly disagreed that Malaria can be prevented 


\section{Texila International Journal of Public Health}

Volume 6, Issue 2, Jun 2018

through Environmental sanitation, also 10 (3\%) are of the view that Malaria cannot be prevented through Environmental sanitation.

The investigation disclosed that majority of pregnant women agreed that malaria can be prevented with the use of insecticide treated net, this can be seen in table 12, wehere 229 Respondents representing 59\% strongly agreed that Malaria can be prevented with the use of insecticide treated net, while 67 Respondents representing $17 \%$ also agreed. Whereas 35 Respondents representing 9\% strongly disagreed and 57 Respondents representing $15 \%$ disagreed that Malaria can be prevented with the use of insecticide treated net.

It could be noticed from table 13 that 135 out of 388 respondents were of the view that Majority of pregnant women use the hospital regularly for antenatal appointments and check-up. While 88, representing 23\% agreed that Majority of pregnant women use the hospital regularly for antenatal appointments and check-up. 79 respondents representing 20\% strongly disagreed and 86 respondents maintained that Majority of pregnant women use the hospital regularly for antenatal appointments and check-up.

Also in table 14, it was stated that 177 of respondents representing $46 \%$ stated that Majority of pregnant women use hospital every time they sick. 144respondents representing $37 \%$ also agreed. While 37 respondents representing 10\% strongly disagreed that Majority of pregnant women use hospital every time they sick, also $30(7 \%)$ and $30(8 \%)$ are of the view that Majority of pregnant women use hospital every time they sick.

Table 15 showed that 137 of respondents representing 35\% stated that Majority of pregnant women do not use the hospital at all, 140 respondents representing $36 \%$ also agreed. While 61 respondents representing $16 \%$ strongly disagreed that Majority of pregnant women do not use the hospital at all, also 50 and $13 \%$ are of the view that Majority of pregnant women do not use the hospital at all.

Table 16 also has it that 200 of respondents representing 52\% stated that Majority of pregnant women are unaware of the hospital and resource available before. 118respondents representing 30\% also agreed. While 40 respondents representing 10\% strongly disagreed that Malaria can be prevented through Environmental sanitation, also $30(8 \%)$ are of the view that Majority of pregnant women are unaware of the hospital and resource available before.

In the process of testing hypothesis "Ho " which stated that Pregnant women, attending antenatal clinic in Mile Four Hospital, Abakaliki in Ebonyi State are aware not of malaria preventive measures of malaria. The data in table 7 were used to compute the sample mean score and standard deviation and $Z$ statistics was used to test the hypothesis where $Z$ value of 37.5 is greater than the critical value $\left(\mathrm{Z}_{0.05}\right)$ of 1.64 . The null hypothesis one $\left(\mathrm{Ha}_{1}\right)$ is therefore rejected to conclude that Pregnant women, attending antenatal clinic in Mile Four Hospital, Abakaliki in Ebonyi State are not aware of malaria preventive measures of malaria.

Also data in table 12 were used to compute the sample mean score and standard deviation for test of hypothesis two.

Computing $Z$ value of -20.93is less than the critical value $\left(Z_{0.05}\right)$ of 1.64 . The null hypothesis one $\left(\mathrm{Ho}_{1}\right)$ is therefore accepted to conclude that Pregnant women attending antenatal clinic in Mile Four Hospital, Abakaliki in Ebonyi State are not utilizing malaria preventive measures to prevent themselves.

\section{Summary, conclusion and recommendations}

\section{Summary}

According to WHO 2010, Millions of pregnant women are exposed to malaria and thousands die every year through direct or indirect as a result of its consequences. It further disclosed that in all endemic areas, babies born to mothers infected with malaria parasites have a low birth weight and also at increased risk of death in infancy. Therefore, it is essential to treat pregnant women, who are infected with plasmodium parasites effectively. (White et al.; 2014).

It further stated that a quarter of all malaria cases in Africa occur in Nigeria. This magnitude of occurrence in this part of the world correlates with poverty, ignorant and social deprivations in the community. The problem of malaria in pregnancy possesses a substantial risk to the mother, her foetus and the neonates. It significantly contributes to anaemia in pregnancy as the parasitmia appear 


\section{DOI: $10.21522 /$ TIJPH.2013.06.02.Art014}

\section{ISSN: 2520-3134}

greater in the second trimester and may persist into the early post-partum period, increasing the low birth weight and is associated with preterm deliveries, still birth and perinatal mortality in Nigeria (Centre for Disease and Prevention, 2009)

Furthermore, malaria is responsible for $25 \%$ of infant mortality and $30 \%$ of all childhood death and that is why Nigeria is a signatory to the Abuja declaration that set as one of the Abuja targets that $60 \%$ of pregnant women should receive intermittent preventive treatment drug during pregnancy by end of 2005 (WHO, 2014). Despite the effective launching of the roll back malaria since year 2001 in most African countries. Pregnant women have a higher risk than the non - pregnant ones to be infected with malaria and they are at increased risk of adverse events such as ammonia, risk of miscarriage, still birth, preterm delivery, total growth, restriction and even death.

It should be recalled that, Most Ebonyi people including women and highly involve in agricultural activities, which encourage the breeding of mosquitoes and consequently malaria infection is not an over statement to state that malaria has numerous negative outcomes which may include financial involvement translating into poor standard of living, hospital visitations as well as low productivity and loss of income (Kayentao et al.; 2012).

Based on the negative impact of malaria to pregnant women, this research is aimed at conducting an investigation to ascertain the extent of awareness and utilization of malaria preventive measures to pregnant women, attending antenatal clinic in Mile Four Hospital, Abakaliki in Ebonyi State. The population of the study was all the staff of antenatal section and pregnant women attending antenatal in Mile Four Hospital Abakaliki. The researcher adopted Taro Yamani sampling technique to get the representatives of the entire population.

The finding disclosed that pregnant women, attending antenatal clinic in Mile Four Hospital, Abakaliki

in Ebonyi State are aware of malaria preventive measures, and also that pregnant women attending antenatal clinic in Mile Four Hospital, Abakaliki in Ebonyi State are utilizing malaria preventive measures to prevent them.

\section{Conclusion}

In the process of this study, it was concluded that those pregnant women are aware that mosquito bite causes malaria, that poor environmental sanitation causes malaria, the respondents agreed that Poor nutrition causes malaria, that majority of pregnant women are aware that Poor drainage system causes malaria.

In quest to ascertain if the pregnant women are aware of preventive measure available to prevent malaria, the researcher also concluded that: most of the pregnant women were of the view that malaria can be prevented by avoiding mosquito bite, that the pregnant women are aware that malaria can be prevented with the use of intermittent preventive therapy (IPT), that they are also aware that Malaria can be prevented with the use of insecticide treated mosquito nets, that the pregnant women were also aware that Malaria can be prevented by Health Education and creation of awareness, pregnant women are of the view that Malaria cannot be prevented through Environmental sanitation.

Majority of pregnant women do not use the hospital regularly for antenatal appointments and check-up, that Majority of pregnant women do not use hospital every time they sick, that Majority of pregnant women do not use the hospital at all and that Majority of pregnant women are unaware of the hospital and resource available before them.

Based on the tested hypothesis, the researcher also concluded that, Pregnant women, attending antenatal clinic in Mile Four Hospital, Abakaliki in Ebonyi State are aware of malaria preventive measures and that Pregnant women attending antenatal clinic in Mile Four Hospital, Abakaliki in Ebonyi State are utilizing malaria preventive measures to prevent themselves.

\section{Recommendations}

Having gone through the related literature, analysis of respondent's views on the subject matter and base on the results and findings of this work, the following recommendations were made by the researcher to address the challenges found in the cause of the study that have been militating against the awareness and utilization of malaria preventive measures to pregnant women attending antenatal 


\section{Texila International Journal of Public Health \\ Volume 6, Issue 2, Jun 2018}

clinic in Mile Four Hospital, Abakaliki in Ebonyi State. The researcher recommends as follows: That awareness campaign should be drawn to rural areas so that Pregnant women should be educate on high risk involve in malaria infestation, because if they are fully aware of the risk, Majority of pregnant women will be using the hospital regularly for antenatal appointments and check-up, Most of them will use hospital every time they sick and thereby become aware of the hospital and resource available before them reducing the level of miscarriage, low birth weight, still birth and maternal death.

Awareness campaign should be drawn to rural areas so that pregnant women should know the risk associated with the activities that will encourage the breeding of mosquitoes, mosquito bite, poor environmental sanitation, Poor nutrition, and Poor drainage system causes malaria.

pregnant women in rural areas will also be educate on the prevention of malaria through the use of insecticide treated mosquito nets, intermittent preventive therapy (IPT), Environmental sanitation and by avoiding mosquito bite.

\section{Acknowledgment}

I thank God for his faithfulness, assistance and strength towards me and also my friends who contributed greatly on this work.

\section{References}

[1].Ahmed, R., Levy, E.I., Maratina, S.S, et al; (2010). Performance of four HRP-2/pLDH combination rapid diagnostic tests and field microscopy as screening tests for malaria in pregnancy in Indonesia: a cross-sectional study.

[2].Bhatia, R., Rastogi, R.M. and Ortega, L. (2013). Malaria successes and challenges in Asia. J Vector Borne Dis.

[3].Bugvi, S.M. and Ahmed, N. (2015). Congenital Malaria: ARare Entity. J Coll Physicians Surg Pak.

[4].Centers for Disease Control and Prevention, (2009).Intermittent Preventive Treatment of Malaria for Pregnant Women (IPTp).

[5].Chukwuochaetal, (2010). The World Malaria Report Malaria: guidance, data and analysis.

[6].David, Sinclair. (2012). Malaria and Pregnancy: A Global Health Perspective.

[7].Ducarme, G., Thuillier, C. and Wernet, A. et al. (2008). Malaria in pregnant woman masquerading as help syndrome.

[8].Kayentao, K., Garner, P. and van Eijk, A.M., et al; (2012). Intermittent preventive therapy for malaria during pregnancy using 2 vs 3 or more doses of sulfadoxine-pyrimethamine and risk of low birth weight in Africa: systematic review and meta-analysis.

[9].Minnesola, (2010). Mental Health Care Delivery NetworkMalaria facts.http://www.cdc.gov/malaria/facts.htm. Updated.

[10]. White, N.J. and Breman, J.G. (2014). Malaria. In: Fauci AS, Braunwald E, Kasper DL, et al., editors. Harrison's Principles of Internal Medicine. 17th ed. New York: McGraw-Hill.

[11]. Williams, L.L., Jr (2016). Malaria eradication in the United States. Am J Public Health Nations Health.

[12]. World Health Organization, authors. (2003). Guidelines for the Treatment of Malaria. Geneva: World Health Organization.

[13]. World Health Organization (2010). Web site, authors. Global Malaria Programme: pregnant women and infants.

[14]. World health organization (2013). The World Malaria Report, summarize information received from malaria-endemic countries and other sources, and updates the analyses.

[15]. World Health Organization (2014). Web site, authors. Global Malaria Programme: pregnant women and infants. 


\title{
Menstrual Hygiene Practices of Female Garment Workers
}

\author{
Article by M.M Aktaruzzaman ${ }^{1,}$ Irin Hossain ${ }^{2}$ \\ ${ }^{1} V B D C, D G H S$ \\ ${ }^{2}$ National Institute of Preventive and Social Medicine, Mohakhali, Dhaka \\ E-mail: irin.hossain@gmail.com
}

\begin{abstract}
Readymade garment sector has been playing an important role in enhancing Bangladesh economy. Women represent 85 percent of the total 30 million employees in readymade garment industry. A cross sectional descriptive study was carried out among the garments workers with the objective to assess the menstrual hygiene practices of female garment with structured questionnaire by workers. Majority of the respondents were within the age group of 18-23 years. This study showed that only $30.5 \%$ respondents were maintaining personal hygiene properly during menstruation and 12\% satisfied about their washing facilities in their working place. This study reflected different dimension in their reproductive life which were not upto the level. It should be improved for better standard. Further large scale studies needed to explore the real situation in this regard.
\end{abstract}

Keywords: Menstrual Hygiene practice, garment workers.

\section{Introduction}

Readymade garment sector has been playing an important role in enhancing Bangladesh economy. Women represent 85 percent of the total 24 million employees in readymade garment industry. Bangladesh is a society that has traditionally been characterized by very early marriage and child bearing when this is a period of physiological, emotional and intellectual development. The main objectives of this research were to identify knowledge and behavior of garments workers about menstruation. During the transition to adulthood, lack of knowledge and awareness about reproductive organs, physiological changes, or sexuality can promote psychosocial stress. About 34 million adolescents (10-19 years old) constitute $21 \%$ of total population of Bangladesh [1]. This is particularly so for girls, who also face gender discrimination. In most cases, their mothers are the only source of information. Most girls perceive menstruation as disgusting and as a curse [2]. Female garments workers are also at higher risk of psychosocial stress because of gender discrimination [3]. There is a lack of knowledge and awareness among female garments workers about health issues and problems like puberty, menstruation, physical changes in the body, reproduction, contraception, pregnancy, childbearing, reproductive tract infections, sexually transmitted infections (STIs), and HIV. A study conducted in Madras city revealed that 42 percent of the college and 34 percent of the school-going students reported problems during menstruation. The problems included headache, stomach pain, excessive bleeding, and other vague or non-specific symptoms like lethargy and loss of appetite. Girls are left socially isolated without sufficient knowledge and skills to effectively navigate life's challenges [4] (Urban Adolescent Needs Assessment Survey in Bangladesh, BIED \& BRACU). Nearly two-thirds of those who had problems sought medical treatment. Although most of these are normal symptoms of menstruation among adolescents, these need to be mentioned particularly in the Indian context because most of the girls are not aware of this natural phenomenon. Maternal mortality among mothers aged 15-19 is also very high as compared to the among mothers in the 20-24 years age group [5].They are not aware regarding their menstrual hygiene so they use unhygienic clothes or sanitary kits. According to WHO the cingulate mean age at first marriage for female of Bangladesh in 1995, was 18.8 in rural and 21.6 in urban areas [6]. As they are to work long term in garment factory and there is inadequate and unhealthy environment of bathroom facilities they could not change their pads timely. So they cannot maintain good menstrual hygiene practice. Adolescent girls are vulnerable to reproductive health problems like spasmodic dysmenorrhoea, heavy menstrual bleeding, scanty menstruation, amenorrhoea, irregular menstruation, leucorrhoea, vaginal candidiasis, pruritus 
vulvae, etc. as they have very little access to information and health care. Consequently they face health risk in their future lives.

\section{Methods}

\section{Study design and sample}

This study was conducted to assess the menstrual hygiene practices of female garment workers of Meherun Apparels Ltd Malibag, Dhaka according to the following methodologies:

This cross sectional study was conducted at two garments, Meherun Apparels Ltd Malibag, Dhaka. Data were collected by face to face interview, by asking them questions as per the written questionnaire at the factory. The study populations were interviewed one after another without disturbing their routine works.

\section{Analysis}

Collected data were analyzed after thorough checking, cleaning, editing and compiling by using the SPSS (Statistical package for social science, version 24 for windows) software and scientific calculator. Continuous variables were recorded into categorical variable by creating groups. The data were presented in different Tables, charts. The data were presented in different tables in order to the variables. Frequency tables according to the variables.The test statistics was used to analyze the data is descriptive statistics and inferential statistic according to the demand of the study with 95\% confidence interval. Level of significance was set at 0.05 . Qualitative data were analyzed on the basis of themes.

\section{Result}

This was a cross sectional study, conducted in garment factory with the main objective of the study was to assess the menstrual hygiene practice among the female garment worker. A total of 200 patients were interviewed.

\section{Distribution of the respondents by practice of clean material and materials used for cleanliness during menstruation $\mathbf{n}=\mathbf{2 0 0}$}

Out of the total 200 respondents, most of them 139 (69.5\%) did not use clean materials and less than one third $61(30.5 \%)$ used clean materials during menstruation. Out of the total 200 respondents, most of them 157 (78.5\%) had used old cloths and 41 (20.5\%) had used sanitary pads for maintaining cleanliness during menstruation.

Table 1. Distribution of the respondents by practice of clean material and materials used for cleanliness during menstruation

\begin{tabular}{|l|l|l|}
\hline $\begin{array}{l}\text { Practice of clean material } \\
\text { use }\end{array}$ & Frequency & Percentage \\
\hline Non clean material & 139 & 69.5 \\
\hline Clean material & 61 & 30.5 \\
\hline Materials used for cleanliness & \multicolumn{2}{|l|}{} \\
\hline Sanitary pads & 41 & 20.5 \\
\hline Old cloths & 157 & 78.5 \\
\hline Cotton & 2 & 1.0 \\
\hline
\end{tabular}

\section{Distribution of the respondents by menstrual hygiene practice}

Out of the total 157 respondents who practice using cloths, one fifth 117 (74.5\%) of them had washed with water \& soap, above one tenth $25(16 \%)$ with water only and below one tenth $15(9.5 \%)$ washed by soap \& savlon. Out of the total 157 respondents who practiced using cloths maximum of the respondents $137(87.26 \%)$ dried the cloth properly and more than one tenth $20(12.74 \%)$ of the respondents did not practice drying of cloths. Out of the total 137 respondents who dried the cloth properly, almost all of the respondents $125(91.24 \%)$ kept the cloth in safe place during menstruation. 
Table 2. Distribution of the respondents by menstrual hygiene practice

\begin{tabular}{|c|c|c|}
\hline $\begin{array}{l}\text { Practice of washing process of old } \\
\text { cloth } n=157\end{array}$ & Frequency & Percentage \\
\hline To wash with water only & 25 & 16.0 \\
\hline To wash with water \& soap & 117 & 74.5 \\
\hline To wash with soup \& savlon & 15 & 9.5 \\
\hline To wash with water only & 25 & 16.0 \\
\hline \multicolumn{3}{|c|}{ Practice of proper drying of cloth $n=157$} \\
\hline No & 20 & 12.74 \\
\hline Yes & 137 & 87.26 \\
\hline \multicolumn{3}{|l|}{ Keeping the cloth in safe place $n=137$} \\
\hline No & 12 & 8.76 \\
\hline Yes & 125 & 91.24 \\
\hline
\end{tabular}

\section{Distribution of the respondents by associated symptoms during menstruation $\mathbf{n}=\mathbf{2 0 0}$}

Out of the total 200 respondents, most of the respondents $88(44.0 \%)$ did not face any problem, 84 (42\%) had lower abdominal pain, one tenth 21 (10.5\%) developed weakness and a few $7(3.5 \%)$ developed nausea and vomiting during menstruation.

Table 3. Distribution of the respondents by associated symptoms during menstruation

\begin{tabular}{|l|l|l|}
\hline $\begin{array}{l}\text { Physiological problems } \\
\text { during menstruation }\end{array}$ & Frequency & Percentage \\
\hline No problem & 88 & 44.0 \\
\hline Nausea \& vomiting & 7 & 3.5 \\
\hline Lower abdominal pain & 84 & 42.0 \\
\hline Weakness & 21 & 10.5 \\
\hline
\end{tabular}

\section{Discussion}

The study was carried out to describe the Menstrual Hygiene Practices of Female Garment Workers in Selected Garment Factory. The study was done to assess the menstrual hygiene of female garment workers.

The minimum age was 18 years and the maximum age was 47 years. Out of the total 200 respondents, most of them $139(69.5 \%)$ did not use clean materials and less than one third $61(30.5 \%)$ used clean materials during menstruation. Out of the total 200 respondents, most of the respondents $88(44.0 \%)$ did not face any problem, $84(42 \%)$ had lower abdominal pain, one tenth $21(10.5 \%)$ developed weakness and a few 7 (3.5\%) developed nausea and vomiting during menstruation. most of them $176(88 \%)$ had not enough toilet facilities in their job places and only more than one tenth 24 $(12 \%)$ had enough toilet facilities.

\section{Conclusion}

Female garments Workers are associated with a wide range of negative social and health consequences and contribute to rapid population growth. This study showed that more than half respondents had not used clean material during menstruation. More than half of the respondents did not have any physical sickness during menstruation. But among rest of them majority felt lower abdominal pain, one tenth felt weakness and few felt nausea and vomiting. Maximum respondents were satisfied for enough toilet facilities in their job place and most of the respondents got support from guardian or authority.

\section{Acknowledgement}

I am extremely grateful to my respected teacher Assistant Professor Dr. Md. Shafiur Rahman for his continuous support and scholarly guidance despite his busy schedules. Without his valuable 
advices, constructive suggestions, passion and whole-hearted co-operation, I could never have completed it in time.

I express my sincere gratitude to Prof. Manzurul Haque Khan, PhD, Program in charge MPH $(\mathrm{OEH})$ and Dr. Irin Hossain, Lecturer, Department of Occupational and Environmental Health for their valuable advices, constructive suggestions and support to me regarding the whole task of the thesis.

I express my profound thanks to the Managing Director of Meherun Apparels, Malibag Chowdhury Para, Dhaka. At the same time I would like to extend my sincere thanks to all the respondents of this study for their kind participation.

\section{References}

[1].Acharya Dev Raj, Bhattarai Rabi, Pobalan Amuda, van Teijlingen, Edwin R, Chapman Glyn (2010) on Factors associated with teenage pregnancy in south Asia in Health science Journal, vol 4, issue 1.

[2].BRAC Annual Education Report, (2006).

[3].Gillespie Stuart on Improving Adolescent and Maternal Nutrition: An Overview of Benefits and Options (1997), papers no. 97-002.

[4].Rao.A.R. on "The Need and Challenge of Adolescent Health." Health for the Millions. May-June, (1995).

[5].Sharma A; Verma k; Khatri S. kannan A on Pregnancy in adolescent: a study of risks and outcome in Eastern Nepal, (2001); vol 38; pp 1405-1409.

[6].WHO Adolescent health report on Bangladesh (2016). 


\title{
Pertussis Vaccine; the Past, the Present and the Future (A Mini Review)
}

\author{
Article by Frank Adusei-Mensah \\ Ph.D., Public Health, Texila America University \\ E-mail:drfrank83@gmail.com
}

\begin{abstract}
The inception of the whole cell pertussis vaccine wP saw global reduction in reported cases, mortality and morbidity burden to the disease. But, in the late 90s, wP was replaced with acellular pertussis vaccine $(a P)$ in most countries due to safety reasons. In recent years however, the annual reported cases of pertussis globally have increase greatly even among highly vaccinated groups, ${ }^{1} ;{ }^{2}$. This nurtures concerns about the level of protection aP bestows on the vaccinated individuals, ${ }^{2}$. The aim of this current mini review is therefore to assess some recent reports and developments on the matter, evaluate how alarming the situation is by comparing the present to the past and the recommendations for roadmap into the future.

Methodology: Boolean search was carried out on popular sites like PubMed and Google on publications and reviews on the topic.

Results: Some researchers have attributed the recent surge in reported pertussis cases and deaths to reasons like waning of vaccine induced immunity, inefficacy, resistant strain development and mutated forms in the pathogenic bacteria.

Conclusion: For a successful control and eradication of the pertussis disease, new strategies needed to be implemented to factor in the estimated waning effect; $27 \%$ / year of 4 years in total reduction in efficacy. Multicomponent aP vaccine $(n>3)$ has also been reported to be as effective as the wP vaccine hence modification of the current aP vaccine or re-visiting of $w P$ is can also be considered.
\end{abstract}

\section{Introduction}

Pertussis disease, also known as whooping cough, is a droplets contagious respiratory disease caused by Bordetella pertussis bacterium, ${ }^{3} ;{ }^{4}$. It affects all ages mostly children, ${ }^{5} ;{ }^{6}$ and has burdened humanity and public health care systems for centuries. French scientist; Guillaume de Baillou pioneered research into pertussis disease in 1578 which attracted the interest of many scientists leading to the development and licensing of pertussis vaccines in 1914 in the United States of America (USA), ${ }^{6}$. The bacteria attaches to the cilia of the upper respiratory tract and produces toxins which damages the cilia, inflames the airways and paralyzes parts of the respiratory cells, ${ }^{7} ;{ }^{8}$. Whooping sound may follow bouts of rapid coughing, the toxins produce inflammation in the respiratory tract with mild to severe cough, ${ }^{9} ;{ }^{10}$. The most virulent form of the bacteria strain in infants is the $B$. pertussis pneumonia. According previous studies, the bacteria has complex array of adhesins, aggressins and toxins that are important for colonization, survival and propagation in the human host, ${ }^{8} ;{ }^{11}$. Some scientists believe that the organism has the ability to undergo reversible mutations in response to the environment or treatment as part of its sophisticated mechanism, ${ }^{8}$ and this has been associated to the recent upsurge of the disease and a possible development of mutated and resistant strains ${ }^{3} ;{ }^{4}$

The disease is found in humans and all human race have the chance of catching the disease, ${ }^{7}$. The group specific prevalent rates for the (0-1) years age-group and (10-14) years age-group are high, ${ }^{5} ;{ }^{6}$. Mortality among children under six years old is the highest ${ }^{5}$. Vaccination and health promotion programmes are believed to be the most effective public health arsenal to preventing and controlling the disease, ${ }^{12}$. Immunization against pertussis is the best window in preventing the disease and an effective and reliable vaccine is the ultimate of researchers and health practitioners. Many countries switched to acellular aP vaccine due to its reduced vaccine related interactions compared to $\mathrm{wP}$ vaccine. The disease 
DOI: $10.21522 /$ TIJPH.2013.06.02.Art016

ISSN: $2520-3134$

is once again becoming a public health concern due to increased number of cases in recent years and the resurgence of the disease in many countries. The recent developments raises eyebrows about the efficacy of the current aP vaccine regime, ${ }^{13} ;{ }^{14} ;{ }^{15}$. The aim of this study therefore is to assess some recent reports and developments on the matter, evaluate how alarming the situation is by comparing the present to the past and the recommendations for roadmap into the future.

Conventional vaccines are developed with either killed or inactivated whole pathogenic cell, extract or part of the pathogenic organism to induce immune response in the host system (fig. 1), ${ }^{16}$. It could also be done through the reverse vaccinology path using in-silico computer aided vaccine design approach, 16. Pertactin (Prn) protein, fimbriae 2 (Fim2) and fimbriae 3 (Fim3) of B. pertussis are virulence factors and immunogens used in some aP vaccines whiles the inactivated whole cells are used in wP vaccine, ${ }^{17}$; 18 .

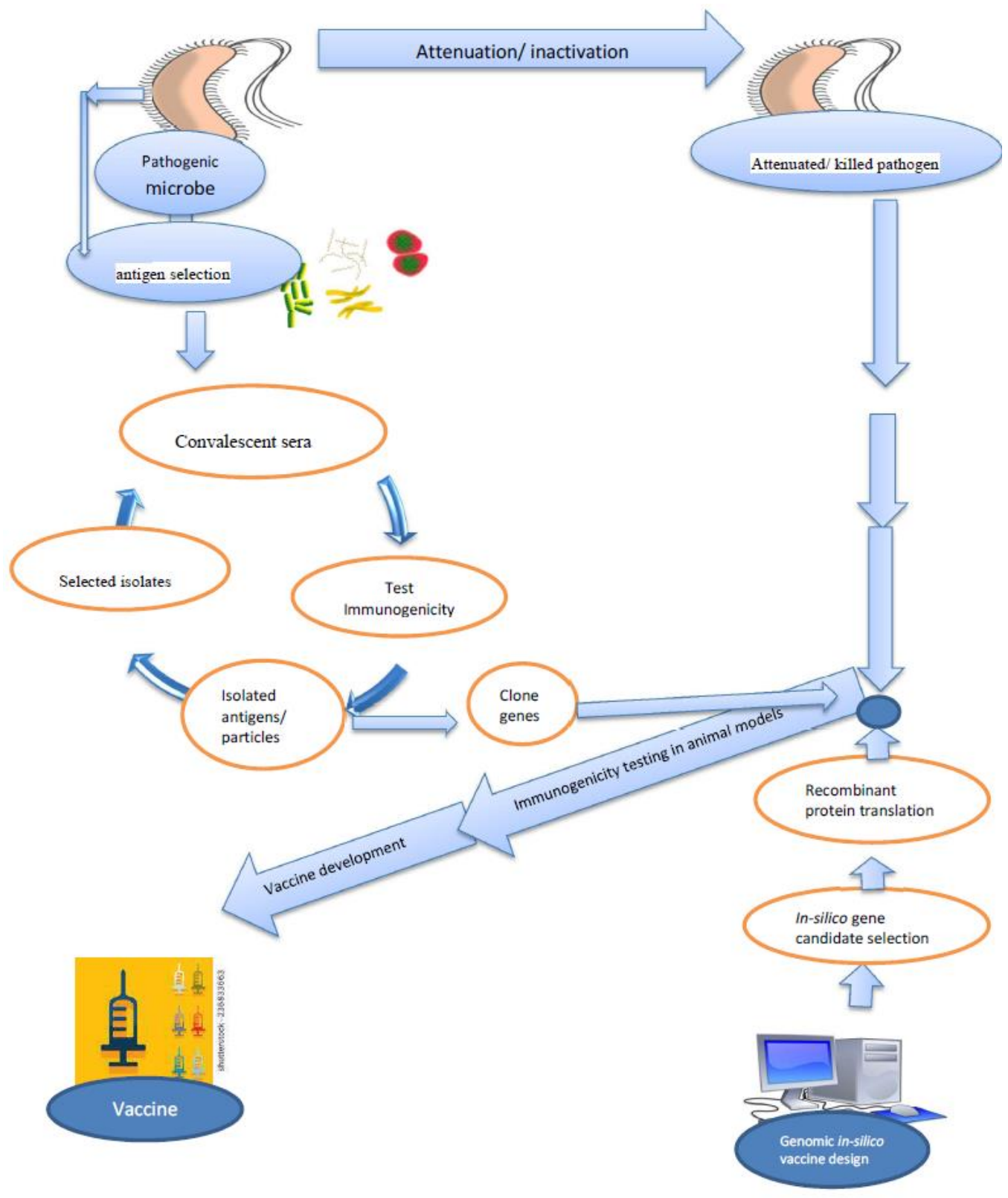

Figure 1. Schematic vaccine representation of conventional vaccine development 


\section{Pertussis disease and ap pertussis vaccine, the past}

Discovered by the American pediatrician Leila Daughtry-Denmark in late 1930s, the whole cell pertussis vaccine was introduced into the mainstream healthcare system in the late $1940 \mathrm{~s},{ }^{19} ;{ }^{20}$. The introduction of the whole cell pertussis vaccine (wP) into the mainstream healthcare system led to over $52 \%$ reduction in incidence of the disease from 156,517 in 1947 to just 74,715 in 1948 (fig. 2) in US alone. Other parts of the globe also experience the efficacies of the wP vaccine marked by reduced infection rates; ${ }^{21}$. In 1976, only 1,010 cases of incidence were reported in the United States ${ }^{22}$. Its introduction led to a drastic drop in the outbreak and mortality of the disease by over $90 \%$ globally, (WHO, 2015). In the US alone, there was a drastic drop in the annual reported cases from 120,718 in 1950 to 2,719 in 1991 (fig. 2) prior to the introduction of the acellular pertussis vaccine (DTaP), ${ }^{23}$. The wP gave immune protection to the individuals well into their teen ages, ${ }^{24}$. The success story of the whole cell vaccine was marred with the reports of severe adverse drug reactions. In the 1990s, the whole cell pertussis vaccine was replaced with acellular antigenic version due to reasons of safety and adverse drug reactions including febrile seizures, high fevers, fainting and unconfirmed reports of brain damage, comas, paralysis and death ${ }^{25}$; CDC 2015).

\section{aP pertussis vaccine; the present}

The pertussis disease is re-emerging in recent years with increasing number of reported annual outbreaks globally despite the high coverage of pertussis vaccination in recent years in many countries ${ }^{14}$; ${ }^{26} ;{ }^{27}$. There was an increase in reported cases and death in England and Wales for the year 2012 in almost a decade after aP vaccine replaced wP vaccine, ${ }^{28}$. An estimated 30.6 - 45 million pertussis cases and 390,000 deaths from pertussis in children younger than 5 years globally was reported for the year 1999, ${ }^{29}$; ${ }^{30}$. In 2015, there were more than 500 cases of pertussis in Maryland County in southern Liberia; the highest in decades ${ }^{31}$. In the United States, the number of annual reported cases begun to increase when the whole cell vaccine was replaced with the acellular version of the vaccine; from 2,719 in 1991 (fig. 2) to 25,827 in year 2004 and to 48,277 in $2012,{ }^{32}$. Vaccination coverage against pertussis infection globally is on the high side especially among developed countries, ${ }^{12} ;{ }^{28}$. Despite the high coverage, the outcome is not to the satisfaction of recipients and providers. The question is; what could be the cause? Some states and countries have modified their immunization strategy as a step towards solving the puzzle. In the US and UK, adults are vaccinated with pertussis vaccine with recommended boosters for pregnant women, ${ }^{33}$. In 2015, New Zealand modified its pertussis control strategy in hope of reducing the resurgence of the

disease, ${ }^{34}$. Chili among other states modified their pertussis control programs in view of the recent resurgence, ${ }^{35}$. Could it also be due to aP vaccine component and efficacy variations among aP vaccines; it was reported in a recent systematic revealed that multicomponent acellular pertussis $(\mathrm{aP})$ vaccine $(\mathrm{n}>$ 3) has protection efficacy of $84 \%$ to $85 \%$ against typical whooping cough, and from $71 \%$ to $78 \%$ in prevention for mild pertussis disease, ${ }^{24}$. The 1-component and 2-compoonent aP vaccines on the other hand gave much lesser protection against pertussis, with $22-41 \%$ odds of getting typical whooping cough and $42 \%-59 \%$ odds of getting mild pertussis disease ${ }^{24}$. Five component aP vaccine has also been reported to have similar effectiveness to wP vaccine whiles 3-component was less effective compared to wP vaccine, ${ }^{36}$.

\section{Waning of immune induced effect of aP vaccine}

It has been revealed that aP gives high immune response within the first few years after vaccination, but it decreases sharply after the fourth year of the last vaccination, ${ }^{37} ;{ }^{38} ;{ }^{39}$. Nicola reported that, after 5consecutive doses of a 3-component aP vaccine, the vaccine induced immunity wans $27 \%$ per year on average, ${ }^{40}$. Long-term follow-up study on vaccinated kids in Sweden by Gustafsson and colleagues revealed a similar pattern of waning and recommended booster dose be administered to children between 4-6 years after last vaccination, ${ }^{41}$. In 2011, Torres and colleagues reported that $86.4 \%$ of the incidence cases in the adolescent group were well vaccinated (Torres et al., 2011). In the US, there is more than six 
DOI: $10.21522 / \mathrm{TIJPH} .2013 .06 .02 . A r t 016$

ISSN: $2520-3134$

fold increase from 7867 in year 2000 to 48,277 in 2012, ${ }^{32}$ and according to Eshofonie and colleagues, all the cases of 2012 outbreak in a Rural Texas were fully vaccinated with $\mathrm{aP}^{13}$. The alarming rate of reemergence of the disease especially among the vaccinated group raises concerns about the longevity and waning effect of the acellular vaccine, ${ }^{42} ;{ }^{1}$. Reduced vaccine effectiveness, waning of vaccine induced protection and new strains/ mutations in the bacterial organism itself cannot be ignored when considering the reemergence of the disease, (fig. 3), ${ }^{43}$.

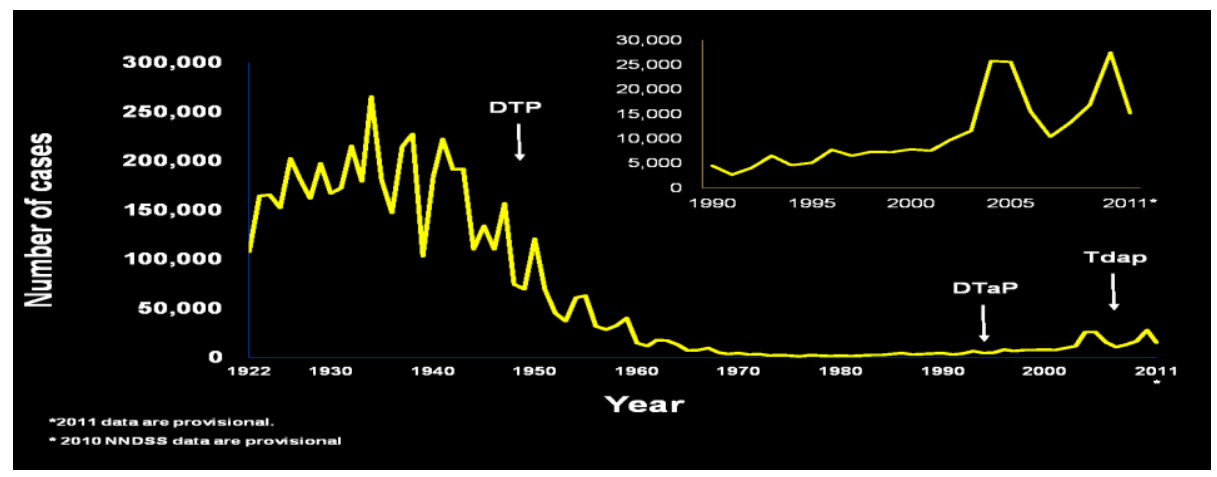

Figure 2. Reported pertussis cases: 1922-2011, USA

Source: CDC, National Notifiable Diseases Surveillance System and Supplemental Pertussis Surveillance System and 1922-1949, passive reports to the Public Health Service. The above chart from CDC shows that the pertussis disease spiked in 2011 despite the great reduction in incidence in the 70 s through to the early 90 s prior to the dawn of the DTaP vaccine.

\section{Reported cases of pertussis}

It is estimated that, 24.1 million cases of pertussis and about 160,700 deaths occur in children under 5 years of age per year globally, ${ }^{29}$. In the US alone, Pertussis has been a major concern since documentation begun in 1922 with tens of thousands of annual incidence recorded every year. According to CDC's report in 2012, annual incidence of 107,473 was recorded in year 1922, Over 264000 cases were reported in 1934 (fig. 2) and 183,866 cases in 1940, ${ }^{32}$. The CDC's 2012 report shows that pertussis disease is once again becoming a public health problem with $92 \%$ increase in incidence from the late 1990s to 2011 and beyond ${ }^{32} ;{ }^{13}$ In recent Valencia outbreak in Spain, about $90 \%$ of the pertussis cases had been vaccinated with DTaP vaccine ${ }^{39}$. There was a similar resurgence in New Zealand from 2011 to 2014 despite the over $90 \%$ success in DTaP vaccination rate ${ }^{44}$. In 2012, according to CDC's report, reported cases had risen by 17.8 folds from 2,719 in 1991 to 48277 in 2012 in US alone, of which 59\% of the 2012 cases had been well vaccinated (CDC, 2012), ${ }^{45}$. We are now witnessing the return of the pertussis epidemic. Surveillance reports from many countries reveals similar pattern about the reemergence of the disease which raises more questions about a possible waning immunity after vaccination with aP and or development of aP resistant strains of the Bordetella pertussis bacteria. Another question is why 9-11year age group in the vaccinated population is prone to the pertussis disease? Other concerns are about the fate of the populace vaccinated and whether it is economical at all to be given multiple shots of aP vaccine.

\section{Possible development of non-susceptible strains}

Possible development of vaccine resistant Bordetella pertussis bacteria strain(s) in the fight against pertussis epidermis should not be over-ruled. Research has shown that microbes can reduce permeability or uptake of a drug or vaccine and enhance efflux of the drug/vaccine from their system, ${ }^{46} ;{ }^{47} ;{ }^{4}$. They can also inactivate or stop producing filaments, enzymes or proteins which serve as target for the drug or vaccine; vaccines that target such proteins and hitherto were effective will no longer be effective against the organism, ${ }^{48} ;{ }^{46}$. The forth mechanism of microbial resistance to antibiotic and vaccines is by 
alteration or over-expression of the drug target ${ }^{48} ;{ }^{46}$. The microbes in this case might increase the quantity of the target protein, enzymes etc so that competitive inhibition will no longer be effective, ${ }^{46}$. Loss of enzymes involved in drug activation, ${ }^{46}$.

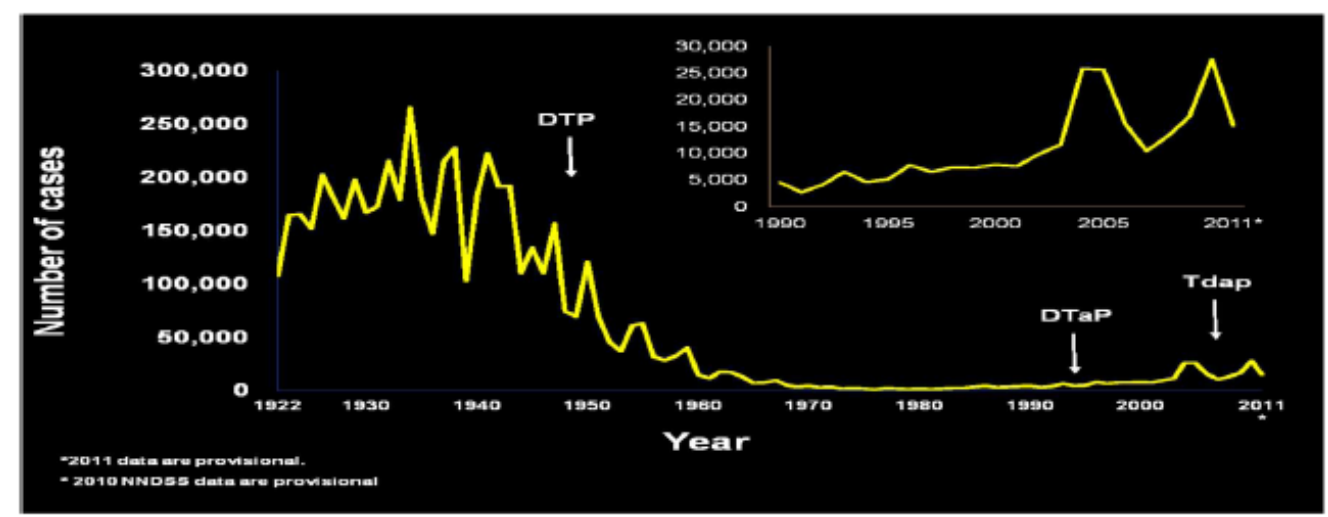

Figure 3. Schematic presentation of aP vaccine. The scheme presents a pictorial view of where we are and where we want to go in the fight towards pertussis disease

\section{DTaP pertussis vaccine, the future}

The whole cell vaccine with a pre-market trial efficacy of $78 \%$ proved to be effective during the 50 years of its reign against the disease (1940s- 1990s) fig 2; whiles the acellular version with $71 \%-85 \%$ efficacy rate from numerous premarket and post market trials kept losing the fight every year since its inception 25 years ago. Different post market field trials have been conducted around the globe but none did prove aP to be much inferior to wP, ${ }^{49} ;{ }^{50}$. Some researchers found the aP to be doing well than wP; $\left({ }^{18} ;{ }^{51} ;{ }^{52} ;{ }^{53}\right.$. Zhang reported in a systematic review carried in 2011 that multi-component aP vaccine is as effective as wP, but the multi-component aP is more effective than less effective wP vaccine, ${ }^{54}$. In Senegal infants' trials in 1996, Simondon found aP to be safer with higher geometric mean titers for aP to $w P,{ }^{55}$. In some field trials, the pertussis toxoid containing filamentous haemagglutinin and pertactin (Bordetella outer membrane protein) were found to be comparable or even superior in efficacy to the whole cell pertussis vaccine (wP), ${ }^{56} ;{ }^{52}$. Is it because the efficacies of accellular aP vaccine is short-live and that the efficacies wans with time compared to the whole cell wP vaccine whose efficacies goes far into the teen age years, ${ }^{38}$ ? It is about time attention is giving in finding out the true cause of the recent surge in the incident rate of the pertussis disease. Could it be waning or vaccine resistance strain development? Researchers have found $B$. pertussis microbe to be a dynamic organism that continues to evolve with emerging new strains ${ }^{11} ;{ }^{57} ;{ }^{8}$. Recent studies by Jongerius et al found $B$. pertussis to have developed mechanism that enables it to suppress the full function of the current vaccines by developing complement evasion proteins such as autotransporter Vag8 ${ }^{58}$. Bordetella pertussis strains resistant to macrolide antibiotic treatment have also been reported ${ }^{37}$. The latest findings indicate that the causal organism is evolving and becoming resistant to the current regime calling for a modification of the current regime or an alternative vaccine. In the future, it is believed that if measures are not taken, pertussis disease will once again take its place among the re-emerged infectious diseases. Public health institutions and health care providers, researchers and the like should give sufficient attention to the disease and the $\mathrm{aP}$ in order to provide long term prevention for the disease and if possible eradicate it. As a result of the reemergence of pertussis disease among highly vaccinated children and adolescents, concerns are being raised about the durability of protection afforded by acellular vaccines, waning of the vaccine and a possible development of resistant Bordetella pertussis bacteria strain.

Future research and prevention strategies can reconsider modifying the current aP vaccine with new antigens; preferably multicomponent aP vaccine with reduced adverse vaccine interaction and improved effectiveness, ${ }^{24}$, using a live-attenuated vaccine ${ }^{59}$, altering the current aP vaccination schedule due to 
DOI: $10.21522 / \mathrm{TIJPH} .2013 .06 .02 . A r t 016$

ISSN: $2520-3134$

waning, ${ }^{60}$, developing a completely new vaccine or returning to the wP vaccine, ${ }^{60}$ could be the way into a brighter pertussis-free future (fig.1, 3).

\section{Conclusion}

The surveillance reports globally reveal that the pertussis disease is taken its place once again in the reemerging infectious diseases. The cause for the slip in protection is still an issue to be considered. It is a known fact that immunity acquired naturally wanes substantially in 7-20 years, ${ }^{38}$ and waning pertussis vaccine few years after vaccination is possible. The surveillance data on the outbreak reveals that the severity of the disease is reduced in the vaccinated group compared to the unvaccinated group. This indicates that the vaccination might have helped to reduce the severity and to a certain extent the number of incidence ${ }^{38}$, but the rate of re-emerging is still a major health concern ${ }^{42}$.

In considering the developments of the latter days based on the available scientific data, it has become imperative for providers and researchers to reconsider modifying the current aP vaccine with new antigens and/or adjuvants or from 1-3 component types into multicomponent, ${ }^{24}$, using a live-attenuated vaccine ${ }^{59}$, altering the current aP vaccination schedule, ${ }^{60}$, developing a completely new vaccine or returning to the $\mathrm{wP}$ vaccine, ${ }^{60}$

\section{Recommendations}

We recommend that pharmaceutical industries and funding agencies can shift their attention into funding field or clinical researches on pertussis vaccine resistant development and to come out with a measure that will once and for all help to eradicate pertussis disease. We also recommend the whole cell vaccine could be revisited by finding ways to reduce the adverse drug reactions to provide better protection with minimal risk or modifying the current regime.

\section{References}

[1]. Aslanabadi A, Ghabili K, Shad K, Khalili M, Sajadi MM. Emergence of whooping cough: notes from three early epidemics in Persia. Lancet Infect Dis. 2015; 15 (12):1480-1484. doi: 10.1016/S1473-3099(15)00292-3Torres J, Godoy P, Artigues A, et al. [Outbreak of whooping cough with a high attack rate in well-vaccinated children and adolescents]. Enferm Infecc Microbiol Clin. 2011; 29 (8):564-567. doi:10.1016/j.eimc.2011.04.005.

[2]. Bettinger JA, Halperin SA, De Serres G, Scheifele DW, Tam T. The effect of changing from whole-cell to acellular pertussis vaccine on the epidemiology of hospitalized children with pertussis in Canada. Pediatr Infect Dis J. 2007; 26 (1):31-35. doi:10.1097/01.inf.0000247055.81541.04.

[3]. Boughton CR. Pertussis vaccines: acellular versus whole-cell. Med J Aust. 1996; 164 (9):564-566.

[4]. Bolotin S, Harvill ET, Crowcroft NS. What to do about pertussis vaccines? Linking what we know about pertussis vaccine effectiveness, immunology and disease transmission to create a better vaccine. Pathog Dis. 2015;73 (8). doi:10.1093/femspd/ftv057.

[5]. Choi YH, Campbell H, Amirthalingam G, van Hoek AJ, Miller E. Investigating the pertussis resurgence in England and Wales, and options for future control. BMC Med. 2016; 14(1):121. doi: 10.1186/s12916-016-0665-8.

[6]. Crowcroft NS, Stein C, Duclos P, Birmingham M. How best to estimate the global burden of pertussis? Lancet Infect Dis. 2003; 3(7):413-418.

[7]. Clark TA. Changing Pertussis Epidemiology: Everything Old is New Again. J Infect Dis. 2014; 209(7):978981. doi:10.1093/infdis/jiu001.

[8]. Eshofonie AO, Lin H, Valcin RP, Martin LR, Grunenwald PE. An outbreak of pertussis in rural Texas: an example of the resurgence of the disease in the United States. J Community Health. 2015; 40(1):88-91. doi: 10.1007/s10900-014-9902-2.

[9]. Fedele G, Bianco M, Debrie A-S, Locht C, Ausiello CM. Attenuated Bordetella pertussis vaccine candidate BPZE1 promotes human dendritic cell CCL21-induced migration and drives a Th1/Th17 response. J Immunol Baltim Md 1950. 2011; 186(9):5388-5396. doi:10.4049/jimmunol.1003765. 
[10]. Forsyth K, Nagai M, Lepetic A, Trindade E. Pertussis immunization in the global pertussis initiative international region: recommended strategies and implementation considerations. Pediatr Infect Dis J. 2005; 24 (5 Suppl):S93-97.

[11]. Gent M van, Bart MJ, Heide HGJ van der, Heuvelman KJ, Mooi FR. Small Mutations in Bordetella pertussis Are Associated with Selective Sweeps. PLOS ONE. 2012; 7(9):e46407. doi:10.1371/journal.pone.0046407.

[12]. Guo B, Page A, Wang H, Taylor R, McIntyre P. Systematic review of reporting rates of adverse events following immunization: an international comparison of post-marketing surveillance programs with reference to China. Vaccine. 2013;31(4):603-617. doi:10.1016/j.vaccine.2012.11.051.

[13]. Gabutti G, Rota MC. Pertussis: A Review of Disease Epidemiology Worldwide and in Italy. Int J Environ Res Public Health. 2012; 9(12):4626-4638. doi:10.3390/ijerph9124626.

[14]. Guiso N. Bordetella pertussis and Pertussis Vaccines. Clin Infect Dis. 2009;49(10):1565-1569. doi: $10.1086 / 644733$.

[15]. Gabutti G, Azzari C, Bonanni P, et al. Pertussis. Hum Vaccines Immunother. 2014; 11(1):108-117. doi:10.4161/hv.34364.

[16]. Gustafsson L, Hessel L, Storsaeter J, Olin P. Long-term Follow-up of Swedish Children Vaccinated With Acellular Pertussis Vaccines at 3, 5, and 12 Months of Age Indicates the Need for a Booster Dose at 5 to 7 Years of Age. Pediatrics. 2006;118 (3):978-984. doi:10.1542/peds.2005-2746.

[17]. Heininger U, Cherry JD, Christenson PD, et al. Comparative study of Lederle/Takeda acellular and Lederle whole-cell pertussis-component diphtheria-tetanus-pertussis vaccines in infants in Germany. Vaccine. 1994; 12(1):81-86.

[18]. Hawken S, Manuel DG, Deeks SL, Kwong JC, Crowcroft NS, Wilson K. Underestimating the safety benefits of a new vaccine: the impact of acellular pertussis vaccine versus whole-cell pertussis vaccine on health services utilization. Am J Epidemiol. 2012; 176(11):1035-1042. doi:10.1093/aje/kws167.

[19]. Johri AK, Paoletti LC, Glaser P, et al. Group B Streptococcus: global incidence and vaccine development. Nat Rev Microbiol. 2006;4(12):932-942. doi: 10.1038/nrmicro1552.

[20]. Jongerius I, Schuijt TJ, Mooi FR, Pinelli E. Complement evasion by Bordetella pertussis: implications for improving current vaccines. J Mol Med Berl Ger. 2015; 93(4):395-402. doi: 10.1007/s00109-015-1259-1.

[21]. Klein NP, Bartlett J, Fireman B, Rowhani-Rahbar A, Baxter R. Comparative Effectiveness of Acellular Versus Whole-Cell Pertussis Vaccines in Teenagers. Pediatrics. May 2013:peds.2012-3836. doi:10.1542/peds.2012-3836.

[22]. Kline JM, Lewis WD, Smith EA, Tracy LR, Moerschel SK. Pertussis: a reemerging infection. Am Fam Physician. 2013; 88(8):507-514.

[23]. Kiedrzynski T, Bissielo A, Suryaprakash M, Bandaranayake D. Whooping cough—where are we now? A review. N Z Med J. 2015; 128(1416):21-27.

[24]. King AJ, van Gorkom T, van der Heide HG, Advani A, van der Lee S. Changes in the genomic content of circulating Bordetella pertussis strains isolated from the Netherlands, Sweden, Japan and Australia: adaptive evolution or drift? BMC Genomics. 2010; 11:64. doi: 10.1186/1471-2164-11-64.

[25]. Klein NP, Bartlett J, Fireman B, et al. Waning protection following 5 doses of a 3-component diphtheria, tetanus, and acellular pertussis vaccine. Vaccine. 2017; 35 (26):3395-3400. doi:10.1016/j.vaccine.2017.05.008.

[26]. Ligon BL. Pertussis: An historical review of the research and of the development of whole-cell and acellular vaccines. Semin Pediatr Infect Dis. 1998; 9(2):168-178. doi: 10.1016/S1045-1870(98)80068-X.

[27]. Liberia battles whooping cough outbreak. Outbreak News Today. March 2015. http://outbreaknewstoday.com/liberia-battles-whooping-cough-outbreak-33731/. Accessed February 10, 2018.

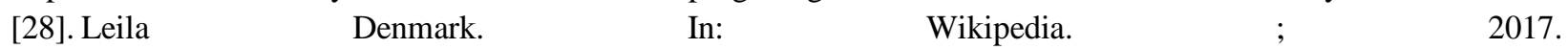
https://en.wikipedia.org/w/index.php?title=Leila_Denmark\&oldid=812452583. Accessed February 10, 2018.

[29]. Lin J, Nishino K, Roberts MC, Tolmasky M, Aminov RI, Zhang L. Mechanisms of antibiotic resistance. Front Microbiol. 2015;6. doi:10.3389/fmicb.2015.00034.

[30]. Lupo A, Coyne S, Berendonk TU. Origin and Evolution of Antibiotic Resistance: The Common Mechanisms of Emergence and Spread in Water Bodies. Front Microbiol. 2012; 3. doi:10.3389/fmicb.2012.00018. 
DOI: $10.21522 / \mathrm{TIJPH} .2013 .06 .02 . A r t 016$

ISSN: $2520-3134$

[31]. Mnookin S. The whole cell pertussis vaccine, media malpractice, and the long-term effects of avoiding difficult conversations. Panic Virus. http://blogs.plos.org/thepanicvirus/2012/09/13/the-whole-cell-pertussis-vaccine-mediamalpractice-and-the-long-term-effects-of-avoiding-difficult-conversations/. Accessed February 10, 2018.

[32]. Miguez Santiyan A, Ferrer Estrems R, Chover Lara JL, Alberola Enguidanos J, Nogueira Coito JM, Salazar Cifre A. Early intervention in pertussis outbreak with high attack rate in cohort of adolescents with complete acellular pertussis vaccination in Valencia, Spain, April to May 2015. Euro Surveill Bull Eur Sur Mal Transm Eur Commun Dis Bull. 2015; 20(27).

[33]. Nowlan M, Turner N, Kiedrzynski T, Murfitt D, Sawicki N. Pertussis control strategies: A consistent approach for New Zealand. Synopsis of Ministry of Health Workshop, April 2015. N Z Med J. 2016; 129(1433):78-85.

[34]. Pertussis | Whooping Cough | Causes and Transmission | CDC. https://www.cdc.gov/pertussis/about/causestransmission.html. Published August 18, 2017. Accessed February 10, 2018.

[35]. Pertussis | Surveillance Trend Reporting and Case Definition | CDC. https://www.cdc.gov/pertussis/survreporting.html. Published February 6, 2018. Accessed February 10, 2018.

[36]. Parton R. Review of the biology of Bordetella pertussis. Biol J Int Assoc Biol Stand. 1999; 27(2):71-76. doi:10.1006/biol.1999.0182.

[37]. Pertuss-surv-report-2013.pdf. https://www.cdc.gov/pertussis/downloads/pertuss-surv-report-2013.pdf.

Accessed February 10, 2018.

[38]. Pertussis | Surveillance Trend Reporting and Case Definition | CDC. https://www.cdc.gov/pertussis/survreporting.html. Published February 6, 2018. Accessed February 10, 2018.

[39]. Porras-Povedano M, Roldán-Garrido A, Santacruz-Hamer V. [Outbreak of Whooping cough in 2016.Écija, Seville, Spain]. Rev Esp Salud Publica. 2017; 91.

[40]. Pertussis Outbreak Among Vaccinated Preschoolers Raises Alarm. Medscape. http://www.medscape.com/viewarticle/857368. Accessed February 10, 2018.

[41]. pertuss-surv-report-2012.pdf. https://www.cdc.gov/pertussis/downloads/pertuss-surv-report-2012.pdf. Accessed February 10, 2018.

[42]. Potin M, Fica A, Véliz L, Moreno G, Wilhelm J, Cerda J. [Strategies to protect the newborn and infants under 6 months of age against pertussis: Statement of the Advisory Committee for Immunizations of the Chilean Infectious Diseases Society]. Rev Chil Infectologia Organo of Soc Chil Infectologia. 2016; 33(5):543-546. doi:10.4067/S0716-10182016000500009.

[43]. Pertussis | Whooping Cough | Surveillance | Cases by Year | CDC. https://www.cdc.gov/pertussis/survreporting/cases-by-year.html. Published February 6, 2018. Accessed February 10, 2018.

[44]. Pichichero ME, Green JL, Francis AB, Marsocci SM, Murphy AM, Buscarino C. Antibody response and reactions to completion of a four-dose series with a two- or three-component acellular pertussis vaccine compared to whole cell pertussis vaccine. Scand J Infect Dis. 1996; 28(2):159-163.

[45]. Rendi-Wagner P, Kundi M, Mikolasek A, Vécsei A, Frühwirth M, Kollaritsch H. Hospital-based active surveillance of childhood pertussis in Austria from 1996 to 2003: estimates of incidence and vaccine effectiveness of whole-cell and acellular vaccine. Vaccine. 2006;24(33-34):5960-5965. doi:10.1016/j.vaccine.2006.05.011.

[46]. Schwartz KL, Kwong JC, Deeks SL, et al. Effectiveness of pertussis vaccination and duration of immunity. CMAJ Can Med Assoc J. 2016; 188(16):E399-E406. doi:10.1503/cmaj.160193.

[47]. Shahcheraghi F, Lotfi MN, Nikbin VS, et al. The First Macrolide-Resistant Bordetella pertussis Strains Isolated From Iranian Patients. Jundishapur J Microbiol. 2014;7(6). doi:10.5812/jjm.10880.

[48]. Simondon F, Yam A, Gagnepain JY, Wassilak S, Danve B, Cadoz M. Comparative safety and immunogenicity of an acellular versus whole-cell pertussis component of diphtheria-tetanus-pertussis vaccines in Senegalese infants. Eur J Clin Microbiol Infect Dis. 1996; 15(12):927-932. doi: 10.1007/BF01690510.

[49]. Sheridan SL, Ware RS, Grimwood K, Lambert SB. Number and order of whole cell pertussis vaccines in infancy and disease protection. JAMA. 2012; 308(5):454-456. doi:10.1001/jama.2012.6364.

[50]. Souder E, Long SS. Pertussis in the Era of New Strains of Bordetella pertussis. Infect Dis Clin North Am. 2015;29(4):699-713. doi:10.1016/j.idc.2015.07.005.

[51]. WHO | Pertussis. WHO. http://www.who.int/biologicals/vaccines/pertussis/en/. Accessed February 10, 2018. 
[52]. Wendelboe AM, Van Rie A, Salmaso S, Englund JA. Duration of immunity against pertussis after natural infection or vaccination. Pediatr Infect Dis J. 2005;24(5 Suppl):S58-61.

[53]. Wagner B, Melzer H, Freymüller G, et al. Genetic Variation of Bordetella pertussis in Austria. PLOS ONE. 2015;10(7):e0132623. doi:10.1371/journal.pone.0132623.

[54]. Xu Y, Wang Y, Tan Y, et al. Production and characterization of recombinant pertactin, fimbriae 2 and fimbriae 3 from Bordetella pertussis. BMC Microbiol. 2009; 9:274. doi: 10.1186/1471-2180-9-274.

[55]. Zhang L, Prietsch SOM, Axelsson I, Halperin SA. Acellular vaccines for preventing whooping cough in children. Cochrane Database Syst Rev. 2014; (9):CD001478. doi:10.1002/14651858.CD001478.pub6.

[56]. Yeung KHT, Duclos P, Nelson EAS, Hutubessy RCW. An update of the global burden of pertussis in children younger than 5 years: a modelling study. Lancet Infect Dis. 2017;17(9):974-980. doi: 10.1016/S14733099(17)30390-0.

[57]. 11_YZhang.pdf. http://www.moleculartb.org/gb/pdf/transcriptions/11_YZhang.pdf. Accessed February 10, 2018.

[58]. 11_YZhang.pdf. http://www.moleculartb.org/gb/pdf/transcriptions/11_YZhang.pdf. Accessed February 11, 2018.

[59]. Zhang L, Prietsch SO, Axelsson I, Halperin SA. Acellular vaccines for preventing whooping cough in children. Cochrane Database Syst Rev. 2011; (1):CD001478. doi:10.1002/14651858.CD001478.pub4. 


\title{
Distribution of Socio-Economic Factors with Malaria Occurrence at Federal Capital Territory Abuja, Nigeria: A Retrospective Hospital Based Study
}

\author{
Article by Ibrahim S. A ${ }^{1}$, Ukaga C.N ${ }^{2}$ \\ ${ }^{1}$ Department of Health Planning, Research and Statistics, FCT HHSS Abuja, Nigeria \\ ${ }^{2}$ Department of Animal \& Environmental Biology Faculty of Science Imo State University, \\ Nigeria \\ E-mail:ohikwo2003@yahoo.com
}

\begin{abstract}
Malaria remains one of the number one killer diseases in sub-Saharan Africa especially in Nigeria. In the Federal Capital Territory (FCT), Abuja, malaria is the leading cause of morbidity. A retrospective hospital based study on the distribution of socio economic factors with malaria occurrence at FCT Abuja Nigeria was carried out using a five years (2012-2016) hospital records from Wuse District Hospital Abuja. Sampling Technique includes all the patients' records that were diagnosed of acute malaria confirmed by Giemsa stained thick and thin peripheral blood films prior to treatment at the General Out Patient and those on admission at Wuse District Hospital Abuja. Data was entered and analyzed using IBM, SPSS Chicago version 25. Appropriate tables, graphs and percentages were displayed. A chi square test was performed to determine the level of significance using $95 \%$ confidence interval and $p$-value. The findings revealed that a total of 22,934 patients were diagnosed with acute malaria based on hospital records between 2012 and 2016 in Wuse District Hospital Abuja. From the analysis, the Non Formal Educational accounted for 57.4\% of the total number of patients diagnosed.Those who are unemployed accounted for $77.3 \%$ and those living in the rural area accounted for $55.7 \%$ of the cases. The study concluded that, The level of educational status, occupational status and residence of patients plays significant roles in the occurrence of malaria infection.
\end{abstract}

Keywords: Socio Economic, Malaria, Distribution, Factors, occurrence.

\section{Introduction}

Malaria remains one of the number one killer diseases in sub-Saharan Africa especially in Nigeria. Africa still bears over 80 percent of the global malaria burden, and Nigeria accounts for about 29 percent of this burden (WHO Malaria Report 2014). This diminutive monster has taken its greatest toll on children under age 5 and pregnant women, although it is preventable, treatable, and curable.

In Nigeria, malaria is responsible for approximately 60 percent of outpatient visits and 30 percent of admissions (FMOH 2014 b). It also contributes up to 11 percent of maternal mortality, 25 percent of infant mortality, and 30 percent of under-5 mortality (FMOH 2014b). It is estimated that about 110 million clinically diagnosed cases of malaria and nearly 300,000 malaria-related childhood deaths occur each year in Nigeria. The disease overburdens the already-weakened health system and exerts a severe social and economic burden on the nation, retarding the gross domestic product (GDP) by 40 percent annually and costing approximately 480 billion naira in out-of pocket treatments, prevention costs, and loss of man hours (WHO Malaria Report 2014).

Other recent study indicates that, 85 percent of Nigerians live in areas of mesoendemic transmission, and only 15 percent live under conditions of hyperholoendemic transmission. There are conditions of hypo endemic transmission in areas of the FCT, Adamawa, and Borno (Snow et al 2013). Also, a malaria transmission intensity mapping study using several data sources and geostatistical modeling techniques has shown changes in parasite risk patterns during the past decade, with parasite risks falling in 19 of the 36 states and the FCT. The study showed a 50 percent reduction in malaria morbidity in these areas (Snow et al. 2013). 
Malaria is caused by plasmodium species and the most prevalent species of malaria parasites in Nigeria is Plasmodium falciparum (greater than 95 percent). It is responsible for the most severe forms of the disease. The other types found in the country include: $P$. ovale and $P$. malariae, which play a minor role. $P$. malaria is commonly isolated from children with mixed infections (WHO Malaria report 2012)

Substantial Malaria control investment in the FCT Abuja has been made during the last decade following the implementation of the FCT Health Sector Strategic Plan of 2010- 2015. The FCT Malaria Control Strategy as part of FCT Strategic Health Development Plan of 2010-2015 was conceived with the vision that, malaria will no longer be a major public health problem in the FCT Abuja as illness and death from malaria will significantly be reduced.

The Global Funds supported FCT with the distribution of six (6) millions nets during mass campaign from 2013 to 2015. Non-Governmental Organizations also distributed LLITNs in some communities of the FCT. The Save One Million Live (SOML) programme funded by World Bank equally distributed a total of 55,000 Nets targeting under 5yrs in the 31 political wards (50\%) of the Federal Capital Territory Abuja (FCT HHSS 2015 report). This was done between 2015 and $3^{\text {rd }}$ quarter of 2017. As at the last quarter of 2017, the support for the provision of the Insecticide Treated Net stopped due to lack funds from donor organizations (FCT HHSS 2017 report) The Global funds and the FCT MDGs office also supported the provision of the ACT drugs which were distributed to the health facilities between 20102015.

Despite these investments, malaria still remains the leading cause of morbidity, followed by Diarrhea, Accident, Pneumonia, Measles and Malnutrition. In the FCT, Abuja, Nigeria, malaria accounted for about $70 \%$ of hospital attendance in the GOPD and 50\% of medical admissions (FCT HHSS 2015b). Malaria prevalence rate in the FCT stood at $43 \%$ based on the 2015 National Malaria Indicator Survey report. Other key findings and challenges on FCT malaria control strategies are presented in the following thematic areas:

\section{a. Integrated vector management situation}

- Non-attainment of universal coverage of Insecticides Treated Nets with \% Distribution of mosquito nets of $49 \%$ compared to Ekiti state that has distribution of $97 \%$ and national target of $100 \%$ (NMIS 2015)

- The rate of utilization of LLINs was as follows: $2014-16.5 \%, 2015-24.5 \%, 2016-28.5 \%$ based on a smart survey done in the FCT. But the National Malaria Indicator reported the rate of utilization to be $17 \%$ in 2015 . This was lower than the national average of $37 \%$.

- Ownership of ITN for FCT $45 \%$ as against 69\% national average (NMIS 2015)

- There were no proper baseline entomological indices in the FCT prior to LLITNs implementation.

- Indoor and Outdoor Residual Spray is still rudimentary in the FCT Abuja.

- Absence of Malaria Technical Working Group in the FCT Abuja

- There was absence of Integrated Community Case Management in the FCT malaria control programme.

\section{b. Diagnosis and treatment situation}

- The Federal Capital Territory (FCT) has 858 rural communities across the six area councils. A total of 633 (74\%) of these communities has no primary healthcare clinics. Of which 336 of these communities belongs to the lowest poor with poverty index of $<1 \mathrm{USD} /$ day. A total of $76 \%$ depend mainly on farming for their means of livelihood. Only $2 \%$ of the residents earn above 140USD per annum (FCT baseline 2009)

- WHO estimated that adequately serving the population of FCT residence in 2009 would require 434 Primary Health Clinics, but only 179 existed. Out of this, only 17\% were fully functioning and many of which were operating at sub-optimal levels or located long distances from rural populations (FCT baseline 2009). All these lead to Inequity in access to appropriate treatment for malaria case for those in the rural areas. 


\section{c. Malaria in pregnancy}

- Intermittent Preventive Treatment (IPT) is one of the preventive strategies of malaria in pregnant women. However, the uptake is still low in FCT with IPT1 at 19.2\% and IPT2 at 14.9\%. However, there were Persistent reports of Sulfadoxine-Pyrimethamine stock out due to lack of sustained funding.

- Based on the situational analysis above, this retrospective study examined how socio economic factors affect malarial control in the FCT Abuja. Indeed studying malaria trends is considered as one of the most important aspect of employing effective control strategies in Malaria prone settings.

\section{Aim of the study}

To show the distribution of socio- economic factors with malaria occurrence at FCT Abuja Nigeria

\section{Materials and methods}

\section{Study area}

FCT is located in the North Central geopolitical zone of the country. The territory hosts the capital city of Nigeria, Abuja. It is bounded by Niger State and Kaduna States in the north, Nasarawa State in the east, Nasarawa and Kogi States in the south and Niger State in the west. It has a land area of 8,000 square kilometres. It falls within the Savannah zone vegetation of the West African sub-region. However, patches of rain forest occur in the Gwagwa plains that form one of the surviving northernmost occurrences of the mature forest vegetation in Nigeria. According to 2006 census, the population was $1,406,239$. However, the projected population for 2017 is $3,740,080$. The rapid rise in the population is as a result of growth rate of $9.3 \%$, a level considerably above the national level of $3.2 \%$.

The study was conducted in Wuse District Hospital Abuja Nigeria in the Abuja Municipal Area Council of the Territory. The hospital was chosen because; it is the most accessible public hospital with the highest number of bed space and high patient load compared to other public hospitals.
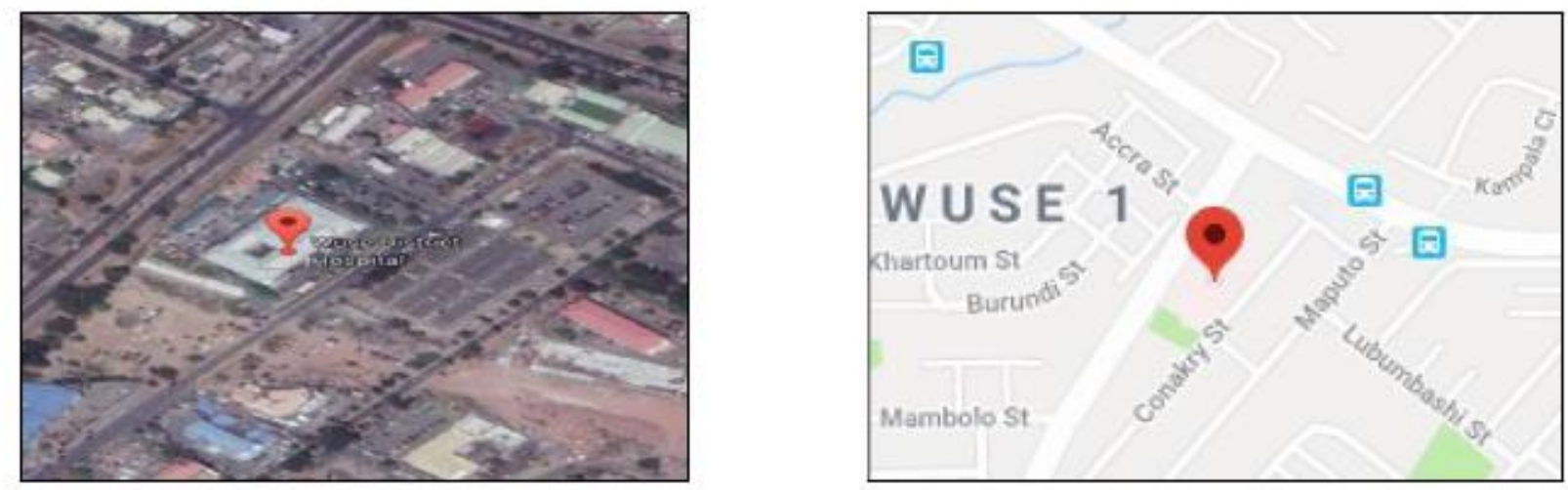

Figure1. Google map showing Wuse district hospital abuja nigeria

\section{Research design}

A retrospective study on the diagnosis and treatment of acute malaria based on hospital records of five years (2012-2016).

Sampling Technique: All the patients' records that were diagnosed of acute malaria confirmed by Giemsa stained thick and thin peripheral blood films prior to treatment at the General Out Patient and those on admission at FCT Abuja were considered.

Data collection: This included hospital records of patient diagnosed of acute malaria in the general outpatient and those on admission between 2012 and 2016 study years. These data were collated by the hospital medical record staff after two days training on data collection using the developed tools. 
DOI: $10.21522 /$ TIJPH.2013.06.02.Art017

ISSN: $2520-3134$

\section{Data analysis}

Data was entered and analyzed using IBM, SPSS Chicago version 25, Statistical software package. The Mean numbers of malaria patients were calculated by dividing total number of malaria patients enrolled in a particular year by 12 . Appropriate tables, graphs and percentages were displayed. A chi square test was performed to determine the level of significance using $95 \%$ confidence interval and $\mathrm{p}$ value.

\section{Ethical consideration}

Approval for the study was obtained from the FCT Health and Human Services Secretariat Ethical Committee. Confidentiality of data was also maintained.

\section{Results}

An overall total of 22,934 patients' records meeting up with the study criteria were obtained from the Wuse District Hospital spanning from 2012 to 2016. Findings from the records showed that the least number of patients diagnosed with malaria was noted for the year 2014 with the record of a total 3409 patients seen in the hospital (Table 1). The year with the highest number of diagnosed acute malaria patients seen in the study hospital was 2015 with a total of 5236 patients. The overall picture of the socio-economic status of the patients diagnosed with acute malaria in the study hospital between 2012 and 2016 study years is shown on Table 1 below.

Distribution of patients diagnosed with acute malaria in the hospital in the year 2013 showed the males to have the highest prevalence within the study period while the least male prevalence was recorded for 2015. Overall more of the males $(50.7 \%)$ than the females $(49.3 \%)$ were diagnosed with acute malaria within the study period (Table 1). 


\begin{tabular}{|c|c|c|c|c|c|c|c|}
\hline f & $<8$ & 䑝 & 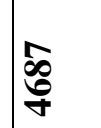 & 户े & గ్ల & 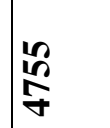 & 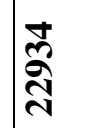 \\
\hline & 怤 & 尽 & 岂 & & 宓 $\frac{n}{n}$ & 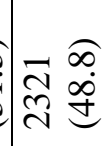 & $\frac{n}{m} \stackrel{9}{g}$ \\
\hline g & $\dot{b}$ & 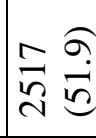 & 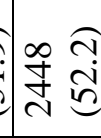 & & 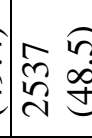 & 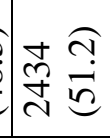 & 응 \\
\hline & 践 & 余 & 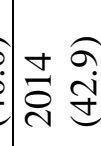 & & 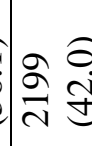 & 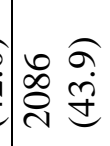 & 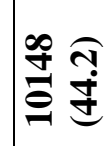 \\
\hline & $\widehat{a}$ & 定 & 柋 & & 宓 & : & 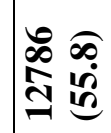 \\
\hline & 禹 & 证 & ల్ల & & రิ & 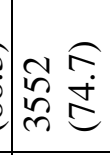 & 产 \\
\hline & 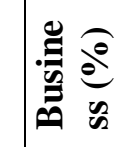 & 옹 & 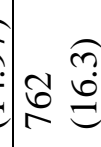 & & {$\left[\begin{array}{l}n \\
\infty \\
m \\
m\end{array}\right.$} & 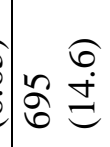 & 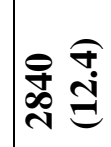 \\
\hline & $\infty \widehat{Q}$ & 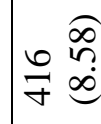 & 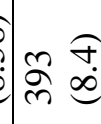 & & \pm & $\stackrel{6}{\sigma}$ & 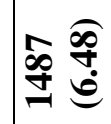 \\
\hline & $\int \widehat{\theta}$ & 亭 & $\therefore \stackrel{0}{0}$ & & 2 & 宅 & $\underset{\infty}{\infty}$ \\
\hline & 空 & 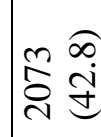 & 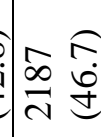 & $\Omega$ & $\bar{m}$ & 完 & 窇 \\
\hline & $\widehat{d e}$ & Љ & 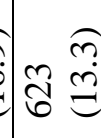 & 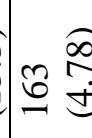 & 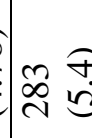 & $\vec{i} \underset{i}{\stackrel{d}{d}}$ & 总 \\
\hline & $\approx \underbrace{0}$ & $\stackrel{0}{\underline{d}}$ & $I_{\infty}$ & 0 & $\stackrel{9}{\stackrel{9}{0}}$ & $\underbrace{}_{0}$ & 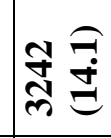 \\
\hline & $=\underbrace{0}$ & 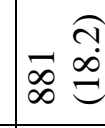 & 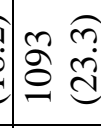 & ले & శֶత & 离 & 突 \\
\hline & & בั & m. & ت্ & 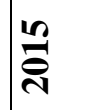 & กั้ & _ \\
\hline
\end{tabular}


From the summary table 1 above, the Non Formal Educational accounted for $57.4 \%$ of the total number patients diagnosed with malaria followed by the patients with the basic primary education. Those with tertiary education accounted for the least number of patients diagnosed with acute malaria 2460 (10.7\%). Occupation-wise, the Public servants accounted for the least number 1487 ( 6.48\%) under the category of the educational status.

while Students, children and unemployed adults who belongs to the group of others accounted for $77.3 \%$ of the total number of patients. Those patients living in the rural accounted for $55.7 \%$ to those in urban settlements.

The findings from the 5 years retrospective study on the educational status of the patients diagnosed with acute malaria in Wuse District Hospital is shown on Table 2.

Table2. Educational status of patients diagnosed with acute malaria in Wuse district hospital

\begin{tabular}{|l|l|l|l|l|}
\hline Year & \multicolumn{4}{|l|}{ Education } \\
\hline & Primary & Secondary & Tertiary & NFE \\
\hline $\mathbf{2 0 1 2}$ & $881(18.2)$ & $1073(22.1)$ & $820(16.9)$ & $2073(42.8)$ \\
\hline $\mathbf{2 0 1 3}$ & $1093(23.3)$ & $784(16.7)$ & $623(13.3)$ & $2187(46.7)$ \\
\hline $\mathbf{2 0 1 4}$ & $399(11.7)$ & $210(6.2)$ & $163(4.8)$ & $2637(77.4)$ \\
\hline $\mathbf{2 0 1 5}$ & $632(12.1)$ & $390(7.4)$ & $283(5.4)$ & $3931(75.0)$ \\
\hline $\mathbf{2 0 1 6}$ & $1067(22.4)$ & $785(16.5)$ & $571(12.0)$ & $2332(49.0)$ \\
\hline Total & $\mathbf{4 0 7 2 ( 1 7 . 8 )}$ & $\mathbf{3 2 4 2 ( 1 4 . 1 )}$ & $\mathbf{2 4 6 0 ( 1 0 . 7 )}$ & $\mathbf{1 3 1 6 0 ( 5 7 . 4 )}$ \\
\hline
\end{tabular}

From the table 2 above, an overall total of 13,160 patients diagnosed within the study period with acute malaria did not have formal education, accounting for $57.4 \%$ of the total number of patients diagnosed with acute malaria. The patients who had up to Tertiary education accounted for the least $(10.7 \%)$ number of diagnosed malaria patients during the study period

Those with primary education accounted for $4072(17.8 \%)$ and was highest in $2013(23.3 \%)$ while those with secondary education accounted for 3242 (14.1\%) and was highest in 2012 (16.9\%)

In 2014, those patients with Non Formal Education were highest 2637 (77.4\%) compared to those with tertiary education which were lowest 163 (4.8\%)

The analysis of the mean for the educational status of the patients diagnosed with acute malaria in Wuse District Hospital within the study period is shown on Table 3.

Table 3. Mean number for the educational status of patients diagnosed with acute malaria in Wuse district hospital between 2012 and 2016

\begin{tabular}{|l|l|l|l|l|}
\hline Year & \multicolumn{4}{l}{ Education } \\
\hline & Primary & Secondary & Tertiary & NFE \\
\hline $\mathbf{2 0 1 2}$ & 73.4 & 89.4 & 68.3 & 172.8 \\
\hline $\mathbf{2 0 1 3}$ & 91.1 & 65.3 & 51.9 & 182.3 \\
\hline $\mathbf{2 0 1 4}$ & 33.3 & 17.5 & 13.6 & 219.8 \\
\hline $\mathbf{2 0 1 5}$ & 52.7 & 32.5 & 23.6 & 327.6 \\
\hline $\mathbf{2 0 1 6}$ & 88.9 & 65.4 & 47.6 & 194.3 \\
\hline
\end{tabular}

From the table, the mean number of malaria patients with Non Formal Education is highest (327.6) in 2015. Those with tertiary education has the lowest mean number of cases (13.6) in 2014

The mean number of patient with primary education is highest in 2013 (91.1) and lowest in 2014 (33.3) compared to the mean number of patient with secondary education was highest in 2012 (89.4) and lowest in 2014 (17.5).

The mean number of patients with tertiary education was highest in 2012 (68.3) 
Figure 2 below shows the analysis of the educational status of patients diagnosed with acute malaria in Wuse District Hospital Abuja. Those patients with no formal education were highest in 2015(3931) and lowest in 2012. Those patients with tertiary education were highest in 2012(820) and lowest in 2014(163).

Those with primary education were highest in 2013(1093) and lowest in 2014(399) while those with secondary education were highest in 2012(1073) and lowest in 2014(210).

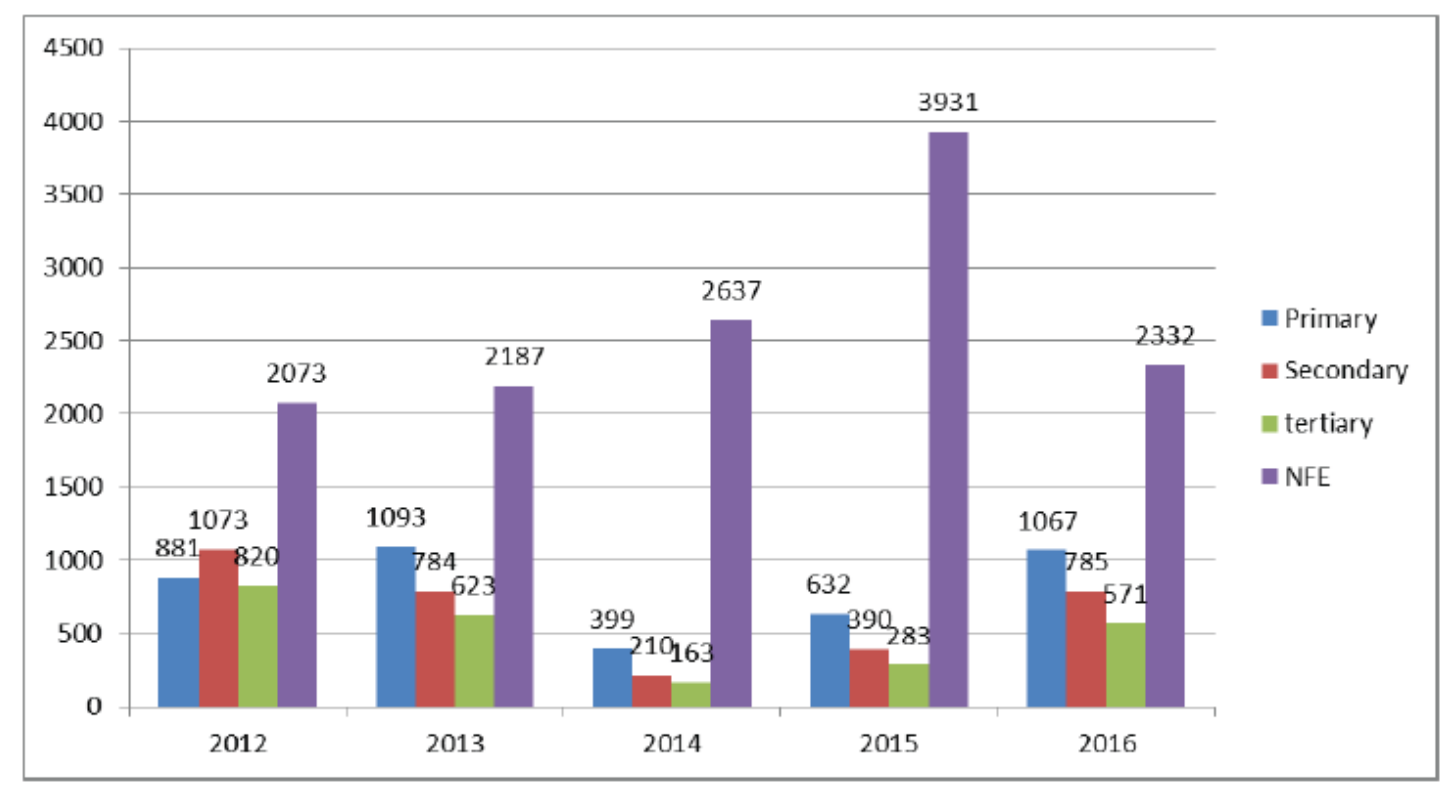

Figure2. Educational status of patients diagnosed with acute malaria in Wuse district Hospital between 2012 and 2016 study period

The chi-square statistic for Education is 180.6571 . The p-value is .00001 . The result is significant at $\mathrm{p}<.05$. Since the $\mathrm{p}$ value is less than the level of significance, we reject the null hypotheses and conclude there is relationship between educational status and malaria infection occurrence.

The correlation analysis shows that the value of $\mathrm{R}$ for primary variable is -0.5306 . This is a moderate negative correlation, the value of $\mathrm{R}$ for secondary variable is -0.6481 . This is a moderate negative correlation also. The value of $\mathrm{R}$ for tertiary variable is -0.6693 . This is a moderate negative correlation also. This means that the higher the level of education, the lower the occurrence of malaria infection and vice versa. In other words the education status plays a role in the occurrence of diagnosed acute malaria.

The result of the five year retrospective study on the occupational status of patients diagnosed with acute malaria in Wuse district hospital Abuja is shown on Table 4.

Table 4. Occupational status of patients diagnosed with acute malaria in Wuse District Hospital between 2012 and 2016 study period

\begin{tabular}{|l|l|l|l|l|}
\hline \multicolumn{5}{|l}{ Occupation } \\
\hline & CS & PS & Business & Others \\
\hline $\mathbf{2 0 1 2}$ & $240(5.0)$ & $416(8.6)$ & $726(15.0)$ & $3465(71.5)$ \\
\hline $\mathbf{2 0 1 3}$ & $171(3.6)$ & $393(8.4)$ & $762(16.3)$ & $3361(71.7)$ \\
\hline $\mathbf{2 0 1 4}$ & $224(6.6)$ & $143(4.2)$ & $309(9.1)$ & $2733(80.2)$ \\
\hline $\mathbf{2 0 1 5}$ & $89(1.7)$ & $174(3.3)$ & $348(6.6)$ & $4625(88.3)$ \\
\hline $\mathbf{2 0 1 6}$ & $147(3.1)$ & $361(7.6)$ & $695(14.6)$ & $3552(74.7)$ \\
\hline & $\mathbf{8 7 1}$ & $\mathbf{1 4 8 7}$ & $\mathbf{2 8 4 0}$ & $\mathbf{1 7 7 3 6}$ \\
\hline & & & & \\
\hline
\end{tabular}


From the table 4 above, the Civil Servants accounted for the lowest number of patients diagnosed with malaria within the study period while 'others' which included; unemployed youths / adults, children and students accounted for the highest number of patients diagnosed with acute malaria.

Those patients who were civil servants were the group of patients with the lowest rate of diagnosed acute malaria $(240 ; 5.0)$ in 2012 and overall least diagnosed in 2015 (89: 1.7). The patients who were captured as business persons recorded the second highest of diagnosed acute malaria cases throughout the study period. Likewise all the persons captured as 'others' which included unemployed youths / adults, children and students, maintained highest rate of diagnosed acute malaria cases throughout the study period with the highest rate of $88.3 \%$ in the year 2015 .

The analysis of the mean number for occupational status of patients diagnosed with acute malaria in Wuse district hospital Abuja in the five years retrospective study is shown on Table 5.

Table 5. Mean number for occupation status of patients diagnosed with acute malaria in Wuse district hospital between 2012 and 2016 study period

\begin{tabular}{|l|l|l|l|l|}
\hline \multicolumn{5}{|l|}{ Occupation } \\
\hline & CS & PS & Business & Others \\
\hline $\mathbf{2 0 1 2}$ & 20 & 34.7 & 60.5 & 288.8 \\
\hline $\mathbf{2 0 1 3}$ & 14.3 & 32.8 & 63.5 & 280.1 \\
\hline $\mathbf{2 0 1 4}$ & 18.7 & 11.9 & 25.8 & 227.8 \\
\hline $\mathbf{2 0 1 5}$ & 7.4 & 14.5 & 29.0 & 385.4 \\
\hline $\mathbf{2 0 1 6}$ & 12.3 & 30.1 & 57.9 & 296.0 \\
\hline & & & & \\
\hline
\end{tabular}

From the table 5 above, the Civil Servants have the lowest mean number of cases (7.4) in 2015 and other years except in 2014, while the group identified as 'others' had the highest mean number of cases through the years under study.

The mean number of cases for public servants were highest in 2012 (34.7) and lowest in 2014 (11.9) while the mean number of patient of those whose occupation is business were highest in 2013 (63.5) and lowest in 2014 (25.8). This is further illustrated on Figure 3.

Figure 3 below shows the analysis of the occupational status of patients diagnosed with acute malaria in Wuse District Hospital in the five years retrospective study. Those patients classified as 'others' were highest in 2015(4625) and lowest in 2014(2733). Those patients that were public servants were highest in 2013(393) and lowest in 2015(89). Those who were public servant were highest in 2012(416) and lowest in 2014(143). 


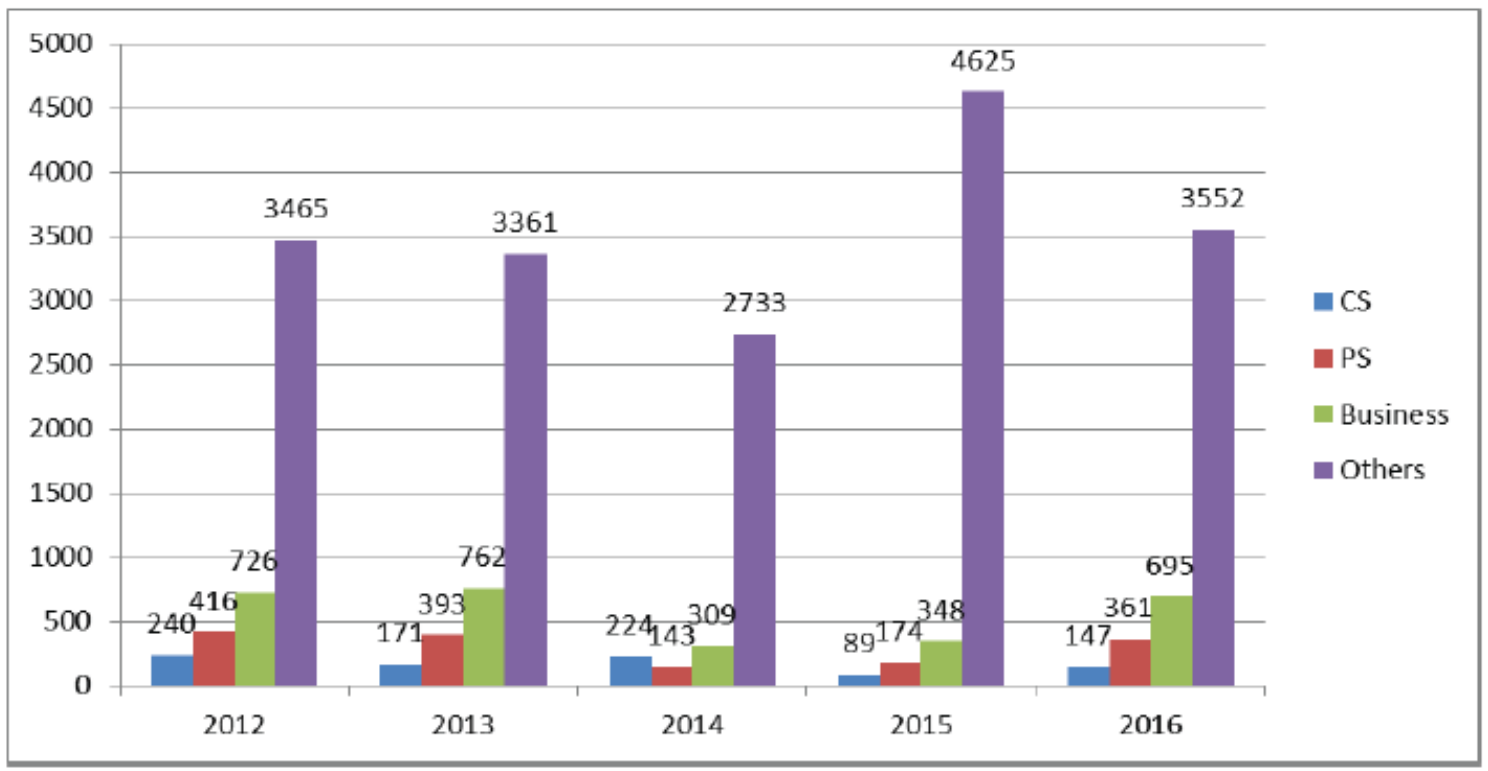

Figure 3. Occupational status of patients diagnosed with acute malaria in Wuse district hospital between 2012 and 2016 study period

The chi-square statistic for Occupation is 62.0118. The p-value is .00001. The result is significant at $\mathrm{p}<.05$.

Since the $\mathrm{p}$ value is less than the level of significance, we reject the null hypotheses and conclude there is a relationship between occupational status and malaria infection occurrence.

The correlation analysis shows the value of $\mathrm{R}$ is -0.8258 . This is a strong negative correlation, which means that, the high the occupational status, the lower the occurrence of malaria infection and vice versa

The geographical or residential location of the patients under study was grouped into 2: rural and urban settings. The analysis of the residential location of patients diagnosed with acute malaria within the study period is shown on Table 8. Those patients who resided in the rural area were highest in 2015 (3037: 58.0\%) and lowest in 2014 (1497: 43.9\%).

Those patients that resided in the Urban areas were highest in 2016 (2086: 43.9\%) and lowest in 2014 (1912: 56.1\%) Table 6

Table 6. Residential Locations of patients diagnosed with acute malaria in Wuse district hospital between 2012 and 2016 study years

\begin{tabular}{|l|l|l|}
\hline \multicolumn{2}{|l|}{ Location } \\
\hline & Rural & Urban \\
\hline $\mathbf{2 0 1 2}$ & $2910(60.0)$ & $1937(40.0)$ \\
\hline $\mathbf{2 0 1 3}$ & $2673(57.0)$ & $2014(43.0)$ \\
\hline $\mathbf{2 0 1 4}$ & $1497(43.9)$ & $1912(56.1)$ \\
\hline $\mathbf{2 0 1 5}$ & $3037(58.0)$ & $2199(42.0)$ \\
\hline $\mathbf{2 0 1 6}$ & $2669(56.1)$ & $2086(43.9)$ \\
\hline & $\mathbf{1 2 7 8 6}$ & $\mathbf{1 0 1 4 8}$ \\
\hline
\end{tabular}

From the table, those patients living in the rural areas accounted for the highest number of patients diagnosed with acute malaria compared with the patients living in the urban areas. In 2014 however, it was observed that more of the patients diagnosed for acute malaria during this period were from the urban areas (1912: 56.1\%) compared to those in the rural areas (1497: 43.9\%). 
DOI: $10.21522 /$ TIJPH.2013.06.02.Art017

ISSN: $2520-3134$

The analysis of the mean number for Location for the study patients diagnosed with acute malaria in Wuse District Hospital Abuja Nigeria within the 2012 -2016 study period is shown on Table 7 and further illustrated on Figure 4.

Table 7. Mean number for Location of patients diagnosed with acute malaria in wuse district hospital within 2012 -2016 study years

\begin{tabular}{|l|l|l|}
\hline \multicolumn{3}{|l|}{ Location } \\
\hline Years & Rural & Urban \\
\hline $\mathbf{2 0 1 2}$ & 242.5 & 161.4 \\
\hline $\mathbf{2 0 1 3}$ & 222.8 & 167.8 \\
\hline $\mathbf{2 0 1 4}$ & 124.8 & 159.3 \\
\hline $\mathbf{2 0 1 5}$ & 253.1 & 183.3 \\
\hline $\mathbf{2 0 1 6}$ & 222.4 & 173.8 \\
\hline
\end{tabular}

From the table 7 above, the mean number for residential location of patients diagnosed with acute malaria showed clearly that the patients that resided in the rural areas over the years had more cases of malaria through the years except in 2014 when the reverse was the case. The highest mean numbers of cases were seen in 2015 with the lowest in 2016. The mean number of cases for urban location was lowest (159.3) in 2014 and highest in 2015(183.3)

Figure 4 below shows the distribution of patients diagnosed with acute malaria in Wuse District Hospital. The number of cases were highest in 2015 (3037) and lowest in 2014 (1497) for those who reside in the rural area. The number of cases were highest in 2015 (2199) and lowest in 2014 (1912) for those residing in the urban areas.

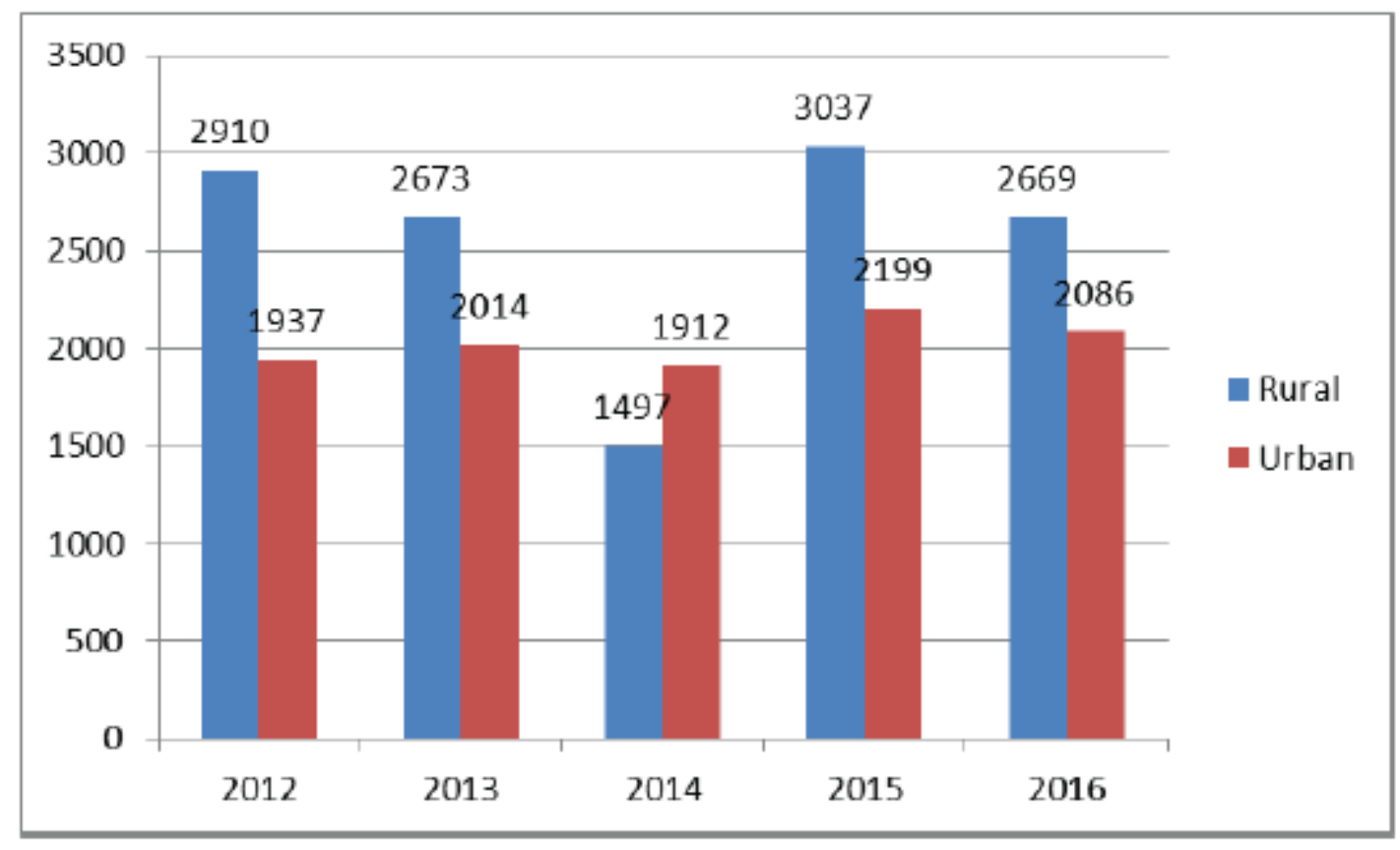

Figure 4. Urban rural distribution of patients diagnosed with acute malaria in wuse district hospital between 2012 and 2016

The chi-square statistic is 20.2199 . The p-value is .000452 . The result is significant at $p<.05$

Since the $\mathrm{p}$ value is less than the level of significance, we reject the null hypotheses and conclude there is a relationship between patients' residential location in the Rural or Urban to malaria infection occurrence. 


\section{Discussion}

This is a five year retrospective study to access Socio-Economic inequalities in the occurrence of diagnosed acute malaria based on hospital records at FCT Abuja. An association between educational status and the occurrence of malaria infection shows that, the lower the educational status, the higher the occurrence of malaria infection. Education plays a role on areas of awareness about malaria prevention and control. Asanterabi Lowassa et al (2012) also observed that education level of the household heads had a significant association with malaria treatment seeking behavior. Incontrast to Kavita Yadav et al (2014) on socioeconomic determinants for malaria transmission observed no significant association between education level and malaria occurrence.

A statistical relationship between the occupational status of the patients and malaria occurrence means that, the lower the occupational status, the higher the occurrence of malaria infection. Furthermore, those who are not employed visited the hospital frequently which has correlation with poverty. This was in line with Ruby Naz et al (2016) who worked on Pattern of Malaria Infection at Tertiary Care Hospital of Haryana- India A Hospital Based Study and found association between educational and occupational status to malaria infection

\section{Conclusion}

The level of educational status, occupational status and residence of patients plays significant roles in the prevention and control of malaria infection.

In view of the above, there is the need to:

i. Imbibe the culture of good health seeking behaviour which is an important strategy to reduce the burden of malaria. This will involve sensitization activities and awareness campaign to the FCT rural populace on the prevention and control of malaria infection. The use of radio and Television jingles in local languages will go a long way in improving knowledge on malaria.

ii. Creation of community empowerment and poverty alleviation programmes so as to improve the income level of house-holds in the rural areas. The above study revealed that, occupational status and residing in the rural area was related to the occurrence of malaria infection.

\section{Contribution to knowledge}

Unlike other retrospective studies on malaria, this current study dwell on the Socio Economic indices of the patients. The study gave details on the educational status, occupational status and urban or rural residential area of the patients.

\section{Acknowledgement}

The authors are grateful to the management and medical records staff of Wuse District Hospital for using their facility for the study. We also acknowledge the staff and faculty members of the Texila America School of Public Health for their support.

\section{References}

[1]. Abate et al.; licensee BioMed Central Ltd. 2013, Community knowledge, attitude and practice about malaria in a low endemic setting of Shewa Robit Town, northeastern Ethiopia. BMC Public Health BMC series open, inclusive and trusted201313:312 DOI: 10.1186/1471-2458-13-312.

[2]. Ahmad Yahaya Maigemu 2015. Influence of Religion on Malaria Control Practices among Household Heads in Zamfara State North West Nigeria Journal of Culture, Society and Development www.iiste.org ISSN 24228400 An International Peer-reviewed Journal Vol.10.

[3]. Asanterabi Lowassa et al 2013 Social economic factors and malaria transmission in Lower Moshi, Northern Tanzania.

[4]. Eve Worrall et al, January 2003, the relationship between socio-economic status and malaria: a review of the literature.

[5]. Federal Capital Territory (FCT) Abuja, Health and Human Health Services Secretariat (HHSS) 2015 Statistical bulletin.

[6]. Federal Capital Territory (FCT) 2009 Baseline survey report.

[7]. Federal Ministry of Health (FMOH) 2014b Malaria Control Report 2015. 
DOI: $10.21522 /$ TIJPH.2013.06.02.Art017

ISSN: $2520-3134$

[8]. Federal Ministry of Health (FMOH) National Malaria Control Programme 2014.

[9]. Humanitarian manual on malarial control 2010, Published in 2010, pages 10 to 15.

[10]. Karunamoorthi K, Bekele M. 2012. Changes in Malaria Indices in an Ethiopian Health Centre: A Five Year Retrospective Analysis. Health Scope 1(3): 118-26. DOI: 10.5812/jhs.7076.

[11]. Merit Mora-Ruiz, et al 2014, Socio economic factors, attitudes and practices associated with malaria prevention in the coastal plain of Chiapas, Mexico. Malaria Journal201413:157.

[12]. National Bureau of Statistics (NBS), National Malaria Indicator Survey (NMIS), 2015.

[13]. National Demographic and Health Survey report 2013.

[14]. Ruby Naz et al 2016. Pattern of Malaria Infection at Tertiary Care Hospital of Haryana-A Hospital Based Study International Journal of Current Microbiology and Applied Sciences ISSN: 2319-7706 Volume 5 Number 2(2016) pp. 330-337 Journal homepage: http://www.ijcmas.com.

[15]. Salwa Dawaki et al 2015. Is Nigeria winning the battle against malaria? Prevalence, risk factors and KAP assessment among Hausa communities in Kano State.

[16]. Snow et al 2013 on Estimating Malaria Burden in Nigeria: A Geostatistical Modelling Approach. License (open-access, http://creativecommons.org/licenses/by-nc/3.0/).

[17]. Vincent Were et al 2018 on socioeconomic health inequality in malaria indicators in rural western Kenya: evidence from a household malaria survey on burden and care-seeking behavior Malaria Journal 17:16https://doi.org/10.1186/s12936-018-2319-0.

[18]. W.P. O'Meara et al 2009. The impact of primary health care on malaria morbidity - defining access by disease burden Tropical Medicine International Health Journal.

[19]. World Health Organization (WHO) Global malaria report 2014.

[20]. World Health Organization (WHO) Global malaria report 2017 ISBN 978-92-4-156552www.who.int/malaria.

[21]. World Health Organization (WHO) World Malaria Report 2012 www.who.int/malaria.

[22]. World Health Organization (WHO) Global Malaria Programme 2015 website at http://www.who.int/ malaria/mpac/mpac-sept2015-erg-mip-report.pdf.

[23]. Yadav et al.; licensee BioMed Central Ltd. 2014. Socio-economic determinants for malaria transmission risk in an endemic primary health centre in Assam, India. 10.1186/2049-9957-3-19. 


\title{
Prevalence of Stress, Psychological Distress and Social Support among Clinical Medical Rehabilitation Students in a Nigeria University
}

\author{
Article by Arilewola Abosede Omotola \\ Ph.D., Public Health, Texila American University, Nigeria \\ E-mail: tolabanjo24@yahoo.com
}

\begin{abstract}
Background: University students are faced with challenges on a regular basis and these could be in form of academics, mental, emotional, social, physical, financial and environmental challenges that predisposes them to stress. The objectives of this study are to assess the prevalence of stress, psychological distress and social support received among clinical medical rehabilitation students of Obafemi Awolowo University, Ile-Ife, Nigeria and also assess for any association with demographic variable.

Methods: This study is a cross - sectional study to investigate the prevalence of stress, psychological distress and social support among clinical medical rehabilitation students in a Nigerian University. Self-administered questionnaires consisting of demographic data, perceived stress scale, psychological distress scale, and perceived social support scale questionnaires were used as survey instruments. Data were collated and analyzed using descriptive and inferential statistics. The level of significance was set at $p<0.05$.

Results: The outcome of the study revealed moderate perceived stress as (69.1\%) having the highest percentage, low (27.3\%) and high (3.6\%). Prevalence for mental distress was (47.3\%). Mild distress was (19.1\%), moderate (18.2\%) severe (10.0\%,) and well/normal was (52.7\%). For social support, low support was (9.1\%), moderate (40.9\%) high (50.0\%). Perceived stress had significant correlation with parent marital status and student level in school; $p$ value was 0.039 and 0.038 respectively. Kessler score had significant correlation with students' living arrangement, $p$ value was 0.050, while social support correlated significantly with family economic status of the students, and $p$ was 0.013. No other factors have been found to be significantly correlated.

Conclusions: There is a high prevalence of perceived stress and below average mental distress, symptoms among the university students. Majority had high social support. This is of a great concern in public health. Therefore, there is need for more concerted efforts, preventive measures against mental distress and more sufficient supportive services need be put in place for this group.
\end{abstract}

Keywords: Prevalence, Perceived stress, psychological distress, social supports.

\section{Introduction}

Stress and psychological wellness among college students in the world is a burden of public health. Health Specialist who are in training (medical, physical therapy, nursing and others) are not left out in this (Jacob and Einstein 2016; Koçyiğit et al 2015). This may not be far from the amount and rate of new knowledge they need to absorb. These groups of students are liable to experience increased levels of perceived stress (Jacob and Einstein 2016). Stress can be referred to as the body's response to psychological perception of pressure. Stress leads to hormonal changes and or response in the body. Stress becomes life threatening or dangerous to the body when it is prolonged, or extended or unexpected.

The issue of stress among undergraduates has been an issue in past studies (Elias et al, 2011; Abdulghani 2008; Basson et al, 2015 and Koochaki et al, 2011). Besides coping with social and academic demands, University students due adapt to many psychosocial changes (Shamsuddin et al 2013). The University make available to student psychological and educational development. It has also been reported that entering University can bring a strain or a stress (Elias et al, 2011). The high expectations regarding academic achievement brings about stressful moment. On daily basis students due encounter challenges which contribute to stress and when and if not well managed escalate to 
hamper academic performance, social and emotional wellbeing (Adonizio 2011; Abouserie 2006; Pariat, 2014). Stress is said to result from the interaction between stressors and individual view and reaction to the stressors. The relative amount of stress experienced is based on individual's ability to cope with situations and stressful events (Ross et al, 1999; Devi and Mohan 2015).

Shamsuddin et al, (2013), cited an article that reported high prevalence of stress, anxiety and depression $27.09 \%, 47.1 \%$ and $27.1 \%$ respectively in certain group of Turkish students. He also cited a work that reported females having high level of stress, anxiety and depression and it was attributed to biopsychosocial factors which included factors like social roles and physiological status. The course of study has been found to be associated with these (Shamsuddin et al, 2013). Parents' low socioeconomic status also contributed to depression, anxiety and stress. Students from families with conflicts were also associated with psychological distress. Likewise students from rural areas score higher in assessment of depression, anxiety and stress.

In Nigeria, epidemiological data about psychological morbidity among undergraduate students are not well-known and there is a paucity of research on prevalence perceived stress, psychological distress and social support among undergraduate students in Nigerian universities. Hence, the need for this study.

\section{Significance of study}

The results of this study will help in providing baseline data on prevalence of perceived stress, psychological distress and social support among the clinical medical rehabilitation students of Obafemi Awolowo University, Ile-Ife, Nigeria. The result can serve as awareness to University, or various departments on the student stressors, psychological distress and social support. In addition, the result will also help in identifying associated factors of perceived stress, psychological distress and social support among the clinical medical rehabilitation students of Obafemi Awolowo University, Ile-Ife, Nigeria.

\section{Statement of problem}

Unmanaged stress has been found or can cause mental, physical, emotional and behavioral problems. Students who mismanaged their stress can have psychological distress.

Several studies have shown that university students in other part of the world experience high levels of mental health problems such as stress, anxiety, burnout, psychological distress and depression. In addition, since early detection and quick prevention of these mental health problems among university students are very important in public health practices, hence, the need for this study to examine prevalence of self-reported perceived stress, psychological distress and social support and associated demographic data among university students in my environment.

Furthermore, through my extensive literature search and to the best of my knowledge, there is no formal study conducted on prevalence of perceived stress, psychological distress and social support among medical rehabilitation university students in Ile-Ife and also in Nigeria at large as at the time of conducting this study. Therefore, this study may serve as a baseline study on perceives stress, psychological distress and social support among university students in Ile-Ife and in Nigeria.

\section{Research questions}

The followings were the research questions for this study:

1. How prevalent is stress, psychological distress and social support among medical rehabilitation students of Obafemi Awolowo University, Ile-Ife, Nigeria?

2. What is the self-reported stress level, psychological distress and social support of clinical medical rehabilitation students.

3. Is there any association between socio demographic variables with stress, psychological distress and social support among the medical rehabilitation students of Obafemi Awolowo University, Ile-Ife, Nigeria?

\section{Research objectives}

The followings were the objectives of this study: 
1. To assess the prevalence of perceived stress, psychological distress and social support among the clinical medical rehabilitation students of Obafemi Awolowo University, Ile-Ife, Nigeria.

2. To investigate possible association of perceived stress, psychological distress and social support with demographic variables among the clinical medical rehabilitation students of Obafemi Awolowo University, Ile-Ife, Nigeria.

\section{Literature review}

Increasing reports on stress have been reported among university students in the last years. Many negative academic, emotional and health problems have been linked to stress in university students (Taha et al, 2017). Undergraduate in the medical schools are faced with multiple stressors such as academic overload, lack of leisure time, emotional pressure to maintain good grades, and specific conditions of learning complex medical procedures while working concurrently with patients. (Backovic et al 2012).

Recently stress during medical training is increasingly being reported in published literature. Past studies revealed fairly high levels of distress, such as symptoms of depression and even suicide thoughts among medical undergraduates. The potential negative effects of emotional distress on medical students include impairment of functioning in class-room performance and clinical practice, stress-induced disorders and deteriorating performance. Perceived medical stress has also been linked to current mental distress and to forthcoming health problems. However, there is very little information about the effect of stress on academic performance during medical training (Shah, 2010).

Most students experience distress during medical school. This distress manifests itself in a variety of forms, including burnout, depressive symptoms, stress, poor QOL, and fatigue. The greater the number of forms of distress experienced by an individual student the higher the risk of recent suicidal ideation or serious thoughts of dropping out of medical school. All six global dimensions of distress assessed were independently associated with suicidal ideation or serious thoughts of dropping out of medical school on multivariable analysis. The findings suggest that efforts to identify students whose degree of distress places them at greatest risk for serious consequences must assess for a variety of manifestations of distress. Dyrbye (2011).

Many studies have revealed that students' performance in school, college and university are affected by symptoms of depression, anxiety and stress which may impair their academic achievement leads to deterioration in relationships, marital problems and affects future employment. (Shamsuddin et al, 2013). College student are exposed to a considerable amount of stress, which necessitate successful and constantly changing coping strategy. These were internal and external pressures from the environment to thrive and succeed. (Patriat et al, 2014).

Stress is a mental as well as a physical phenomenon that occurs from cognitive appraisal of a stimulation from individual's interaction with the environment. (Devi and Mohan 2015; Eva et al 2015). Stressors are anything that challenges an individual's adaptability or stimulate an individual's body or mentality (Devi and Mohan 2015). Stress can be caused by environmental factors, psychological, biological and social factors. It can be negative or positive to an individual depending on the strength and persistence of the stress, the individual's personality, cognitive appraisal of the stress and support (Devi and Mohan, 2015). Stress is said to be part and parcel of life. (Kumar and Bhumar, 2013; Kumar and Hegde 2012). A healthy life style is an essential companion to any stress reduction programme. Stress occurs when pressure exceeds beyond its perceived ability to cope. Pertinent to the gender difference in stress experience, it is noted that across many nations, cultures and ethnicities, females are about twice as male to develop depression which is linked to anxiety. (Backovic et al, 2012; Dyrbye et al, 2008). Ffemales face a number of chronic burdens on daily basis as a result of their social status and roles relative to males and these tends to contribute to their higher rates of depressive anxiety (Kumar and Bhukar 2013). Studies suggest that mental health worsens after students begin medical school and remains poor throughout training. On a personal level, this distress due contribute to the issue related to substance abuse, broken relationships, sometimes suicide, and attrition from the profession. With these students, distress has been found to contribute to cynicism. This subsequently affect their care of patients, relationship with faculty, and likewise the medical profession (Dyrbye et al, 2005). Depression among medical students in India represents a 
neglected public health isssue. It is of great importance to prevent the negative effects of depression on individuall's educational attainment and career through early detection and proper interventional measures. (Kumar and Hegde, 2012).

For a student, stress may be caused by failure in academic or sports, financial problems or close friend. Such events that brings about stress are called stressors. (Elias et al 2011). Social support and positive reappraisal among others are found effective. College students are faced with many obstacles which they have to overcome for optimal performance. Stressors such as anxiety, depression, physical health, housing, grades, paper assignments, presentation assignment and group assignment all pose threats to students. Perceived stress as seen in college students sometimes takes the form of academic stress that involves multiple stressors I the likes of academic demands (grades, paper assignments, quizzes/test, presentations assignments, physical health and health related issues and self-imposed type of stressors (Pamela, 2009). Major depressive disorder is associated with substantial symptom severity distributed in the population, with ease in treatment, it seems encouraging, while inadequate treatment will be a serious concern. Emphasis on screening and expansion of treatment needs to be accompanied by a parallel emphasis on treatment quality improvement (Kessler et al, 2003).

Stress is a subjective phenomenon that results from an event that produces physical and psychological pain. It is normal part of everyday life. It may be healthy or unhealthy. Healthy stress is beneficial as a coping strategy to keep awareness, balance and connection. Also, it can help to produce desirable effects such as tolerance of ambiguity, self-confidence, maturity and it may stimulate the acquisition of knowledge and skills (Abdulghani et al. 2014) unhealthy or negative stress, which is referred to as excessive stress can interfere with efficient learning, impair memory, increase anxiety, decrease sleep, causing eating habit related problems lead to accident loneliness, and decrease problem solving abilities. High level of stress may have a negative effect on mastery of the academic curriculum. Stress, health and problems increase during period of undergraduate medical education. This can lead to mental distress and has a negative impact on cognitive functioning and learning. (Abdulghani, 2008). Psychological distress has been reported to be associated with disability and equally with lower academic achievement. university time to be a time of heightened distress, there is need to ensure that students receive the support necessary throughout their studies to enable them successfully complete their degree course, enabling them to negotiate the transition to university and then ultimately into the workforce female more stressed than male( Abouserie 2006).

Psychological distress/Mental distress is a term used by mental health practitioners and also in mental health services, to describe a range of symptoms and experiences of a person's internal life that are commonly held to be troubling, confusing or out of the ordinary. Psychological distress is sometimes defined as a distinct concept often embedded in the context of stress, strain, and distress (Ridner, 2004). Psychological distress can present in various ways and at many levels of severity. But in very general terms it is psychological discomfort. It can be expressed sometimes as sadness, anxiety, distraction, and as cases of psychotic symptoms. It causes varies from a severe stressor, daily stressors, medical illness, or mental illness. It is having a sense of discomfort, feeling unsettled, and usually at a level that is getting in the way of activities of daily living (e.g. work, school, caregiving, self-care). Mild psychological distress can be managed through rest and self-care that includes exercise. But if the distress and the symptoms are really interfering with life or leading to thoughts of harming self or others - intervention is required as quickly as possible - with a licensed medical or mental health professional. Reduced immune response to a certain variety of vaccinations has been associated with psychological stress (Burns et al, 2002). Mental disorders are a majorcontributor to the burden of diseases in all regions of the world (Ekpenyong et al 2011).

Perceived stress is all about feelings about the unpredictability and uncontrollability of one's life, how often one has to deal with irritating hassles, how much change is occurring in one's life, and confidence in one's ability to deal with problems or difficulties. It does not measure frequencies or types of stressful events which have happened to a person, but rather how an individual feels about the general stressfulness of their life and their ability to handle such stress. People may suffer negative life events but appraise the extent or severity of these to different extents as a result of factors such as personality and coping resources. In this way, perceived stress reflects the interaction between an individual and their environment which they appraise (Shah et al, 2010). The Perceived Stress Scale 
(PSS) is a tool for assessing the perception of stress. It measures the degree to which situations in an individual's life are assessed as stressful. It is designed to assess how overloaded, unpredictable and uncontrollable, individuals find their lives.

Social support: Social support is the perception and actuality that one is cared for, has assistance available from other people, and that one is part of a supportive social network. Social support is important for maintaining proper physical and mental health. In all, it showrs that positive social support of high quality can build resilience to stress, help protect against developing trauma-related psychopathology, decrease the functional consequences of trauma-induced disorders, such as posttraumatic stress disorder (PTSD), and reduce medical morbidity and mortality (Ozbay et al, 2007; Fairbrother 2011). Social support is exceptionally important for maintaining good physical and mental health. Overall, it appears that positive social support of high quality can enhance resilience to stress, help protect against developing trauma-related psychopathology, decrease the functional consequences of trauma-induced disorders, such as posttraumatic stress disorder (PTSD), and reduce medical morbidity and mortality. Numerous epidemiological studies have reported that poor social support is associated with the onset and relapse of depression, negative treatment response to dysthymia, seasonality of mood disorder, and the presence of depression comorbid in several medical illnesses, such as multiple sclerosis, cancer, and rheumatoid arthritis (Ozbay et al, 2007). Supportive behaviors are of four types: emotional, instrumental, informational and appraisal (Fairbrother 2011).

Various socio-demographic characteristics such as sex, level of education, and income and financial difficulty, being a house wife and relationship problems are associated with depressive and anxiety disorders. Most studies indicate that sex and socioeconomic status are the most important predictors of these disorders (Mirza and Jenkins 2004,) Females are reported to have higher level of depression, anxiety and stress which can be attributable to biopsychosocial factors such as social roles and physiological status (Dyrbye et al., 2006). Females tend to be on the receiving end in terms of stress, burn out and psychological distress (Glozah 2013; Shah, 2010; Kumar and Hegde; 2012) Moreover, studies have shown that the rates of mental disorders, particularly depression, are associated with various environmental stressors, including family discord (divorce or marital conflict), economic hardship, and stressful life events (Kessler et al., 2003). Some variables such as marital status, urban or rural status, and living arrangements have been found to be related to depressive and anxiety disorders in the literature ( Mirza and Jenkins, 2004).Previous studies showed that belowaverage income was a risk factor for depressive and anxiety disorders (Mirza and Jenkins, 2004). No studies have shown any particular ethnicity to be susceptible to depression, anxiety and stress. However, the minority ethnic group may predispose to these psychological distress (Dyrbye et al., 2007).

\section{Methods}

\section{Research design, study area and population}

A cross sectional descriptive study design was employed for the study and was conducted among undergraduate clinical rehabilitation students those in year 4 and 5 of Obafemi Awolowo University, Ile-Ife, Osun State, Nigeria in April, 2017. Obafemi Awolowo University is a well- known federal Government University located at Ile-Ife, in Osun state, south-western part of Nigeria.

\section{Data collection}

Survey instrument for this study consisted of self-administered questionnaire which was divided into two sections: section one consisted of 9 questions based on demographic variables and source of stress. The section two consisted of three pre tested questionnaire, the Perceived Stress Scale (PSS), Multidimensional Scale of Perceived Social Support (MSPSS), and Kessler Psychological Distress Scale (K10). In administering the scales (PSS, KESSLER10 and MSPSS) the students were asked to rate the extent to which they have experienced various symptoms over the past four weeks. The Perceived Stress Scale is a 10 item self-reported questionnaire designed to assess and measure their feelings and thought in the last one month about stress and has been well accepted worldwide as a reliable and easy-to-use screening instrument. PSS was scored on a 5-point scale with each item ranging from 0 never, 1 almost never, 2 sometimes, 3 fairly often, and 4 very often during the last 
month. In all there are 10 items making a total of 40 . The range is between 0 and 40. KESSLER 10 scale, is a 10 item scale, scored on 5 likert scale, with each item ranging from 1 none of the time, 2 "a little of the time", 3" some of the time", 4" most of the time" and 5 "all of the time". The score range is between 10 and 50. MSPSS scale is a 12 item scale scored on a 7 point scale as 1 very strongly disagree, 2 strongly disagree, 3 mildly disagree, 4 neutral, 5 mildly agree, 6 strongly agree and 7 very strongly agree. The total score ranged from 12 to 84 and then divided by 12 . Score range is from 1 and 7.

\section{Ethical consideration of the study}

Permission to conduct the study was sought and obtained from the head of department and the academic coordinator before embarking on the study. Informed consent was also obtained from every participant before carrying out the study. The confidentiality of information supplied in the questionnaires were assured as no name is required.

\section{Sampling size determination}

The minimum sample size was calculated using Yamane (1967) using the equation $n=N / 1+N(e)^{2}$ , where $\mathrm{n}$ is the sample size, $\mathrm{N}$ is the population size which is 135 clinical medical rehabilitation students and $\mathrm{e}$ is the level of precision at $\pm 5 \%$ (A 95\% confidence level and $\mathrm{P}=0.5$ are assumed for the equation). Therefore $\mathrm{n}=100$. To give allowance for an anticipated non-response rate of $10 \%$ (10 respondents), the sample size was increased by 10 to make 110 respondents. A total of 120 questionnaires were then taken to the students to be distributed for the study. Each respondent was provided with an assurance of confidentiality of information he or she provides in the questionnaire.

\section{Sampling method}

A purposive sample of 110 clinical medical rehabilitation students of Obafemi Awolowo University (60 males and 50 females) were successfully involved using self-administered questionnaires to record their socio-demographic variables and their responses to the Perceived stress scale, (PSS), Kessler psychological distress scale (K10) and Multidimensional scale of perceived social support.(MSPSS) Each respondent was provided with an assurance of confidentiality of information he or she provides in the questionnaire.

\section{Data analysis}

Completed questionnaires were collated and analyzed, descriptive and inferential statistics were used. Statistical analyses were done using the Statistical Package for the Social Sciences, (SPSS software version 17.0). Analysis of socio-demographic variables such as age groups, academic level, ethnicity, gender, living arrangement, academic performance, social life situation, parent marital status, family economic situation and source of stress were presented using frequency distributions and percentages. Means and standard deviation were used to present the scores of the outcome variables which are perceived stress, psychological distress and social support scores. Independent sample t-tests were used to test the differences in means of perceived stress, psychological distress and social support scores by gender and school level variables obtained from the study. Chi square was use to analyze the differences among the PSS, MSPSS and social support in relation to age group, living arrangement, academic performance social life situation, parent marital status and family economic situation. The level of significance was set at $\mathrm{p}<0.05$.

\section{Results}

\section{Demographic characteristics of the respondents}

A total of 110 undergraduate medical rehabilitation students of Obafemi Awolowo University participated in the study. $54.5 \%$ were males $(\mathrm{N}=60)$ and $45.5 \%$ were females $(\mathrm{N}=50)$. They were between the ages of 20 and 33 years. Majority of these participants were in the age group 20-24 years, $88(80 \%)$. Their mean age was 23.20 years $(\mathrm{SD} \pm 1.94)$. $(59.1 \%)$ of the respondents were in Clinical 1, while $(40.9 \%)$ were in clinical 2. The largest percentage among these students were Yoruba (85.5\%), majority of them $(47.3 \%)$ were living with friends/in hostels, most of the 
respondents $(78.2 \%)$ were moderately satisfied with their academic performance,. The majority of the respondents $(72.7 \%)$ were moderately satisfied with their social life. The parent marital status of the respondents revealed that majority $(60.9 \%)$ were married and family economic situation of the students the distribution showed that (40.9\%) of them were good, as seen in Table 1.

\section{Respondents' sources of stress}

The respondents were asked to identify exact sources of their stress by ticking either - Yes or -No from a list of 20 stressors. Out the 110 respondents, $6(5.5 \%)$ did not report any stressors, 68 (61.8\%) reported having 1-5 stressors, 27 (24.5\%) had 6-10 stressors, 7 (6.4\%) had 11-15 stressors, and $2(1.8 \%)$ had 16-19 stressors. Frequencies and percentages for the number of stressors selected by respondents are presented in table 2

Table 1. Descriptive statistics of socio-demographic data of the respondents

\begin{tabular}{|c|c|c|c|}
\hline s/no & Variables & Frequency & Percentage $(\%)$ \\
\hline \multirow[t]{4}{*}{1} & \multicolumn{3}{|l|}{ Age (years) } \\
\hline & $20-24$ & 88 & 80.0 \\
\hline & $25-29$ & 21 & 18.9 \\
\hline & $30-34$ & 1 & 0.9 \\
\hline \multirow[t]{3}{*}{2} & \multicolumn{3}{|l|}{ Gender } \\
\hline & Male & 60 & 54.5 \\
\hline & female & 50 & 45.5 \\
\hline \multirow[t]{4}{*}{3} & \multicolumn{3}{|c|}{ Clinical level (year in school) } \\
\hline & Clinical level 1 (year4) & 65 & 59.1 \\
\hline & Clinical level 2 (year5) & 45 & 40.9 \\
\hline & \multicolumn{3}{|l|}{ Ethnicity } \\
\hline \multirow[t]{4}{*}{4} & Yoruba & 94 & 85.5 \\
\hline & Igbo & 6 & 5.5 \\
\hline & Hausa & 1 & 0.9 \\
\hline & others & 9 & 8.2 \\
\hline \multirow[t]{5}{*}{5} & Living arrangement & & \\
\hline & Living with parents & 37 & 33.6 \\
\hline & $\begin{array}{l}\text { Living with friends in } \\
\text { school/in hostels }\end{array}$ & 52 & 47.3 \\
\hline & Living alone & 19 & 17.3 \\
\hline & others & 2 & 1.8 \\
\hline \multirow[t]{5}{*}{6} & Academic performance & & \\
\hline & Highly satisfied & 19 & 17.3 \\
\hline & Moderately satisfied & 86 & 78.2 \\
\hline & Least satisfied & 2 & 1.8 \\
\hline & others & 3 & 2.7 \\
\hline \multirow[t]{5}{*}{7} & \multicolumn{3}{|l|}{ Social life } \\
\hline & Highly satisfied & 21 & 19.1 \\
\hline & Moderately satisfied & 80 & 72.7 \\
\hline & Least satisfied & 7 & 6.4 \\
\hline & others & 2 & 1.8 \\
\hline \multirow[t]{2}{*}{8} & Parent marital status & & \\
\hline & Married & 67 & 60.9 \\
\hline
\end{tabular}


DOI: $10.21522 / \mathrm{TIJPH} .2013 .06 .02 . A r t 018$

ISSN: $2520-3134$

\begin{tabular}{|l|l|l|l|}
\hline & Separated/divorced/widowed & 13 & 11.8 \\
\hline & Never married & 30 & 27.3 \\
\hline 9 & Family economic situation & & \\
\hline & Good & 45 & 40.9 \\
\hline & Moderate & 60 & 54.5 \\
\hline & Poor & 3 & 2.7 \\
\hline & others & 2 & 1.8 \\
\hline
\end{tabular}

Table 2. Table showing the frequency of the stressors as identified by the respondents

\begin{tabular}{|l|l|l|}
\hline Variables & Frequency & Percentages (\%) \\
\hline 0 & 6 & 5.5 \\
\hline 1 & 13 & 11.8 \\
\hline 2 & 19 & 17.3 \\
\hline 3 & 17 & 15.5 \\
\hline 4 & 6 & 5.5 \\
\hline 5 & 13 & 11.8 \\
\hline 6 & 9 & 8.2 \\
\hline 7 & 4 & 3.6 \\
\hline 8 & 2 & 1.8 \\
\hline 9 & 4 & 3.6 \\
\hline 10 & 8 & 7.3 \\
\hline 11 & 2 & 1.8 \\
\hline 13 & 3 & 2.7 \\
\hline 14 & 1 & .9 \\
\hline 15 & 1 & .9 \\
\hline 18 & 1 & .9 \\
\hline 19 & 1 & .9 \\
\hline
\end{tabular}

\section{Prevalence of Stress, psychological distress and social support}

The prevalence of perceived stress, psychological distress and social support among undergraduate clinical medical rehabilitation students of Obafemi Awolowo University were shown in Table 3. Perceived stress is divided into 3 categories of severity, namely, low, moderate and high perceived stress. Psychological distress as normal, mild, moderate, and severe mental disorder. Social support as low, moderate and high support. Mean and standard deviation for perceived stress score obtained was $16.62 \pm 5.94$. Perceived stress scores showed that $(27.3 \%)$ of the respondents have low perceived stress, more than half $(69.1 \%)$ showed moderate perceived stress and 3.6 showed high perceived stress. Also, mean and standard deviation for Psychological distress score was $20.15 \pm 7.47$. Psychological distress scores showed that $(52.7 \%)$ of the respondents are normal (free mental disorder) while the rest (47.3\%) showed prevalence of psychological distress with(19.1\%) as mild mental disorder, $(18.2 \%)$ as moderate, $(10 \%)$ as severe mental disorder. Lastly, mean and standard deviation for social support score was $4.89 \pm 1.34$. Social support scores showed that $(50.0 \%)$ of the respondents have low support. (40.9\%) showed moderate support and $(9.1 \%)$ reported high social support.

Table 3. Prevalence of perceived distress, psychological distress and social support of the respondents, $n=110$

\begin{tabular}{|l|l|l|}
\hline Variables & Frequency & Percentages (\%) \\
\hline Perceived stress scale & & \\
\hline Low perceived stress ( scores 0-13) & 30 & 27.3 \\
\hline Moderate perceived stress ( scores 14-26) & 76 & 69.1 \\
\hline High perceived stress ( scores 27-40) & 4 & 3.6 \\
\hline Mean 16.62, SD =5.94 & \\
\hline
\end{tabular}




\begin{tabular}{|l|l|l|}
\hline $\begin{array}{l}\text { Multidimensional scale of perceived social } \\
\text { support }\end{array}$ & \\
\hline Low support (scores 1- 2.9) & 10 & 9.1 \\
\hline Moderate support ( scores 3 - 5) & 45 & 40.9 \\
\hline High support ( scores 5.1 - 7) & 55 & 50 \\
\hline Mean 4.89, SD =1.34 & \multicolumn{2}{|l|}{} \\
\hline Kessler Psychological distrress scale K10 & 58 & 52.7 \\
\hline Normal /Well ( scores under 20) & 21 & 19.1 \\
\hline Mild mental disorder ( scores 20- 24) & 20 & 18.2 \\
\hline Moderate mental disorder ( scores 25-29) & 11 & 10.0 \\
\hline Severe mental disorder (scores 30 above) & \multicolumn{2}{|l}{} \\
\hline Mean 20.15, SD=7.47 &
\end{tabular}

\section{Association between socio demographic variables and mean scores of PSS, K10 and MSPSS}

Table 4 showed the relationships between socio- demographic factors and mean perceived stress, psychological distress and social support scores among the students. No significant association was found between age, gender, ethnicity, academic performance, living arrangement, social life, family economic situation and the mean perceived stress score. However, there was a significant association between parental marital status and student level with perceived stress score. No significance association was found between psychological distress score with age, gender, student level, ethnicity, academic performance, social life, family economic situation and the mean psychological distress score. However, an association was seen in relation to living arrangement. Similarly, there was no statistical significant relationship between age, gender, student level, ethnicity, academic performance, living arrangement, social life situation, living arrangement and the mean scores of social support.

Statistical significant relationship was found between family economic situation and social support score of the students.

Table4. Socio-demographic factors and their relationship with perceived stress, psychological distress and social support scores

\begin{tabular}{|c|c|c|c|c|}
\hline Variables & $\mathrm{N} \%$ & Perceived stress & $\begin{array}{l}\text { Psychological } \\
\text { distress }\end{array}$ & Social support \\
\hline & & Mean SD & Mean SD & Mean SD \\
\hline All & 110100 & 16.625 .94 & 20.157 .47 & 4.891 .34 \\
\hline \multicolumn{5}{|l|}{ Age } \\
\hline $20-24$ & 8880 & 16.995 .98 & 20.747 .79 & 4.861 .35 \\
\hline $25-29$ & 2119 & 15.195 .78 & 17.435 .42 & 4.941 .35 \\
\hline $30-34$ & 1.9 & $\begin{array}{l}x^{2}=1.754 \\
p=0.781\end{array}$ & $\begin{array}{l}x^{2}=9.129, p=0.1 \\
66\end{array}$ & $\begin{array}{l}\mathrm{x}^{2}=1.048, \mathrm{p}=0.90 \\
2\end{array}$ \\
\hline \multicolumn{5}{|l|}{ Gender } \\
\hline Male & 6054.5 & 17.025 .45 & 20.627 .42 & 4.681 .35 \\
\hline \multirow[t]{2}{*}{ Female } & 5045.5 & 16.146 .49 & 19.587 .56 & 5.141 .29 \\
\hline & & $\begin{array}{l}t=0.770, \\
p=0.093\end{array}$ & $\mathrm{t}=0.723, \mathrm{p}=0.471$ & $\begin{array}{l}\mathrm{t}=- \\
1.815, \mathrm{p}=0.072\end{array}$ \\
\hline \multicolumn{5}{|c|}{ Academic level } \\
\hline Clinical 1 & 6559.1 & 15.655 .75 & 19.226 .37 & 4.771 .35 \\
\hline \multirow[t]{2}{*}{ Clinical 2} & 4540.9 & 18.025 .99 & 21.498 .73 & 5.061 .33 \\
\hline & & $t=-$ & $t=-$ & $t=-$ \\
\hline
\end{tabular}


DOI: 10.21522/TIJPH.2013.06.02.Art018

ISSN: $2520-3134$

\begin{tabular}{|c|c|c|c|c|}
\hline & & $2.096, \mathrm{p}=0.038$ & $1.580, \mathrm{p}=0.117$ & $1.131, \mathrm{p}=0.260$ \\
\hline \multicolumn{5}{|l|}{ Ethnicity } \\
\hline Yoruba & 9485.5 & 16.575 .99 & 20.347 .60 & 4.871 .33 \\
\hline Igbo & 65.5 & 18.175 .46 & 18.675 .99 & 5.030 .88 \\
\hline Hausa & 1.9 & 15.115 .56 & 18.227 .24 & 4.711 .69 \\
\hline Others & 98.2 & $\begin{array}{l}x^{2}=2.681 \\
p=0.848\end{array}$ & $\begin{array}{l}x^{2}=8.564, p=0.47 \\
8\end{array}$ & $\begin{array}{l}\mathrm{x}^{2}=4.802, \mathrm{p}=0.56 \\
9\end{array}$ \\
\hline \multicolumn{5}{|c|}{ Living arrangement } \\
\hline $\begin{array}{l}\text { Living with } \\
\text { parent }\end{array}$ & 3733.6 & 17.195 .93 & 18.877 .66 & 4.971 .56 \\
\hline $\begin{array}{l}\text { Living with } \\
\text { friends/hostel }\end{array}$ & 5247.3 & 16.816 .06 & 20.317 .23 & 4.741 .33 \\
\hline Living alone & 1917.3 & 16.214 .80 & 23.007 .19 & 5.180 .84 \\
\hline \multirow[t]{2}{*}{ Nil response } & 21.8 & 5.001 .41 & 12.502 .12 & 4.201 .13 \\
\hline & & $\begin{array}{l}x^{2}=7.649, p=0.2 \\
65\end{array}$ & $\begin{array}{l}x^{2}=16.945, p=0.0 \\
50\end{array}$ & $\begin{array}{l}\mathrm{x}^{2}=8.749, \mathrm{p}=0.18 \\
8\end{array}$ \\
\hline \multicolumn{5}{|c|}{ Academic performance } \\
\hline $\begin{array}{l}\text { Highly } \\
\text { satisfied }\end{array}$ & 1917.3 & 15.056 .06 & 19.425 .38 & 5.461 .42 \\
\hline $\begin{array}{l}\text { Moderately } \\
\text { satisfied }\end{array}$ & 8678.2 & 16.895 .92 & 20.197 .85 & 4.791 .27 \\
\hline \multirow[t]{2}{*}{$\begin{array}{l}\text { Least } \\
\text { satisfied }\end{array}$} & 21.8 & 20.007 .07 & 21.0012 .73 & 2.752 .05 \\
\hline & 32.7 & 16.676 .35 & 22.678 .08 & 5.300 .96 \\
\hline \multicolumn{5}{|c|}{ Social life situation } \\
\hline $\begin{array}{l}\text { Highly } \\
\text { satisfied }\end{array}$ & 2119.1 & 15.956 .43 & 17.766 .04 & 5.121 .71 \\
\hline $\begin{array}{l}\text { Moderately } \\
\text { satisfied }\end{array}$ & 8072.7 & 16.635 .67 & 20.287 .48 & 4.791 .26 \\
\hline $\begin{array}{l}\text { Least } \\
\text { satisfied }\end{array}$ & 76.4 & 20.215 .56 & 28.006 .50 & 4.770 .89 \\
\hline \multirow[t]{2}{*}{ Nil response } & 21.8 & 10.5010 .61 & 12.503 .54 & 6.350 .07 \\
\hline & & $\begin{array}{l}x^{2}=4.284, p=0.6 \\
38\end{array}$ & $\begin{array}{l}\mathrm{x}^{2}=15.813, \mathrm{p}=0.0 \\
71\end{array}$ & $\begin{array}{l}\mathrm{x}^{2}=7.814, \mathrm{p}=0.25 \\
2\end{array}$ \\
\hline \multicolumn{5}{|c|}{ Parental marital status } \\
\hline Married & 6760.9 & 16.366 .45 & 19.467 .13 & 4.991 .27 \\
\hline $\begin{array}{l}\text { Separated/div } \\
\text { orced/widow } \\
\text { ed }\end{array}$ & 1311.8 & 17.236 .78 & 23.159 .56 & 5.081 .52 \\
\hline \multirow{2}{*}{$\begin{array}{l}\text { Never } \\
\text { married }\end{array}$} & 3027.3 & 16.934 .27 & 20.377 .15 & 4.571 .41 \\
\hline & & $\begin{array}{l}x^{2}=10.116, p=0 \\
039\end{array}$ & $\begin{array}{l}\mathrm{x}^{2}=4.382, \mathrm{p}=0.62 \\
5\end{array}$ & $\begin{array}{l}x^{2}=1.977, p=0.74 \\
0\end{array}$ \\
\hline \multicolumn{5}{|c|}{ Family economic situation } \\
\hline Good & 4540.9 & 15.315 .78 & 18.876 .74 & 4.901 .51 \\
\hline Moderate & 6054.5 & 17.576 .03 & 21.287 .81 & 4.981 .10 \\
\hline
\end{tabular}




\begin{tabular}{|l|l|l|l|l|}
\hline Poor & 332.7 & 19.674 .16 & 17.6710 .69 & 2.831 .55 \\
\hline Nil response & 21.8 & 13.002 .83 & 18.509 .19 & 4.802 .40 \\
\hline & & $\begin{array}{l}\mathrm{x}^{2}=3.599, \mathrm{p}=0.7 \\
31\end{array}$ & $\begin{array}{l}\mathrm{x}^{2}=10.376, \mathrm{p}=0.3 \\
21\end{array}$ & $\begin{array}{l}\mathrm{x}^{2}=16.121, \mathrm{p}=0.0 \\
13\end{array}$ \\
\hline
\end{tabular}

\section{Discussion}

The objective of this study is to assess the prevalence of perceived stress, psychological distress and social support among clinical rehabilitation students of Obafemi Awolowo University, Ile-Ife, Nigeria. In this study, the prevalence obtained for the presence of perceived stress, psychological distress and social support were $69.1 \%, 47.3 \%$ and 50\% respectively. Prevalence of depression was $71.25 \%$ in a study reported by Kumar and Hegde (2012). (80.0\%) had mild - moderate degree of depression. Koochaki et al (2011), found $61.3 \%$ (18.0\% mild, $22.5 \%$ moderate and $20.8 \%$ severe) the result obtained from this study $47.3 \%$ (19.1\% for mild, $18.2 \%$ for moderate and $10.0 \%$ for severe) is lower compared to Koochaki's result. There was no significant difference in the stress level between clinical 1 and 2 students or between sexes. This is in line with the work of Abdulghani, 2008 and Koochaki et al, 2012. This result contradict the work of (Basson et al,2015; Shah et al, 2010; Saleh et al, 2017 and Shamsuddin et al, 2013) who reported significant difference in sexes, with females more affected. Males more affected as reported by Kumar and Hedge 2012. Glozah 2013 reported females are more depressed. The result also showed that prevalence of perceived stress is higher in comparison to that of psychological distress among the clinical medical rehabilitation students of Obafemi Awolowo University, Ile- Ife, Nigeria. The prevalence of stress was lower in this study compared to a study by Koochaki et al 2011. The outcome shows that prevalence of stress exists at lower rate among the clinical medical rehabilitation students in this study as compared to some other environment outside Nigeria.

In this study, no statistical significant relationship was found between age and perceived stress in line with the work of Koochaki et al 2011. There was also no significance relationship between PSS and gender in line with Koochaki et al 2011. Prevalence of elevated psychological distress were found in $30 \%$ of randomly sampled undergraduate students attending 16 different universities in Canada. Adlaf et al, (2001) and Stallman et al, (2010) reported estimated prevalence of 19.2\% with 67.4\% reporting subsyndromal symptoms. Also, $77.6 \%$ into moderate stress, $10.4 \%$ serious stress. Adonizio (2011) reported prevalence of $10 \%$ and $40 \%$ in mental health problems in studies conducted in the 1970s and 1980s and the mean depression, anxiety and stress scores among American students.

\section{Limitation}

This study has some limitations. The questionnaire used for this study depends upon self- reported measures. Therefore, the accuracy of the information provided in the questionnaire can be influenced, mistaken perceptions of a situation by the respondents. This limitation was controlled to some extent by making the questionnaire a closed ended type. Also, since the study was conducted in one university among the clinical medical rehabilitation students of the institution, the outcome of this study cannot be generalized on the entire population of all university students in Nigeria.

\section{Conclusion}

This study shows that there is high prevalence of perceived stress and slight below average psychological distress among undergraduate clinical rehabilitation students of Obafemi Awolowo University, Ile-Ife, Nigeria and about half of the population considered had high support. The implication of this is that students having stress or perceived stress with associated psychological distress, are to have more support from necessary quarters. Neglected public health problem in institutes of higher learning, can lead to adverse effects on the mental health quality of life and the need to have more support from necessary quarters. In this study, perceived stress was found to be associated with parental marital status and student level. Psychological distress was associated with living arrangement while social support was associated with family economic status. No other factors have been found to be significantly associated. 
DOI: $10.21522 / \mathrm{TIJPH} .2013 .06 .02 . A r t 018$

ISSN: $2520-3134$

\section{Recommendation}

The followings are therefore recommended:

1. There is need for mandatory workshops and seminars explaining anxiety, stress and coping methods at all year of study.

2. Need for concerted efforts and provision of necessary supports for the undergraduate by the people who surrounds them and from the environment

3. There is also need for much more attention to the psychological wellbeing of undergraduate students in order to improve their quality of life.

4. Preventive screening, mental health services and relevant coping strategies should be put in place as an important aspect of college education, and this should be regular basis so as to prevent mental health problems among students admitted into the universities.

5. Early diagnosis, treatment and counseling as necessary to vulnerable students

\section{References}

[1]. Abdulghani Hamza. M (2008): Stress and depression among medical students: A cross sectional study at a medical college in Saudi Arabia. Pakistan Journal of Medical Sciences. Quarterly, Vol 24, No 1, $12-17$.

[2]. Adiaf EM, Gliksman L, Demers A, Newton Taylor B (2001): The prevalence of elevated psychological distress among Canadian undergraduates: findings from the 1998 Canadian campus survey. J AM College of Health Sept, 50 (2), $67-72$

[3]. Anna C Phillips (2013): Perceived stress. Encyclopaedia of Behavioral Medicine. pg 1453 - 1454.

[4]. Azza Ali Taha, Etemad AA El-Shereef, Wedad Althobaiti, Mai Muaimedh Algethami (2017): Study of perceived stress among female students, Taif University, Saudi Arabia. America Journal of Public health research. 5(3): 50 - 55. doi. 10.12691/ajphr-5-3-1.

[5]. Basson W.J., Nel K.A. and Bhat S.B. (2015): Stress amongst dental students at an emerging medical university. J Psychology 6(1): 87 - 90.

[6]. Bridgette Bewick, Gina Kontsopoulou, Jeremy Miles, Esther Slaa and Michael Barkham (2010): Changes in undergraduate students' psychological wellbeing as they progress through university. Studies in higher education. Vol. 35, Issue 6, pages $633-645$.

[7]. Burns VE, Drayson M, Ring C, Carrol D (2002): Perceived stress and psychological wellbeing are associated with antibody status after meningitis C conjugate vaccination. Psychosom Med. Nov - Dec, 64(6): $963-70$.

[8]. Dalia Saleh, Nathalie Camart and Lucia Romo (2017): Predictors of stress in college students. Front. Psychology. Vol. 8: 19. January.

[9]. Dusan V. Backovic, Jelema IIic Zivojinovic, Jadrankamak Simovic, Milos Maksimovic (2012): Gender differences in academic stress and burnout among medical students in final years of education. Psychiatria Danubina. Vol. 24, No 2. Pages 175 - 181.

[10]. Dyrbye L.N. et al 2006. Systematic Review of depression, anxiety and other indications of psychological distress among US and Canadian medical students. "Academic Medicine 81(4): 354 - 373.

[11]. Ekpenyong C.E., Davis K.J., Akpan U.P. and Daniel N.E. (2011): Academic stress and menstrual disorders among female undergraduates in Uyo, South Estern Nigeria. The need for heath education. Niger. J. Physiol. Sc: 26 (December) 193 - 198. Mental disorders are a major contribution to the burden of diseases in all regions of the world.

[12]. Eliza Omar Eva, Md Zakiru Islam, Abu Syed Md Mosaddek, Md Faizur Rahman, Rini Juliet Rozario, Af Md Hassan Iftekhar, Tarafder Shahniam Ahmed, Iffat Jahan, Rabiu Abubakar, Wan Putri Elena Han Dali, Mohammed S Razzaque, Rahat Bin Habib and Mainul Haque (2015): Prevalence of stress among medical students: a comparative study between public and private medical schools in Bangladesh. BMC Research Notes 8.327. DOI: 10.1186/S 13104-015-1295-5.

[13]. Faith Ozbay, Douglas C Johnson, Eleni Dimoulas, C.A. Morgan Dennis Charney and Steven Southwick (2007): Social Support and resilience to stress: from Neurobiology to clinical practice. Psychiatry (Edgmont). May; 4(5): 35 - 40.

[14]. Figen Kocyigit, Emel Dikbas Torun, Ummuhan Bas Aslan (2015): Anxiety, depression, physical activity and quality of life in student physical therapists; A cross sectional study. American Journal of Educational Research Vol. 3, No 10A, pp 26 - 29. http://pubs.sciepub.com/education/3/10A/4 
[15]. Frank Patrick Addonizio (2011): Stress, coping, social support and psychological distress among MSW students. University of South Carolina, ProQuest Disertations Publishing, UMI Number: 3481178.

[16]. Franklin N. Glozah (2013). Effects of academic stress and perceived social support on the psychological wellbeing of adolescents in Ghana. Open Journal of Medical Psychology. 2. $143-150$. http://dx.doi.org/10.4236/ojmp.2013.24022.

[17]. Ganeshs Kumar, Animesh Jain and Supriya Hegde (2012): Prevalence of depression and its associated factors using Beck Depression Inventory among students of a medical college in Karnataka. Indian J. Psychiatry. July - September. 54(3); 223 - 226.

[18]. Habibah Elias, Wong Siew Ping and Maria Chong Abdullah (2011): Stress and Academic Achievement among Undergraduate Students in University Putra Malaysia. Procedia - Social and Behavioural Sciences 29: $646-655$.

[19]. Helen M. Stallman (2010): Psychological distress in university students: A comparison with general population data. Australian Psychologist. Vol 45, Issue 4 page 249 - 257.

[20]. Khadijah Shamsuddin, Fariza Fadzil, Wan Salwina, Wan Ismail, Shamsul Azhar Shah, Khairani Omar, Noor Azimah Muhammad, Aida Jaffar, Aniza Ismail, Raynuha Madadevan (2013): Correlates of depression, anxiety and stress among Malaysian University Students. Asian Journal of Psychiatry, 6, 318 - 323.

[21]. Koochaki GM, Charkazi A, Hasanzadel A, Saedain M, Qorbani M, Marjani A (2011): Prevalence of stress among Iranian medical students: a questionnaire survey. East Mediterranean Health J. July; 17(7); 593 - 8.

[22]. Lakyntiew Pariat, Angelyne Rynjah, Joplin. M.G. Kharjana (2014). Stress levels of college students: Interrelationship between stressors and coping strategies. IOSR Journal of Humanities and Social Science, Vol. 19. Issue 8; Ver. III (Aug). Pg 40 - 46.

[23]. Liselotte N. Dyrbye, Matthew R. Thomas, Standford Massie, David V. Power, Anne Eacker, William Harper, Steven Durning, Christine Moutler, Daniel, W. Szydlo, Paul J. Novotry, Jeff A. Sloan and Talt, D.Shanafelt. (2011). Patterns of distress in US medical students (2011): Medical Teacher Vol. 33: 834 - 839.

[24]. Liselotte N. Dyrbye, Matthew R. Thomas, Standford Massie, David V. Power, Anne Eacker, William Harper, Steven Durning, Christine Moutler, Daniel, W. Szydlo, Paul J. Novotry, Jeff A. Sloan and Talt, D. Shanafelt. (2008).Medical student Burnout and suicidal ideation. Annals Internal Medicine Medical Teacher Vol. 149 (5): $334-341$.

[25]. Lisolette N. Dyrbye, Matthew R. Thomas, Tait D. Shanafekt (2005): Medical Students Distress: causes, consequences and proposed solutions. Vol. 80, Issue 12, pages 1613 - 1622. Elsevier.

[26]. Mohsin Shah, Shahid Hasan, Samina Malik and Chandrashekhar T Sreeramaredoly (2010). Perceived stress, sources and severity of stress among medical undergraduates in a Pakistan Medical School. BMC Med Educ. Vol. 10:2.

[27]. Nicole Fairbrother (2011): Social Support. Issues of visions Journal Vol. 6(4) pg 7.

[28]. Nirza I, Jenkins R (2004): Risk factors, prevalence and treatment of anxiety and depression disorders in Pakistan: Systematic review BMJ. April. Vol 328 (7443): 794.

[29]. Pamela L. (2009): Premenstrual syndrome and academic stress in emerging adulthood women. Available at (http://www.nursingarizona.edu/library/091) as cited by Ekpenyong et al 2011.

[30]. Purna Prabhakar Nandamuri and Gowthami Ch. Sources of academic stress - A study on management students, http://JMS.nonolympictime.org/Articles/4.pdf.

[31]. Reda Abouserie (2006): Sources and levels of stress in relation to locus of control and self-esteem in university students http://dx.doc.org/10.1080/0144341940140306 published online, pg 323-330.

[32]. Reda Abouserie (2009): Sources and levels of stress in relation to locus of control and self-esteem in university students. Educational Psychology. (An international journal of experimental educational psychology). Vol. 14, Issue 3, pages $323-330$.

[33]. Richard Cooke, Bridgette M. Bewick, Michael Barkham, Margaret Bradley and Kerry Audin (2007): Measuring, monitoring and managing the psychological wellbeing of the first year students. British Journal of Guidance and Counselling, Vol. 34, Issue 4, pages $505-517$.

[34]. Ridner SH (2004): Psychological distress; Concept analysis. J. Advanced Nursing. March, Vol. 45(5):536 -545 .

[35]. Ronald C. Kessler, Patricial Berglund Olga Demler, Jin R, Koretz D, Merikanga SKR, Rush AJ, Walter's EE, Wang PS (2003). June. Vol. 289(23): 3095 - 105. 
DOI: $10.21522 /$ TIJPH.2013.06.02.Art018

ISSN: $2520-3134$

[36]. Ross, Shannon E, Niebling, Bradley C and Heckert, Teresa M. 1999. Sources of stress among college students. College Student Journal; June, vol. 33, Issue 2, pg 312, 6p.

[37]. Sanjeev Kumar and J.P. Bhukar (2013): Stress level and coping strategies of college students. Journal of Physical Education and Sports Management, Vol. 4(1): pp 5 - 11, January.

[38]. Sathya R. Devi and Shaj Mohan (2015): A study on stress and its effects on college students. International Journal of Scientific Engineering and Applied Science (IJSEAS) - Vol. 1, Issue 7, Oct.

[39]. Sherry A. Benton, John M. Robertson, Wen-Chin Tseng, Fred B-Newton and Stephen L. Benton (2003): Changes in counselling centre client problem across 13 years. Professional Psychology; Research and Practice. Vol 34, No 1, 66- 72 .

[40]. Tamar Jacob and Ofira Einstein (2016): Stress among bachelor of physical therapy students in Israel during clinical practice and its association with academic achievements - Result of a longitudinal study. The Internet Journal of Allied Health Sciences and Practice, January, 12; 14(1), Article 9.

[41]. Tomlinson M, Grimsrud, Stein. J. Dan Anna T., William David R, Myer Landon (2009). The epidemiology of major depression in South Africa: Results from the South African Stress and Health Study: South African Medical J, 99: 368 - 373.

[42]. Uma K and Manikardan K (2013): Influence of locus of control, self-esteem and sex on academic stress among adolescents. Guru Journal of Behavioral and Social Sciences. Vol. 1, Issue 4 (Oct - Dec) 186- 193.

[43]. Wong. P.T.P, Wong L.C.J. and Scott G. (2006). The positive psychology of transformation beyond stress and coping. In Wong, P.T.P. and Wong, L.C.J. (Eds), Handbook of multicultural perspectives on stress and coping. New York, Nt: Springer. 


\title{
Assessment of Antiretroviral Therapy Outcomes among Key Populations after 6 Months of Initiation in Nigeria
}

\author{
Article by Ugbena, Eneojo Richard ${ }^{1}$, Iwuagwu, Stella ${ }^{2}$, Okekearu, Ifeanyi ${ }^{3}$, Wole, \\ Fajemisin ${ }^{4}$, Ioytim Isa ${ }^{5}$ \\ ${ }^{1}$ Society for Family Health, Nigeria \\ ${ }^{2}$ Centre for the right to Health \\ ${ }^{3}$ Society for Family Health, Nigeria \\ ${ }^{4}$ Society for Family Health, Nigeria \\ ${ }^{5}$ USAID, Nigeria \\ E-mail: rugbena@yahoo.com ${ }^{1}$
}

\begin{abstract}
Introduction: Key Populations are disproportionately affected by HIV/AIDS in all settings. Unfortunately, reaching KPs with HIV intervention is a huge challenge because of stigma, discrimination, violence, and criminalization of KPs lifestyles. Because of lack of KP specific interventions, data on KPs ART outcomes is lacking. This study determined ART outcomes among KPs 6-months after initiation.

Methodology: The study was a longitudinal study of all HIV positive KPs initiated on ART in 7 One-Stop-Shops from October 2016-March 2017. Both Time-1 and Time-2 data were abstracted from facility record after initiation and 6-month after for each patient. Data abstracted include: age, sex, marital status, educational level, employment status and ART outcome 6 months after initiation.

Results: Sixty-seven percent of patients were retained on ART, $1.8 \%$ died, $20.6 \%$ were lost to follow up, $4.5 \%$ transferred to other facilities and 6.2\% stopped ART by the end of the $6^{\text {th }}$ month. PWID had highest retention rate (74.6\%) more than MSM (70.2\%), while FSW had the least retention rate $(65.4 \%)$ but highest transfer out rate (4.9\%) more than MSM (4.7\%). Factors positively associated with retention at $6^{\text {th }}$ months include: Being a male $P=0.007$; higher education $P=0.000$; employed patient $P=0.000$; living with sex partner $P=0.000$.

Conclusion: This study has laid a baseline data for ART outcomes among KPs in Nigeria. Further study is however required to identify factors that could improve retention on ART among KPs. This is important if we must achieve the second and third 90s of UNAIDs 90.90 .90 goals.
\end{abstract}

Keywords: HIV/AIDS, Antiretroviral therapy; Key Population in Nigeria; One-Stop-Shop; Antiretroviral therapy outcomes.

\section{Introduction}

HIV/AIDS has remained a significant public health concern for over three decades and even though a lot of studies were carried out among the general population, data is less available for KPs owning to challenges associated with reaching KPs with health services and data collection especially in Africa. Majority of the world's new HIV infections occur in resource poor-countries, [1] with twothirds of the world's HIV-infected population living in Africa [2] Nigeria has the second largest HIV epidemic in the world and has one of the highest new infection rates in sub-Saharan Africa [3]. However, in recent years there has been a remarkable achievement in combating global HIV with new infection declining in most part of the world except for Eastern Europe and Central Asia region where since 2010, the annual number of new infections in the region has climbed by an alarming $60 \%$ [4]. In 2016, there were roughly 1.8 million new HIV infections [1], a decline from 2.1 million new infections in 2015 [4].

In all countries and settings, KPs are disproportionately affected by HIV infection [5]. KPs are groups that have a high risk and disproportionate burden of HIV in all epidemic settings due to their behavioural patterns and specific legal and social challenges that increase their vulnerability to HIV, including barriers to accessing HIV prevention, treatment and other health and social services [6], [7]. 
Key populations include Men who have Sex with Men (MSM), People Who Inject Drugs (PWID), and Sex Workers (SW), people in prisons and closed settings, and transgender people [8]. UNAIDS estimates that between 40 and 50 percent of all new HIV infections among adults worldwide occur in these key populations and among their sex partners [5], [9]. In Nigeria, It was estimated that SWs, MSM, and PWID make up 3.4\% of Nigerian population, yet they account for $32 \%$ of new HIV infections [10]. The prevalence of HIV among MSM, brothel-based FSW, none brothel-based FSW and PWID in Nigeria was $23 \%, 19.4 \%, 8.6 \%$ and $3.4 \%$ respectively [11] compared to the national prevalence of 3.0 [12]. This clearly shows a disproportionately higher burden among KPs in Nigeria and they will continue to drive the epidemic. HIV/AIDS intervention among KPs remain a priority if we must achieve the ambitious UNAIDS 90.90 .90 goals by 2020 [9]. However, reaching KPs with HIV intervention is a huge challenge because of stigma, discrimination, violence and in some cases criminalization of KP behavioural patterns [5]. These factors have often limited KPs access to and utilization of comprehensive HIV prevention, treatment, care, and support services [13]. Even when services are available, HIV-related stigma within healthcare settings may act as a barrier to the uptake and delivery of HIV care [14]. In Nigeria, there is stigma and discrimination as well as legislation against MSM, PWID and SWs lifestyle. Punitive laws [3], against homosexuality have meant that men who have sex with men are now even more vulnerable to HIV infection and face many difficulties accessing HIV services.

After HIV diagnosis [15], timely entry into HIV medical care and retention in care are essential to the provision of effective antiretroviral therapy. ART programmatic success requires that patients who are taking ART remain on treatment and are followed up regularly to monitor ART service outcomes. Recent data from the U.S. Centres for Disease Control and Prevention [15] in the USA reveal that of those who knew they had HIV, only $69 \%$ were linked to care, and only 59\% were retained in care. Once patients are in care and are receiving treatment [15], high levels of adherence are required to prevent the selection of resistance mutations and subsequent virologic failure. From existing literature [16] adherence to ART was reported to be influenced by age, access to healthcare, the burden of multiple vulnerabilities, policy involving risk behaviours and mental health. In addition, programmatic factors such as quality of counselling, location of service point, health worker attitude may be some factors why some patients initiated on ART may not be retained or adhere to ART service guidelines. There are various notable event that occurs among patients on ART over time; the patient may adhere to treatment by keeping to clinic appointment and pill intake; others may be lost to follow up when they failed to show up in clinic 90 days after the last clinic visit and effort to trace and return them to services failed; some may die from the disease complication, some may stop ART completely for any reason or stopped at a point and then re-start again. These various outcomes are characteristic of a typical ART program. Some of long-term retrospective studies in Nigeria have described various ART outcomes among the general population. In a study of long-term outcomes on antiretroviral therapy carried out in multiple sites from 2008- 2012, [17] of the 70,002 patients, $1.8 \%$ were reported as having died, $30.1 \%$ were lost to follow-up, and $0.1 \%$ withdrew from treatment. Another retrospective cohort analysis of 3,496 patients initiated on ART from 35 sites across the country between 2004 to 2012 showed that $1.1 \%$ died, 12.3\% LTFU, 13.9\% stopped ART with the highest attrition in the first 3 months [18] However, a similar 10 years retrospective study conducted in a facility [19] showed that attrition is highest in the first year of initiation (Overall attrition rate was 1.52 per 1000 person-months (PM) with 2.68/1000 PM in the first year, 1.81/1000 PM in the first 5 years, and 0.75 in the last 5 years. Similar data among KPs is currently lacking in Nigeria. While the MSM population does better than other HIV infected KPs with regard to linkage to and retention in care, little is known about engagement in care outcomes for important subpopulations of MSM [19] like the homosexual or bisexual MSMs. In a national cohort of American veterans, being MSM was associated with improved adherence to a visit in each of the 4 quarters of a year [20]. For PWID, while retention was found to be less at early years of initiation and improved after some years [21] a study in Vietnam showed good retention and immunological response to ART among a predominantly PWID group of patients despite advanced HIV infections at baseline; $88.4 \%$ after 6 months to $74.6 \%$ at 36 months [22] Among FSW, retention was more among FSW who have positive perception of HIV service providers [23]. With expanded ART programs in resource-limited settings which have 
improved treatment access to millions of People Living with HIV (PLHIV), inadequate retention in care has been a real challenge for the programs and has undermined efforts to optimize patient and program outcomes [24]. This challenge on ART retention may be worst for KPs in Africa because of the challenges with accessing health services due to social stigma, gender-based violence, discriminatory policies including criminalization of the lifestyles of key populations, which has hindered their access to care and treatment. In addition, these groups are hard to reach with health interventions and behaviour change interventions because they are often mobile and "hidden." [25]

Because KPs are drivers of HIV epidemic, reaching members of these communities with evidencebased interventions that improve their access to and uptake of services across the HIV prevention, care, and treatment cascade is essential to achieving the UNAIDS 90-90-90 goals [5] Currently the government of Nigeria does not provide any KP specific health services thus, public health intervention for KPs is only provided through donor-supported projects. One of such project is the Strengthening HIV Prevention Services for Most at Risk Population (SHiPS for MARPS), a PEPFAR funded project through USAID Nigeria with focus on providing comprehensive prevention services including treatment as prevention for KPs within the communities. The project implemented minimum prevention package for KPs conducted HIV counselling and testing and established OneStop-Shops for comprehensive health services for KPs. The SHiPS for MARPS project was implemented by Society for Family Health Nigeria in consortium with Population Service International and Center for the Right to Health in 7 states. The community health services provided by SHiPS for MARPS project offers an opportunity for KPs who hitherto, had a poor attitude to HIV counselling and testing to know their HIV status. With increased uptake of HIV counselling and testing among KPs in the communities, more HIV positive KPs were identified and linked to treatment. The project implemented "test and treat" strategy in line with WHO guideline. This implies that all newly identified positive KPs were initiated same day or at most, within the next 2 weeks. This strategy increased the number of KPs initiated on treatment. However, retention of treatment after initiated may be an issue particularly for mobile and hidden population such as KPs. Couple with poor health seeking behaviours, stigma and discrimination, maintaining those already initiated on ART may be a serious challenge. It is therefore important to determine the various ART outcomes such as retention rate, stopped ART, lost to follow up, transferred-out and death among the subpopulations of KPs. These factors are important for an effective HIV intervention, particularly among the KPs. This study will determine what proportion of positive KPs linked to ART are retained on treatment 6 months after initiation, and for those not retained on treatment, what event happened.

\section{Objectives}

To evaluate ART outcomes among KPs attending OSS in the first 6-7 months after initiation

\section{Specific objectives}

- To determine the proportion of KPs who are retained on ART 6-7 months after initiation of ART.

- To determine the attrition rate (Loss to follow up, dead, stopped ART) in the first 6-7 months after initiation on ART.

- To determine the proportion of KPs who transferred to other facilities in the first 6-7 months of initiation on ART.

- To determine what proportion re-started ART in the first 6-7 months of initiation on ART.

\section{Methodology}

\section{Site}

This study was carried out across 7 states supported by SHiPS for MARPS project. In each of the state, the project established One-Stop-Shop facility to provide HIV prevention, treatment, and care services for KPs and their partners. Other services provided at the sites include cervical cancer screening, syndromic management of other sexually transmitted diseases, partner notification services. 


\section{Study design}

The study was a longitudinal study of all HIV positive KPs who were initiated on ART in 7 OSS from October 2016 to March 2017. After initiation, time 1 data were abstracted from medical record of each patient to obtain their baseline characteristics. Each patient was then followed up for at least six months when they are eligible for viral load testing according to national ART guideline. Thus, the last patient attained 6 months by September 2017. The second data abstraction was carried out after the $6^{\text {th }}$ month of initiation for each patient to determine ART outcome if they are still receiving ART services. The $6^{\text {th }}$-month visit for some patients fell within 6 to 8 months after initiation depending on the clinic appointment.

\section{Sampling technique}

All patients initiated on ART between October 2016 and March 2017 in the 7 OSS were eligible for the study and data was abstracted for all of them. But all patients who were transferred to the facilities during the enrolment period were excluded to avoid the influence of quality of care in the first facility which may positively or negatively affect ART outcome in the first 6-months. At the second phase of data abstraction, information on each patient was obtained with respect to whether they are still alive and receiving ART services and if not, what happened?

\section{Data collection}

Data were abstracted from already existing medical records in the OSS. Each facility maintained a national patient register which captured all the variables for analysis in this study. The following data were abstracted: At T1, socio-demographics of patients, the state where OSS is located, and at T2, information on clinic follow up such as appointment keeping, drug adherence, lost to follow up, transferred out, stopped ART, death, and re-start ART. A line listing of the patients was developed on an Excel template to capture all the variables required for analysis on the study. The final Excel template merged for all the states was imported to SPSS version 20 for analysis.

\section{Ethical consideration}

Ethical clearance specifically for this study was obtained from the Nigeria Institute of Medical Research. Only information documented in routine patient care register was abstracted and use for analysis with no additional patient contacts or study specific inquiries.

\section{Study limitation}

The loss to follow up constituted most of the attrition by patients. A patient is declared lost to follow up when patient fails to show up in the clinic 90 days after the last missed appointment and all effort by the health worker to trace and return the patient to the facility has failed. Some patients assumed to be lost to follow up in this study may be alive but self-transfer to other facilities or the patient may be dead or stopped ART. Because many KPs will not provide correct contact information, it is difficult for the health worker to trace them when the need arises. This factor could result in overestimation of lost to follow up as an outcome but may also underestimate actual outcomes like death and stopped ART among the study cohort.

Similarly, the study could no way determine the status of patients who transferred to other facilities. Therefore the estimate of death, stopped ART and LTF could not be ascertained for those patients that initiated ART at the OSS but transferred to other facilities.

\section{Result}

The study was conducted between October 2016 and September 2017 in 7 OSS facilities each located in one of the 7 states supported by SHiPS for MARPS project. Data were collected at baseline (T1) and at 6-7 months (T2) after initiation of ART for each patient. A total of 3,611 KPs including their partners were initiated between October 2016 and March 2017. Out of the 3,611 KPs initiated during the period, 2351(65\%) were FSW, 688(20\%) were MSM, 339(9\%) were partners (PT) of KPs, 155(4\%) were male PWID and 78(2\%) were female PWID. The baseline characteristics and the outcomes of ART services at 6-7 months after initiation are presented below: 
Texila International Journal of Public Health

Volume 6, Issue 2, Jun 2018

Table 1. Baseline characteristic of patients

\begin{tabular}{|l|l|l|l|}
\hline Characteristics & Type & Number & Percentage \\
\hline \multirow{4}{*}{ Sex } & Male & 1135 & 31 \\
\cline { 2 - 4 } & Female & 2476 & 69 \\
\hline \multirow{5}{*}{$\begin{array}{l}\text { Occupational } \\
\text { status }\end{array}$} & None & 507 & 14.0 \\
\cline { 2 - 4 } & Primary & 720 & 19.9 \\
\cline { 2 - 4 } & Secondary & 1764 & 48.9 \\
\cline { 2 - 4 } & Tertiary & 620 & 17.2 \\
\hline Marital status & Employed & 1265 & 35.1 \\
\cline { 2 - 4 } & Student & 304 & 8.4 \\
\cline { 2 - 4 } & $\begin{array}{l}\text { Un- } \\
\text { employed }\end{array}$ & 2042 & 56.5 \\
& Married & 1185 & 33 \\
\cline { 2 - 4 } & Single & 1874 & 52 \\
\cline { 2 - 4 } & Divorced & 239 & 6.5 \\
\cline { 2 - 4 } & Separated & 26 & 0.7 \\
\cline { 2 - 4 } & Widowed & 268 & 7.3 \\
\cline { 2 - 4 } & $\begin{array}{l}\text { Co- } \\
\text { habituating }\end{array}$ & 19 & 0.5 \\
\hline Age & $\begin{array}{l}15-24 \\
\text { (young } \\
\text { person) }\end{array}$ & 933 & 25.8 \\
\cline { 2 - 4 } & $\begin{array}{l}\geq 25 \text { years } \\
\text { (adults) }\end{array}$ & 2678 & 74.2 \\
\cline { 2 - 4 } Min =15, Max=75, Mean =30.9, std = 8.7 \\
\hline
\end{tabular}

$\mathrm{N}=3611$.

Sixty-nine percent of the patients were female, while $86 \%$ had primary education and above. Unemployed accounted for $56.5 \%$ while only $35.1 \%$ were employed and the remaining $8.4 \%$ were the student. 52\% of the patients were single while $33 \%$ were married. Majority of the patients were adult (74.2\%) and the rest were the young persons (25.8\%). Mean age was 30.9 \pm 8.7 (range 15-75).

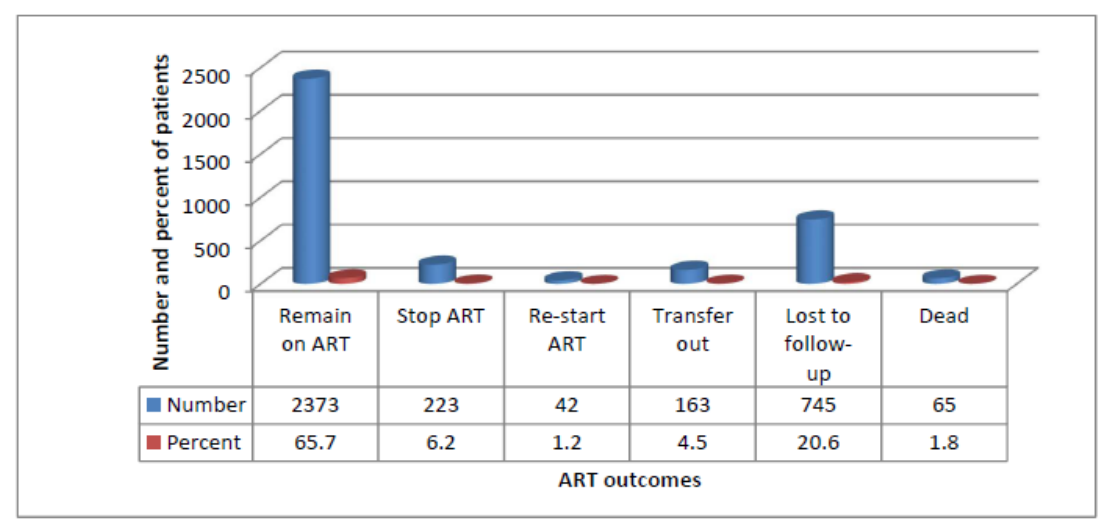

Figure 1. ART outcomes among KPs at 6-7 months after initiation on ART at OSS

Out of 3,611 initiated of ART, 65.7\% remain on ART throughout the 6-7 months. 1.2\% stopped but re-started before the end of $7^{\text {th }}$ month, $6.2 \%$ stopped ART completely, $4.5 \%$ were transferred to other facilities, while $20.6 \%$ were lost to follow up and $1.8 \%$ died. 


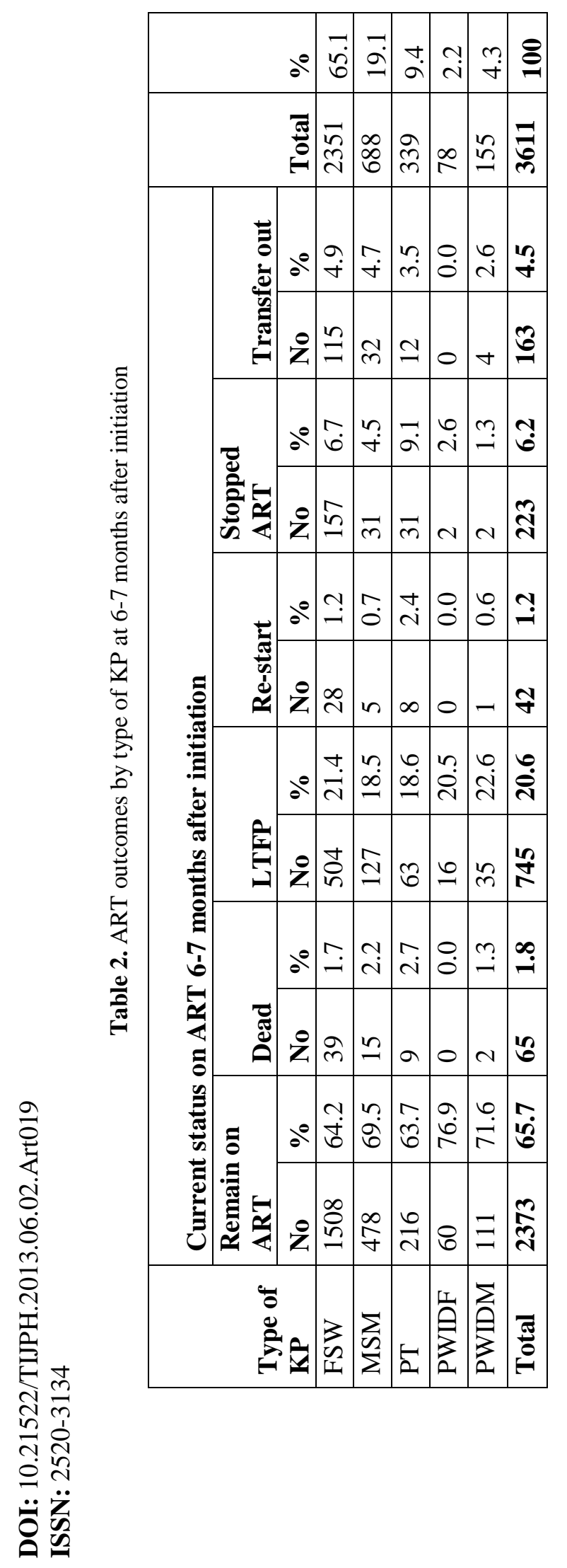


Retention rate includes those patients who remained on ART or re-start ART as at 6-7 months. PWIDF had the highest retention rate (76.9\%) followed by PWIDM (72.2\%). MSM had retention rate of $70.2 \%$, PT was $66.1 \%$ and the least was FSW with $65.4 \%$ retention rate. Most death occurred among PT $(2.7 \%)$ followed by MSM $(2.2 \%)$ then FSW (1.7\%). No death was recorded among PWIDF. PWIDM had the highest lost to followed rate with $22.6 \%$, followed by FSW (21.4\%), while PT and MSM were $18.6 \%$ and $18.5 \%$ respectively. $2.4 \%$ of PT stopped but re-started ART before the end of $7^{\text {th }}$ months followed by FSW (1.2\%). No PWIDF re-started ART. 9.1\% among PT stopped ART completely as at $7^{\text {th }}$ month followed by FSW (6.7\%) and then MSM (4.5\%). The least was among PWIDM with 1.3\%; Most transferred out occurred among FSW (4, 9\%) followed by MSM (4.7\%) and then PT (3.5\%). None of the PWIDF transferred to other facilities.

Table 3. Retention on ART at 6-7th months by age group

\begin{tabular}{|l|l|l|l|}
\hline Age group & Still on ART (\%) & Lost out of ART (\%) & Total \\
\hline $\begin{array}{l}10-24 \text { years (young } \\
\text { person) }\end{array}$ & $604(69 \%)$ & $277(31 \%)$ & 881 \\
\hline$\geq 25$ Years (old adults) & $1811(71 \%)$ & $756(29 \%)$ & 2567 \\
\hline Total & $\mathbf{2 4 1 5}$ & $\mathbf{1 0 3 3}$ & $\mathbf{3 4 4 8}$ \\
\hline
\end{tabular}

$\mathrm{X}^{2}=1.239 ; \mathrm{P}=0.27$ at $95 \%$ CI.

Sixty-nine percent of the young people (10-24 years) were still on ART at 6-7 months after initiation while among older people ( $\geq 25$ years) $71 \%$ were retained on ART at 6-7 months. Retention on ART at 6-7 months was not significantly different between the young people and old adults. $P$ Value $=0.27$.

Table 4. Retention on ART at 6-7 months after initiation by sex

\begin{tabular}{|l|l|l|l|}
\hline Sex & Still on ART (\%) & Lost out of ART (\%) & Total \\
\hline Female & $1620(69 \%)$ & $741(31 \%)$ & 2361 \\
\hline Male & $795(73 \%)$ & $292(27 \%)$ & 1087 \\
\hline Total & $\mathbf{2 4 1 5}$ & $\mathbf{1 0 3 3}$ & $\mathbf{3 4 4 8}$ \\
\hline
\end{tabular}

$\mathrm{X} 2=7.254 ; \mathrm{P}=0.007$ at $95 \% \mathrm{CI}$, Cramer's V=0.046.

Sixty-nine percent of all females initiated on ART was still receiving ART services as at 6-7 months after initiation while $73 \%$ of all males were retained on ART at the same period. More male patients were significantly retained on ART at 6-7 months after initiation than female. $P$-Value $=$ 0.007 .

Table 5. Retention on ART at 6-7 months after initiation by educational status

\begin{tabular}{|l|l|l|l|}
\hline $\begin{array}{l}\text { Educational level } \\
\text { completed }\end{array}$ & $\begin{array}{l}\text { Still on ART } \\
(\%)\end{array}$ & Lost out of ART (\%) & Total \\
\hline Illiterate & $252(53 \%)$ & $224(47 \%)$ & 476 \\
\hline Literate & $2163(73 \%)$ & $809(27 \%)$ & 2972 \\
\hline Total & $\mathbf{2 4 1 5}$ & $\mathbf{1 0 3 3}$ & $\mathbf{3 4 4 8}$ \\
\hline
\end{tabular}

$\mathrm{X} 2=76.949 ; \mathrm{P}=0.000$ at $95 \% \mathrm{CI}$, Cramer's V $=0.149$.

Seventy-three percent of those who had at least primary education and above were retained on ART at 6-7 months, while only 53\% of those who had no education at all were retained on ART. The difference was statistically significant, $P$-Value $=0.000$. 
DOI: $10.21522 /$ TIJPH.2013.06.02.Art019

ISSN: $2520-3134$

Table 6. Retention on ART at 6-7 months by partner's status

\begin{tabular}{|l|l|l|l|}
\hline Sex partners status & Still on ART $(\boldsymbol{\%})$ & $\begin{array}{l}\text { Lost out of ART } \\
(\boldsymbol{\%})\end{array}$ & Total \\
\hline Living with partner & $768(66 \%)$ & $393(44 \%)$ & 1161 \\
\hline Living separately & $1647(72 \%)$ & $640(28 \%)$ & 2287 \\
\hline Total & $\mathbf{2 3 9 9}$ & $\mathbf{1 0 4 9}$ & $\mathbf{3 4 4 8}$ \\
\hline
\end{tabular}

$\mathrm{X} 2=12.627 ; \mathrm{P}-$ Value $=0.0001$ at $95 \% \mathrm{CI}$, Cramer's V $=0.061$.

Seventy-two percent of patients leaving separately were retained on ART while only $66 \%$ of those leaving with their partners were retained. The difference was statistically significant; P-Value $=0.001$.

Table 7. Retention on ART at 6-7months by occupational status

\begin{tabular}{|l|l|l|l|}
\hline Occupation & Still on ART (\%) & Lost out of ART (\%) & Total \\
\hline Employed & $923(77 \%)$ & $280(23 \%)$ & 1203 \\
\hline Unemployed & $1492(66 \%)$ & $753(34 \%)$ & 2245 \\
\hline Total & $\mathbf{2 4 1 5}$ & $\mathbf{1 0 3 3}$ & $\mathbf{3 4 4 8}$ \\
\hline
\end{tabular}

$\mathrm{X}^{2}=39.340$ : P-Value 0.000 at $95 \%$ CI; Cramer's V $=0.107$.

Retention on ART was highest among employed respondent $77 \%$ more than $66 \%$ among unemployed. The difference was statistically significant. P-Value $=0,000$.

\section{Discussion}

The main outcomes of the ART programme are improved quality of life and reduced mortality [26] however; patients enrolled on ART may experience other outcomes in the course of receiving treatment. Events such as retention on ART, lost to follow up, death, transfer out, re-start ART, stopped ART and measurement of CD4 and viral load are commonly used to assess the effectiveness and outcomes of the ART program. Most ART outcomes studies conducted in Sub-Saharan African reviewed long-term outcome among the general populations in the clinical settings and thus, data on short-termed outcomes particularly for KPs is lacking. Our study is a short-term assessment of ART outcomes among KPs receiving ART services in community-based One-Stop-Shops facilities. We found that $66.9 \%$ (remain on ART and re-start ART) were retained on ART, $1.8 \%$ died, $20.6 \%$ were lost to follow up, $4.5 \%$ transferred to other facilities, and $6.2 \%$ stopped ART by the end of $6^{\text {th }}$ months. This finding only shows similarity in the number of loss to follow up when compared with a recent study across 22 Sub-Saharan Africa countries [27]. The study which reviewed ART outcomes among general population after 5 years of initiation showed that $76.8 \%$ were retained on ART, $19.6 \%$ were lost to follow up and $3.5 \%$ died. Also, two similar long-termed retrospective studies conducted among the general population in Nigeria, reported similarity only on a number of retention rate and deaths but differs on the loss to follow up and stopped ART. The first study [17], reported $68 \%$ of the patients were retained on ART, with $1.8 \%$ death rate, $30.1 \%$ lost to follow up, and $0.1 \%$ stopped ART after 8 years of initiation of ART. In the second study [18], the retention rate was $61.7 \%$, the death rate was $1.1 \%$, loss to follow up was $12.3 \%$ and stopped ART was $13.9 \%$ after 4 years of initiation of ART. Even though these two studies in Nigeria were 4-8 years retrospective analysis of ART services among the general population, the retention rate in our study $(66.9 \%)$ is similar to retention rate found in the two studies $68 \%$ and $61.7 \%$ in the first and second studies respectively. Similarly, the attrition rate in our study for 6 months also collaborates with the attrition rate described by the two studies. While the first study reported that attrition was highest in the first 6 months [17], the second study reported that attrition was highest in the first 3 months [18]. It is therefore important to note that community-based ART services for KPs if well managed will have a similar outcome with ART services at clinical setting for the general population. The SHiPS for MARPS project focused on KPs and with the establishment of OSS that provided comprehensive services for KPs, this has removed the fear of stigma and discrimination which are part of reasons why KPs may be reluctant to access 
services in public health facilities. At the OSS, the staffs were trained to provide MARPS friendly services and with ambient created in the facilities, MARPS found it a convenient place even at leisure times to interact freely. Counselling was provided at every point of contact at the OSS and each patient was linked to case management officers who were constantly in communication with the patients.

Retention on ART has remained a major challenge to the success of ART services [24] particularly for KPs with social challenges that have prevented access to and utilization of health services. Patient's retention on antiretroviral therapy is required to minimize the likelihood of treatment interruptions and discontinuation [28], which not only reduces patient morbidity and mortality but also minimizes the risk of developing drug resistance and promote viral suppression [29]. Despite these and other benefits, retention on ART is Sub-Saharan African even among the general population remains low at the various point due to high attrition rate. In our study, PWID had highest retention rate $(74.6 \%)$ more than MSM (70.2\%). This is contrary to the finding in a study in the US [20] that MSM had better linkage and retention on ART more than other KPs. However, a study in Vietnam has shown retention rate among PWID as high as $88.4 \%$ after 6 months on ART [22]. FSW had the least retention rate $(65.4 \%)$ but highest transfer out rate (4.9\%) than MSM (4.7\%). Both brothel base and non-brothel based FSWs are highly mobile and can change location from time to time. Because of multiple client patronages for FSWs who are normally found in a location, an HIV positive FSW is more likely to relocate for fear of her status being disclosed to potential customers by her competing colleagues. Thus, a good number of FSW declared loss to follow up may be a case of self-transfer because of relocation to other places.

There are several definitions of loss to follow up on ART [30] which vary across different programs and studies [31] but in this study, a patient is declared loss to follow up if 90 days after the last missed clinic appointment, all efforts to trace and return the patient to service has failed [27]. Lost to follow-up is a major challenge that hinders the success of antiretroviral treatment [32] and it is the major cause of attrition from ART services. In sub-Saharan African countries, rates of loss to follow up vary as exhibited in the two studies in Nigeria and the study in 22 Sub-Saharan African countries. In another systemic review of patient retention following ART initiation in Sub-Saharan African countries, it was evident that 1 year after initiation, approximately $25 \%$ of patients were no longer in cares, with loss to follow up figures escalating to $40 \%$ after 2 years [32]. However, it is reasonable to think that a patient lost to follow up may belong to any of the following categories: death, change of residence, self-transfer to other facilities without the knowledge of the treatment facility. An operational research study in Northern Malawi [33] to determine the true outcomes of patients declared as loss to follow up has shown that, $50 \%$ had died, $15 \%$ had stopped therapy, and $8 \%$ had transferred to another clinic and failed to inform their original clinic of this move. From field experience, some KPs will not provide accurate contact information thus making it impossible to trace them when the need arises. A study in Gabon found that part of the reason why patients do not adhere to care is that of poor supportive counselling by healthcare providers [34]. On SHiPS for MARPS project, adherence counselling was important and it was provided at various levels starting from point of testing. When the patient is positive and enrolled in care, all point of services at the OSS provided supportive counselling; starting with the adherence counsellor, the clinician, the pharmacist and the case management officer who is attached to the patient.

While death may be due to the complication of the disease, it is unclear why patients on ART would decide to stop their medication despite the known fact that antiretroviral drugs are life-saving drugs. Further study is therefore required to trace and ascertain reasons why some patients decide to stop taking their drugs. In Nigeria, some traditional healers and churches have laid claim to cure of HIV/AIDS and some of these patients who deliberately stopped ART have been traced to such areas. In our study, $1.2 \%$ of the patients stopped ART and re-start again. From our experience, some of the patients may stop because they wanted to try an alternative treatment, but when their symptoms resurface or get worsened, they return to ART services.

Various factors [16] [34] [35] [36], have been found to impact negatively on patient retention including; fear of stigma and social exclusion, distance and lack of access to facility, lack of money for transportation to the clinic, younger age, lack of education and minimal social support for the 
patients, the burden of multiple vulnerabilities, policy involving risk behaviours and mental health, work and child care burden, self transfer to more convenient clinic without the knowledge of health provider, death, suboptimal quality of health care due to practitioners' work overload and medical record keeping problems. In this study, even though retention among the adult ( $\geq 25$ years) was $71 \%$ more than $69 \%$ among young people (15-24 years), the difference was not statistically significant. $\mathrm{P}=$ 0.27 , at $95 \%$ CI. However, a study in Zimbabwe reported that younger adults suffered more attrition from ART care compared to older adults [37] Perhaps, the number of young persons who participated in this study $(30 \%)$ is not sufficient to show a significant difference. We also found that illiterate patients were less likely to be retained on ART. P $=0.000$ at $95 \% \mathrm{CI}$. This finding collaborate with other studies in Nigeria which reported that patients with post-secondary education $(\mathrm{HR}=0.80$, 95\%CI: $0.65-0.99)$ or other unspecified education ( $\mathrm{HR}=0.61,95 \% \mathrm{CI}$ : $0.41-0.93)$ were less likely to become lost to follow up compared to individuals with no primary or some primary education [38] and that lower-than-secondary level education is a predictor of loss to follow up [18]. Since years of education can be a measure of health literacy, lower education levels may lead to lower retention of ART. Furthermore, a patient with lower education level may have difficulties in comprehending the instructions at ART clinics [39]. This finding suggests that providing educational materials in local languages may contribute to improved retention [18]. This study also found that being a male was associated with higher retention rate on ART P $=0.007$ at $95 \%$ CI. However, this is contrary to other findings where attrition was higher among male patients [18], [40] due to poorer clinical status prior to initiating ART [41]. We also found that patients who were employed were retained on ART more than unemployed or being a student, $\mathrm{P}=0.000$ at $95 \% \mathrm{CI}$. An earlier study [39] had described that those who were unemployed had a higher rate of treatment discontinuation than employed patients. This may be attributed to financial constraint which is one of the reasons why some patients are unable to access health services [34]. Moreover, unemployment may be considered as a factor negatively affecting the quality of life and it has been shown that lower quality of life is associated with lower retention [39]. Another finding in our study was that patients who were single or live separately from their sex partners had a higher retention rate $\mathrm{P}=0.001$ at $95 \% \mathrm{CI}$. This is contrary to another finding [39] that being single were associated with loss to follow up.

\section{Conclusion}

Community-based ART services among key populations when properly managed will show similar outcomes as in the general population in the clinical settings.

The recent WHO guideline recommended "test and treat" which will facilitate the attainment of UNAIDS 90-90-90 goals. While implementation of this guideline will increase the coverage of ART among KPs, the major challenge will be how to link and retain identified positives on ART. With the high level of stigmatization of people living with HIV/AIDS, KPs face an additional barrier in accessing health services and even when they do; maintaining them on the service could still be a challenge. Most studies on retention rate were conducted on long-term analysis of general population. Currently, there is no baseline data describing retention rate in a KP focused ART services in Nigeria. This study has provided short-term baseline data on retention rate and other ART outcomes in a KP focused services.

A loss to follow up was the major cause of attrition on ART in this study but comparable to loss to follow described among the general population. While some of the patients declared loss to follow up maybe dead or self-transfer to other facilities, others may have stopped ART or receiving some nonspecific treatment. The grave danger associated with stopping antiretroviral drugs is the development of drug resistance which will mar the efforts already made to control the epidemic. Further study is therefore required to trace and ascertain reasons why some patients decide to stop taking their drugs.

The finding from this study suggests that achieving UNAIDS 90.90.90 goals is possible in Nigeria if only KPs focused intervention could be innovative early enough to identify causes of loss to follow up and address them on time. Factors predicting improved retention rates are: being single, higher education, being a male, and gainfully employed. 


\section{Acknowledgement}

The authors gratefully acknowledge the patients and the incredible work and dedication of the OSS staffs and particularly the MIS staff and the state M\&E officers who ensure that accurate data was abstracted for this study. None of the authors have any conflict of interest to declare.

\section{References}

[1].Abebe Megerso, ${ }^{1}$ Sileshi Garoma, ${ }^{1}$ Tolosa Eticha, ${ }^{2}$ Tilaye Workineh, ${ }^{1}$ Shallo Daba, ${ }^{3}$ Mihretu Tarekegn, ${ }^{3}$ andZelalem Habtamu3 (2016); Predictors of loss to follow-up in antiretroviral treatment for adult patients in the Oromia region, Ethiopia HIV AIDS (Auckl). 2016; 8: 83-92. doi: 10.2147/HIV.S98137.

[2].Andreas D Haas, Elizabeth Zaniewski, Nanina Anderegg, Nathan Ford, Matthew P Fox et al (2018) Retention and mortality on antiretroviral therapy in sub-Saharan Africa: collaborative analyses of HIV treatment programmes. Journal of ineternational AIDS society February 2018 https://doi.org/10.1002/jia2.25084.

[3].Annals of Internal Medicine (2012); Guidelines for Improving Entry Into and Retention in Care and Antiretroviral Adherence for Persons with HIV: Evidence-Based Recommendations from an International Association of Physicians in AIDS Care Panel. http://annals.org/aim/fullarticle/1170890.

[4].Anthony D Harries, 1, 2 Rony Zachariah, 3 Stephen D Lawn, 2, 4 and Sydney Rosen5, 6 (2010) Strategies to improve patient retention on antiretroviral therapy in sub-Saharan Africa Trop Med Int Health. 2010 Jun; 15(s1): 70-75. doi: 10.1111/j.1365-3156.2010.02506.x.

[5].Avert (2016); Global HIV and AIDS statistics. https://www.avert.org/global-hiv-and-aids-statistics.

[6].Avert (2016); HIV/AIDS in Nigeria; Available at https://www.AVERT.org/Professionals/HIV-aroundworld/Sub-Saharan-Africa/Nigeria.

[7].Averts (2018); HIV and AIDS in Nigeria. Available at https://www.avert.org/professionals/hiv-aroundworld/sub-saharan-africa/nigeria.

[8].Azadeh Khalatbari Limaki1, Behnam Farhoudi1, Mehrnaz Rasoolinejad2, Saeed Safari3 Patient Retention in Antiretroviral Therapy Programs; A Retrospective Cohort Study in a Triangular HIV Clinic. DOI: 10.22086/GMJ.V6I2.819 http://gmj.ir/index.php/gmj/article/view/819/html.

[9].Bryan E. Shepherd, Meridith Blevins, Lara M. E. Vaz, Troy D. Moon, Aaron M. Et al (2013); Impact of Definitions of Loss to Follow-up on Estimates of Retention, Disease Progression, and Mortality: Application to an HIV Program in Mozambique. American Journal of Epidemiology, Volume 178, Issue 5, 1 September 2013, Pages 819-828, https://doi.org/10.1093/aje/kwt030.

[10]. C.M.J. Matyang, K.C. Takarinda, P.Owiti, T. Utasa-Apollo, O. Mugurungi et al (2016); Outcomes of antiretroviral therapy among younger versus older adolescents and adults in an urban clinic, Zimbabwe. Public Health Action 2016 Jun 21; 6(2):97-104. Doi: 10.5588/pha.15.0077.

[11]. CA Onoka,1 BS Uzochukwu,2 O E Onwujekwe,3 C Chukwuka,4 J Ilozumba,5 et al. (2012); Retention and loss to follow-up in antiretroviral treatment programmes in Southeast Nigeria. Pathog Glob Health. 2012 Mar; 106(1): 46-54.doi: 10.1179/2047773211Y.0000000018

https://www.ncbi.nlm.nih.gov/pmc/articles/PMC4001511.

[12]. Cameron D. Factors associated with retention in HIV care at Sediba Hope Medical Centre. S Afr J HIV Med. 2015; 16 (1), Art. \#347, 6 pages. http://dx.doi. org/10.4102/sajhivmed.v16i1.347.

[13]. Charurat M, Oyegunle M, Benjamin R, Habib A, Eze E, Ele P, et al. (2010) Patient Retention and Adherence to Antiretrovirals in a Large Antiretroviral Therapy Program in Nigeria: A Longitudinal Analysis for Risk Factors. PLoS ONE 5(5): e10584. https://doi.org/10.1371/journal.pone.0010584.

[14]. Dalhatu I1, Onotu D1, Odafe S1, Abiri O2, Debem H1, Agolory S3, (2016) Outcomes of Nigeria's HIV/AIDS Treatment Program for Patients Initiated on Antiretroviral Treatment between 2004-2012. PLoS One. 2016 Nov 9; 11(11):e0165528. doi: 10.1371/journal.pone.0165528. Collection 2016.

[15]. doi: 10.5144/0256-4947.2015.303;

[16]. Elvin H. G. Denis N. Andrew K. Yao Z. Paula B. et al (2011); Retention in Care among HIV-Infected Patients in Resource-Limited Settings: Emerging Insights and New Directions. Available at Curr HIV/AIDS Rep https://www.ncbi.nlm.nih.gov/pmc/articles/PMC3021803/.

[17]. Elvin H. Geng, David R. Bangsberg, Nicolas Musinguzi, Nneka Emenyonu, Mwebesa Bosco Bwana, et al (2010); Understanding Reasons for and Outcomes of Patients Lost to Follow-Up in Antiretroviral Therapy Programs in Africa Through a Sampling-Based Approach J Acquir Immune Defic Syndr. 2010 Mar; 53(3): 405411. doi: 10.1097/QAI.0b013e3181b843f0. 
DOI: $10.21522 /$ TIJPH.2013.06.02.Art019

ISSN: $2520-3134$

[18]. Federal ministry of health, Nigeria (2014); integrated biological and behavioural surveillance survey (IBBSS) 2014.

Available

at

https://www.google.com.ng/search?q=11.+Federal+ministry+of+health\%2C+Nigeria+(2014)\%3B+Integrated+b iological+and+behavioural+surveillance+survey\&oq $=11 .+$ Federal+ministry+of+health $\% 2 \mathrm{C}+$ Nigeria+(2014)\%3 B+Integrated+biological+and+behavioural+surveillance+survey\&aqs=chrome..69i57.1253j0j7\&sourceid=chro me\&ie $=$ UTF- 8 .

[19]. Federal ministry of health, Nigeria (2014); National HIV sero-prevalence sentinel survey among pregnant women attending antenatal clinic in Nigeria. Available at

https://www.google.com.ng/search?q=12.+Federal+ministry+of+health\%2C+Nigeria+(2014)\%3B+National+HI V+sero-

prevalence+sentinel+survey+among+pregnant+women+attending+antenatal+clinic+in+Nigeria\&oq=12.+Federa 1+ministry+of+health\%2C+Nigeria+(2014)\%3B+National+HIV+sero-

prevalence+sentinel+survey+among+pregnant+women+attending+antenatal+clinic+in+Nigeria\&aqs=chrome.. 6 9i57.1456j0j7\&sourceid=chrome\&ie=UTF- 8 .

[20]. Health care worker attitudes and behaviours towards key populations in South Africa and Zambia: a crosscountry analysis within the HPTN 071 (PopART) trial AIDS 2016 Conference, Durban, South Africa available at http://programme.aids2016.org/Abstract/Abstract/4352.

[21]. HIV cascade framework for key population 2015. Available at https://www.fhi360.org/sites/default/files/media/documents/linkages-hiv-cascade-framework-oct15.pdf

[22]. HIV clinical resource (2017); Benefit and risk of antiretroviral therapy. Available at https://www.hivguidelines.org/adult-hiv/antiretroviral-therapy/goals-benefits-risks/.

[23]. HIV.gov 2016, the Global HIV/AIDS Epidemic. https:/www.hiv.gov/hiv-basics/overview/data-andtrends/global-statistics.

[24]. http://www.who.int/mediacentre/news/releases/2015/hiv-treat-all-recommendation/en/.

[25]. International AIDS Society (2014); Maximizing the benefits of antiretroviral therapy for key populations. Available at http://www.iasociety.org/WebContent/File/KAPs_WhitePaper_2014.pdf.

[26]. Janssen S, Wieten RW, Stolp S, Cremers AL, Rossatanga EG, Klipstein-Grobusch K, et al. (2015) Factors Associated with Retention to Care in an HIV Clinic in Gabon, Central Africa. PLoS ONE 10(10): e0140746. https://doi.org/10.1371/journal.pone.0140746.

[27]. Jennifer L. Weinberg and Carrie L. Kovarik, MD (2010); The WHO Clinical Staging System for HIV/AIDS, American Medical Association Journal Ethics, Volume 12, Number 3: 202-206.

[28]. Katerina AC, Moupali D, and Grant NC (2011); Linkage and Retention in HIV Care among Men Who Have Sex with Men in the United States. Available at

http://cid.oxfordjournals.org/content/52/suppl_2/S214.full.

[29]. Kudakwashe C. Takarindaab, Anthony D. Harriesbc Ray W. Shiraishid Tsitsi Mutasa-Apolloa Abu AbdulQuaderd Owen Mugurungia (2015); Gender-related differences in outcomes and attrition on antiretroviral treatment among an HIV- infected patient cohort in Zimbabwe: 2007-2010. International Journal of Infectious Diseases. Volume 30, January 2015, Pages 98-105 https://doi.org/10.1016/j.ijid.2014.11.009.

[30]. Mazvita Naome Mberi, Lazarus Rugare Kuonza, Nomathemba Michelle Dube, Cornelius Nattey, Samuel Manda and, Robert Summers (2015); Determinant of loss to follow in patients on antiretroviral treatment, South Africa, 2004-2012: a cohort study. BMC Health Services Research201515:259. https://doi.org/10.1186/s12913015-0912-2.

[31]. MEASURE Evaluation; Key Populations; Available at https://www.measureevaluation.org/our-work/keypopulations.

[32]. Musa BM, Coker M, Bussell S, Aliyu M, Babashani M, Muhammad H et al. (2015) Long-term outcomes of antiretroviral therapy in an adult HIV program: a 10-year retrospective cohort study in Kano, Nigeria. Ann Saudi Med 2015; 35(4): 303-311.

[33]. N MlangeniI; F SenkubugeII (2016); Antiretroviral therapy programme outcomes in Tshwane district, South Africa: A 5-year retrospective study. SAMJ, S. Afr. med. j. vol.106 n.4 Cape Town Apr. 2016 http://dx.doi.org/10.7196/samj.2016.v106i4.9375.

[34]. Nguyen DB, Do NT, Shiraishi RW, Le YN, Tran QH, Huu Nguyen H, et al. (2013) Outcomes of Antiretroviral Therapy in Vietnam: Results from a National Evaluation. PLoS ONE 8(2): e55750. https://doi.org/10.1371/journal.pone.0055750. 
[35]. PAHO; Towards a Caribbean Consensus. Improving Access to Key Populations to Comprehensive HIV Services available

http://www.paho.org/hq/index.php?option=com_docman\&task=doc_view\&gid=23834\&Itemid=270\&lang=en. [36]. Priya Lall, Sin How Lim, Norliana Khairuddin, Adeeba Kamarulzaman (2015); Review: An urgent need for research on factors impacting adherence to and retention in care among HIV-positive youth and adolescents from key populations. Journal of international AIDS society. https://doi.org/10.7448/IAS.18.2.19393.

[37]. Rose Wilcher (2017); Call for paper: Optionizing the impact of key population programming across HIV cascade. Available at https://researchforevidence.fhi360.org/call-for-papers-optimizing-the-impact-of-keypopulation-programming-across-the-hiv-cascade.

[38]. S. Krishnaratne1, H. Mathema2, A. Stang13, G. Hoddinott4, V. Bond5, J. Hargreaves1;

[39]. Seema T. Meloni, Charlotte A. Chang, Geoffrey Eisen, Toyin Jolayemi, Bolanle Banigbe, Prosper I. Okonkwo, Phyllis J. Kanki (2016) Long-Term Outcomes on Antiretroviral Therapy in a Large Scale-Up Program in Nigeria. PLOS https://doi.org/10.1371/journal.pone.0164030;

[40]. Van der Kop ML, Ekström AM, Awiti-Ujiji O, Chung MH, Mahal D, et al. (2014) Factors Associated with Attrition from HIV Care during the First Year after Antiretroviral Therapy Initiation in Kenya. J AIDS Clin Res 5:354. doi:10.4172/2155-6113.1000354.

[41]. WHO (2014); Consolidated guidelines on HIV prevention, diagnosis, treatment and care for key populations. Available at

http://apps.who.int/iris/bitstream/10665/128048/1/9789241507431_eng.pdf?ua=1\&ua=

[42]. WHO (2015); Treat all people living with HIV, offer antiretrovirals as additional prevention choice for people at "substantial" risk; News release ! GENEVA. Available at.

[43]. WHO (2016); Consolidated Guidelines on HIV Prevention, Diagnosis, Treatment and Care for Key Populations - 2016 Update. https://www.ncbi.nlm.nih.gov/books/NBK379696/.

[44]. Yibeltal A, Achamyeleh A, Meskele L, Lut L, Edwin W, and Wim V (2014); Scaling up antiretroviral treatment and improving patient retention in care: lessons from Ethiopia, 2005-2013 Globalization and Health201410:43 DOI: 10.1186/1744-8603-10-43. 


\title{
A Peer Review of the Relationship of Socio-Economic Status on Contraction of Tuberculosis among Tb Patients in Windhoek District, Namibia: A Public Health Practice Perspective
}

\author{
Article by Francis Farai Chikuse \\ PhD Public Health Student of Texila America University, Namibia) \\ Email: francis.chikuse@gmail.com
}

Source: Murimba W. (2014). The Relationship of Socio-Economic Status on Contraction of Tuberculosis among TB Patients in Windhoek District, Namibia: A Public Health Practice Perspective. Online Journal of Medicine and Medical Science Research

http://www.onlineresearchjournals.org/JMMSR

\begin{abstract}
The article by Murimba Winnie titled "The Relationship of Socio-Economic Status on Contraction of Tuberculosis among TB Patients in Windhoek District, Namibia: A Public Health Practice Perspective" is reviewed. It is published in Online Journal of Medicine and Medical Science Research Volume 3, Issue 2 of 2014. The review engage the logical presentation of writing, follow of ideas, content and structure and its efficacy in tackling the risk factors of in-patients infected with tuberculosis. Socio-economic factors which predispose people to TB diseases have been investigated before and therefore the review will focus on the relevancy, objective and accuracy of this article on this topic.
\end{abstract}

Keywords: Socio-Economic Status, Poverty, Katutura Intermediate Hospital, Tuberculosis, Poverty, Namibia.

\section{Article structure and summary}

The article presents an abstract which asserts that the study is a quantitative descriptive study. It was conducted among TB inpatients at Katutura Intermediate Hospital in Windhoek, between June and August 2011. Using a universal sampling method, all 38 TB inpatients were enrolled in the study. The socio-economic factors which predispose people to the transmission of TB infection among urban participants were identified and described. Corbett and colleagues (2009) postulate that the socially and economically disadvantaged urban poor are the most vulnerable to TB because of poor living standards, which enhance transmission of TB infection. The majority of the respondents in this article were residents of severely poverty stricken informal settlements in Windhoek District. The authors used some reputable sources, for example, TB case notification rates, incidence rates, treatment success rates and mortality rates to elucidate the magnitude of TB burden in Namibia. These statistics are derived from the Republic of Namibia, Ministry of Health and Social Services, World Health Organization (WHO) and World Bank reports.

Descriptive statistics, a table and a pie chart are used to present the study findings. Thereafter, interpretation and discussion of the results is done leading to a conclusion. The evidence based relationship between the socio-economic factors and TB infection are informative to the policies that tackle the risk factors which make people susceptible to TB infection among the urban poor. There are links to references, citation, subjects and author allowing the reader to easily review and evaluate the article. However, a thought consideration could have been given not only to the results of the study but also the rigor of the research to enhance its quality. Rigor refers to the extent to which the researchers worked to ensure the quality of the article. Issues of validity of the study could have been addressed extensively. For example, face validity could have been done where experts in the subject matter could have been asked whether the instrument measures the concepts intended. A data collecting instrument can 
be reliable but not valid. The article states that data was collected by five final year nursing students. There was no indication that prior training was provided to data collectors and how missing data was addressed during the collection and analysis stages.

The authors could have enumerated the incidence,prevalence and mortality rates of drug resistant TB among the inpatients. Recent reports by the Namibia, National Tuberculosis and Leprosy Programme avers that cases of drug resitance tuberculosis are increasing since 2007. For example, during 2015, 190 patients commenced treatment for MDR-TB, compared to 137 cases reported in 2014. Furthermore, three XDR-TB cases were notified, whereas, the number of cases of poly-drug resistance TB cases increased to seventeen in 2015 up from seven cases reported in 2014 (MOHSS, 2017). The unfavourable outcomes were stated as death (4\%), failure (4\%) and loss to follow up (4\%). For MDR-TB patients, the treatment success rate declined to $63 \% \%$ in 2013 down from $68 \%$ for the 2012 cohort. This illustrates that current control strategies have a weakness of containing the drug resistance tuberculosis epidemic. TB is disease closely linked to gender differences, poverty, unemployment and overcrowding. Globally, DR-TB is a continuing threat. In its 2017 annual report, WHO confirms that there were 600000 incident cases with rifampicin resistance tuberculosis (RRTB) in 2016, the most efficacious first-line regimen. Among these incident cases, 490000 has MDR-TB. MDR-TB is estimated to account for approximately $20 \%$ of TB mortality, with mortality rates approximated at $40 \%$ for MDR-TB patients and $60 \%$ among XDR-TB patients (WHO, 2015). The article could have documented the incidence, prevalence and mortality rates of DR-TB among study participants. Future studies should focus on comparison of age-standardized incidence, prevalence and mortality rates among DR-TB and drug resistance in other high burden diseases like malaria and HIV in Namibia. Other studies can compare socio-economic risk factors for TB and DRTB.

\section{Literature review}

TB is a major global health problem affecting many poor countries. According to WHO (2013), 22 high TB burden countries are developing countries where $25 \%$ of world' poorest population lives and this account for $80 \%$ of the global TB cases. David (2010) confirms that highest prevalence rates of TB are found among the productive age group of 20 to 55 years. This age group is at most risk for exposure to TB bacillus. Gender has also been implicated as a major risk factor for TB. Omara and colleagues (2012) reported gender disparities in TB cases, with highest prevalence rate of the disease among woman as compared to their male counter parts. Treatment for TB is free in most countries including Namibia and hence unemployment people have access to free TB diagnosis and treatment. Availability of financial resources often affects supportive measures to health seeking such as transport fees. David (2010) asserts that major factors that make people vulnerable to TB infection include poor housing, overcrowding, exposure to environmental pollution, personal habits like smoking and alcohol abuse. HIV co-infection has also been reported as a major predisposing factor. Globally, WHO (2015) reported a decrease in the TB incident cases over the past two decades in most parts of the world. However, the decrease in TB incidence rates is still lower than the mortality rates in sub-Saharan African region. The setting for this article is Windhoek Namibia and indeed the increase in TB mortality rates is attributable to co-infection with HIV. Namibia is ranked among top ten countries with highest HIV prevalence levels in world. WHO (2015) estimate adult HIV prevalence rate at $18.8 \%$.

\section{Article critique}

\section{Author}

The author Murimba Winnie and colleagues are lecturers in School of Nursing and Public Health Department of University of Namibia in Windhoek. This established the credibility of the authors. The article is written in a logical format highlighting paucity in literature of socio-economic factors which predispose people to TB infection. The language used throughout is clear with no ambiguities. The authors focused on ideas and therefore managed to set the stage for the problem they are reporting. 


\section{Accuracy}

To illustrate the burden of TB and HIV diseases in Namibia, the authors use credible and current sources like WHO and World Bank reports. List of all in-text sources is given at the end of the article. They used this information to justify why understanding risk factors of TB disease are important in advocacy and social mobilization efforts to support diagnosis and treatment programs. However, a closer analysis of the study method reveals a major limitation of a small sample size of 38 participants. Murimba and colleagues could have increased the target population by enrolling those TB patients attending the outpatient department but not hospitalized. The article makes use of passive case finding method. They could have included cases in the communities through active case finding of TB among household and neighboring contacts to increase the sample size. The authors acknowledged that due to small sample size the results cannot be generalized to all TB patients in Namibia. An explanation of the inclusion criteria for participation in the study is given and a pilot study was conducted to ensure reliability of the study.

\section{Relevance}

A quantitative descriptive research design are used to identify and describe the socio-economic risk factors for TB among inpatients. The article is meant to inform researchers and scholars and not entertain. This is an academic journal on a reputable academic data base. The authours managed to identify socioeconomic factors as gender, places of residence, exposure to enviromental pollution, employment status, nutritional status, social habits, HIV co-infection and knowledge about TB disease. One weakness of the method used is that analysis of data is mainly descriptive using frequencies and percentage distributions. Thus, the article failed to provide a statisitical test to show an association or relationship of these variables with TB disease. The title of the article is about the relationship of socio-economic status on contraction of TB. Therefore, a fair conclusion could have been that out of $38 \mathrm{~TB}$ inpatients the age range of respondents was 14-50 years, majority of them were from informal settlement who lived in shacks and were exposed to dust. Most of the respondents were HIV positive and were taking alocohol. Therefore, these factors could be drivers of TB infection among respondents.

\section{Objective}

The purpose for the study was to identify the risk factors of inpatient infected with TB at Katutura Intermediate Hospital in Windhoek District of Namibia. This objective was met. The objective of the study is clearly stated, limitations outlined and issues of ethical clearance are addressed. However, the data analysis plan could have been improved as it is mainly descriptive using frequency and percentage distributions. This is the major weakness of the study as the relationship between the risk factors and TB is difficult to establish from the given data. Parametric tests like analysis of variance (ANOVA) and Pearson correlation tests or non-parametric tests like Spearman correlation tests and Kruskal-Wallis test could have been employed to establish association and relationship between the risk factors and TB disease.

\section{Stability}

The article is published in Online Journal of Medicine and Medical Science Research journal. Online Journal of Medicine and Medical Science Research (ISSN 2277-0879) is a monthly open access, double blind peer reviewed, international and multidisciplinary journal.

\section{Analysis of graphs and tables}

The authors used one table and one pie chart to summarize the data according to gender and employment status respectively. A balance was struck between the text and the use of tables and graphs. 
DOI: $10.21522 /$ TIJPH.2013.06.02.Art020

ISSN: $2520-3134$

\section{Advance knowledge on the topic}

TB diagnosis has been taken by the tides of innovation, with development of new molecular techniques for diagnosis of TB and DR-TB. WHO (2015) approved the use of Xpert MTB/RIF in 2010 and this assay transformed the field of TB diagnosis by offering sensitive and rapid diagnosis as well as detecting rifampicin resistance. According to WHO (2017), by 2016, more than 23 million Xpert MTB/RIF tests had been processed in 130 countries and MDR-TB detection has more than tripled. However, the major limitation of Xpert MTB/RIF is that its sensitivity is low in smear-negative and HIV associated TB. Currently new approaches are Xpert Ultra (Cephaid) and those targeted whole-genome sequencing are in the final stages of development. Ultra is a second-generation test that is designed to overcome sensitivity imperfect of Xpert MTB/RIF. The Xpert MTB/RIF Ultra assay was redesigned to boost analytical sensitivity more than ten times and improve reliability of detecting rifampicin resistance based mutations. Its sensitivity, accuracy and precision almost equals that of liquid culture based assays with an added advantage of being faster and user friendly at point of care.

At population level, Ultra is useful in detecting epidemics and monitoring drug surveillance. More work still needs to be done to explore potential utility of this test for public health intervention. On the treatment side, small studies indicate that treatment regimens that include Linezolid can be used to successfully treat MDR-TB and Sutezolid is also in phase II studies (Field et al., 2012). Preliminary evidence suggest that these drugs offer more hope as they have a satisfactory bioavailability and may be better tolerated by patients. Additionally, two fluoroquinolones moxifloxacin and gatifloxacin are currently in phase III clinical trials (Field et al., 2012).

\section{Conclusion}

The article by Murimba Winnie is admissible as it provides evidence that can be utilized to improve socio-economic status of marginalized people to support TB and HIV diagnosis and treatment. Improvement is socio-economic status removes barriers to treatment initiation. This calls for the strengthening of policies that integrate and intensify HIV and TB infections interventions into community health initiatives. Vitalizing the health systems for early detection of drug susceptible and DR-TB and furtherance in diagnosis, treatment and follow-up should therefore be the prime targets. Namibia has a higher burden of TB than predicted by her socio-demographic index and should enhance investigating reasons for this mismatch and appropriate solutions. Future studies can focus on risk factors for TB infection at community levels among close contacts and ways of addressing stigma and rehabilitations efforts among people with co-morbidities. Pilot studies can be done to establish the role of social protection programs in TB control arsenal. The content, structure, strengths sand limitations of the article were analyzed and critiqued.

\section{References}

[1].Corbett E.L., Bandason T., Cheung Y.B., Makamure B., Dauya E., Munyati S.S., Churchyard G.J., Williams B.G., Butterworth A.E., Mungofa S., Hayes R.J., Mason P.R (2009). Prevalent Infectious Tuberculosis in Harare, Zimbabwe: Burden, Risk Factors and Implications for Control. Int J Tuberculosis Lung Disease; 13(10): 1231-1237.

[2].David Y. (2010). An Examination of Known Tuberculosis Risk Factors and their Correlation across the United States. (Master's Thesis). USA: Georgia State University.

[3].Field S.K., Fisher D., Jarand J.M., Cowie R.L. (2012). New treatment options for multidrug-resistant tuberculosis. The Adv Respir Dis' 6: 255-268

[4].Omara F.D., Sarwat K.S., Abrar A.C., Ejaz Q. (2012). Gender disparity in tuberculosis cases in Eastern and western provinces of Pakistan. BMC Infect Diseases, 12(244).

[5].Republic of Namibia, Ministry of Health and Social Services (2017). National Tuberculosis and Leprosy Control Programme 2015/2016 Annual Report. MOHSS: Republic of Namibia.

[6].WHO (2011). Global Tuberculosis control: WHO Report. Geneva: World Health Organization.

[7].WHO (2015). Global Tuberculosis Report. Geneva: World Health Organization. 
Texila International Journal of Public Health Volume 6, Issue 2, Jun 2018

[8].WHO (2017). Global Tuberculosis Report. Geneva: World Health Organization.

[9].World Health Organization website. WHO monitoring of Xpert MTB/RIF roll-out. Accessed January 302018. http://www.who.int/tb/areas-of-work/laboratory/status_xpert_rollout_dec_2016.pdf. 


\title{
Prevalence and Correlates of HIV Testing and Counseling among Sexually Active Adolescents and Young Adults in Harare City, Zimbabwe
}

\author{
Article by Notion Gombe ${ }^{1,2}$, Nicholas Midzi ${ }^{3}$ \\ ${ }^{1}$ Public Health, Texila American University, Guyana, South America \\ ${ }^{2}$ Department of Community Medicine, University of Zimbabwe \\ ${ }^{3}$ Department of Medical Microbiology, University of Zimbabwe \\ E-mail: ntgombe@gmail.com ${ }^{1}$, midzinicholas@gmail.com ${ }^{3}$
}

\begin{abstract}
The HIV prevalence in the Zimbabwean population aged 15-49 years remains high at 15.2\%. Most adolescents do not know their HIV status. This is despite knowing a place to get tested. We determined the prevalence and correlates of HIV testing and counseling (HCT) among sexually active adolescents and young adults in Harare City.

We conducted a cross-sectional study among sexually active adolescents and young adults. Data were collected using a pretested self-administered questionnaire. Epi-Info 7 was used to capture and analyze data for frequencies, odds ratios and their corresponding 95\% confidence intervals. Chi-square tests and logistic regression models were used to assess independent correlates of HIV testing. Statistical significance was set at $p<0.01$.

A total of 427 adolescents and young adults were recruited. The majority (56.9\%) were female. The overall prevalence of HIV testing among participants was $56.4 \%$. On multivariate analysis, knowing a facility that offers HIV testing [aOR=5.05; 95\% CI (2.55-10.00)], reporting being involved in a sexual relationship with one's partner [aOR=3.24; 95\%CI (1.67-6.30)], being afraid of a positive result $[a O R=0.07 ; 95 \% \mathrm{CI}(0.01-0.30)]$ and being male $[a O R=0.43 ; 95 \% \mathrm{CI}(0.23-0.80)]$ were independent correlates of HCT among adolescents and young adults in Harare City.

Although comparable to other settings in Sub-Saharan Africa, HIV testing among adolescents and young adults in Harare City is still considered very low. Interventions should therefore aim at raising awareness on the importance of HIV testing. In addition city authorities should consider addressing barriers for HCT observed in this study including fear of living with a positive result.
\end{abstract}

Keywords: Adolescents, HIV Testing, Correlates, Prevalence, Harare City.

\section{Introduction}

Globally, there is an estimated 1.2 billion adolescents (10-19 year-olds), constituting $18 \%$ of the world's population (United Nations Children's Fund, 2013). About 2.2 million of these are living with HIV (UNICEF, 2013), and many are unaware of their infection (World Health Organization, 2016). HIV is the second highest cause of mortality after road injury among adolescents and young adults (WHO, 2014). In contrast to reductions in other population groups, estimates suggest that the number of HIV related deaths are on the increase in adolescents (50\% increase) (WHO, 2014). This increase had predominantly occurred in the African region, resulting in AIDS being the leading cause of mortality among adolescents in Africa and second leading cause of death worldwide.

Routine HIV testing for adolescents and adults aged 13-64 years is one of the most important strategies Centers for Disease Control and Prevention (CDC) recommends for reducing the spread of HIV (CDC, 2006). HCT provides an entry point to prevention, care, treatment and support. It contributes to reduction of the stigma and discrimination that surrounds HIV and AIDS. In Zimbabwe, access to knowledge of one's HIV status has mainly been through the client-initiated and provider initiated approaches (Ministry of Health and Child Care, 2014). The government first emphasized on Voluntary 
Counselling and Testing (VCT) for HIV in the National AIDS Policy of 1999. Since then there has been a remarkable increase in the number of health facilities offering HIV testing and counseling from 395 in 2005 to 1,456 in 2014(United Nations General Assembly, 2014).

In Zimbabwe adolescents continue to be vulnerable to HIV infection. In 2013, it was estimated that a total of 8,366 new HIV infections occurred among children below the age of 15 years, with mother-tochild transmission accounting for up to $90 \%$ of these childhood infections (MOHCC, 2014). In response to the surge in new HIV infections amongst this key population the government of Zimbabwe launched the guidelines for HCT in children and adolescents (MOHCC, 2014). Under these guidelines, a child aged 16 years is considered able to give full consent for HIV testing and counseling. This study sought to determine the prevalence and correlates of HIV testing and counseling among sexually active adolescents and young adults in Harare City, Zimbabwe.

\section{Methods}

A cross-sectional study was conducted in Harare City and the study participants comprised of adolescents and young adults aged 13-24 years. For purposes of this study a resident of Harare City was classified as someone who has lived in Harare for at least three months. All those who fell within the required age range (13-24 years), able to speak and read English and Shona were eligible to participate. Mmen and women who fell outside the 13-24 years age range and visitors to Harare metropolitan province were excluded from participating in the study. Adolescents under age 16 who met the inclusion criteria but whose parents did not provide consent were excluded. Assuming an error risk of 1.96 and a proportion (P), of those tested for HIV (52.2\%) from a previous study conducted by Pelzer et al (2013) in South Africa and a margin of error of 5\%, a minimum sample size of 422 was obtained after factoring in $10 \%$ attrition rate.

Data were collected using a pretested self-administered questionnaire designed using the guidance from previous acceptability studies and translated into the local language, Shona. Check codes, and legal values were used to reduce errors of data collection and entry. Data were cleaned for errors and inconsistencies before analysis. Data were analyzed using Epi Info 7 statistical package to generate means, frequencies, proportions, prevalence odds ratios (POR), and their corresponding $95 \%$ confidence intervals (CI). PORs excluding the null value (1) in the $95 \%$ confidence interval were considered statistically significant. Stratified analysis was performed to check for effect modification and to control for confounding. Factors associated with ever being HIV-tested were determined using multivariate logistic regression.

To ensure protection of study participants, permission was sought from Harare City Council institutional review board and the Medical Research Council of Zimbabwe (Approval Number: MRCZ/A/2216). Further, informed written consent was obtained from adolescents aged 16 and older and adolescent assent and parental/guardian consent was obtained from those aged $13-15$ years. Consent was obtained after explaining the purpose of the study, and assuring confidentiality. Confidentiality was maintained throughout the study by not including the participants name on the questionnaires. In addition the questionnaire was self-administered owing to the sensitive nature of the questions.

\section{Results}

\section{Sample characteristics}

Socio demographic characteristics of study participants are reported in Table 1. A total of 427 participants were enrolled into this study and females comprised the majority $(56.91 \%)$. The majority (82.67) of participants had attained secondary education and the least $(4.45 \%)$ were those who had never been to school. Students comprised more than half of the population $(51.76 \%)$ followed by those not employed at $39.58 \%$. High density dwellers formed the majority $(66.04 \%)$ of participants compared to $33.96 \%$ from the low density suburbs. Majority (75.18\%) of participants were single. 
DOI: $10.21522 /$ TIJPH.2013.06.02.Art021

ISSN: $2520-3134$

\section{Prevalence of HIV testing}

In this study the overall prevalence of HIV testing among participants was $56.44 \%$ (241/427). On stratification by sex, prevalence of HIV testing among females was $60 \%$ compared to $51 \%$ for males. Of those that had been tested, $44 \%$ had their most recent test less than 3 months ago. The majority (55.8\%) were tested at council clinics followed by new start centre $(17.4 \%)$.

\section{Bivariate correlates of HCT}

Bivariate analysis results show that participants who reported fearing a positive result $[\mathrm{OR}=0.07$; 95\% CI (0.02-0.25)], requiring permission from parents/guardians to test [OR=0.06; 95\% CI (0.01-0.43)], having attained only primary education [OR=0.53; 95\%CI (0.30-0.94)], being aged less than 18 years $[\mathrm{OR}=0.32 ; 95 \mathrm{CI}(0.21-0.49)]$, being worried about confidentiality $[\mathrm{OR}=0.07 ; 95 \% \mathrm{CI}(0.01-0.58)]$ and perceiving oneself not to be at risk of contracting HIV [OR=0.01; 95\% CI $(0.00-0.08)]$ were less likely to be tested for HIV. On the other hand those who reported being involved in a sexual relationship [OR=3.14; 95\% CI (1.77-5.57)], ever being pregnant [OR=5.63; 95\% CI (1.64-19.31)], perceiving oneself to be at risk of contracting HIV [OR=2.36; 95\% CI (1.45-3.84)], having had sexual intercourse in the past year $[\mathrm{OR}=4.44 ; 95 \% \mathrm{CI}(2.60-7.58)]$ among other variables were more likely to be tested for HIV. Participants who knew the location of testing facilities [OR=8.89; 95\% CI (5.30-14.90)] were more likely to be tested for HIV than those who did not know. This was the major determinant for ever being tested in this study population (Table 2).

\section{Multivariate correlates of HCT}

The logistic regression model accounted for 263 cases (Table 3). After controlling for confounding, knowing a facility that offers HIV testing $(\mathrm{aOR}=5.05, \mathrm{p}<0.01)$, reporting being involved in a sexual relationship with one's partner $(\mathrm{aOR}=3.24, \mathrm{p}<0.01)$ being afraid of a positive result $(\mathrm{aOR}=0.07, \mathrm{p}<0.01)$ and being male $(\mathrm{aOR}=0.43, \mathrm{p}=0.008)$ were independent correlates of HIV testing and counseling among adolescents and young adults in Harare City.

\section{Discussion}

The current study sought to determine the prevalence and correlates of HIV testing and counseling among adolescents and young adults in Harare City, Zimbabwe. This information is critical, as promotion of HCT is the first step to getting medical care and treatment that can improve health, save lives, and prevent the spread of HIV (Bekker \& Hosek, 2015). HCT provides an entry point to prevention, care, treatment and support. It contributes to reduction of the stigma and discrimination that surrounds HIV and AIDS.

The results indicate that $56 \%$ of the study population had ever received an HIV test. Although slightly higher than the proportions reported in similar studies conducted in South Africa (Peltzer \& Matseke, 2013) and Ethiopia (Dirar, Mengiste, Kedir, \& Godana, 2014) such low utilization of VCT in this young key population might pose a challenge to the scale-up of HIV prevention efforts. The results from the South African study indicated that over half $(52.2 \%)$ of the youth reported testing for HIV, with more young females testing for HIV compared to their male counterparts (Peltzer \& Matseke, 2013). In Ethiopia the prevalence of HIV testing was slightly higher at $52.8 \%$ (Dirar, Mengiste, Kedir, \& Godana, 2014).

Considering the high HIV prevalence in Zimbabwe, such a low proportion of adolescents and young adults reporting ever having been tested for HIV in this population remains a barrier to early HIV treatment and care among those HIV-infected and this could impact negatively on their survival and result in poor ART response upon initiation.

Females were 1.5 times more likely to be tested compared to their male counterparts. This is supported by other studies. Takarinda et al (2016) in a study on factors associated with ever being HIV tested in Zimbabwe noted that fewer men than women had ever been tested for HIV. Similar trends were noted in a 
review of 23 out of 29 demographic and health surveys conducted in other sub-Saharan African countries by Staveteig et al (2013). In five countries thus Lesotho, Madagascar, Mozambique, Senegal, and Zimbabwe women are at least 50 percent more likely than men to have ever been tested.

The difference in testing rates between males and females can be attributed to the fact that women have many opportunities for HIV testing for instance during antenatal care and hence this may explain their higher level of HIV testing and generally females compared to males are more responsive to health programs including HIV testing and counseling. In addition it can also be argued that perhaps more females were more likely to be tested since they engage in more sexual relationships at a younger age with 'sugar daddies' than males, hence they could as a precautionary measure get tested to check if their behavior had not resulted in them contracting HIV. In a study done in Kenya and Zambia, for example, prevalence in the 15-19 age group was found to be at least five times higher among the girls (Glynn et al., 2001). This may be due, in part, to the high incidence of consensual, unsafe cross-generational sexual relationships that is, unprotected sex between teenage girls and adult men five or more years their senior (Baltazar, G. M et al. 2001). Men involved in these relationships, are more likely to be infected with HIV than teenage boys since they have been sexually active for longer.

In HIV endemic countries, Zimbabwe included, the World Health Organization (WHO) recommends universal HIV testing for all pregnant women and prompt treatment among HIV-positive women in order to prevent vertical transmission of the virus. Thus, adoption operationalization of longstanding WHO guidelines coupled with national policies may add to the higher prevalence of HIV testing among females than males. In addition traditional masculine roles cast men as risk takers who do not need or seek help or health services (Inungu et al., 2011). Such perceptions delay access to health care including HIV prevention services among men (Varga, 2001).

The study also found out that younger $(<18$ years) participants were significantly less likely to test for HIV than those aged 18years and older. Thus the odds of ever being tested increased with age $\geq 18$ years. Low risk perception reported in this study among younger participants may explain this difference between older and younger participants. It is also important to note that challenges do exist concerning access to HIV testing for persons $<18$ years old as they require parental consent which may explain the low testing uptake for both sexes (Takarinda et al., 2016).

In this study $53.5 \%$ females compared to $36.4 \%$ males reported that they needed permission to go for HIV testing and counseling. In addition, some at-risk youth may not seek medical care due to perceived lack of confidentiality among healthcare providers whereas others may feel inhibited by fear of a positive result or embarrassment associated with seeking reproductive and sexual healthcare. (Swenson et al., 2009; Lichtenstein, 2000; Lindberg, Lewis-Spruill, \& Crownover, 2006).

In this study we conducted both bivariate and multivariate analysis. This allowed us to efficiently determine correlates of HCT and at the same time control for possible confounders that may result in the distortion of the relationships between various exposures and the outcome of interest.

On bivariate analysis several factors were associated with HCT among adolescents and young adults. Those who reported fearing a positive result, parents who would not allow them to test, having attained only primary education, being aged less than 18 years, being worried about confidentiality and perceiving oneself not to be at risk of contracting HIV were less likely to be tested for HIV (Kabiru, Beguy, Crichton, \& Zulu, 2011; Njagi \& Maharaj, 2006). On the other hand those who reported being involved in a sexual relationship, ever being pregnant, perceiving oneself to be at risk of contracting HIV , having had sexual intercourse in the past year were more likely to be tested. Participants who knew the location of testing facilities were more likely to be tested for HIV than those who did not know. This was the major determinant for ever being tested in this study population.

On multivariate analysis, knowing a facility that offers HIV testing, reporting being involved in a sexual relationship with one's partner, being afraid of a positive result and being male were independent correlates of HIV testing in this study. 
DOI: $10.21522 /$ TIJPH.2013.06.02.Art021

ISSN: $2520-3134$

Participants who knew of a facility that offers HIV testing were more likely $(\mathrm{aOR}=5.05)$ to take up an HIV test than those who did not know. The majority (73.54\%) of participants knew of a facility nearby which offers HIV testing and counseling. As expected females comprised the majority (76.95\%) compared to males $(69.02 \%)$. The majority $(79.8 \%)$ of participants who knew of a facility were from the high density suburbs compared to $61.4 \%$ from the low density suburbs. This is consistent with what Leta et al (2012) found out in a cross-sectional study conducted among men in Ethiopia. In that study 53\% of the study participants reported that they knew a place where they could get tested for HIV.

Being involved in a sexual relationship with one's partner was independently associated with HIV testing. Sexually active participants were three times more likely to be tested than those not sexually active. This may be due to self-perceived risk of HIV infection considering that the commonest route for transmitting HIV is through sexual intercourse. A cross sectional study done in Ethiopia, showed that youths who reported having sex with their partners were more likely to be tested (Dirar, Mengiste, Kedir, \& Godana, 2014). This finding is also supported by Leta et al, (2012).

Another significant finding was that those who reported being afraid of a positive result were less likely to be tested for HIV. This was true for both sexes albeit with a marginal difference. This is evident in the 2004 Glasgow study, which assessed the intention of gay men in taking the HIV test. Here, for MSM who had recently engaged in unprotected anal sex, their intention to actually seek testing weakened in the presence of increased fear of a test result that is positive for HIV (Sohn, Cho, \& Kennedy, 2015). This is supported by other studies in the African region (Addis et al., 20103; Strauss, Rhodes, \& George, 2015; Musumari et al., 2016).

This study had some limitations. A key limitation of this study is recall bias and social desirability bias. Data on HIV testing were self-reported by participants without any attempts to validate the report through medical record review. However we tried to minimize the bias through triangulation. In addition there could be other important reasons for these participants not getting tested such as stock-outs of HIV test kits at city clinics which our study did not address. Despite these limitations we are confident that, the survey design and sampling enabled us to draw conclusions which are nationally representative and can be inferred to the general youth population in other urban settings in Zimbabwe and probably beyond.

\section{Conclusion}

Although comparable to other settings in Sub-Saharan Africa, HIV testing among adolescents and young adults in Harare City is still considered very low. This is a significant public health problem as many high-risk individuals are not aware of their serostatus. Independent correlates of HCT among adolescents and young adults in Harare City were, knowing a facility that offers HIV testing, reporting being involved in a sexual relationship with one's partner, being afraid of a positive result and being male. In view of this evidence, Harare City health authorities should urgently come up with innovative strategies to increase the number of adolescents and youth who become aware of their HIV serostatus.

\section{Tables}

Table 1. Socio-demographic characteristics of adolescents and young adults, Harare, Zimbabwe, 2017

\begin{tabular}{|l|l|l|}
\hline Variable & Frequency (n) & \% \\
\hline Sex & 184 & 43.09 \\
\hline Male & 243 & 56.91 \\
Female & 212 & 49.65 \\
Age-group & 177 & 41.45 \\
\hline $13-<18$ & 21 & 4.92 \\
$18-<23$ & 17 & 3.98 \\
$23-<24$ & $24+$ & \\
\hline \multicolumn{2}{|l|}{ Level of education } \\
\hline
\end{tabular}


DOI: $10.21522 /$ TIJPH.2013.06.02.Art021

ISSN: $2520-3134$

\begin{tabular}{|l|l|l|}
\hline $\begin{array}{l}\text { Never been to } \\
\text { school }\end{array}$ & 19 & 4.45 \\
$\begin{array}{l}\text { Primary } \\
\text { Secondary } \\
\text { Tertiary }\end{array}$ & $\begin{array}{l}35 \\
20\end{array}$ & $\begin{array}{l}8.20 \\
82.67 \\
4.68\end{array}$ \\
\hline Occupation & 39.58 \\
\hline $\begin{array}{l}\text { Not employed } \\
\text { Informally } \\
\text { employed }\end{array}$ & 169 & 4.45 \\
$\begin{array}{l}\text { Formally } \\
\text { employed } \\
\text { Student }\end{array}$ & 19 & 4.77 \\
\hline Area of residence & 221 & 33.96 \\
\hline $\begin{array}{l}\text { Low density } \\
\text { High density }\end{array}$ & 145 & 66.04 \\
\hline Marital status & 282 & 75.18 \\
\hline $\begin{array}{l}\text { Single } \\
\text { Married }\end{array}$ & 321 & 24.82 \\
\hline
\end{tabular}

Table 2 Correlates of HIV testing in adolescents and young adults, harare city, zimbabwe, 2017

\begin{tabular}{|c|c|c|c|c|}
\hline \multirow[t]{2}{*}{ Variable } & \multicolumn{2}{|c|}{$\begin{array}{l}\text { Ever been tested } \\
\text { for HIV }\end{array}$} & \multirow[t]{2}{*}{$\operatorname{POR}(95 \% \mathrm{CI})$} & \multirow[t]{2}{*}{ p-value } \\
\hline & Yes & No & & \\
\hline $\begin{array}{l}\text { Do you know of any } \\
\text { facility? } \\
\text { Yes } \\
\text { No }\end{array}$ & $\begin{array}{l}218 \\
23\end{array}$ & $\begin{array}{l}96 \\
90\end{array}$ & $8.89(5.30-14.90)$ & $<0.001$ \\
\hline $\begin{array}{l}\text { Have you ever been } \\
\text { pregnant? } \\
\text { Yes } \\
\text { No }\end{array}$ & $\begin{array}{l}23 \\
124 \\
\end{array}$ & $\begin{array}{l}3 \\
91 \\
\end{array}$ & $5.63(1.64-19.31)$ & 0.002 \\
\hline $\begin{array}{l}\text { In the last year have } \\
\text { you had sex? } \\
\text { Yes } \\
\text { No }\end{array}$ & $\begin{array}{l}84 \\
156 \\
\end{array}$ & $\begin{array}{l}20 \\
165\end{array}$ & $4.44(2.60-7.58)$ & $<0.001$ \\
\hline $\begin{array}{l}\text { Residence status } \\
\text { High density } \\
\text { Low density }\end{array}$ & $\begin{array}{l}188 \\
53\end{array}$ & $\begin{array}{l}94 \\
92\end{array}$ & $3.47(2.28-5.28)$ & $<0.001$ \\
\hline $\begin{array}{l}\text { Are you involved in } \\
\text { sexual relationship } \\
\text { Yes } \\
\text { No }\end{array}$ & $\begin{array}{l}88 \\
88 \\
\end{array}$ & $\begin{array}{l}21 \\
66 \\
\end{array}$ & $3.14(1.77-5.57)$ & $<0.001$ \\
\hline $\begin{array}{l}\text { Do you have a } \\
\text { boyfriend/girlfriend? } \\
\text { Yes } \\
\text { No }\end{array}$ & $\begin{array}{l}152 \\
89\end{array}$ & $\begin{array}{l}71 \\
115\end{array}$ & $2.77(1.86-4.11)$ & $<0.001$ \\
\hline $\begin{array}{l}\text { Have you ever } \\
\text { discussed about HIV } \\
\text { testing with your } \\
\text { partner? }\end{array}$ & & & & \\
\hline
\end{tabular}


DOI: $10.21522 /$ TIJPH.2013.06.02.Art021

ISSN: $2520-3134$

\begin{tabular}{|c|c|c|c|c|}
\hline $\begin{array}{l}\text { Yes } \\
\text { No }\end{array}$ & $\begin{array}{l}87 \\
41\end{array}$ & $\begin{array}{l}19 \\
23\end{array}$ & $2.57(1.26-5.24)$ & 0.009 \\
\hline $\begin{array}{l}\text { Do you feel that you } \\
\text { are at risk of } \\
\text { contracting HIV? } \\
\text { Yes } \\
\text { No }\end{array}$ & $\begin{array}{l}71 \\
170 \\
\end{array}$ & \begin{tabular}{|l}
28 \\
158 \\
\end{tabular} & $2.36(1.45-3.84)$ & $<0.001$ \\
\hline $\begin{array}{l}\text { Sex } \\
\text { Male } \\
\text { Female } \\
\end{array}$ & $\begin{array}{l}147 \\
94\end{array}$ & $\begin{array}{l}96 \\
90 \\
\end{array}$ & $1.47(1.00-2.16)$ & 0.059 \\
\hline $\begin{array}{l}\text { I am not at risk } \\
\text { Yes } \\
\text { No }\end{array}$ & $\begin{array}{l}1 \\
240 \\
\end{array}$ & \begin{tabular}{|l}
53 \\
133 \\
\end{tabular} & $0.01(0.00-0.08)$ & $<0.001$ \\
\hline $\begin{array}{l}\text { My parents will not } \\
\text { allow me to get tested } \\
\text { Yes } \\
\text { No }\end{array}$ & $\begin{array}{l}1 \\
240 \\
\end{array}$ & \begin{tabular}{|l|}
13 \\
173 \\
\end{tabular} & $0.06(0.01-0.43)$ & $<0.001$ \\
\hline $\begin{array}{l}\text { Fear of a positive } \\
\text { result } \\
\text { Yes } \\
\text { No }\end{array}$ & $\begin{array}{l}3 \\
238\end{array}$ & $\begin{array}{l}27 \\
159 \\
\end{array}$ & $0.07(0.02-0.25)$ & $<0.001$ \\
\hline $\begin{array}{l}\text { I am worried about } \\
\text { confidentiality } \\
\text { Yes } \\
\text { No }\end{array}$ & $\begin{array}{l}1 \\
240\end{array}$ & $\begin{array}{l}10 \\
176\end{array}$ & $0.07(0.01-0.58)$ & 0.001 \\
\hline $\begin{array}{l}\text { Age } \\
<18 \\
>18\end{array}$ & $\begin{array}{l}91 \\
150\end{array}$ & $\begin{array}{l}121 \\
65\end{array}$ & $0.33(0.22-0.49)$ & $<0.001$ \\
\hline $\begin{array}{l}\text { Education level } \\
\text { Primary and below } \\
\text { Above primary }\end{array}$ & $\begin{array}{l}23 \\
218\end{array}$ & $\begin{array}{l}31 \\
155\end{array}$ & $0.53(0.30-0.94)$ & 0.028 \\
\hline
\end{tabular}

Table 3. Multivariable model of predictors of HCT in adolescents and young adults, Harare City, Zimbabwe, 2017

\begin{tabular}{|l|l|l|l|}
\hline Term & $\mathrm{aOR}^{1}$ & $95 \% \mathrm{CI}^{2}$ & $\mathrm{p}$-value \\
\hline $\begin{array}{l}\text { Do you know any facitity that } \\
\text { offers HIV testing? }\end{array}$ & 5.05 & $2.55-10.00$ & $<0.001$ \\
\hline $\begin{array}{l}\text { Are you involved in a sexual } \\
\text { relationship? }\end{array}$ & 3.24 & $1.67-6.30$ & $<0.001$ \\
\hline $\begin{array}{l}\text { Being afraid of a positive } \\
\text { result }\end{array}$ & 0.07 & $0.01-0.30$ & $<0.001$ \\
\hline Sex(Male/Female) & 0.43 & $0.23-0.80$ & 0.008 \\
\hline
\end{tabular}

1 aOR is adjusted odds ratio

$295 \% \mathrm{Cl}$ is $95 \%$ confidence interval 
DOI: $10.21522 /$ TIJPH.2013.06.02.Art021

ISSN: $2520-3134$

\section{References}

[1].Addis, Z., Yalew, A., Shiferaw, Y., Alemu, A., Birhan, W., Mathewose, B., \& Tachebele, B. (2013). Knowledge, attitude and practice towards voluntary counseling and testing among university students in North West Ethiopia: a cross sectional study. BMC Public Health, 13, 714. https://doi.org/10.1186/1471-2458-13-714.

[2].Baltazar, G. M et al. (2001) AIDS in Kenya: Background, Projections, Impact, Interventions and Policy, eds. 6th Ed, Nairobi, AIDS Control Unit of Ministry Of Health and National AIDS Control Council.

[3].Bekker, L.-G., \& Hosek, S. (2015). HIV and adolescents: focus on young key populations. Journal of the International AIDS Society, 18(2Suppl 1). https://doi.org/10.7448/IAS.18.2.20076.

[4].CDC. Revised Recommendations for HIV Testing of Adults, Adolescents, and Pregnant Women in Health-Care Settings. (2006). Retrieved February 7, 2018, from https://www.cdc.gov/mmwr/preview/mmwrhtml/rr5514a1.htm

[5].Dirar, A., Mengiste, B., Kedir, H., \& Godana, W. (2014). Factors Contributing to Voluntary Counseling and Testing Uptake among Youth in Colleges of Harar, Ethiopia. Science Journal of Public Health, 1(2), 91. https://doi.org/10.11648/j.sjph.20130102.17.

[6].Fact sheet on adolescent health. Geneva: WHO (2014). Retrieved May 18, 2016, from http://www.unaids.org/en/media/unaids/contentass

[7].Glynn, J. R., Caraël, M., Auvert, B., Kahindo, M., Chege, J., Musonda, R. ... Study Group on the Heterogeneity of HIV Epidemics in African Cities. (2001). Why do young women have a much higher prevalence of HIV than young men? A study in Kisumu, Kenya and Ndola, Zambia. AIDS (London, England), 15 Suppl 4, S51-60.

[8].Inungu, J., Lewis, A., Younis, M. Z., Wood, J., O’Brien, S., \& Verdun, D. (2011). HIV Testing among Adolescents and Youth in the United States: Update from the 2009 Behavioral Risk Factor Surveillance System. The Open AIDS Journal, 5, 80-85. http://doi.org/10.2174/1874613601105010080.

[9].Joint United Nations Programme on HIV/AIDS (UNAIDS). Global AIDS Response Progress. Reporting 2014: Construction of Core Indicators for Monitoring the 2011 UN Political Declaration on HIV and AIDS. Geneva, Switzerland: UNAIDS; 2014.

[10]. Kabiru, C. W., Beguy, D., Crichton, J., \& Zulu, E. M. (2011). HIV/AIDS among youth in urban informal (slum) settlements in Kenya: what are the correlates of and motivations for HIV testing? BMC Public Health, 11, 685. https://doi.org/10.1186/1471-2458-11-685.

[11]. Leta, T. H., Sandøy, I. F., \& Fylkesnes, K. (2012). Factors affecting voluntary HIV counselling and testing among men in Ethiopia: a cross-sectional survey. BMC Public Health, 12, 438. https://doi.org/10.1186/1471-2458$12-438$.

[12]. Lindberg, C., Lewis-Spruill, C., \& Crownover, R. (2006). Barriers to sexual and reproductive health care: urban male adolescents speak out. Issues in Comprehensive Pediatric Nursing, 29(2), 73-88. https://doi.org/10.1080/01460860600677577.

[13]. Lopez-Quintero, C., Shtarkshall, R., \& Neumark, Y. D. (2005). Barriers to HIV-testing among Hispanics in the United States: analysis of the National Health Interview Survey, 2000. AIDS Patient Care and STDs, 19(10), 672683. https://doi.org/10.1089/apc.2005.19.672.

[14]. MOHCC- Zimbabwe National Guidelines for HIV Testing and Counselling in Children and Adolescents (2014). Retrieved January 13, 2018, from https://aidsfree.usaid.gov/sites/default/files/hts_zimbabwe_2014.pdf.

[15]. Musumari, P. M., Tangmunkongvorakul, A., Srithanaviboonchai, K., Yungyuankul, S., Techasrivichien, T., Suguimoto, S. P., ... Chariyalertsak, S. (2016). Prevalence and Correlates of HIV Testing among Young People Enrolled in Non-Formal Education Centers in Urban Chiang Mai, Thailand: A Cross-Sectional Study. PLOS ONE, 11(4), e0153452. https://doi.org/10.1371/journal.pone.0153452.

[16]. Njagi, F., \& Maharaj, P. (2006). Access to voluntary counselling and testing services: Perspectives of young people. South African Review of Sociology, 37(2), 113-127. https://doi.org/10.1080/21528586.2006.10419150.

[17]. Peltzer, K., \& Matseke, G. (2013). Determinants of HIV testing among young people aged 18 - 24 years in South Africa. African Health Sciences, 13(4), 1012-1020. https://doi.org/10.4314/ahs.v13i4.22.

[18]. Strauss, M., Rhodes, B., \& George, G. (2015). A qualitative analysis of the barriers and facilitators of HIV counselling and testing perceived by adolescents in South Africa. BMC Health Services Research, 15(1), 250. https://doi.org/10.1186/s12913-015-0922-0. 
DOI: $10.21522 /$ TIJPH.2013.06.02.Art021

ISSN: $2520-3134$

[19]. Swenson, R. R., Rizzo, C. J., Brown, L. K., Payne, N., DiClemente, R. J., Salazar, L. F., .. Hennessy, M. (2009). Prevalence and Correlates of HIV Testing among Sexually Active African American Adolescents in Four U.S. Cities. Sexually Transmitted Diseases, 36(9), 584-591. https://doi.org/10.1097/OLQ.0b013e3181b4704c.

[20]. Takarinda, K. C., Madyira, L. K., Mhangara, M., Makaza, V., Maphosa-Mutsaka, M., Rusakaniko, S., ... Harries, A. D. (2016). Factors Associated with Ever Being HIV-Tested in Zimbabwe: An Extended Analysis of the Zimbabwe Demographic and Health Survey (2010-2011). PLOS ONE, 11(1), e0147828. https://doi.org/10.1371/journal.pone.0147828.

[21]. UNAIDS Fast track strategy to end AIDS epidemic by 2030, UNAIDS,(2014).Retrieved December 15, 2014, from http://www.unaids.org/en/resources/campaigns/World-AIDS-Day-Report-2014.

[22]. UNAIDS- The gap report (July 2014). Retrived January 13, 2018, from http://files.unaids.org/en/media/unaids/contentassets/documents/unaidspublication/2014/UNAIDS_Gap_report_en.p df.

[23]. UNGASS- Zimbabwe Global Aids Response Progress Report (2014). Retrieved January 13, 2018, from http://files.unaids.org/en/dataanalysis/knowyourresponse/countryprogressreports/2014countries/ZWE_narrative_rep ort_2014.pdf.

[24]. UNICEF- Analysis of UNAIDS2012 HIV and AIDS Estimates (2013). Retrieved January 13, 2018, from United Nations. United Nations General Assembly (UNGASS) Report: Jan 2006-Dec 2007. United Nations, New York; 2008.

[25]. United Nations General Assembly: country report on the follow up to the declaration of commitment on HIV/AIDS. Reporting period 2006-2007. National Aids Control Program. Pakistan [Internet]. 2008 [cited 18/5/16].:http://aidsdatahub.org/dmdocuments/pakistanUNGASSReport2008.pdf.

[26]. Varga, C. A. (2001). The forgotten fifty per cent: a review of sexual and reproductive health research and programs focused on boys and young men in sub-Saharan Africa. African Journal of Reproductive Health, 5(3), $175-195$.

[27]. WHO. HIV/AIDS fact sheet. (June, 21, 2015). Retrieved July, 21, 2015, from

http://www.who.int/mediacentre/factsheets/fs360/en/ 


\title{
Family Planning Knowledge, Attitude and Practice among Married Couples in Abakpa Nike, Enugu East Local Government Area, Enugu State, Nigeria
}

\author{
Article by Mgbe Chinenye $\mathrm{G}^{1}$, Mgbe Emeka Kevin ${ }^{2}$, Rita Uzoamaka Nwali ${ }^{3}$, Odenigbo \\ Josephine C \\ ${ }^{1}$ Ph.D, Enugu State University Teaching Hospital \\ ${ }^{2} \mathrm{MBBS}$, fWACS, University of Nigeria Teaching Hospital Ituku \\ E-mail: chinenyemgbe@yahoo.com ${ }^{1}$, champlinks2001@yahoo.com ${ }^{2}$, \\ makasonchrist@yahoo.com ${ }^{3}$
}

\begin{abstract}
This study set out to assess family planning knowledge, attitude and practice among married couples in Abakpa Nike, Enugu East Local Government Area, Enugu State. A survey design approach was adopted for the study. Out of a population of 1130 married couples, 295 of them were randomly selected through taro yamane. Four research questions were formulated and analyzed in the course of this study. The mean value statistical analysis was used to analyze the research questions of the study. The results showed that there is positive knowledge of family planning methods among married couples in Abakpa. Husband's involvement in family decision, support of national policy of 4 children per family and Contraceptives actually being effective in planning families; control the attitude of married couple towards the use family planning methods in Abakpa Nike, Enugu. There is adequate practice of family planning methods among married couples in Abakpa. Effectiveness and Partner involvement were the major factors influencing the Choice of Family Planning in Abakpa Nike, Enugu. Consequent upon the findings, the following recommendations, among others, were made: It is therefore necessary for religious leaders to be targeted and carried along in the campaign for modern contraceptive methods. The mass media should also be encouraged to do more in public (eg traditional method) have been associated with high enlightenment on the benefits of modern contraceptive methods. So, awareness and pattern of utilizing family planning services among married couples in Abakpa Nike, Enugu should be encouraged.
\end{abstract}

Keywords: Family planning, Contraceptives, married couples, Mortality.

\section{Introduction}

\section{Background of the study}

The alarming rate at which the population of the world is increasing demands adequate and immediate attention ${ }^{14}$. This is needed to curb problem of social, ecological, economic and general welfare problems of all individuals. As a matter of fact, the survival of the human race is endangered if population growth is not checked adequately.

In a developing country like Nigeria, over population is a major concern and the main reason is that our resources are no longer enough to cater for the citizens, hence the increased poverty. Despite the progress recorded from making contraception widely available, there is poor acceptance of contraceptive methods either due to ignorance or fear of complications or side effects using them ${ }^{13}$. Inadequate knowledge about contraception and its methods, incomplete or erroneous information about their use or where they procure them and the attitudes of the health care providers at the clinics are the main reasons for not accepting family planning ${ }^{22}$. There is a trade-off between safety and efficiency of contraceptives in practice. The decisions about family planning are made by people themselves based on accurate and choosing from a range of contraceptive options. Family planning can be used by people who make informed choice. Providers and their programs have the responsibility to help people make informed family planning choices. Approximately $60 \%$ of all pregnancies are unplanned and knowledge about the various methods of contraception preventing 
unwanted pregnancy is directly related to education and knowledge about the various methods of contraception ${ }^{12}$.

According to Rozina ${ }^{20}$ family planning is now recognized as a basic human right and it must be seen as part of preventive health. Despite all endeavours to reduce the number of birth through family planning in Nigeria, there are a lot of problems still emanating. Considering the population of Nigeria which was estimated at 100 million in the year 2000 and with a growth rate of over three percent; it was projected that there might be 150 million heads swinging around in the country by the year 2010 . This has come to pass. Also, Nigerian's report on the implementation of the Beijing platform for action and common wealth plan of action by the Federal Ministry of Women Affairs (2004) cited in Olakojo $^{12}$, estimates that Nigeria's population was about 120 million and an annual growth rate of $2.8 \%$ spread over 350 ethnic groups and two major religions, Islam and Christianity. It is, however, projected that there may be as many as 174 million heads in the country by the year 2020 and the repercussion of such a growth rate in the nation's economic development and social services call for great concern (Federal Ministry of Women Affairs, 2004). Dixon-mullen cited in Olakojo, ${ }^{12}$ states that African from time of their ancestors is known to bear many children. It was believed that having many children was a pride and a way of boosting one's ego. Providing enough labour and increasing the productivity on the farms. Fajobi cited in Olakojo, ${ }^{12}$ discovers that another major problem hindering modern family planning in Nigeria is illiteracy, he describes illiterates as the worst offenders of unplanned families. Majority of the married people in the rural areas of the six geo political zones are illiterates and they are ignorant of the importance and necessity of the modern family planning programme and alternatively, they rather prefer to ask their children to stay or live with other family members who are financially capable than themselves.

US Department of Agriculture Centre for Nutrition Policy and Promotion ${ }^{24}$ have pointed out various ways of controlling birth before the modern family planning came into existence and natural traditional method of family planning have been in use before the introduction of contraceptives. Family planning is a vital issue to investigate considering the rapid increase of Nigeria's population. The population of Nigeria today increases tremendously thus, posing problem of survival to the members of individual families. Africans have now advanced to the stage of developing modern family planning devices which are more effectives than the method that were adopted in the early years or century. The types of family planning methods used in the old days include: abstinence, polygamy, celibacy, menstruation, douching, oral method, scarification, charms, spiritual power, local herbs in the vagina to stimulate contraction and dilation of the cervix. In the modern times, contraceptives used are: condoms, intrauterine devices (U.I.D) oral, sterilization, injectables, implant; sterilization, Diaphragm and safe period are also used in Nigeria ${ }^{7}$.

\section{Statement of the problem}

The relevance of family planning cannot be over emphasized since is now recognized as a basic human right and seen as part of preventive health measures ${ }^{19}$. Fortunately, majority of Nigerian married couples are aware of family planning, but very few of them make use of it for birth control. Different factors such as culture, low education, poverty and poor access among other numerous factors have been identified by scholars to militate against the use of family planning methods ${ }^{24}$. For example, ${ }^{17}$ alleged that traditionally, most Nigerian cultures are highly patriarchal, value high fertility and male child preference. This perhaps could have a negative impact on the utilisation of family planning services. A study carried out by Isiugo-abanihe cited in Lasisi, Bassey, Ita, \& Awoyemi ${ }^{9}$ on reproductive motivation and family size preferences among Nigerian men revealed that the characteristic male dominant and patrilineal traditions support large family sizes and that men's reproductive motivation to a large extent, affect the reproductive behaviour of their wives. These cultural values undermine the utilisation of family planning in many communities in Nigeria like the traditional core areas of Enugu especially Abakpa Nike, where families still support large family sizes of more than four children per woman, and where polygamy is commonly practiced.

More so, in most cases especially in rural areas, women do not have a say when it comes to family planning issues and reproductive health care independency and survival Olutayo, cited in Lasisi, Bassey, Ita, \& Awoyemi, ${ }^{9}$. Also, Ozumba ${ }^{19}$ maintained that many rural women have been threatened, 
abused, beaten and sometimes overpowered when it comes to sexual play and matter that concerns family planning. A lot of research has been done on this subject in the past but heavily skewed to married women's self-identified barriers on the use of family planning measures but sparse literature exist in Nigeria on the area of knowledge, attitude and practice of family planning among married couples.

\section{Objectives of the study}

The objective of this study is to assess family planning knowledge, attitude and practice among married couples in Abakpa Nike, Enugu East Local Government Area, Enugu State

\section{Scope and delimitation of the study}

This project work is structured to cover family planning knowledge, attitude and practice among married couples with Abakpa Nike as study reference. Abakpa is composed of five district areas which include Ugboghe, Ogwuago, Ugbene I, Ugbene II, and Ugboezeji.Abakpa Nike was chosen due to proximity reason and easy accessibility of data and that it would serve as good sample to assess family planning knowledge, attitude and practice among married couples. Drawbacks were actually observed which contradict the initial plan, which aimed at covering all areas in Enugu State, but due to financial incapacitation, time and uneasy accessibility of data, the researcher however delimited the scope, selecting only Abakpa Nike in Enugu East.

\section{Definition of operational terms}

Family planning: Family planning involves a conscious effort by couple to limit or space the number of children they want to have through the use of contraceptive methods. It also refers to the steps, practices and techniques adopted to determine, influence or decide when to have children ${ }^{11}$.

Contraception: Contraception as a concept can also be defined as means of controlling fertility by using various methods that prevent conception ${ }^{18}$.

Marriage: Marriage, also called matrimony or wedlock, is a socially or ritually recognized union or legal contract between spouses that establishes rights and obligations between them, between them and their children, and between them and their in-laws

Couple: two people who are married or otherwise closely associated romantically or sexually

Married Couple: two people who are married to each other.

Mortality: The incidence of death in the population in a given period.

\section{Literature review}

The review commenced with the conceptual framework of the study which encompassed the concept of family planning, Factors Influencing the Choice of Family Planning, Contraception, Types of Contraceptives and their Function. This was followed with the theoretical framework where theory that has direct bearing to this study was reviewed and finally, empirical evidence from different scholars was covered under this chapter.

\section{Conceptual framework}

\section{Concepts of family planning}

Family planning is the planning of when to have and use birth techniques to implement such plans ${ }^{13}$. Other techniques commonly used include sexual education, prevention and management of sexually transmitted diseases, pre-conception counselling, management and infertility management ${ }^{2}$. The concept of informed choice in family planning can be applied to a wide range of sexual and reproductive health decisions. It focuses on whether to seek, to avoid pregnancy, whether to space and time one's 'childbearing, whether to use contraception, what family methods to be used, and whether or when to continue or switch methods. The term family planning choice could also refer to the family decision making ${ }^{3}$. The principles of informed choice focus on the individual; however, it also influences a range of outside factors such as: social, economic and cultural norms, gender roles, social networks, religious and local beliefs, ${ }^{4}$. To a large extent, these community norms determine individual childbearing preferences and sexual and reproductive behaviour. It is usually thought that community 
and culture affect a person's attitudes towards family planning, desire for sex of children, preferences about family size, family pressures to have children and whether or not family planning accords with customs and religious beliefs ${ }^{4}$. Community norms also reflect how much autonomy individuals have in making family planning decisions. The larger the differences in reproductive intentions within a community, the more likely that community norms support individual choices ${ }^{5}$. Household and community influences can be so powerful that they can obscure the line between individual desires and community norms. For instance, in some culture, many women reject contraception because bearing and raising children is the path to respect and dignity in the society ${ }^{13}$. In either country, most women use contraception because having small families is the norm ${ }^{13}$. People are often unaware that such norms influence their choices. In other cases, they are particularly aware. For example, young people often decide not to seek family planning because they do not want their parents or other adults to know that they are sexually active, while many fear ridicule, disapproval and hostile attitude from service providers and others. A person's social environment usually has more influence on family planning decisions that influence the attributes of specific contraceptives.

\section{Factors influencing the choice of family planning}

A myriad of different factors affect a person's personal decisions about what types of family planning method he should use:

\section{a. Effectiveness}

People who are not in a financial or emotional situation to have children might opt for the most effective type of family planning in order to avoid pregnancy. A couple or woman with a casual approach towards parenthood, such as not actively pursuing it, but not unwilling to take it on, might choose a less certain form of contraception, such as natural family planning.

\section{b. Religion}

Some religions, such as Catholicism, have restrictions on contraception based on the belief that it is God's will to bring children into the world. According to Dixon-Muller cited in Olaitan ${ }^{13}$, religious believers or observers might choose to avoid certain methods of family planning, such as birth control pill, in an effort to live their lives according to the teachings of their religion.

\section{c. Cost}

Some forms of contraception, such as minor surgery (like vasectomy), carry a fairly significant amount of one's time and is very cost as compared to other options, such as condom or the calendar cycle methods which are less expensive; hence, couples engage in them.

\section{d. Health risk}

For people with multiple sexual partners, the choice to use family planning devices helps them to keep healthy. For example, using condoms can reduce the chance of contracting sexually transmitted diseases.

\section{e. Permanence}

Some contraception choices, such as vasectomy, are usually permanent. So couples who do not want to have children at present, but would like to have one in the future, might want to choose a less - permanent option such as condoms or birth control pills.

\section{f. Partner involvement}

One has to consider the preferences of his or her partner when choosing a birth control option. For example, some men do not like to have sex using a condom. In that case, birth control pills might be a better choice for preventing an unwanted pregnancy, according to the National Institute of Health ${ }^{16}$.

\section{g. Socio-economic factors}

There are some contraceptive methods of family planning that are expensive, and some couples cannot afford to use or purchase them due to their financial situations in the society. For instance, 
people in rural areas cannot afford to use the expensive contraceptive methods of family planning such as vasectomy, Intra-uterine devices (IUD) (which are small, flexible, plastic frame inserted in the vagina of women) and female sterilization method.

\section{h. Cultural norms factors}

This is the most important factor influencing the choice of family planning among couples. This includes: community norms, religious belief and gender role.

\section{i) Community norms}

Community norms also prescribe how much autonomy an individual has in making family planning decisions. The larger the differences in reproductive intentions within a community, the more likely the community norms support individual choices. Household and community influence can be so powerful that they can obscure the line between individual desires and community norms

\section{Religious factors}

Family planning choice depends on the religion of the couple. It may be Islam or Christianity that calls for raising and bearing of more children in the society. Some religions, such as Catholicism, have restriction on contraception based on the belief that it is "God's will to bring children" into the world.

\section{ii) Gender role}

Some couples want to have a male child; and in cases when the child born to them is female, the family is unhappy. Therefore, the couple may wish to have another child in order to have a male child $^{6}$.

\section{Male involvement in family planning}

In recent times, many in the reproductive health field have come to appreciate the need for the constructive involvement of men in programs and services. The 1994 International Conference on Population Development (ICPD) held in Cairo articulated why and how male involvement should occur. Recognition is growing that men are interested in and need reproductive health information and services, both for their partners and for themselves ${ }^{6}$ and that the reproductive health of individuals depends heavily on the relationship between two people concerned. Awareness has increased that services should be directed not only towards women but also towards men and couples ${ }^{6}$. Before the current concern for male involvement began, reproductive health issues and services had become synonymous with women's reproductive health, and men were assumed to have no special interest in such matters. Indeed, the characteristic lack of male involvement in reproductive initiatives, including family planning, is a major obstacle to a speedy fertility decline in sub-Saharan Africa given the considerable authority and power vested on men as decision makers in the home and society ${ }^{6}$.

\section{Contraception}

Contraception as a concept can also be defined as means of controlling fertility by using various methods that prevent conception. These methods can be traditional or modern. Traditional methods include: withdrawal method, abstinence, douche method and vaginal sponge ${ }^{1}$. Withdrawal method, also referred to as coitus interruptus ${ }^{18}$, is probably the oldest technique which couples adopted in order to avoid having children. It refers to the withdrawal of the penis from the woman's vagina just prior to ejaculation so that the semen is deposited outside of the genital tract. Another oldest method is the Douche. It consists of flushing out the vagina with water after sexual intercourse in an effort to prevent pregnancy by removing semen. In 1958, the first oral contraceptive pill was tested and subsequently introduced in May 1960. Before then however, a German physician, Ernest Graefenberg, had developed the intrauterine device (IUD) in $1929^{21}$; but the knowledge of the existence of IUD was limited to a few countries in Europe and America. Other modern medical advances in family planning include surrogacy and sperm donor. In surrogacy, a woman agrees to become pregnant and deliver a child for another couple or person. There are two types of surrogacy: Traditional Surrogacy and Gestational Surrogacy. In traditional surrogacy, a woman uses her own 
eggs and carries the child for her intended parents. This type involves a genetic connection between the surrogate and the child. On the other hand, a gestational surrogacy occurs when the intended mother's or a donor egg is fertilized outside the body and then the embryos are transferred into the uterus. The woman who carries the child is often referred to as a gestational carrier ${ }^{23}$. The method is not popular in Africa, but records show that is a common practice in some parts of India, and now a preferred destination to many North American women who patronize the system ${ }^{18}$. In sperm donor, pregnancies are usually achieved by using donated sperm through artificial insemination (either by intracervical insemination or intrauterine insemination) and less commonly by Invitro fertilization (IVF), usually known in this context as Assisted Reproductive Technology (ART). Insemination may also be achieved by a donor having sexual intercourse with a woman for the sole purpose of initiating conception. This method is known as natural insemination ${ }^{23}$. Olawepo ${ }^{15}$ notes that there is a generally a demand for sperm donors who have no genetic problems in their family, 20/20 eyesight, with excellent visual acuity and sometimes, a value on a certain height and age.

\section{Research design and methodology}

\section{Study area}

This study is pegged on Abakpa Nike, Enugu East local government area of Enugu State. Abakpa Nike is from Enugu East and is comprising of five district areas, namely: Ugboghe, Federal Housing, Ogwuago, Ugboezeji Ugbene I and Ugbene II. Enugu east is one of the seventeen (17) local governments in Enugu state. Its headquarter is in the town of Nkwo Nike. It has an area of $383 \mathrm{~km}^{2}$ and a population of 279,089 at the 2006 census. The postal code of the area is 400 .

\section{Source of data}

Data used for the study were collected from both Primary and Secondary sources.

\section{Primary source of data}

A primary source is an original object or document- the raw material or first-hand information.

\section{Secondary source of data}

This can be defined as any published or unpublished work that is one step removed from the original source, usually describing, summarizing, analyzing, evaluating, derived from, or based on primary source materials

\section{Determination of sample size}

To ensure effective study, the researcher used a statistical formula (Yaro Yamane's formula) for a finite population size of 1130 married couples (N) to obtain 295 as the sample size (n) which represents also the number of the questionnaires administered accordingly.

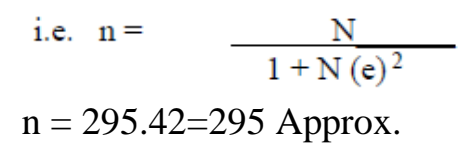

Using Bowley's formula, the sample size of 295 will be allocated to different strata

$$
\mathrm{ni}=\frac{\mathrm{Nixn}}{\mathrm{N}}
$$

Where ni $=$ strata sample

$\mathrm{Ni}=$ Population size of the strata

$\mathrm{N}=$ Population size of the strata

Ogwuago $=\frac{220 \times 295}{1130}=58$
Federal Housing $=\frac{100 \times 295}{1130}=26$
Ugboghe $-=\frac{250 \times 295}{1130}=65$ 
Ugboezeji $\quad \frac{230 \times 295}{1130}=60$
Ugbene I $\quad \frac{200 \times 295}{1130}=52$
Ugbene II $=\frac{130 \times 295}{1130}=\underline{34} 295$

However, the researcher distributed 295 copies of questionnaire, in an attempt to ensure greater validity of the study and was able to collect back 290. This gave a response rate of about $98 \%$. This was considered high enough for this study. However, three (3) copies of the questionnaire were not returned while two (2) copies were rejected because it was not properly completed.

\section{Research instrument}

The main instrument used in data collection was Questionnaire. The survey questionnaire was organized on a - 5 Likert scale response options Strongly Agree (SA), Agree (A), Undecided (U), Strongly Disagree (SD), and Disagree (D) and also on "Yes" or "No" as well as "Suggestive options" questions. Also, the researcher also used "Content Validity" which emphasized mainly on the adequate coverage by the instrument of the scope implies by the topic of study.

It was revealed that the entire questions asked in the questionnaire fully exhausted all implied by the research questions.

\section{Administration and collection of the questionnaire}

The face to face method of distribution of questionnaire was adopted .The researcher administered 295 copies of questionnaire, in an attempt to ensure greater validity of the study and was able to collect back 290 copies. This gave a response rate of about $98 \%$. This was considered high enough for this study. However, 2 copies of questionnaire were rejected because they were not properly completed while 3 are non-returnable. In sum, 290 copies of questionnaire were collected which gave a response rate of about $98 \%$ and same were used for analysis.

\section{Method of data analysis}

The data collected were analyzed through the use of tables and simple percentages and mean value. Mean value will be determined as follows:

$$
\frac{5+4+3+2+1}{5}=3.00
$$

The implication is that any items with mean value of 3.00 is accepted as "agree" while any item with mean value less than 3.00 is "disagree".

\section{Ethical issue}

Ethical clearance was obtained from the Esut Teaching Hospital Parklane Enugu Ethical Committee. Informed consent will be obtained from all participants.

\section{Results, analysis and findings}

The copies of questionnaire were administered to the married couples in Abakpa Nike, Enugu. A total of 295 copies of questionnaire were issued to the. Out of the 295 questionnaire issued, 290 were dully filled and returned to the researcher by the respondents. Three (3) copies of questionnaire were however not returned and Two (2) copies of questionnaire were not properly filled which both represents $2 \%$ of the issued questionnaires. Therefore, the $98 \%$ of the copies of the questionnaire which were duly filled returned and were used for the presentation and analysis for this research study. 
DOI: $10.21522 /$ TIJPH.2013.06.02.Art022

ISSN: $2520-3134$

\section{Analysis and results}

Table 1. Socio-demographic characteristics of respondents $(\mathrm{n}=290)$

\begin{tabular}{|c|c|c|}
\hline $\begin{array}{l}\text { Variables/Options } \\
\text { Age Group } \\
\text { (Years) } \\
\end{array}$ & $\begin{array}{l}\text { No. of } \\
\text { Respondent }\end{array}$ & Percentage (\%) \\
\hline 19 and less & 35 & 12 \\
\hline $20-24$ & 43 & 15 \\
\hline $25-29$ & 73 & 25 \\
\hline $30-34$ & 54 & 19 \\
\hline 35 and above & 85 & 29 \\
\hline \multicolumn{3}{|l|}{ Religion } \\
\hline Christianity & 280 & 97 \\
\hline Islam & 9 & 3 \\
\hline Traditional & 1 & - \\
\hline \multicolumn{3}{|c|}{ Educational Status } \\
\hline $\begin{array}{l}\text { No formal } \\
\text { education }\end{array}$ & 33 & 11 \\
\hline Primary School & 71 & 24 \\
\hline Secondary School & 147 & 51 \\
\hline Tertiary & 39 & 14 \\
\hline \multicolumn{3}{|l|}{ Family Setting } \\
\hline Monogamy & 235 & 81 \\
\hline Polygamy & 55 & 19 \\
\hline \multicolumn{3}{|l|}{$\begin{array}{l}\text { Children ever } \\
\text { born: }\end{array}$} \\
\hline $0-2$ & 94 & 32 \\
\hline $3-4$ & 93 & 32 \\
\hline $5-6$ & 58 & 20 \\
\hline Above 7 & 45 & 16 \\
\hline \multicolumn{3}{|c|}{ Additional child wanted } \\
\hline Yes & 210 & 72 \\
\hline No & 80 & 80 \\
\hline \multicolumn{3}{|l|}{ Occupation } \\
\hline Farming & 1 & - \\
\hline Trading & 5 & 2 \\
\hline Civil Servant & 36 & 15 \\
\hline Housewife & 6 & 2 \\
\hline Student & 39 & 16 \\
\hline Unemployed & 33 & 14 \\
\hline Others & 123 & 51 \\
\hline
\end{tabular}

Source: Field survey, 2016.

More of the respondents were in the age range of 35 years and above, 85(29\%) followed by 25 to 29 years 73(25\%), with a mean age of $29.59 \pm 8.57$ years. Most of them were Christian 280(97\%), and had secondary school education $147(51 \%)$, majority of the married couples were monogamy 235(81\%) with Children ever born not mostly exceed 4 children, the response rate shown $0-2(32 \%)$ and 3-4 93(32\%), upon this, majority of respondents, 210(72\%) gave consent for additional child while other occupation unspecified was the major vocation, $123(51 \%)$ among the respondents (Table 1). 
Table 2. Knowledge of respondents about contraception $(\mathrm{n}=290)$

\begin{tabular}{|l|l|l|}
\hline Variables/Options & $\begin{array}{l}\text { No. of } \\
\text { Respondent }\end{array}$ & Percentage (\%) \\
\hline Meaning of Contraception & 51 \\
\hline $\begin{array}{l}\text { Prevention of } \\
\text { unwanted } \\
\text { pregnancy }\end{array}$ & 149 & 16 \\
\hline Child spacing & 46 & 28 \\
\hline Limit family size & 80 & 5 \\
\hline Prevent sexually & 15 & \\
\hline Sources of Information & 20 \\
\hline Friends / Relatives & 59 & 53 \\
\hline Health personnel & 153 & 4 \\
\hline $\begin{array}{l}\text { Printed medial } \\
\text { (postal, hand bill) }\end{array}$ & 12 & 23 \\
\hline $\begin{array}{l}\text { Electric media } \\
\text { (Radio, TV) }\end{array}$ & 66 & \\
\hline Knowledge of Side - effects & 90 \\
\hline None & 260 & 1 \\
\hline Weight gain & 3 & 1 \\
\hline Weight loss & 2 & 5 \\
\hline Condom burst & 15 & 1 \\
\hline $\begin{array}{l}\text { Extra marital } \\
\text { affairs }\end{array}$ & 3 & 1 \\
\hline Amenorrhea & 2 & 1 \\
\hline $\begin{array}{l}\text { Secondary } \\
\text { infertility }\end{array}$ & 3 & - \\
\hline Heavy menses & 1 & - \\
\hline Dislodgement & - & 21 \\
\hline Irregular menses & 1 & \\
\hline Decider of Family Planning Method & \\
\hline Husband & 109 & \\
\hline Wife & 62 & \\
\hline Both & 119 & \\
\hline & & \\
\hline & & \\
\hline
\end{tabular}

Source: Field survey, 2016.

In Table.2, some of the respondents understood contraception to mean prevention of unwanted pregnancy $149(51 \%)$ and limiting the family size $80(28 \%)$, their source of information was mainly the health personnel, 322(52.6\%). Majority of the women, 260 (90\%) did not know any side-effect of contraceptives and $15(5 \%)$ of them reported condom burst/spillage as a side-effect of condom use. One hundred and nine, 109 (38\%) respondents felt the husband should solely decide on family planning, while $62(21 \%)$ felt it was the wife, but $119(41 \%)$ felt it is a joint responsibility of husband and wife/partner. 
DOI: $10.21522 /$ TIJPH.2013.06.02.Art022

ISSN: $2520-3134$

Table.3. Knowledge about contraceptive methods $(n=290)$

\begin{tabular}{|l|l|l|}
\hline Variables/Options & $\begin{array}{l}\text { No. of } \\
\text { Respondent }\end{array}$ & $\begin{array}{l}\text { Percentage } \\
(\%)\end{array}$ \\
\hline Traditional & & \\
\hline Armlet & 89 & 31 \\
\hline Ring & 180 & 62 \\
\hline Pad lock & 112 & 39 \\
\hline Waist band & 109 & 38 \\
\hline Natural & & \\
\hline Periodic Abstinence & 264 & 91 \\
\hline Rhythm & 172 & 59 \\
\hline $\begin{array}{l}\text { Lactational } \\
\text { amenorrhoea }\end{array}$ & 144 & 50 \\
\hline Coitus interruptus & 168 & 58 \\
\hline Barrier & & \\
\hline Male condom & 286 & 99 \\
\hline Female condom & 3 & 1 \\
\hline Diaphragm & 90 & 31 \\
\hline IUCD & 183 & 63 \\
\hline Hormonal & & \\
\hline Injectable & 246 & 85 \\
\hline Implants & 92 & 32 \\
\hline Pills & 243 & 84 \\
\hline Surgical & & 1 \\
\hline Vasectomy & 2 & - \\
\hline $\begin{array}{l}\text { Bilateral tubal } \\
\text { ligation }\end{array}$ & - & \\
\hline
\end{tabular}

Source: Field survey, 2016

From table.3 above, Rings 180(62\%), abstinence 264(91\%), male condom 286(99\%) and injectable $246(85 \%)$ were the most well-known traditional, natural, barrier and hormonal methods respectively.

Table.4. Distribution of respondents, on whether there is positive knowledge of family planning methods among married couples in Abakpa

\begin{tabular}{|l|l|l|}
\hline Response & Frequency & $\begin{array}{l}\text { Percentages } \\
(\%)\end{array}$ \\
\hline Strongly Agree & 180 & 62 \\
\hline Agree & 90 & 31 \\
\hline Undecided & 15 & 5 \\
\hline Strongly Disagree & 3 & 1 \\
\hline Disagree & 2 & 1 \\
\hline Total & 290 & 100 \\
\hline
\end{tabular}

Source: Field survey 2016

From the table 4.1 .4 above, $62 \%$ of the respondents strongly agree that there is positive knowledge of family planning methods among married couples in Abakpa supported by $31 \%$ of the respondents representing respondents that agree on the fact. As could be seen on the table, only $1 \%$ of the respondents strongly disagree while $1 \%$ gave them support as they just disagree with the fact. These two groups do not think that there is positive knowledge of family planning methods among married couples in Abakpa. The remaining 5\% with undecided representing 15 out of 290 respondents do not belong to either side. Based on these observations, it can be deduced that there is positive knowledge of family planning methods among married couples in Abakpa. 


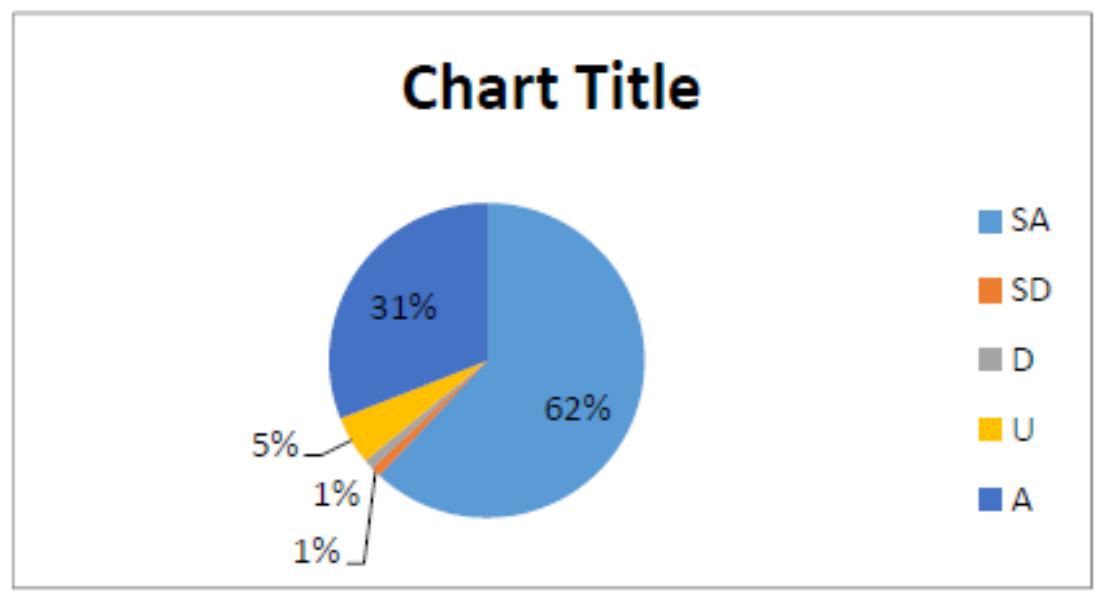

Figure 1. Pie chart showing the distribution of respondents, on whether there is positive knowledge of family planning methods among married couples in Abakpa

From the pie chart above, strongly agree received the biggest chunk of the respondents representing $62 \%$ that there is positive knowledge of family planning methods among married couples in Abakpa followed by $31 \%$ of the respondents representing respondents that agree on the fact. As could be seen on the pie chart, only $1 \%$ of the respondents strongly disagree while $1 \%$ gave them support as they just disagree with the fact. These two groups do not think that there is positive knowledge of family planning methods among married couples in Abakpa. The remaining 5\% with undecided representing 15 out of 290 respondents do not belong to either side.

Table 5. Practices of contraceptives/family planning $(\mathrm{n}=290)$

\begin{tabular}{|l|l|l|}
\hline Variables & frequency & $\begin{array}{l}\text { Percentage } \\
(\%)\end{array}$ \\
\hline \multicolumn{2}{|l|}{ If currently using a method of family planning } \\
\hline Yes & 250 & 86 \\
\hline No & 40 & 14 \\
\hline If approve the use of modern methods of family planning \\
\hline Yes & 240 & 83 \\
\hline No & 50 & 17 \\
\hline $\begin{array}{l}\text { Intend to use a modern method of family planning to } \\
\text { prevent pregnancy in the future }\end{array}$ \\
\hline Yes & 200 & 69 \\
\hline No & 90 & 31 \\
\hline Method(s) ever used & 243 & 84 \\
\hline Pills & 246 & 85 \\
\hline Injection & 286 & 99 \\
\hline Male condom & 5 & 2 \\
\hline Norplant & 183 & 63 \\
\hline IUD & 5 & 2 \\
\hline Female sterilization & 75 & 26 \\
\hline Why using contraceptives & 49 \\
\hline No reason & 75 \\
\hline $\begin{array}{l}\text { Affordable and } \\
\text { available }\end{array}$ & 142 & 21 \\
\hline $\begin{array}{l}\text { Little or no side } \\
\text { effect }\end{array}$ & 58 & \\
\hline $\begin{array}{l}\text { Suitable effective / } \\
\text { reliable }\end{array}$ & 62 & \\
\hline
\end{tabular}


DOI: $10.21522 /$ TIJPH.2013.06.02.Art022

ISSN: $2520-3134$

\begin{tabular}{|l|l|l|}
\hline Why not using contraceptives & 2 \\
\hline $\begin{array}{l}\text { It is sin in my } \\
\text { religion }\end{array}$ & 7 & 16 \\
\hline No reason & 45 & 4 \\
\hline Side effect & 13 & 2 \\
\hline $\begin{array}{l}\text { Husband's } \\
\text { disapproval }\end{array}$ & 6 & 1 \\
\hline $\begin{array}{l}\text { Desire for more } \\
\text { children }\end{array}$ & 4 & \\
\hline
\end{tabular}

Source: Field survey 2016

In table 5, majority of the respondents $250(86 \%)$ were currently using a modern contraceptive method. A good proportion of the respondents indicated their continued practice of modern contraceptive method even in the future as evident by 200(69\%) accepting to use a modern method of family planning to prevent pregnancy in the future. The respondents mostly practice Male condom, Injection, Pills and IUD with 286(99\%), 246(85\%), 243(84\%) and 183(63\%) as their response rates respectively. The main reason given for choice of contraceptive methods was affordability and availability, 142 (49\%), followed by reliability by $21 \%$ of the respondents. Most of the non-users $45(16 \%)$ did not have any reason for not using any method.

A close look on the bar chart above indicates that majority of the respondents $250(86 \%)$ were currently using a modern contraceptive method. A good proportion of the respondents indicated their continued practice of modern contraceptive method even in the future as evident by 200(69\%) accepting to use a modern method of family planning to prevent pregnancy in the future. The respondents mostly practice Male condom, Injection, Pills and IUD with 286(99\%), 246(85\%), $243(84 \%)$ and $183(63 \%)$ as their response rates respectively. The main reason given for choice of contraceptive methods was affordability and availability, 142 (49\%), followed by reliability by $21 \%$ of the respondents. Most of the non-users 45(16\%) did not have any reason for not using any method.

Table 6. Distribution of respondents, on whether there is adequate practice of family planning methods among married couples in Abakpa

\begin{tabular}{|l|l|l|}
\hline Response & Frequency & $\begin{array}{l}\text { Percentage } \\
\text { ( }(\%)\end{array}$ \\
\hline Strongly Agree & 120 & 41 \\
\hline Agree & 140 & 48 \\
\hline Undecided & 15 & 5 \\
\hline Strongly Disagree & 3 & 1 \\
\hline Disagree & 2 & 1 \\
\hline Total & 290 & 100 \\
\hline
\end{tabular}

Source: Field survey 2016

From the table 6 above, $41 \%$ of the respondents strongly agree that there is adequate practice of family planning methods among married couples in Abakpa supported by $48 \%$ of the respondents representing respondents that agree on the fact. As could be seen on the table, only $1 \%$ of the respondents strongly disagree while $1 \%$ gave them support as they just disagree with the fact. These two groups do not think that there is adequate practice of family planning methods among married couples in Abakpa. The remaining 5\% with undecided representing 15 out of 290 respondents do not belong to either side. Based on these observations, it can be deduced that there is adequate practice of family planning methods among married couples in Abakpa.

\section{Analysis and results of the research questions}

This involves collation and analysis of data according to the research questions. To arrive at a conclusion, the average of the five likert point scale would be taken thus: 


$$
\overline{\mathrm{X}}=\frac{\sum \mathrm{FX}}{\sum \mathrm{F}}=\frac{5+4+3+2+1}{5}=\frac{15}{5}=3.0
$$

The implication is that any items with mean value of 3.0 is accepted as "agree" while any item with mean value less than 3.0 is "disagree".

Research question one -To what extent does knowledge of family planning influences usage of family planning methods among married couples in Abakpa Nike?

Table 7. Positive knowledge of family planning methods among married couples in abakpa

\begin{tabular}{|l|l|l|l|}
\hline Response & F & $\mathbf{X}$ & $\mathbf{F x}$ \\
\hline Strongly Agree & 180 & 5 & 900 \\
\hline Agree & 90 & 4 & 360 \\
\hline Undecided & 15 & 3 & 45 \\
\hline Strongly Disagree & 3 & 2 & 6 \\
\hline Disagree & 2 & 1 & 2 \\
\hline Total & 290 & 15 & $\begin{array}{l}1313 \\
\overline{\mathbf{X}}=\frac{\mathbf{1 3 1 3}}{\mathbf{2 9 0}}=\mathbf{4 . 5}\end{array}$ \\
\hline
\end{tabular}

Source: Author's computations

From the above table, it can be seen that 4.5 is greater than mean value of the likert,3.0.Therefore, it can be concluded that there is positive knowledge of family planning methods among married couples in Abakpa.

Research question two -What are the attitudes of the married couples towards family planning methods in Abakpa Nike?

From the responses above, the married couples described their attitudes towards family planning methods as to constitute, husbands involvement in family decision, support of national policy of 4 children per family and that Contraceptives actually effective in planning families in Abakpa Nke, Enugu with mean score value of 4.6,4.4 and 4.2 respectively. On the other hand, the outcome of the above analysis indicates the following do not portray the attitudes of the married couples towards family planning methods in the area under study, i.e, It is against culture and religion, Only females should use contraceptives, Contraceptives are ineffective, It encourages promiscuity, Diminishes sexual pleasure, It is only for the literate, family planning make its users promiscuous, Contraceptives harmful because of their side effects and Family planning services somewhat expensive with mean score value of 1.8, 1.7, 1.6, 2.7, 2.5, 1.5, 1.8, 2.4 and 1.5 respectively. By this analysis, it can be concluded that husband's involvement in family decision, support of national policy of 4 children per family and Contraceptives actually being effective in planning families control the attitude of married couple towards the use family planning methods in Abakpa Nke, Enugu.

Research question three- How is the extent of practice of family planning methods among married couples in Abakpa Nike?

Table 8. Distribution of respondents, on whether there is adequate practice of family planning methods among married couples in Abakpa

\begin{tabular}{|l|l|l|l|}
\hline Response & F & X & Fx \\
\hline Strongly Agree & 120 & 5 & 600 \\
\hline Agree & 140 & 4 & 560 \\
\hline Undecided & 15 & 3 & 45 \\
\hline Strongly Disagree & 3 & 2 & 6 \\
\hline Disagree & 2 & 1 & 2 \\
\hline Total & 290 & 15 & $\begin{array}{l}1213 \\
\overline{\mathbf{X}}=\frac{1213}{290}=4.2\end{array}$ \\
\hline
\end{tabular}

Source: Author's computations 
From the above table, it can be seen that 4.2 is greater than mean value of the likert,3.0.Therefore, it can be concluded that there is adequate practice of family planning methods among married couples in Abakpa.

Research question four-What are the factors that influence family planning practice among married couples in Abakpa Nike?

\section{Summary of findings}

From the data presented and analyzed above, the following deduction could be made:

1. There is positive knowledge of family planning methods among married couples in Abakpa.

2. Husbands involvement in family decision, support of national policy of 4 children per family and Contraceptives actually being effective in planning families control the attitude of married couple towards the use family planning methods in Abakpa Nke, Enugu.

3. There is adequate practice of family planning methods among married couples in Abakpa.

4. Effectiveness and Partner involvement were the major factors influencing the Choice of Family Planning in Abakpa Nike, Enugu,

\section{Discussion of findings}

From the study, it was obvious that there is positive knowledge of family planning methods among married couples in Abakpa. Generally high among the respondents with an average of 266 in 290 respondents knowing male condom and injectables were the most well-known methods in Abakpa Nike. This high level of awareness has been similarly reported by previous studies within and outside Nigeria. (Anyanwu, 2015; Rozi et al.; 2008; Lundgren et al.; 2005; Mkangi, 2001) The knowledge of respondents about contraception/family planning was also high with about 270 respondents having good knowledge of contraception. This was also corroborated by Gbalahan (2015) in their study carried out in south western Nigeria. This pattern should be expected in light of much enlightenment that is on-going on the issue of family planning in the country. It is however still worthy of note that some contraceptive methods were very unpopular among the respondents. Only about a quarter knew about the diaphragm and implants and not up to $1 \%$ of the respondents knew about female condoms as methods of contraception. This is most likely due to the fact these methods are not readily available and are relatively more expensive than the other commoner methods like the male condoms.

Most of the respondents were favourably disposed towards contraception with more than fourfifths having a positive attitude towards contraception. However about 88 in 290 respondents felt contraception encourages promiscuity. This may be due to the conservative nature of typical African societies and could be one of the complex sociological factors (Eko, 2013) affecting contraceptive usage in African communities. Furthermore, nearly $90 \%$ of the respondents felt the husbands should be involved in family planning decisions and this is important because man approval and decision making has been said to be very important in utilizing family planning services, (Donati, Shah et al, 2008;) and this further stresses the need to carry men along in family planning campaigns.

The prevalence of modern contraceptive methods usage among the respondents was $89 \%$ with Effectiveness and Partner involvement being the predominant reasons for choice of contraceptive methods. This prevalence is higher than the findings of other studies in rural areas in Nigeria (Lundgren et al.; 2005) and other developing countries.

\section{Conclusion}

Knowledge of modern contraceptives is high in a study population. Substantial proportion of married couples had positive attitude towards modern contraceptives and hence more room for increasing more contraceptive use in a study population, though negative attitude of husbands towards modern contraceptive and lack of spousal communication on family planning could be a limitation. Regarding modern contraceptive prevalence rate, although there was some improvement compared to the past national averages, however, the current figure for prevalence rate is still low when compared to the national target. Likelihood (chances) of being current user of modern contraceptives by a woman increased with increase in education level, having higher number of living children, spousal communication on modern contraceptives, (i.e., Frequently talking/discussing family 
planning/modern contraceptives among married couples), woman participation in decisions making regarding fertility in a family, husband approval of modern contraceptives and having positive attitudes towards modern contraceptives (i.e., tinking that benefits of modern contraceptives outweighs negative effects). If had ever encountered side effects and living far from health facility by a woman were associated with reduction in odds (chances) of being current user of modern contraceptives.

\section{Recommendations}

The following recommendations were made based on the findings:

It is therefore necessary for religious leaders to be targeted and carried along in the campaign for modern contraceptive methods.

The mass media should also be encouraged to do more in public (eg traditional method) have been associated with high enlightenment on the benefits of modern contraceptive methods. Awareness and pattern of utilizing family planning services among married couples in Abakpa Nike, Enugu.

Furthermore, campaigns to empower women such as emphasis on their education, encouraging gender balance by changing community attitude towards position/status of women in a household and in a society as a whole should be strengthened. This would improve their participation in household decisions including those related to fertility and contraceptive use.

More education/counseling services to women on how to handle/deal with side effects associated with various modern contraceptives methods should be given due weight and campaigns against myths and misbeliefs that negatively affect use of modern contraceptive in the study population should be initiated

\section{Suggestion for further study}

Given the imperative of family planning knowledge, attitude and practices in our nation Nigeria, the researcher therefore suggests that "family planning knowledge, attitude and practices in rural area" should be considered for further studies.

\section{Acknowledgment}

My thanks goes to Amoge Udeani for your physical support to the success of this work. I also want to thank my Chief Mr Ngene C.I for his financial support. May God bless you all.

\section{References}

[1]. Akin, A. (2007). "Emergence of Family Planning Programme in Turkey," in Robinson W.C. and J.A. Ross (eds.) the Global Family Planning Revolution: Three Decades of Population Policies and Programmes. Washington: Green Press Initiative: 85-102.

[2]. Anyanwu, J. I., Ezegbe, B.N., \& Eskay, M. (2015). Family planning in Nigeria: a myth or reality? Implications for education: Journal of Education and Practice, 4, (15):108-113Bell, S. (1992). "Birth Control," in the Boston Women's Health Book Collective: The New Our Bodies, Ourselves. New York: Touchstone.

[3]. Diaz, M. et al (1999). Informed choice in international family planning service delivery: strategies for the 21st century, New York: AVSC International:22

[4]. Dixon-Mueller, R. (1993) "The Sexuality Connection in Reproductive Health," in Studies in Family Planning, 24(5):269-282.

[5]. Donati S, Hamam R, Medda E. (2000). Family planning KAP survey in Gaza. SocSci Med; 50:841-849.

[6]. Ekhareafo, D.O. \& Moyaki, M.G (2015). Knowledge, Attitude and Practice of Family Planning Among Air Men in the Sam Ethnan Air Force Base, Ikeja, Lagos: An International Multidisciplinary Journal, Ethiopia, 9(1):183-198.

[7]. Eko, J. E, Kalu, O. O.\& Offiong, D.A (2013). Prevalence of contraceptive use among women of reproductive age in Calabar metropolis, southern Nigeria: International Journal of Humanities and Social Science Invention. 2(6):27-34.

[8]. Gbolahan, A., Oni \& James, M. (2015). Family Planning Knowledge, Attitudes and Practices of Males in llorin, Nigeria: International Family Planning Perspectives, 17(2):50-54. 
DOI: $10.21522 /$ TIJPH.2013.06.02.Art022

ISSN: $2520-3134$

[9]. Lasisi, C. J., Bassey, T. I., Ita, A. E., \& Awoyemi, O. K. (2014). Awareness and Utilization of Family Planning among Married Women in the Traditional Core Areas of Ibadan, Oyo State: Nova Journal of Humanities and Social Sciences, 3(2): 1-8.

[10]. Mkangi K (2001). The Social Cost of Smaller Nuclear Families: A Critique of demographic transition. Dev. Stud., (2): 43 - 49.

[11]. National Population Commission (NPC) [Nigeria] \& ICF Macro (2009). NigeriaDemographic and Health Survey 2008. Abuja, Nigeria: National Population Commission and ICF Macro. AFRREV, 9 (1).

[12]. Nwokocha, E. E. (2006). Pregnancy Outcomes among the Ibani of Rivers State, Nigeria: Findings from Case-studies. African Population Studies, 21(1).

[13]. Olaitan, O.L (2011). Factors influencing the choice of family planning among couples in southwest Nigeria: International Journal of Medicine and Medical Sciences, 3(7): 227-232.

[14]. Olakojo, O. A. (2012). Knowledge, attitudes and practices of married women in Nigeria towards family planning: Journal of Sociology, Psychology and Anthropology in Practice, (3):18-25.

[15]. Olawepo, R. A. \& Okedare, E.A. (2006). Men's Attitudes towards Family Planning in a Traditional Urban Centre: An Example from Ilorin, Nigeria. Journal of Social Sciences. 13 (2): 83-90.

[16]. Olugbenga-Bello, A., Abodunrin, O., \& Adeomi, A.A. (2011).Contraceptive Practices among women in a rural communities in South-Western Nigeria. Global Journal of Medical Research: 11(2):12-19.

[17]. Oyefara, J.L. (2011). Socio-Cultural Context of Adolescent Fertility in Yoruba Society: Insight from Osun State, Nigeria. Lagos: Concept Publications.

[18]. Oyefara, J.L. (2012). Women age at first birth and knowledge of family planning methods in Yoruba society, Nigeria: Journal of Sociological Research, 3(2):249-271.

[19]. Ozumba, C. O. I. (2011). Family planning among married men: a pilot study in Abakpa Nike Enugu State Nigeria. Retrieved from: http://uaps2011.princeton.edu/papers/110374.

[20]. Rozina, M. Uzma, A and Haleema, A. H (2008). Contraceptive knowledge, attitude and practice among rural women: Journal of the College of Physicians and Surgeons Pakistan, 18 (9): 542-545.

[21]. Sanhueza, H. (2007). "Family Planning in Chile: A Tale of the Unexpected," In Robinsin, W.C. \& J.A. Ross (eds.). The Global Family Planning Revolution: Three Decades of Population Policies and Programmes. Washington: Green Press Initiative: 105-129.

[22]. Sezer, K. Simge, Z \& Leyla, D (2013). Influence of age on the usage of family planning methods by turkish married men living in south eastern turkey: Turkish Journal of Medical Sciences, 43: 756-763.

[23]. Timothy, C. O., Nelson, W. W \& Tom, K. M (2011). Contraceptive Use among Women of Reproductive Age in Kenya's City Slums: International Journal of Business and Social Science, 2(1):22-43.

[24]. USAID. (2007). "Contraceptive Trends in Developing Countries: DHS Comparative Report 16." Maryland: Macro International Inc., World population projection. 


\title{
Reproductive Health Practices of Female Garment Workers
}

\author{
Article by Mita Rahman ${ }^{1}$, Shafiur Rahman ${ }^{2}$, Ummul Khair Alam ${ }^{3}$, Irin Hossain ${ }^{4}$ \\ ${ }^{1,2,3}$ National Institute of Preventive and Social Medicine, Mohakhali, Dhaka \\ Email: irin.hossain@gmail.com
}

\begin{abstract}
A cross sectional descriptive study was carried out among the garments workers in two garments factory to assess the reproductive health practices of female garment workers with structured questionnaire by face to face interview. A total of two hundred female garment workers were selected purposively in this area who were married within 18-45 years of age. The proportion of women seeking abortion was 75\%. Among 28 respondents who were pregnant, highest proportion of them (89.3\%) were under regular ANC in pregnancy. More than one third (10.7\%) of the respondent were not under regular ANC. Among the 28 respondents half of the respondents (21.43\%) did not take Tetanus vaccination and half $(78.57 \%)$ took tetanus vaccination. This study reflected different dimension in their reproductive life, for improved their better standard. Large scale studies needed.
\end{abstract}

Keywords: Reproductive health practice, garment workers.

\section{Introduction}

About 34 million adolescents (10-19 years old) constitute 21\% of total population of Bangladesh [1]. Adolescents experience rapid social, physical and emotional changes [2]. More over reproductive life, nutrition, drug, early marriage, divorce, sexually transmitted disease play in important role in this time. The fertility rate among the 15-19 years old age group is one of the highest rates in the world. The percentage of married adolescent aged 15-19 is 11.4 and the fertility rate of this age group is 113 per 1,000 married women [3]. Teen pregnancy and motherhood is a major social and health concern. About $31 \%$ of female garments worker in Bangladesh have begun childbearing; about one in four teenagers has given birth and another 6\% are pregnant with their first child. As expected, the proportion of women age 15-19, who have begun childbearing rises rapidly with age, from $9 \%$ among women age 15 to 58 percent among women age 19. The information on Adolescent Reproductive Health (ARH) knowledge and behavior is extremely limited. Overall adolescent reproductive health issues are un-addressed for both married and unmarried females and males. Information about sexual behavior is not easy to obtain, partly because of a long-held assumption that young people do not engage in sex before marriage in Bangladesh's conservative culture. The limited information available indicates that conservative may not be protecting either gender from sexual experimentation with potentially negative effects on RH. In most cultures, boys are more likely to experiment sexually than girls, usually because the consequences are less severe. This appears to be true in Bangladesh as well, though there are sharp urban and rural differences.

Readymade garment sector has been playing an important role in enhancing Bangladesh economy. Women represent 85 percent of the total 24 million employees in readymade garment industry. Bangladesh is a society that has traditionally been characterized by very early marriage and child bearing when this is a period of physiological, emotional and intellectual development. Maternal mortality among mothers aged 15-19 is also very high as compared to among mothers in the 20-24 years age group [4]. Study in Turkey reported that approximately 90 percent of adolescent pregnancies are unplanned and a great amount unplanned adolescent pregnancies are unintended. They are not conscious about receiving antenatal and postnatal care. For this reason they have suffered various reproductive health related problems such as severe anaemia, nutritional deficiency, abortion, maternal and infant mortality, premature and low birth weight baby and even death. Mothers are at a risk of having anaemia in pregnancy, which is considered to be mainly responsible for the prevailing high maternal mortality and high incidence of low birth weight deliveries in India. Many adverse outcomes have been associated with teenage pregnancy including premature delivery, small 
for gestational age infants, low birth weight infants, increase neonatal mortality, anaemia and pregnancy induced hypertension [5]. Different reports suggested that adolescent are associate with increase incident of medical and obstetrical complications including anaemia, pregnancy-induced hypertension and prematurity. The pregnancy-related maternal and fetal complications in most cases were observed in a higher proportion when compared with those found in other studies in developing countries.

\section{Methods}

\section{Study design and sample}

This study was conducted to assess the reproductive health practices of female garment workers according to the following methodologies:

This study was conducted at two garments, Meherun Apparels Ltd Malibag, Dhaka. From the workers the sample was taken by convenient sampling. Among the female workers, those who were married and age between 18-45 years, willing to participate in the interview were interviewed at the factory total 200 women were interviewed. A semi structured questionnaire was used as research instrument. After adequate correction and thorough checking, the questionnaire was divided into part a. contained the questions related to the socioeconomic status, part $b$. contained the questions related to their reproductive health, part c. reproductive health practice questions to assess reproductive health practices of female garment workers. Data were collected by face to face interview, by asking them questions as per the written questionnaire at the factory. The study populations were interviewed one after another without disturbing their routine works. The interview was taken by the researcher herself at the site of the study.

\section{Analysis}

Collected data were analyzed after thorough checking, cleaning, editing and compiling by using the SPSS (Statistical package for social science, version 24 for windows) software and scientific calculator. Continuous variables were recorded into categorical variable by creating groups. The data were presented in different Tables, charts. The data were presented in different tables in order to the variables. Frequency tables according to the variables. Cross tables to see the reproductive health practice according to the socio-demographic variables. Chi-square test was done to see the relationship between reproductive health practice and some selected variables. The test statistics was used to analyze the data is descriptive statistics and inferential statistic according to the demand of the study with 95\% confidence interval. Level of significance was set at 0.05 . Qualitative data were analyzed on the basis of themes.

\section{Result}

This was a cross sectional study, conducted in garment factory with the main objective of the study was to assess the reproductive health practice among the female garment worker. A total of 200 patients were interviewed.

\section{Socio-demographic status of female workers}

Table 1 shows distribution of the respondents by age group. The minimum age was 18 years and the maximum age was 47 years. The mean age was $27.63( \pm 7.01)$ years. About one third $(33.5 \%)$ of the respondents were within the age group of 18-23 years, one third (32\%) was within 24-29 years, about one fifth (18.5\%) was within 30-35 years. Most 183 (91.5\%) of the respondents were Muslim, one twelfth $12(6 \%)$ were Hindu and rest of were Buddhists (1.5\%) and Christians (1\%) respectively.

Almost half $(49.5 \%)$ of the respondents were educated up to primary and one fourth $(24 \%)$ of the respondents were educated up to degree and $1 / 5^{\text {th }}(20 \%)$ of the respondents were illiterate. Out of the total 200 respondents minimum family members are 2 person and maximum family members are 6 persons. Mean family member is 4 persons $(\mathrm{SD} \pm 0.83)$. 
Table 1. Socio-demographic characteristics of the respondents $n=200$

\begin{tabular}{|l|l|l|}
\hline Characteristics & Frequency & Percent \% \\
\hline Age (Years) & 67 & 33.5 \\
\hline 18-23years & 64 & 32.0 \\
\hline 24-29years & 37 & 18.5 \\
\hline 30-35 years & 23 & 11.5 \\
\hline 36-41 years & 9 & 4.5 \\
\hline 42-47 years & \multicolumn{2}{|l|}{} \\
\hline Mean=27.63,SD =7.01 & 91.5 \\
\hline Religion & 183 & 6 \\
\hline Muslim & 12 & 2.5 \\
\hline Hinduism & 5 & 20.0 \\
\hline Others & 40 & 49.5 \\
\hline Respondent's education level & 6.0 \\
\hline Illiterate & 99 & .5 \\
\hline Primary & 12 & 24.0 \\
\hline Secondary & 1 & 48 \\
\hline Higher secondary & & \\
\hline Degree &
\end{tabular}

\section{Reproductive characteristics of the respondent $\mathbf{n}=\mathbf{2 0 0}$}

Table shows that out of 200 participants $94(47 \%)$ got married before 18 years that is early marriage was $47 \%$. Out of the total 200 respondents one third $66(33.0 \%)$ had 1 child and less than one third $63(31.5 \%)$ had 2 children and about one tenth $23(11.5 \%)$ had more than two children. Minimum number of children is 1 and maximum number of children is 4 . Average number of children is 2 ( $\mathrm{SD} \pm 0.96)$. Out of the total 200 respondents most of them $172(86 \%)$ were not pregnant and 28 (14\%) were pregnant.

Table 2. Reproductive characteristics of the respondent $n=200$

\begin{tabular}{|l|l|l|}
\hline Characteristics & Frequency & Percent \% \\
\hline \multicolumn{2}{|l|}{ Early Marriage (Years) } & 47.0 \\
\hline Less than 18 years & 94 & 53.0 \\
\hline 18 years and above & 106 & 24.0 \\
\hline 2. Number of living children & 33.0 \\
\hline No child & 48 & 31.5 \\
\hline One child & 66 & 11.5 \\
\hline Two child & 63 & 0.96 \\
\hline More than two & 23 & 86 \\
\hline Minimum=1, Maximum=4, Mean=2, SD $=4$ \\
\hline 3. Pregnancy status & 172 \\
\hline No
\end{tabular}




\begin{tabular}{|l|l|l|}
\hline Yes & 28 & 14 \\
\hline
\end{tabular}

\section{Distribution of the respondents by history of unplanned or unwanted pregnancy $n=152$}

Out of the total 152 respondents who had children, majority (70\%) of them had no history of unplanned or unwanted pregnancy and less than one third (30\%) had history of unplanned or unwanted pregnancy.

Table 3. Distribution of the respondents by history of unplanned or unwanted pregnancy

\begin{tabular}{|c|c|c|c|}
\hline $\begin{array}{l}\text { History of unplanned or } \\
\text { unwanted pregnancy }\end{array}$ & $\begin{array}{l}\text { History of unplanned or } \\
\text { unwanted pregnancy }\end{array}$ & Frequency & Percentage \\
\hline No & \multirow[t]{3}{*}{152} & 106 & 70 \\
\hline Yes & & 46 & 30 \\
\hline Total & & 152 & 100.0 \\
\hline
\end{tabular}

Distribution of the respondents by current pregnancy unplanned or unwanted $\mathbf{n}=\mathbf{2 8}$

Out of the total 28 respondents who were pregnant most of them $(71.4 \%)$ had history of planned pregnancy and more than one fifth $(28.6 \%)$ had unplanned or unwanted pregnancy.

Table 4. Distribution of the respondents by current pregnancy unplanned or unwanted

\begin{tabular}{|l|l|l|}
\hline $\begin{array}{l}\text { Present pregnancy planned } \\
\text { or not }\end{array}$ & Frequency & Percentage \\
\hline Planned & 20 & 71.4 \\
\hline Not planned & 8 & 28.6 \\
\hline Total & 28 & 100 \\
\hline
\end{tabular}

\section{Distribution of the respondents by history of $M R$ and number of MR $\mathbf{n}=\mathbf{2 0 0}$}

Out of the total 200 respondents three fourth $150(75 \%)$ of the respondents had history of MR and one fourth $50(25 \%)$ had no history of miscarriage or MR. Out of the total 150 respondents who had history of MR majority $105(70 \%)$ had once history of MR, one fourth $38(25 \%)$ had history for two times and only less than one tenth 7 (4.6\%) had history for more than two times.

Table 5. Distribution of the respondents by history of MR and number of MR

\begin{tabular}{|l|l|l|}
\hline History of MR & Frequency & Percentage \\
\hline History of MR & 150 & 75 \\
\hline No History of MR & 50 & 25 \\
\hline Number of MR & \multicolumn{2}{|l|}{} \\
\hline 1 & 105 & 70 \\
\hline 2 times & 38 & 25.4 \\
\hline$>2$ times & 7 & 4.6 \\
\hline Total & 150 & 100.0 \\
\hline
\end{tabular}

Distribution of the respondents by consultation about gap between children with husband $n=$ 152

Out of the total 152 respondents who had one child, two child or more, most of them $114(75 \%)$ talked about gap between two children and one forth 38 (25\%) did not consult with their husbands. 
Table 6. Distribution of the respondents by consultation about gap between children with husband

\begin{tabular}{|l|l|l|}
\hline $\begin{array}{l}\text { Consultation about gap between } \\
\text { children with husband }\end{array}$ & Frequency & Percentage \\
\hline No & 38 & 25 \\
\hline Yes & 114 & 75 \\
\hline Total & 152 & 100.0 \\
\hline
\end{tabular}

Distribution of the respondents by taking ANC in pregnancy, place of taking ANC and caregiver of $\mathrm{ANC}$ in previous pregnancy $\mathrm{n}=\mathbf{2 8}$

Out of the total 28 respondents, most 25 (89.3\%) had history of regular ANC in pregnancy and 3 $(10.7 \%)$ were irregular in taking ANC in pregnancy. Out of the total 27 respondents, majority 12 (40.74\%) had taken ANC in upazila health complex, 6 (22.22\%) in private doctor and $9(33.33 \%)$ in other places. Out of the total 88 respondents, most of the respondents $20(71.43 \%)$ was visited by dai in ANC of previous pregnancy, about one tenth $3(10.71 \%)$ and $5(17.86 \%)$ were visited by MBBS and paramedics respectively.

Table 7. Distribution of the respondents by taking ANC in pregnancy, place of taking ANC and caregiver of ANC in previous pregnancy

\begin{tabular}{|l|l|l|}
\hline Taking ANC in pregnancy & Frequency & Percentage \\
\hline No & 1 & 3.57 \\
\hline Irregular & 3 & 10.7 \\
\hline Regular & 25 & 89.3 \\
\hline Place of taking ANC & 12 & 44.44 \\
\hline Upazila Health Complex & 6 & 22.22 \\
\hline Private Doctor & 9 & 33.33 \\
\hline Others & 9 & 17.86 \\
\hline caregiver of ANC in previous pregnancy \\
\hline M.B.B.S & 5 & 10.71 \\
\hline Paramedics & 3 & 71.43 \\
\hline Dai & 20 & 100 \\
\hline Total & 28 & \\
\hline
\end{tabular}

\section{Distribution of the current pregnancy by tetanus vaccination $\mathbf{n}=\mathbf{2 8}$}

Out of the total 28 respondents, most of the respondents who were pregnant $22(78.57 \%)$ took tetanus vaccination and one fifth $6(21.43 \%)$ did not took tetanus vaccination.

Table 8. Distribution of the current pregnancy by tetanus vaccination

\begin{tabular}{|l|l|l|}
\hline $\begin{array}{l}\text { Tetanus vaccination } \\
\text { in current pregnancy }\end{array}$ & Frequency & Percentage \\
\hline No & 6 & 21.43 \\
\hline Yes & 22 & 78.57 \\
\hline Total & 28 & 100.0 \\
\hline
\end{tabular}

\section{Distribution of the respondents by full term delivery and type of delivery $n=152$}

Out of the total 152 respondents who had children, most of them 120 (78.95\%) had history of full term delivery and more than one fifth $32(21.05 \%)$ did not history of full term delivery. Out of the total 152 respondents who had children, most of them 130 (85.53\%) had normal delivery as mode of delivery and $22(14.47 \%)$ had caesarian section. 
DOI: $10.21522 /$ TIJPH.2013.06.02.Art023

ISSN: $2520-3134$

Table 9. Distribution of the respondents by full term delivery and type of delivery

\begin{tabular}{|l|l|l|}
\hline Full term delivery & Frequency & Percentage \\
\hline No & 32 & 21.05 \\
\hline Yes & 120 & 78.95 \\
\hline Type of delivery \\
\hline Caesarian section & 22 & 14.47 \\
\hline Normal delivery & 130 & 85.53 \\
\hline Total & 152 & 100.00 \\
\hline
\end{tabular}

\section{Discussion}

The study was carried out to describe the Reproductive Health Practices of Female Garment Workers in Selected Garment Factory. The study was done to assess the reproductive practices of female garment workers and to determine the socio-demographic characteristics of reproductive health practices.

The minimum age was 18 years and the maximum age was 47 years. The mean age was 27.63 $( \pm 7.01)$ years. About one third $(33.5 \%)$ of the respondents were within the age group of 18-23 years, one third (32\%) was within 24-29 years, about one fifth (18.5\%) was within 30-35 years. Almost half $(49.5 \%)$ of the respondents were educated up to primary and one fourth $(24 \%)$ of the respondents were educated up to degree and 1/5th (20\%) of the respondents were illiterate. Most 183(91.5\%) of the respondents were Muslim, one twelfth $12(6 \%)$ were Hindu and rest of were Buddhists (1.5\%) and Christians (1\%) respectively. Out of the total 200 respondents minimum family members are 2 person and maximum family members are 6 persons. Mean family member was 4 persons ( $\mathrm{SD} \pm 0.83)$. Out of 200 participants $94(47 \%)$ got married before 18 years that is early marriage was $47 \%$. Out of the total 200 respondents one third $66(33.0 \%)$ had 1 child and less than one third $63(31.5 \%)$ had 2 children and about one tenth $23(11.5 \%)$ had more than two children. Minimum number of children is 1 and maximum number of children is 4 . Average number of children is $2(\mathrm{SD} \pm 0.96)$. Out of the total 200 respondents most of them i.e. $172(86 \%)$ were not pregnant and $28(14 \%)$ were pregnant. Out of the total 152 respondents who had one child, two child or more, most of them 114 (75\%) talked about gap between two children and one forth $38(25 \%)$ did not consult with their husbands.

Out of the total 27 respondents, majority $12(40.74 \%)$ had taken ANC in upazila health complex, 6 (22.22\%) in private doctor and $9(33.33 \%)$ in other places. Out of the total 28 respondents, majority $16(57.14 \%)$ had history of taking ANC in previous pregnancy and $12(1.56 \%)$ did not take ANC in previous pregnancy. Out of the total 28 respondents, majority $16(57.14 \%)$ had history of taking ANC in previous pregnancy and $12(1.56 \%)$ did not take ANC in previous pregnancy. Out of the total 28 respondents, more than half $16(57.1 \%)$ had visited ANC two times in previous pregnancy, $8(28.6 \%)$ visited o Out of the total 88 respondents, most of the respondents20 $(71.43 \%)$ was visited by dai in ANC of previous pregnancy, about one tenth $3(10.71 \%)$ and $5(17.86 \%)$ were visited by MBBS and paramedics respectively. Out of the total 28 respondents, most of the respondents who were pregnant $22(78.57 \%)$ took tetanus vaccination and one fifth $6(21.43 \%)$ did not took tetanus vaccination. Out of the total 152 respondents who had children, most of them 120 (78.95\%) had history of full term delivery and more than one fifth $32(21.05 \%)$ did not history of full term delivery. Most of them 130 $(85.53 \%)$ had normal delivery as mode of delivery and $22(14.47 \%)$ had caesarian section. Out of the total 200 respondents, most of them 139 (69.5\%) did not use clean materials and less than one third 61 (30.5\%) used clean materials during menstruation. Out of the total 200 respondents, most of the respondents $88(44.0 \%)$ did not face any problem, $84(42 \%)$ had lower abdominal pain, one tenth 21 (10.5\%) developed weakness and a few 7 (3.5\%) developed nausea and vomiting during menstruation. most of them $176(88 \%)$ had not enough toilet facilities in their job places and only more than one tenth $24(12 \%)$ had enough toilet facilities.

\section{Conclusion}

Early marriage and childbearing among girls is often associated with a wide range of negative social and health consequences for young mothers and their infants, and contributes to rapid population growth. Regarding early marriage it was found that less than half female respondents were 
below 18 years and among that respondents majority having children, few of them were mother before their first anniversary. Among the respondents, less than one third had history of unplanned or unwanted pregnancy and three fourth had history of miscarriage or abortion. About antenatal checkup in pregnancy, among the 27 respondents who were presently pregnant higher portion of the respondents were taking regular ANC in pregnancy and few respondents were irregularly taking ANC. Majority of the respondents who were currently pregnant received Tetanus vaccination.

\section{Acknowledgement}

I am extremely grateful to my respected teacher Assistant Professor Dr. Md. Shafiur Rahman my supervisor for his continuous support and scholarly guidance despite his busy schedules. I express my sincere gratitude to Prof. Manzurul Haque Khan, PhD, Program in charge MPH (OEH). I also express special thanks to Dr. Shaheen Bin Abdul Hai and Dr. Irin Hossain, Lecturer, Department of Occupational and Environmental Health for their valuable advices, constructive suggestions and support to me regarding the whole task of the thesis.

I express my profound thanks to the Managing Director of Meherun Apparels, Malibag Chowdhury Para, Dhaka. At the same time I would like to extend my sincere thanks to all the respondents of this study for their kind participation.

\section{References}

[1].Afrin S, Rahman MR, Jahan AA, Zaman UKS, Rahman N, Rahman S. Reproductive health problems among the adolescent girls. Bangladesh Medical Journal 2010; 39 (2): 22-25.

[2].Akhter HH, Korim F, MEEK, Rahman MH. A study to identify the risk factors affecting nutritional status of adolescent girls in Bangladesh. BIRPERHT, Dhaka, Bangladesh 2000: II-X.

[3].Bangladesh Bureau of Statistics. Statistical pocket book. Dhaka 1999; 384-404.

[4].BDHS, 2014

[5].BRAC Annual Education Report, (2006).

[6].Dutta DC. Text book of Gynecology including contraception, Chapter-3: 2nd edition. New Central Book Agency P. Ltd., Calcutta, India. 1994: 480-483.

[7].Gupta. An assessment of reproductive health related problems of adolescent girls, India, AULAST 2004; 71(9): 797-801.

[8].Hassen F. An intervention program regarding adolescent health. NIPSOM, Bangladesh 1999: 65-70.

[9].Khan MR, Huq N. A Study on menstruation: Belief and practices of adolescents' girls. Dhaka: BRAC, 1991: 1415 .

[10]. Majumder PP, Begum A. Policy Research Report on Gender and Development. Working paper series no. 12.Dhaka, Bangladesh, 2000: 8.

[11]. Nahar Q, Tunon C, Houvras I, Gazi R, Reza M, Huq NL, et al. Reproductive Health needs of Adolescents in Bangladesh : A Study Report. Dhaka, ORP: ICDDR, B. Bangladesh 1999: 17-36.

[12]. Parveen T, Ali HM, Haque AM. Reproductive health related complaints of adolescent school girls of Dhaka city, JOPSOM 2003; 22(2):1-5.

[13]. Pathak, K.B \& Ram, F: Adolescent motherhood: Problems and consequences. The Journal of Family Welfare, (1993), March 15, vol 39(1), pp 17-23.

[14]. Sharma A; Verma k; Khatri S. kannan A on Pregnancy in adolescent: a study of risks and outcome in Eastern Nepal, (2001); vol 38; pp 1405-1409.

[15]. WHO Adolescent health report on Bangladesh (2016). 
Texila American University, Lot 2442, Plantation Providence, East Bank Demerara (EBD), Guyana, South America.

\section{Global office}

Texila Educational \& Management Services (P) Ltd, Module 310, III Floor, TIDEL Park,

ELCOT-SEZ,

Aerodrome Post, Coimbatore-641014, Tamil Nadu, India.

E-mail: ejournal.assist@tau.edu.org

Skype: texila.aco32

Whatsapp: +918056580933 